Supporting Information for:

\title{
Synthesis and Characterization of an Isoreticular Family of Calixarene- Capped Porous Coordination Cages
}

Michael R. Dworzak, ${ }^{\dagger}$ Meaghan M. Deegan, ${ }^{\dagger}$ Glenn P. A. Yap, ${ }^{\dagger}$ and Eric D. Bloch ${ }^{*,}$

Department of Chemistry and Biochemistry, University of Delaware, Newark, Delaware 19716, United States

*email: edb@udel.edu 
List of Contents

\begin{tabular}{|l|r|}
\hline${ }^{1}$ H NMR Spectra & S3-S5 \\
\hline IR Spectra & S6-S15 \\
\hline Ultraviolet Visible Spectroscopy (UV-Vis) Spectra & S16-S39 \\
\hline Thermogravametric Analysis (TGA) & S40-S43 \\
\hline Gas Adsorption Measurements & S44-S62 \\
\hline Powder X-Ray Diffraction Patterns & S63-S69 \\
\hline Crystal Structures & S70-S76 \\
\hline Benzene Freeze Dried Sample Pictures & S77 \\
\hline Table of Crystallographic Data & S78 \\
\hline References & S78 \\
\hline
\end{tabular}




\section{${ }^{1}$ H NMR Spectra}
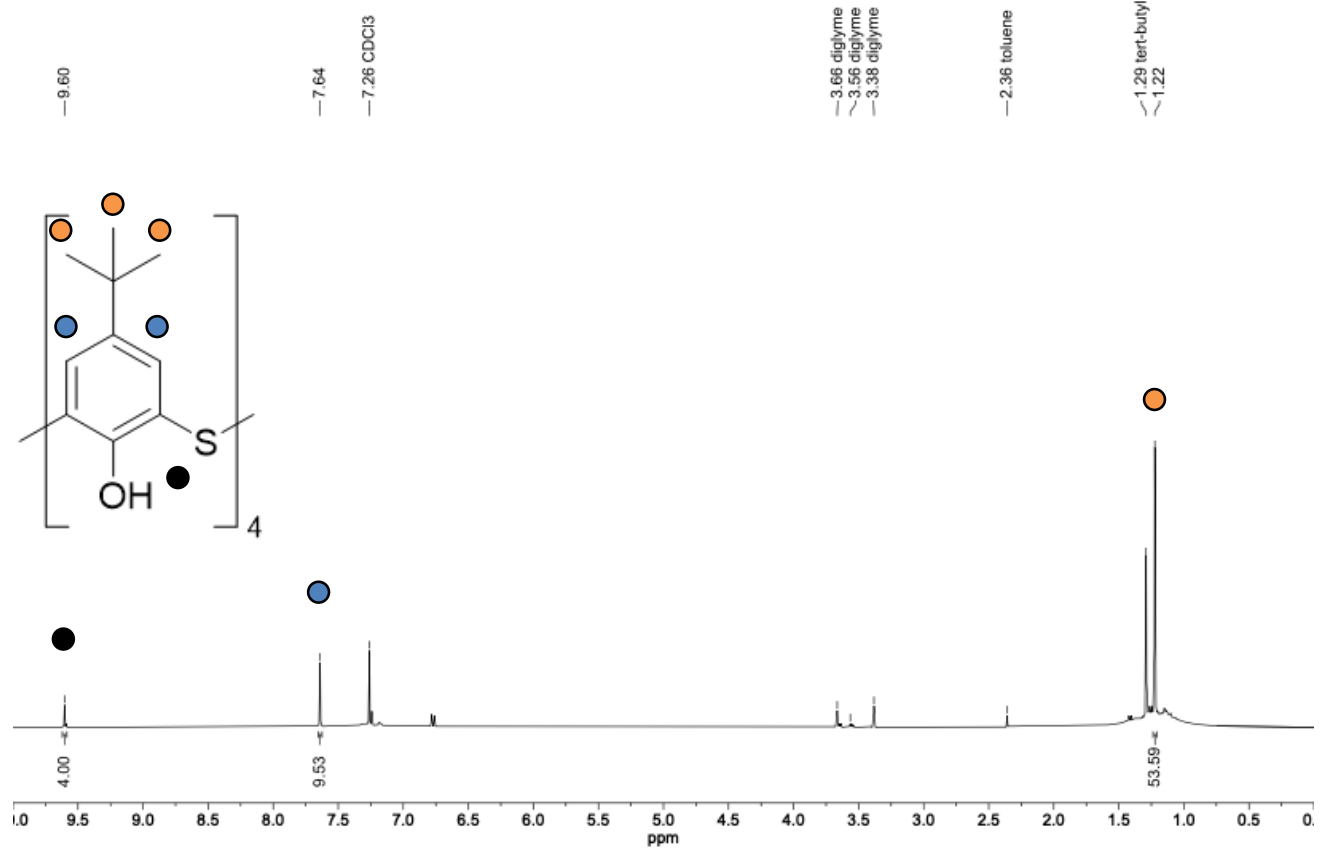

Figure S1. ${ }^{1} \mathrm{H}-\mathrm{NMR}\left(400 \mathrm{MHz}, \mathrm{CDCl}_{3}\right)$ spectrum of $p$-tert-butylthiacalix[4]arene.

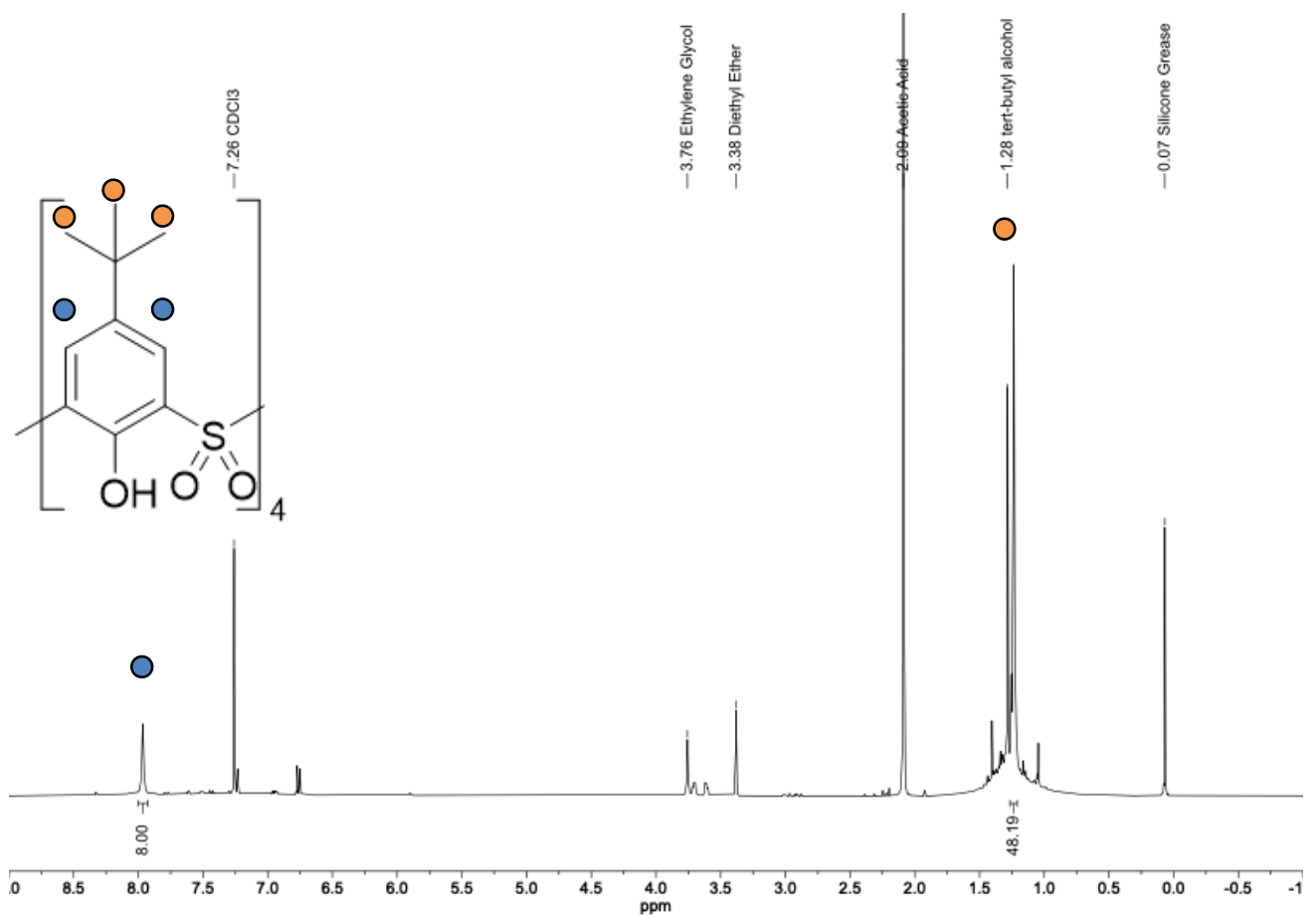

Figure S2. ${ }^{1} \mathrm{H}-\mathrm{NMR}\left(400 \mathrm{MHz}, \mathrm{CDCl}_{3}\right)$ spectrum of $p$-tert-butylsulfonylcalix[4]arene. 


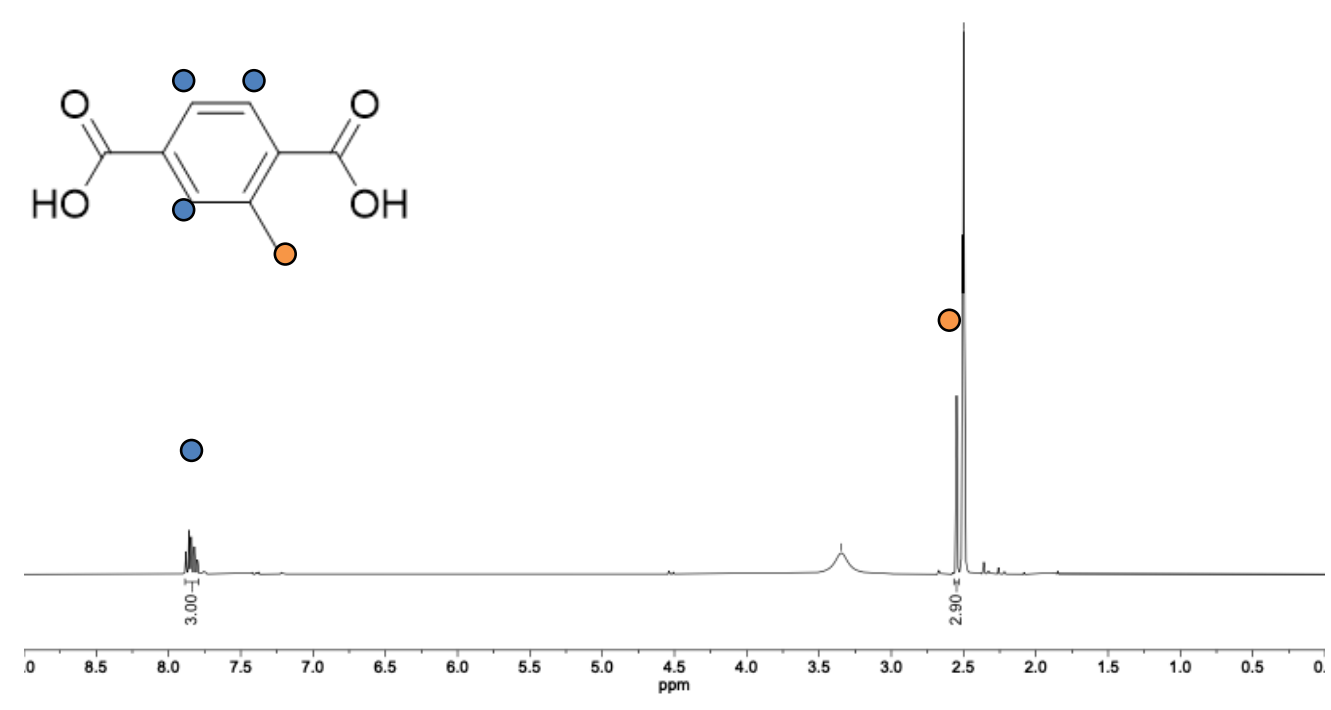

Figure S3. ${ }^{1} \mathrm{H}-\mathrm{NMR}\left(400 \mathrm{MHz}, \mathrm{DMSO}-\mathrm{d}_{6}\right)$ spectrum of 2-methyl-1,4-benzenedicarboxylic acid.

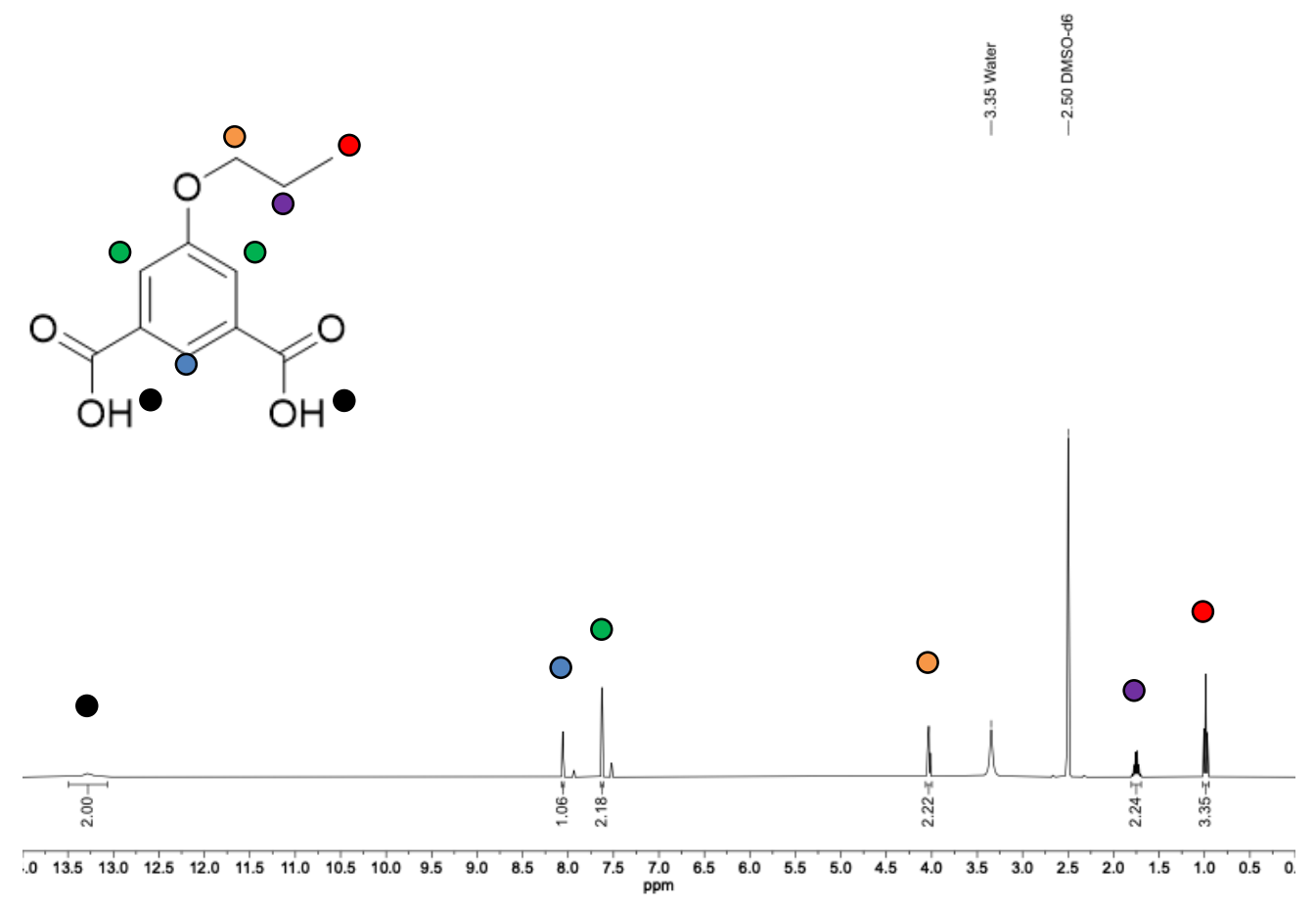

Figure S4. ${ }^{1} \mathrm{H}-\mathrm{NMR}$ (400 MHz, DMSO-d $)$ spectrum of 5-propyloxy-1,3-benzenedicarboxylic acid. 

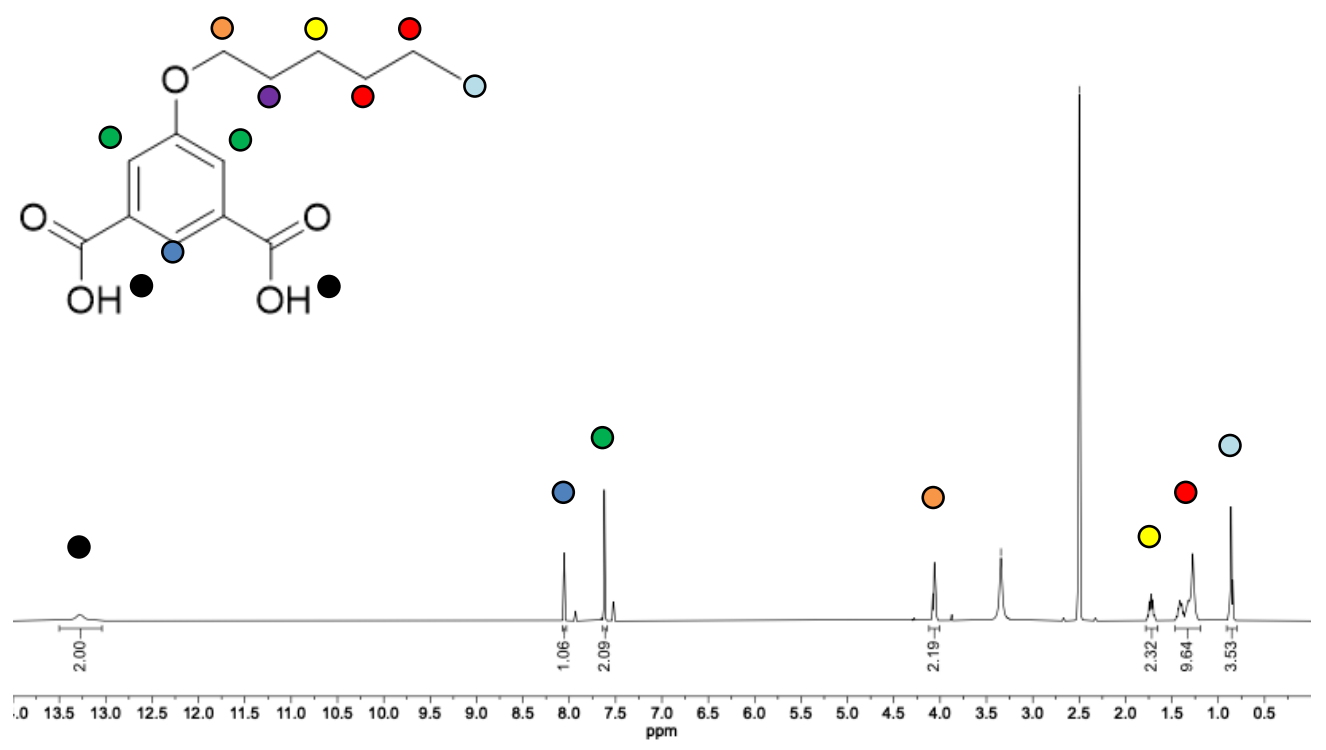

Figure S5. ${ }^{1} \mathrm{H}-\mathrm{NMR}\left(400 \mathrm{MHz}, \mathrm{DMSO}-\mathrm{d}_{6}\right)$ spectrum of 5-heptyloxy-1,3-benzenedicarboxylic acid. 


\section{$\underline{\text { IR Spectra }}$}

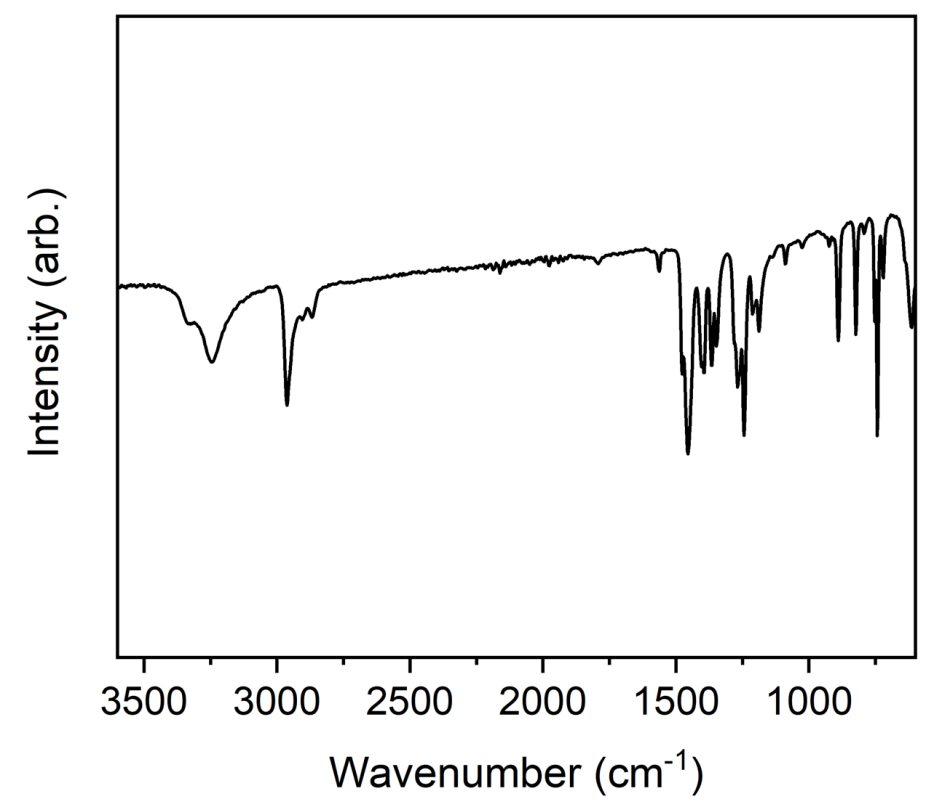

Figure S6. IR spectrum of $p$-tert-butylthiacalix[4]arene

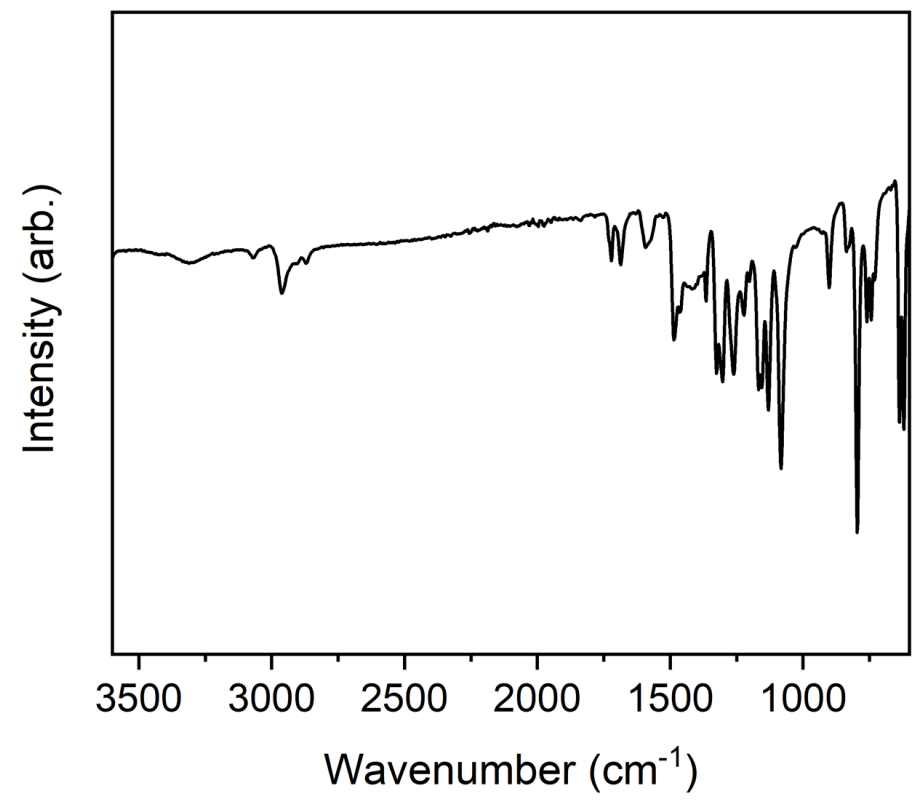

Figure S7. IR spectrum of p-tert-butylsulfonylcalix[4]arene. 


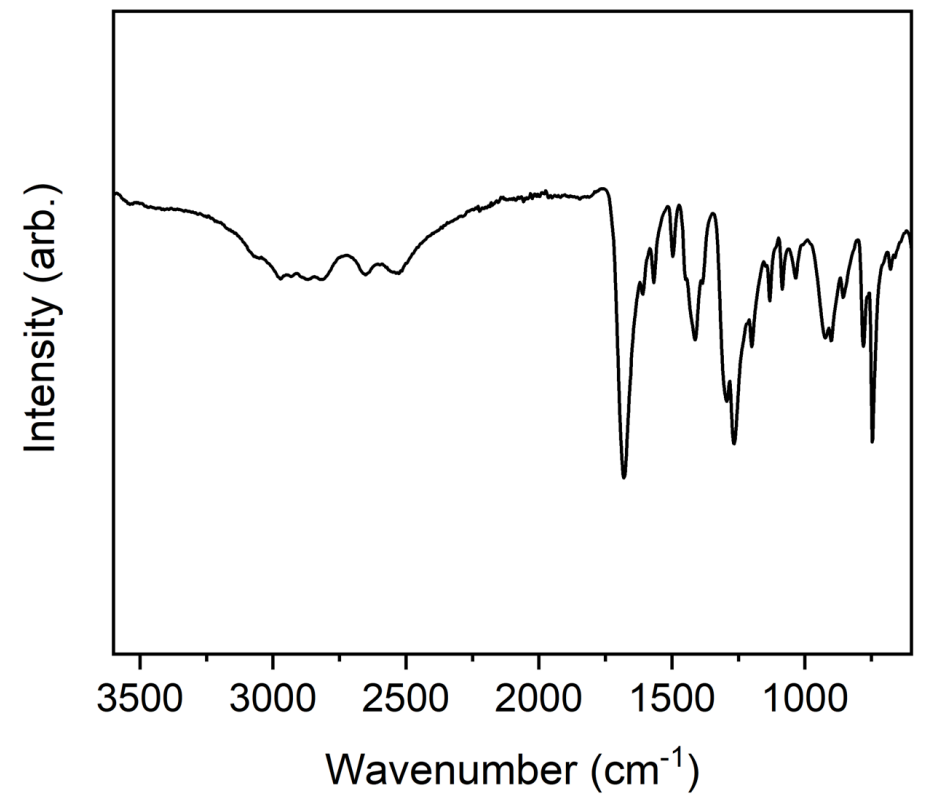

Figure S8. IR spectrum of 2-methyl-1,4-benzenedicarboxylic acid.

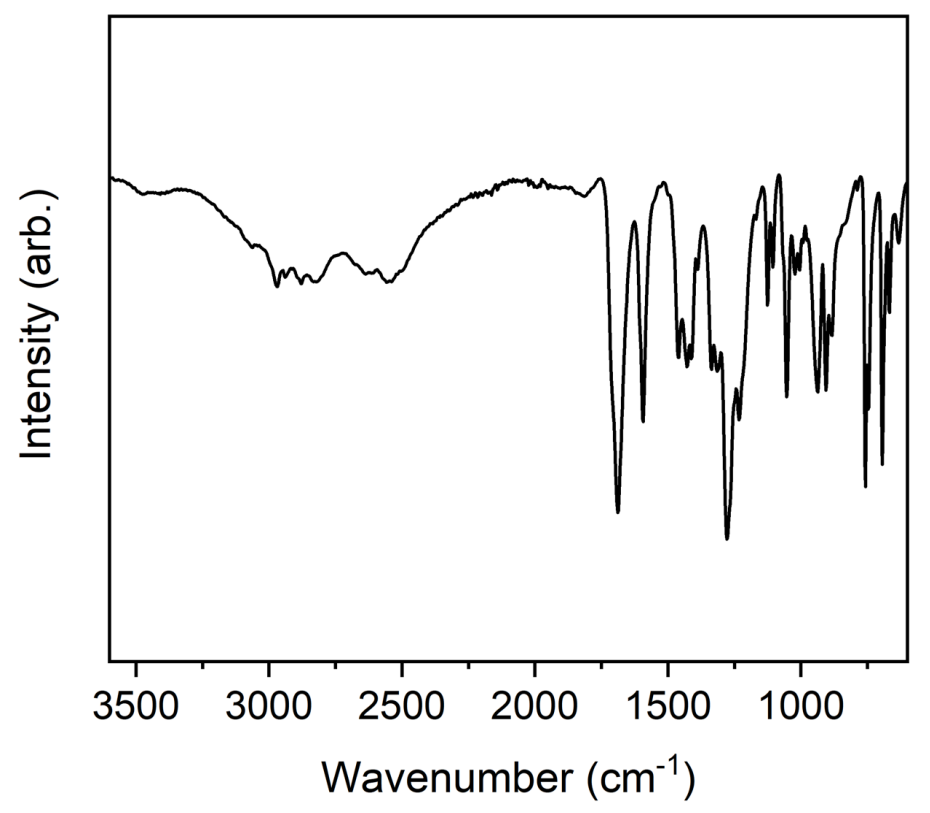

Figure S9. IR spectrum of 5-propyloxy-1,3-benzenedicarboxylic acid. 


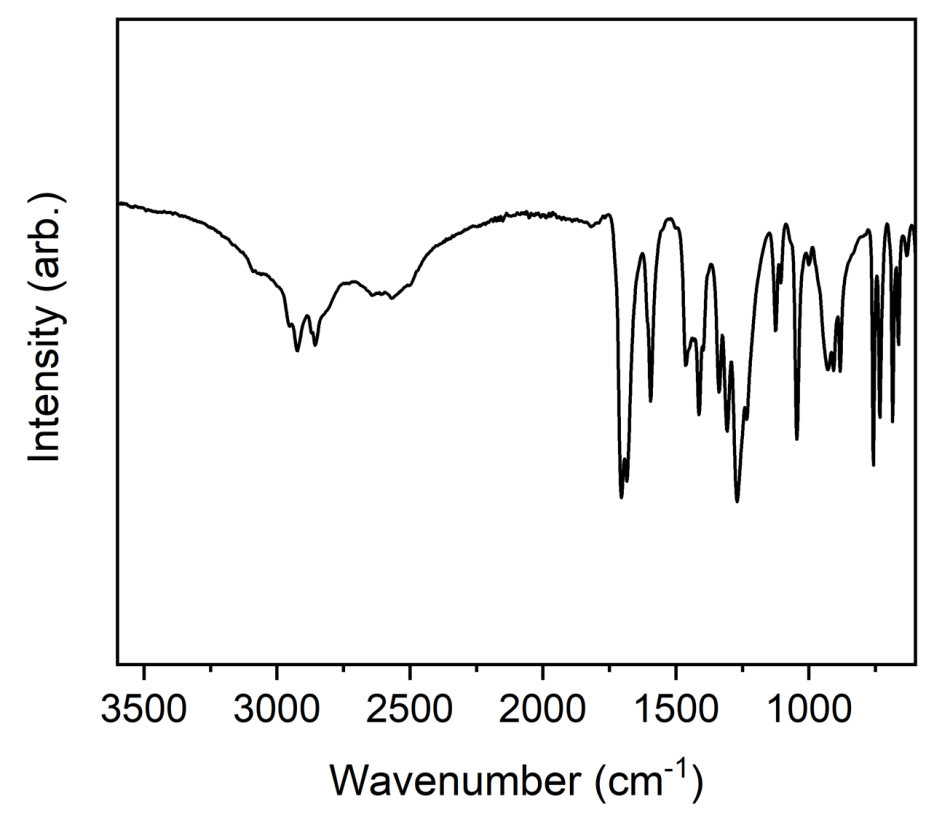

Figure S10. IR spectrum of 5-heptyloxy-1,3-benzenedicarboxylic acid.

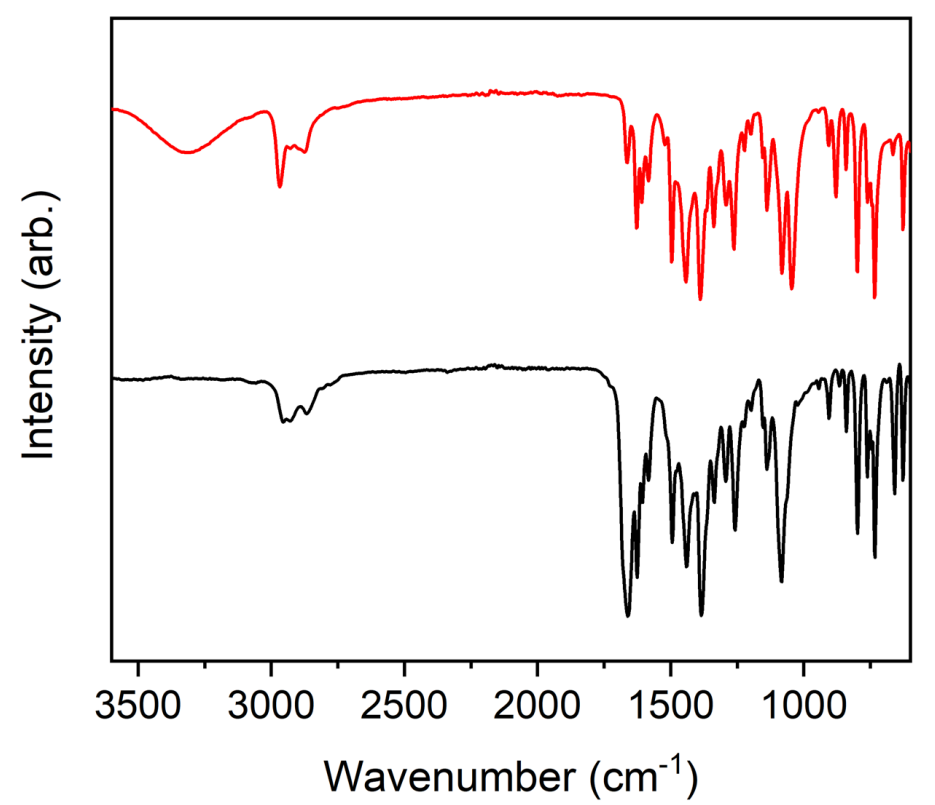

Figure S11. IR spectra of Ni-(btc) as synthesized (black) and solvent exchanged with EtOH (red). 


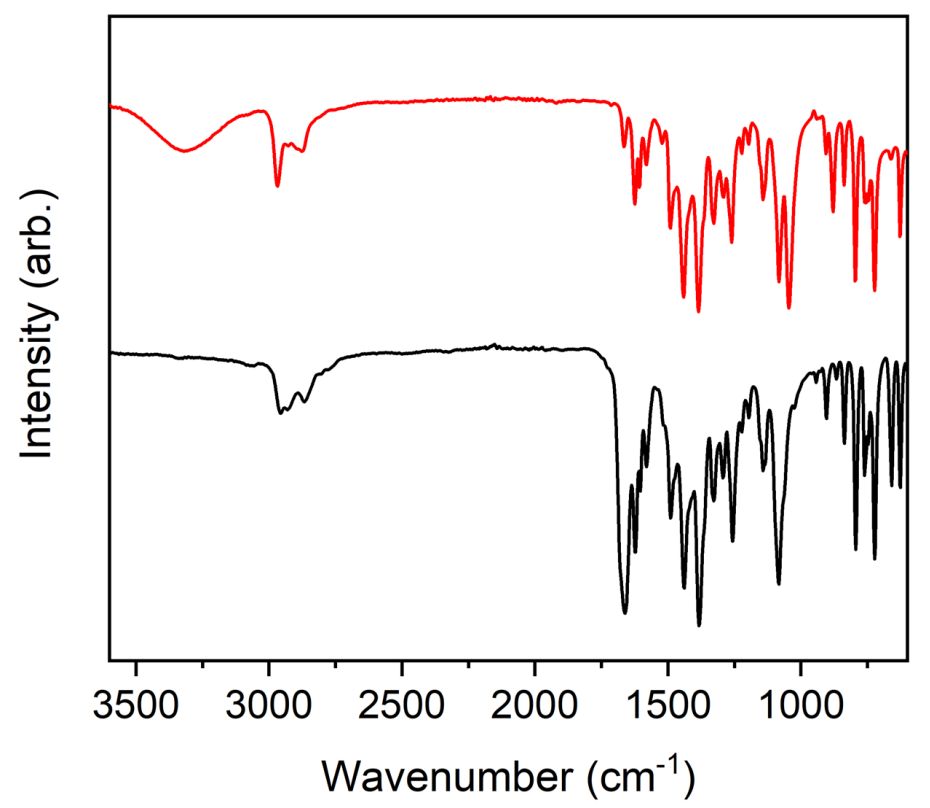

Figure 12. IR spectra of Co-(btc)as synthesized (black) and solvent exchanged with EtOH (red).

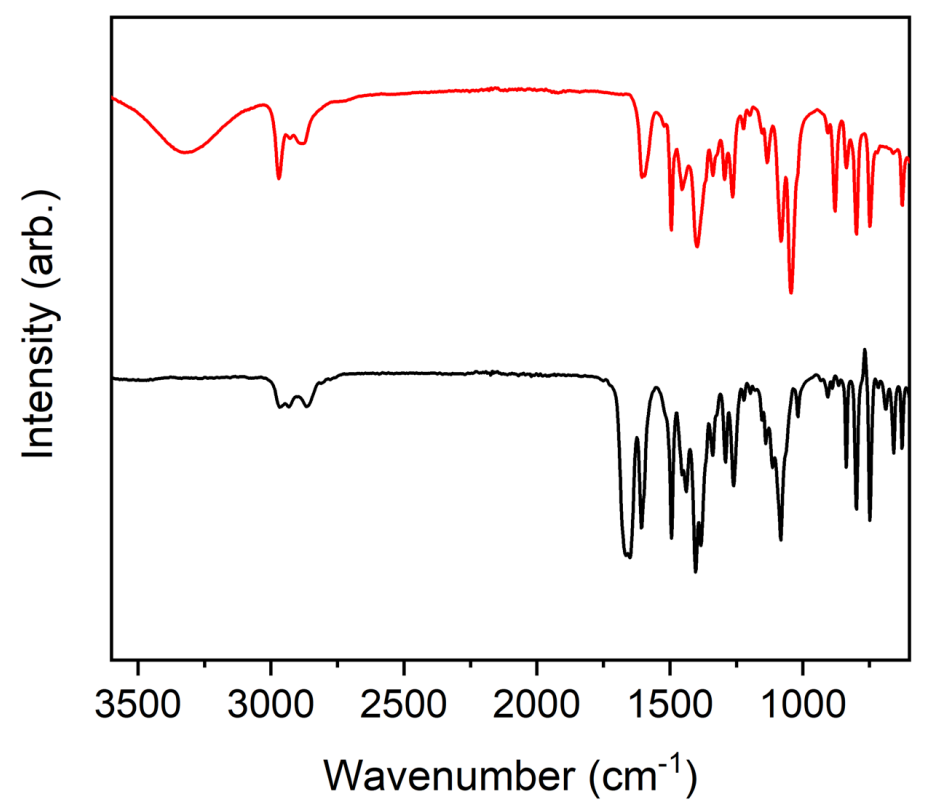

Figure S13. IR spectra of $\mathrm{Ni}-(\mathrm{p}-\mathrm{bdc})$ as synthesized (black) and solvent exchanged with EtOH (red). 


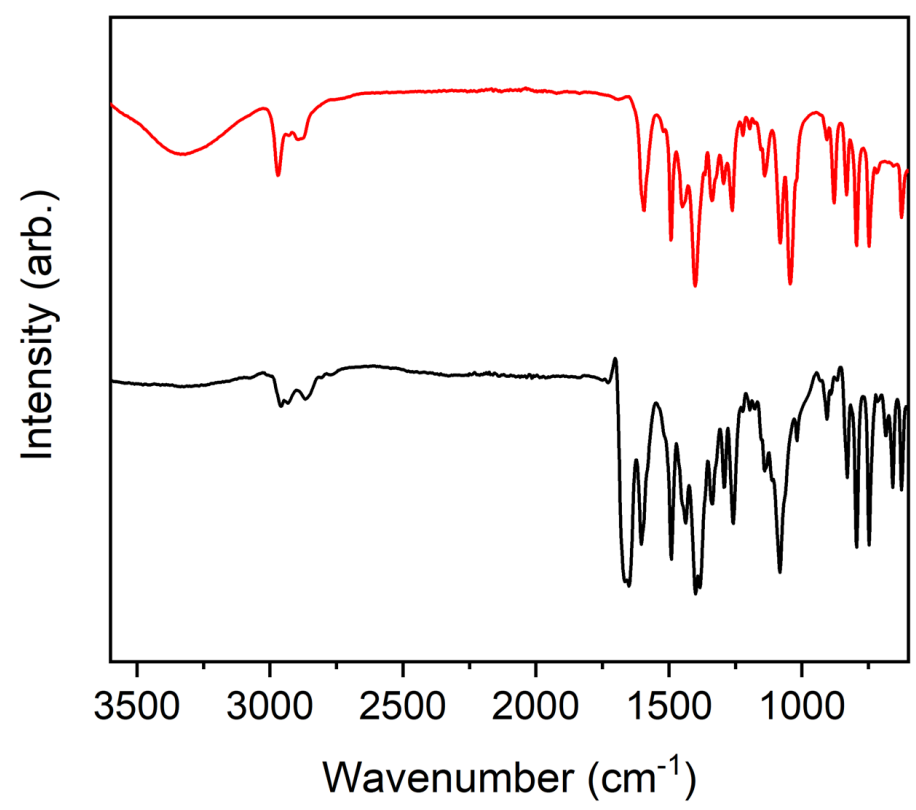

Figure S14. IR spectra of Co-(p-bdc) as synthesized (black) and solvent exchanged with EtOH (red).

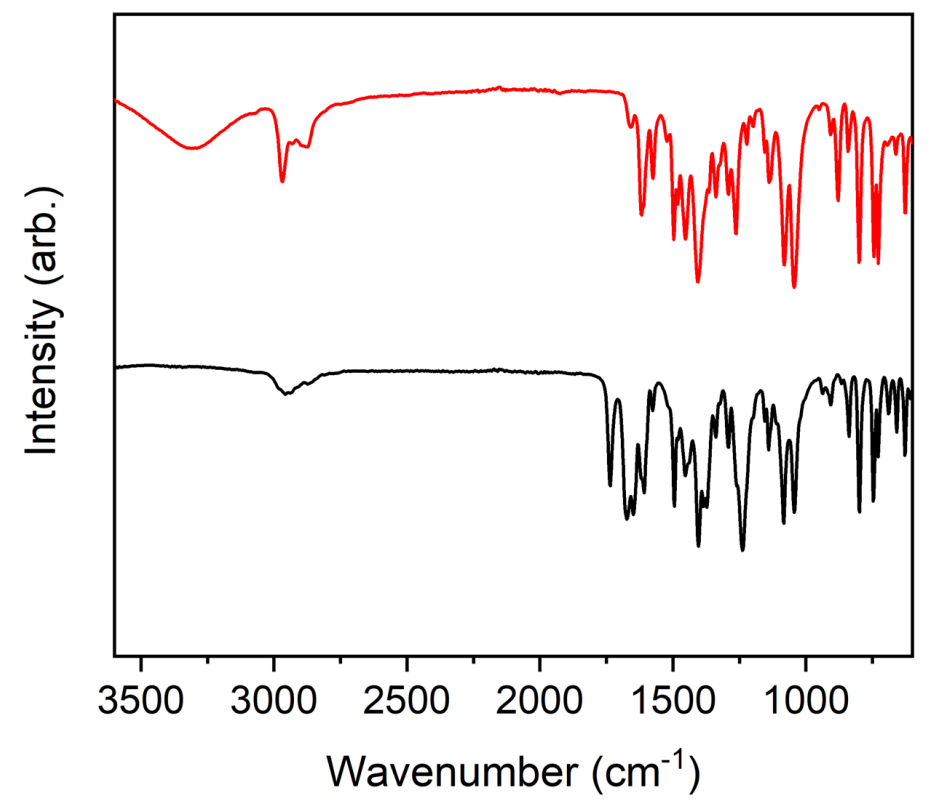

Figure S15. IR spectra of Ni-(m-bdc) as synthesized (black) and solvent exchanged with EtOH (red). 


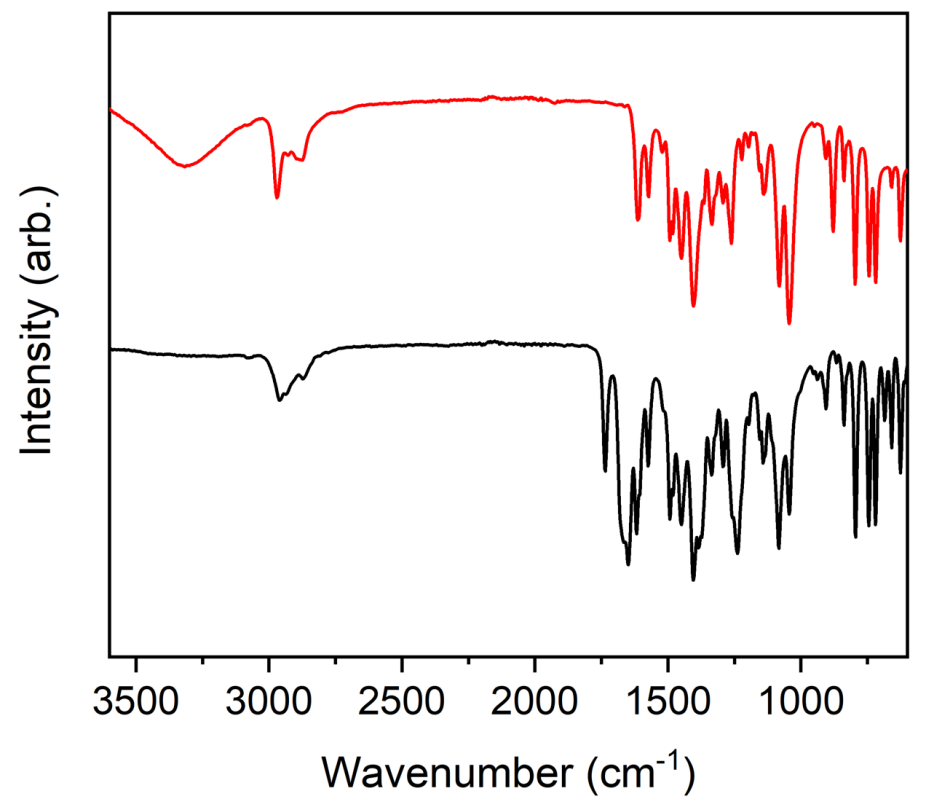

Figure 16. IR spectra of Co-III as synthesized (black) and solvent exchanged with EtOH (red).

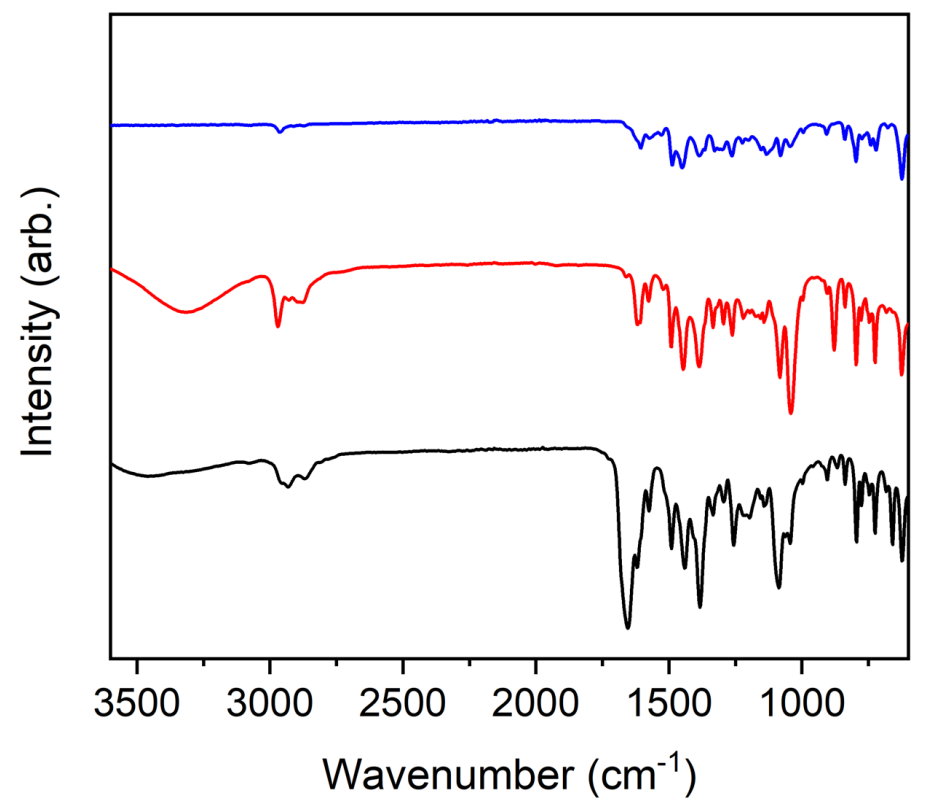

Figure S17. IR spectra of Co-(5-Sulfo) as synthesized (black), solvent exchanged with EtOH (red), and activated (blue). 


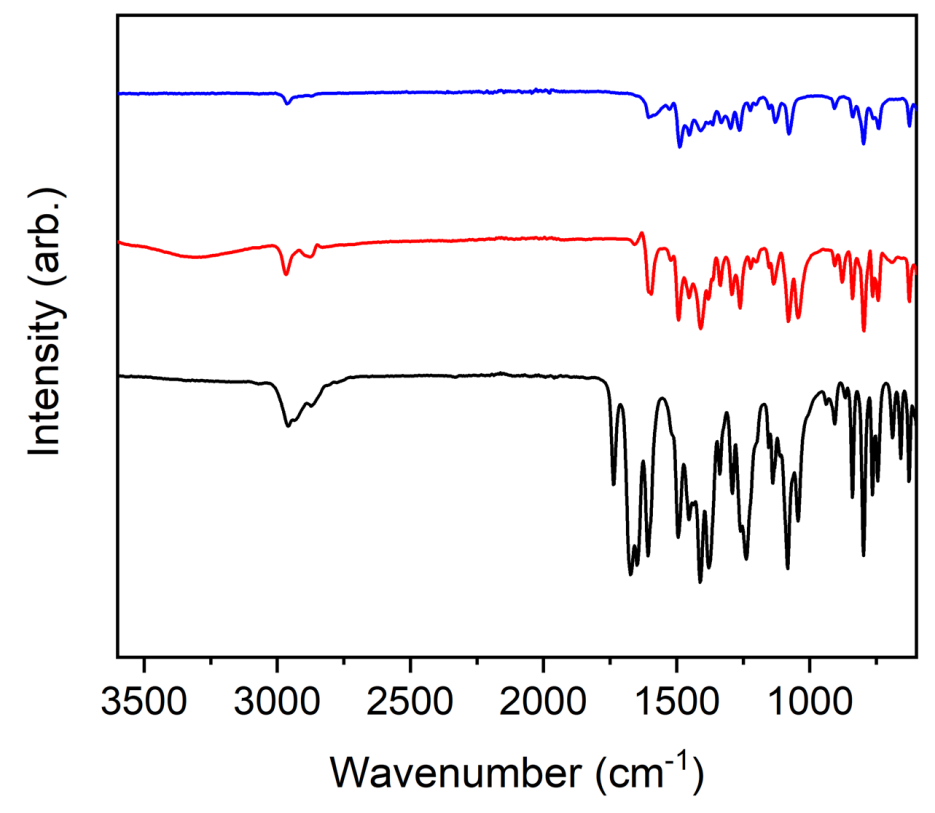

Figure S18. IR spectra of Ni-(2-CH3) as synthesized (black), solvent exchanged with EtOH (red), and activated (blue).

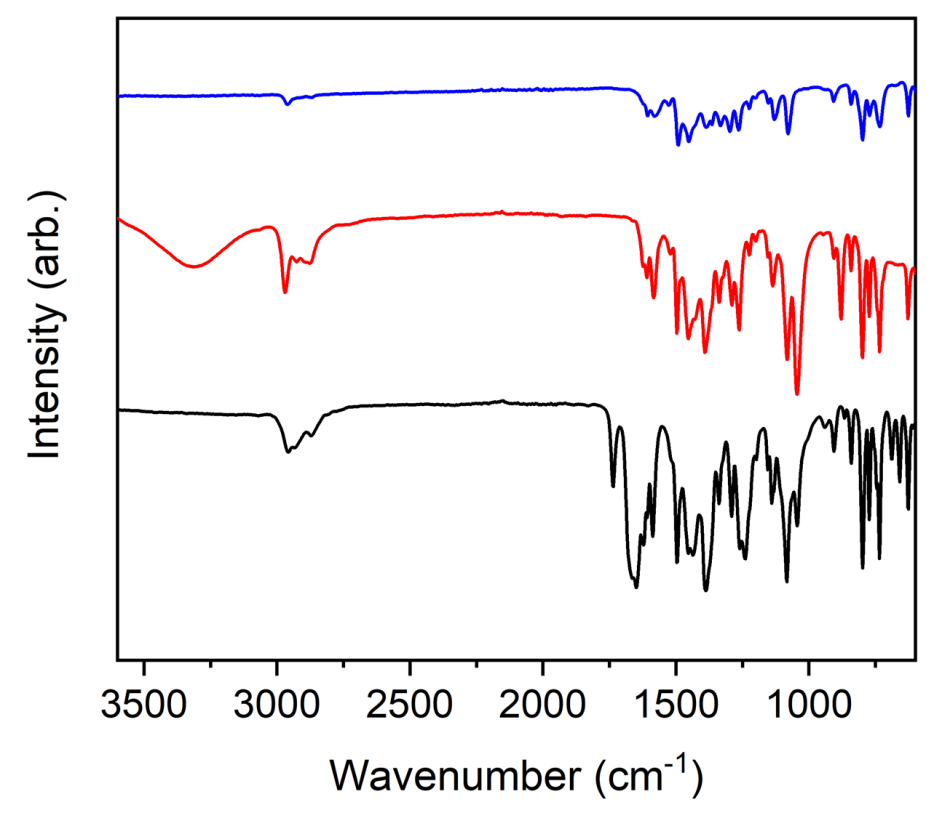

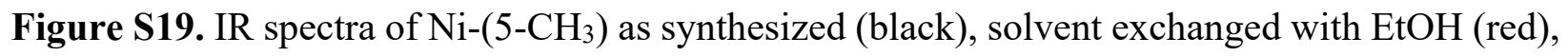
and activated (blue). 


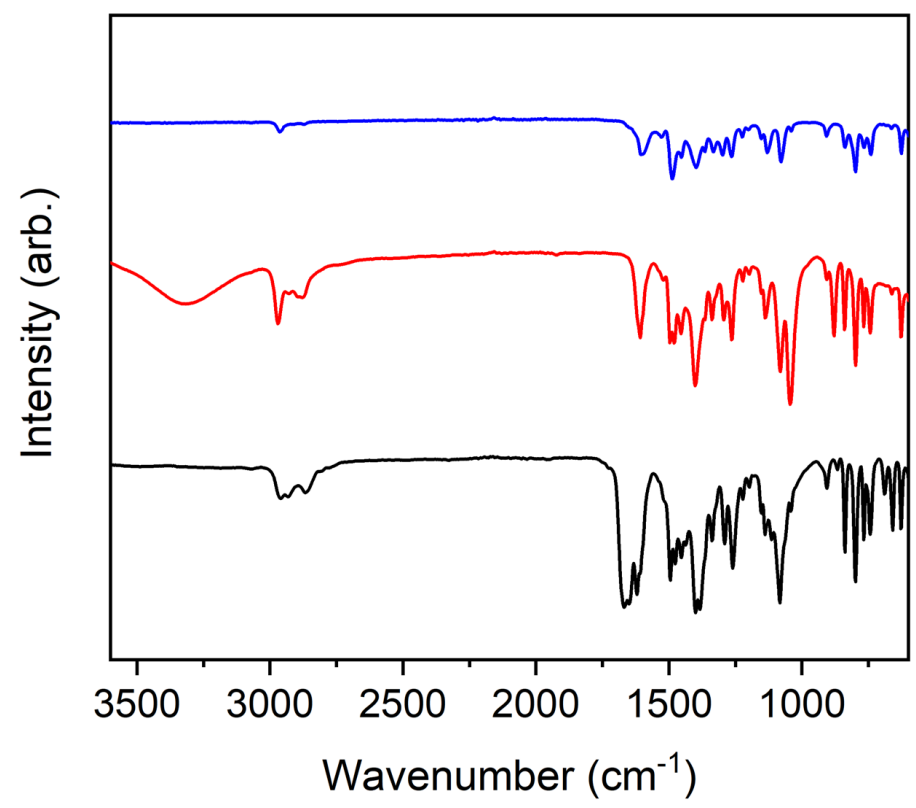

Figure S20. IR spectra of Ni-(2-Br) as synthesized (black), solvent exchanged with EtOH (red), and activated (blue).

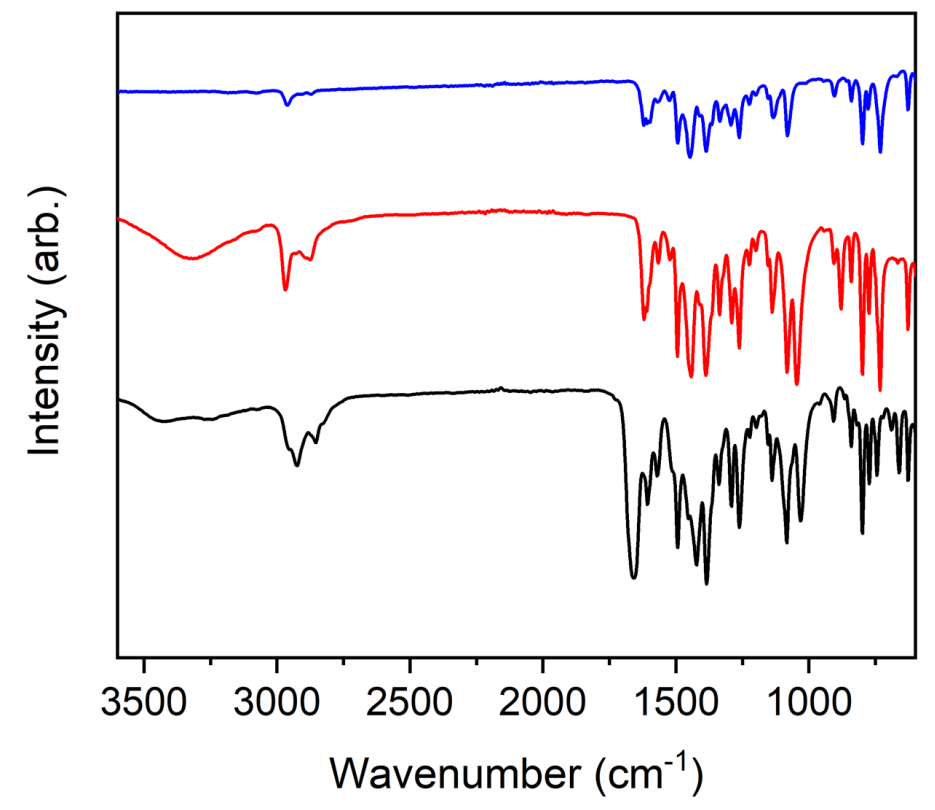

Figure S21. IR spectra of Ni-(5-Br) as synthesized (black), solvent exchanged with EtOH (red), and activated (blue). 


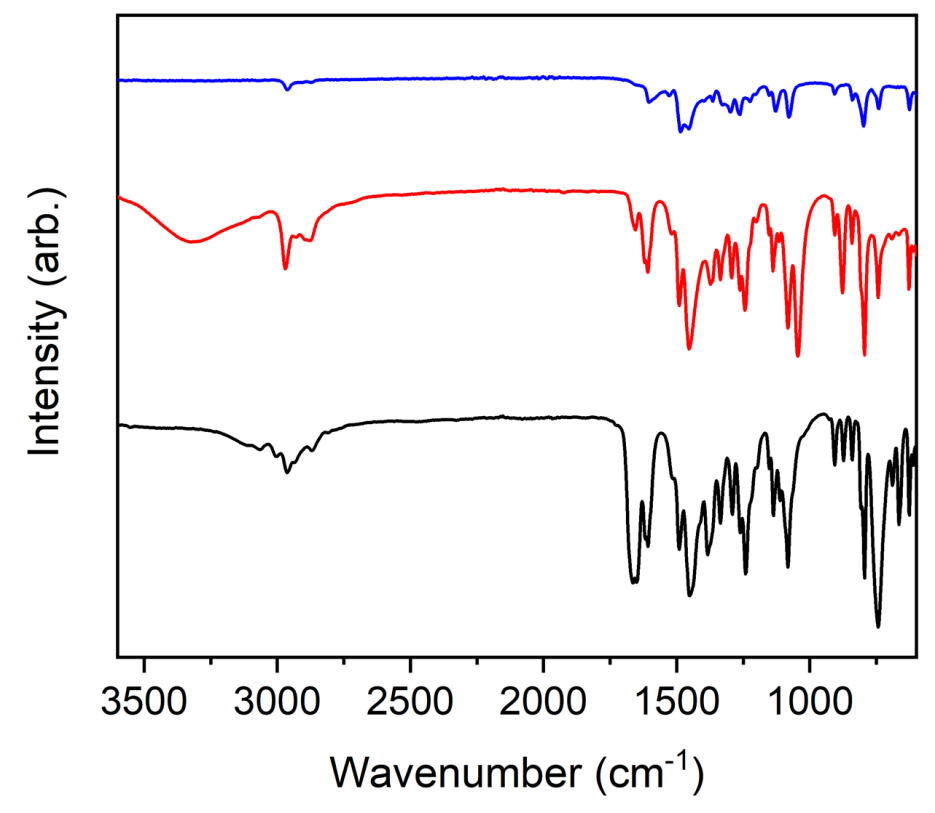

Figure S22. IR spectra of Ni-(dobdc) as synthesized (black), solvent exchanged with EtOH (red), and activated (blue).

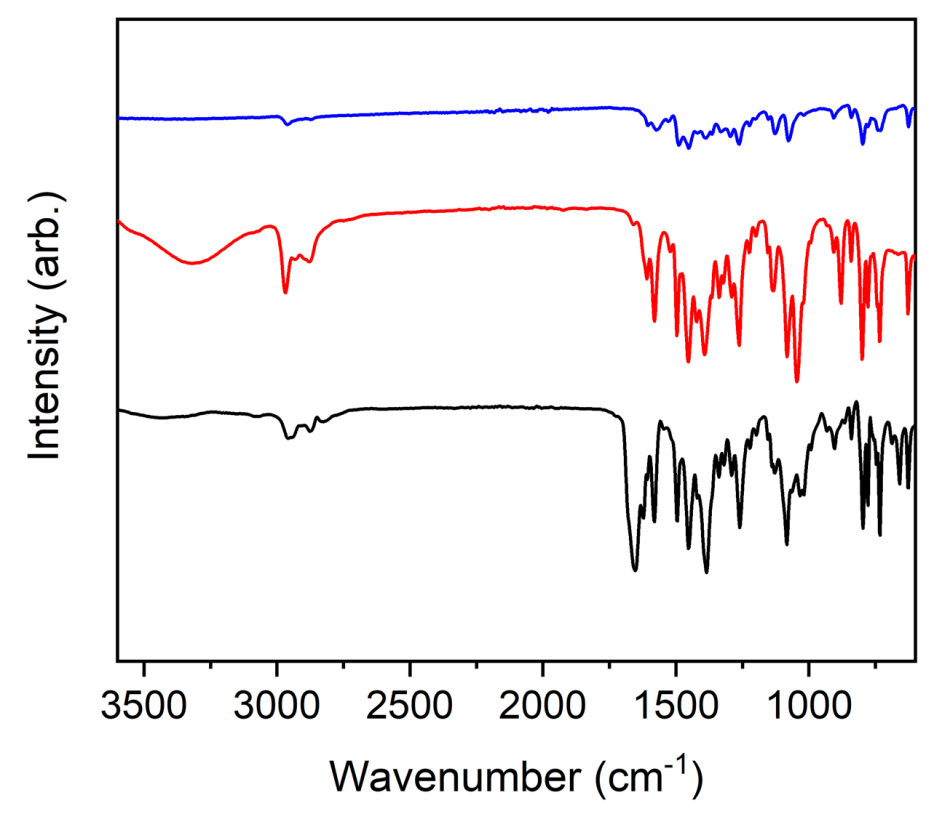

Figure S23. IR spectra of Ni-(5-OProp) as synthesized (black), solvent exchanged with EtOH (red), and activated (blue). 


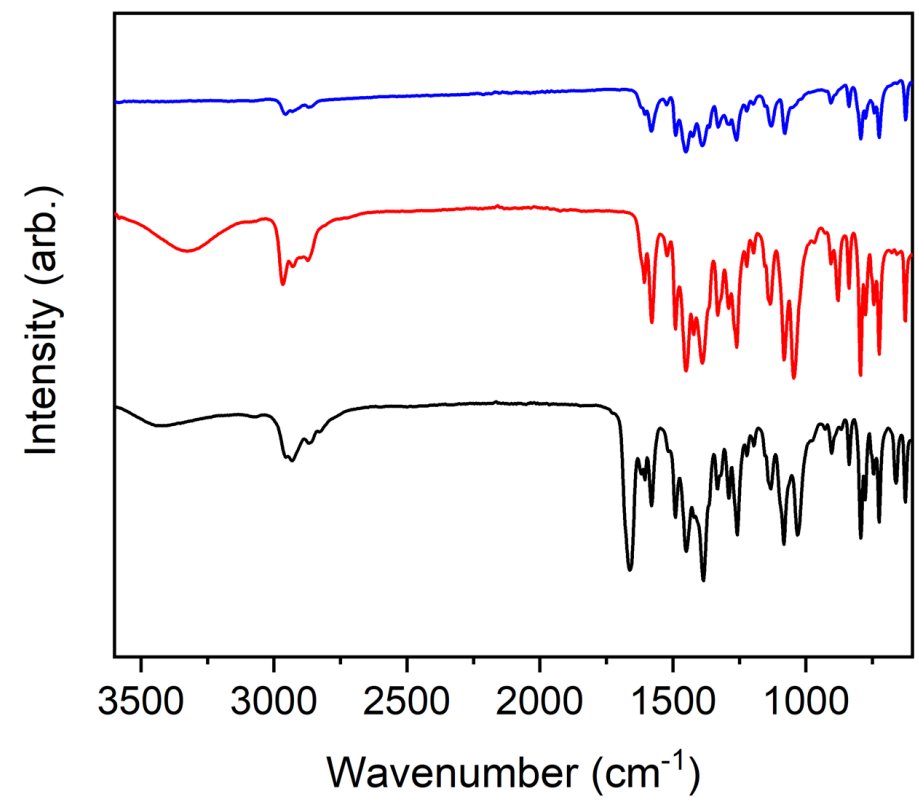

Figure S24. IR spectra of Co-(5-OHept) as synthesized (black), solvent exchanged with EtOH (red), and activated (blue). 


\section{Ultraviolet Visible Spectroscopy (UV-Vis) Spectra}

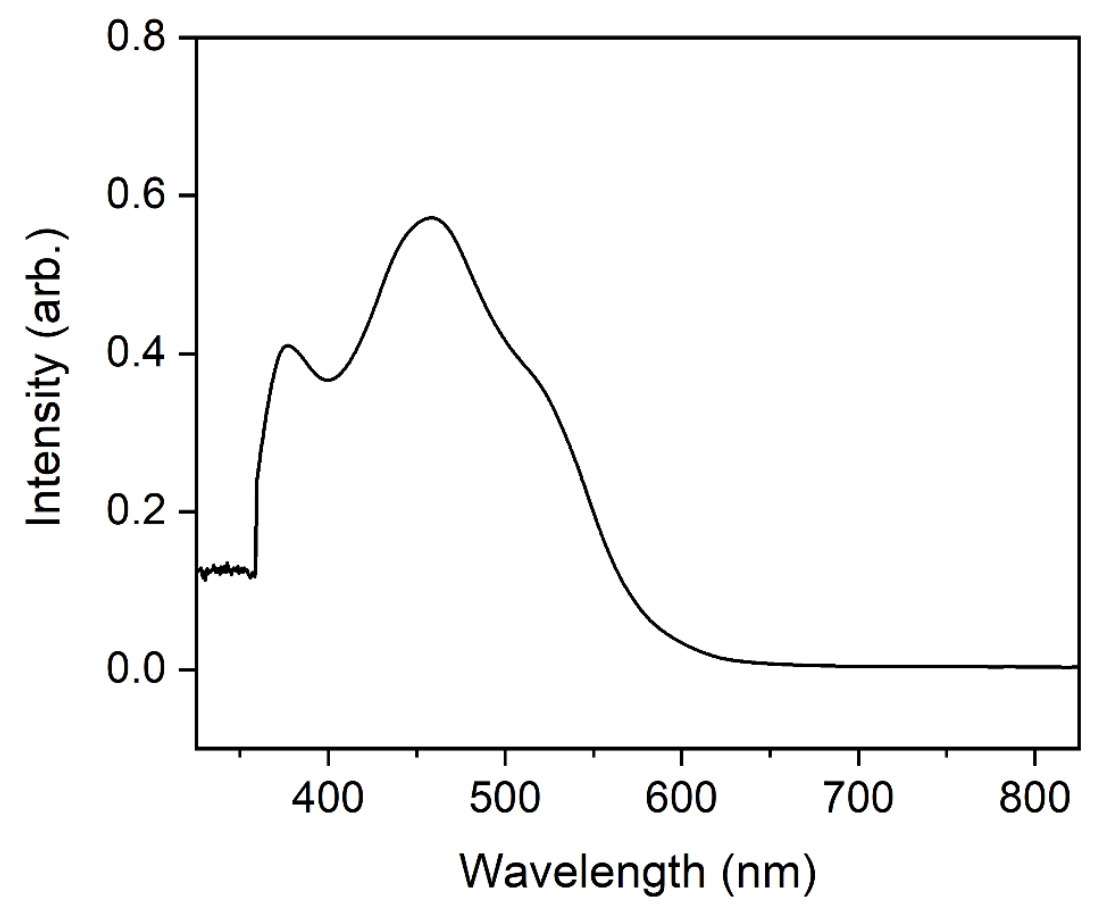

Figure S25. UV-Vis spectrum of Ni-(p-bdc) solvated in DMF at a concentration of $0.01 \mathrm{mM}$.

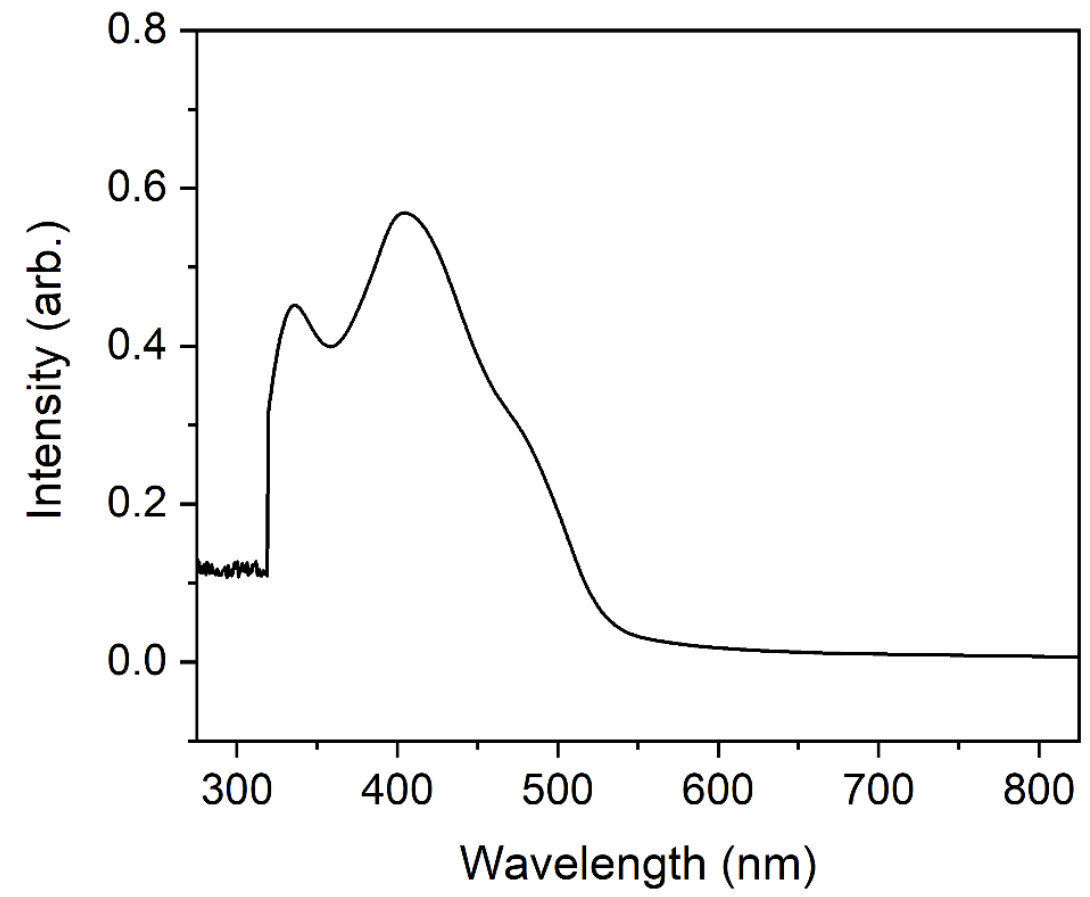

Figure S26. UV-Vis spectrum of Ni-(p-bdc) solvated in $\mathrm{CHCl}_{3}$ at a concentration of $0.01 \mathrm{mM}$. 


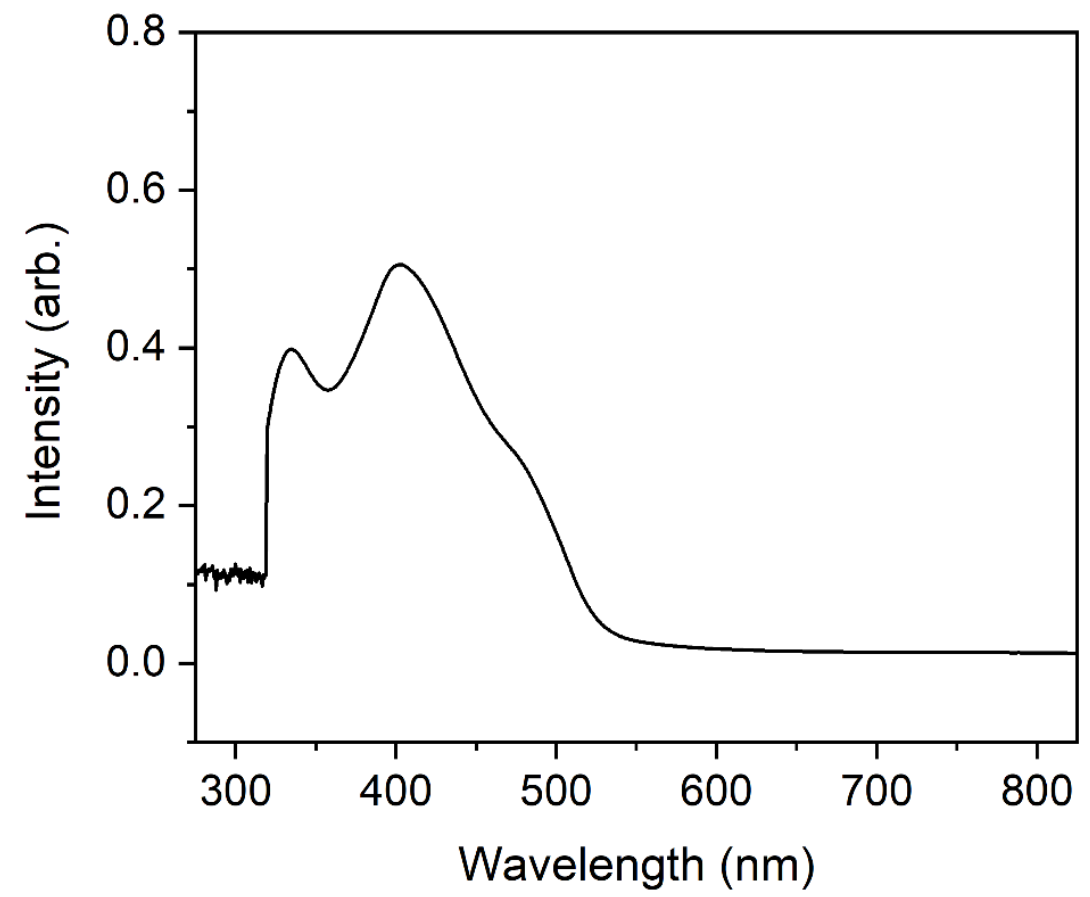

Figure S27. UV-Vis spectrum of Ni-(p-bdc) solvated in DCM at a concentration of $0.01 \mathrm{mM}$.

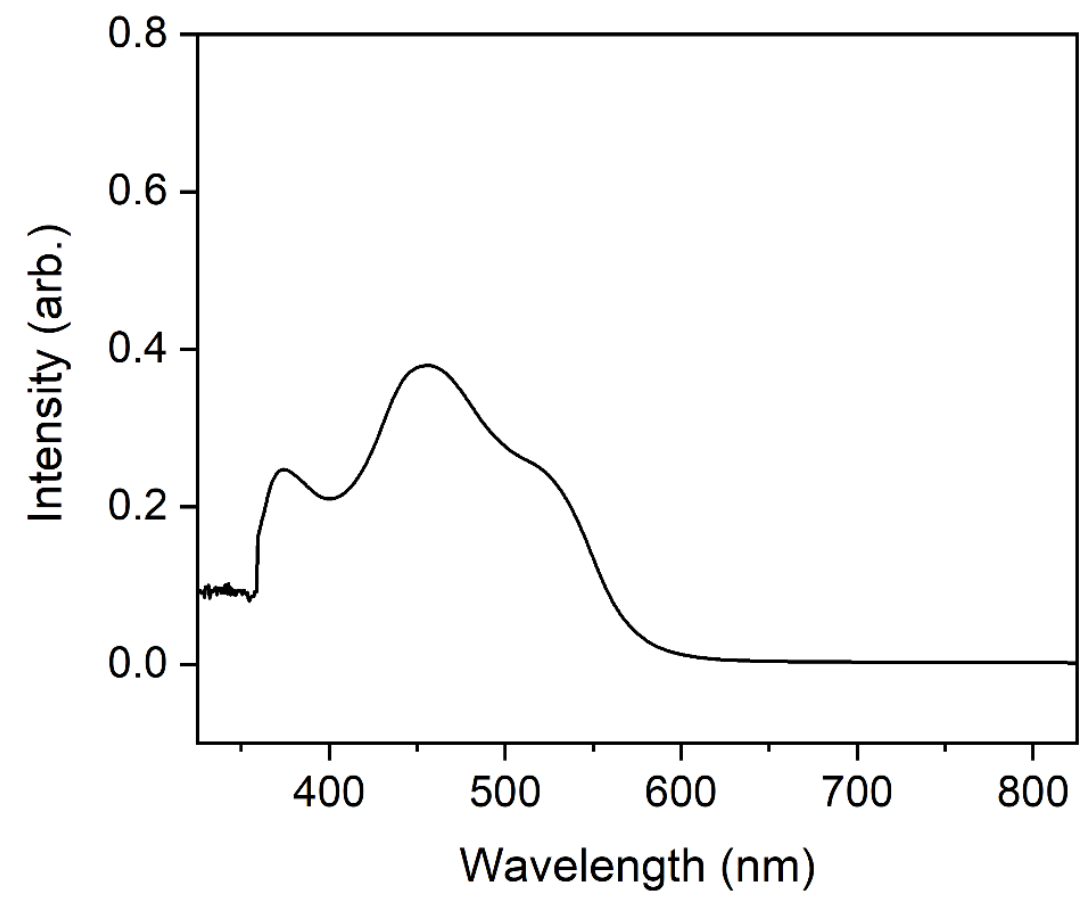

Figure S28. UV-Vis spectrum of $\mathrm{Ni}-(\mathrm{m}-\mathrm{bdc})$ solvated in $\mathrm{DMF}$ at a concentration of $0.01 \mathrm{mM}$. 


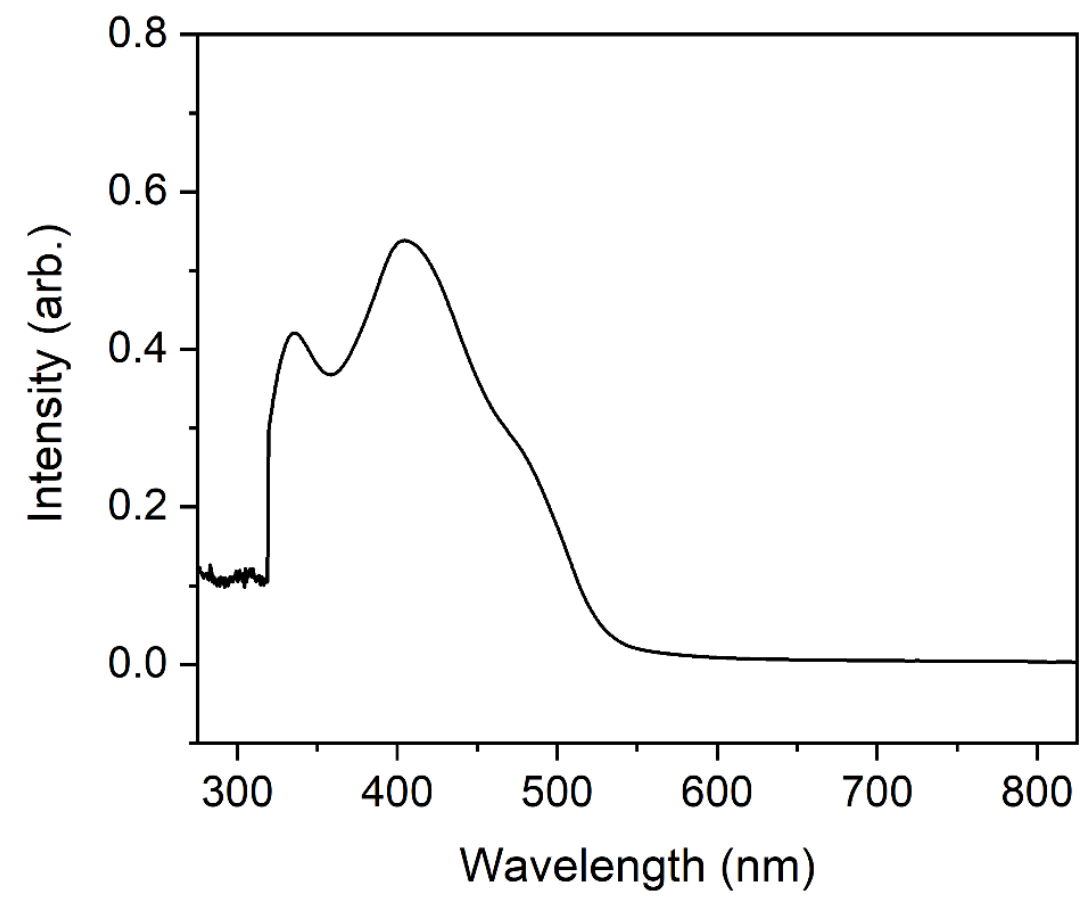

Figure S29. UV-Vis spectrum of $\mathrm{Ni}-(\mathrm{m}-\mathrm{bdc})$ solvated in $\mathrm{CHCl}_{3}$ at a concentration of $0.01 \mathrm{mM}$.

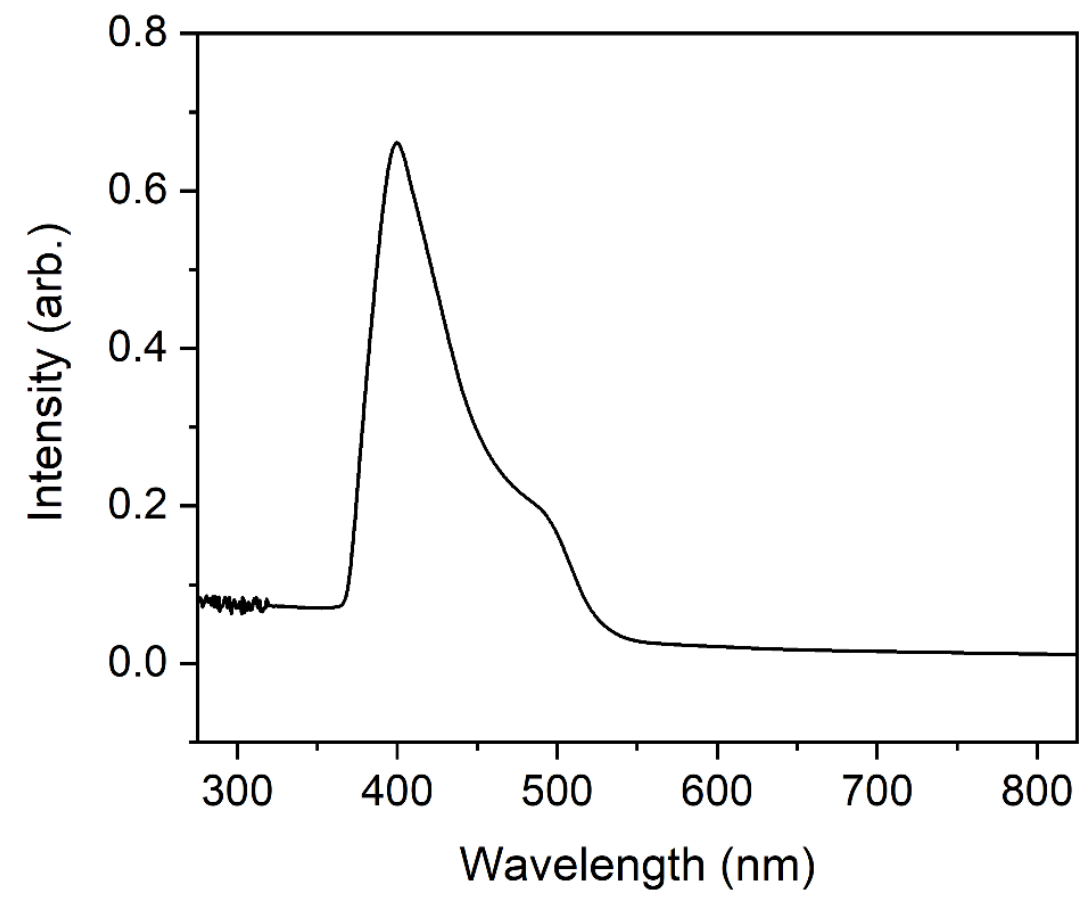

Figure S30. UV-Vis spectrum of Ni-(m-bdc) solvated in acetone at a concentration of $0.01 \mathrm{mM}$. 


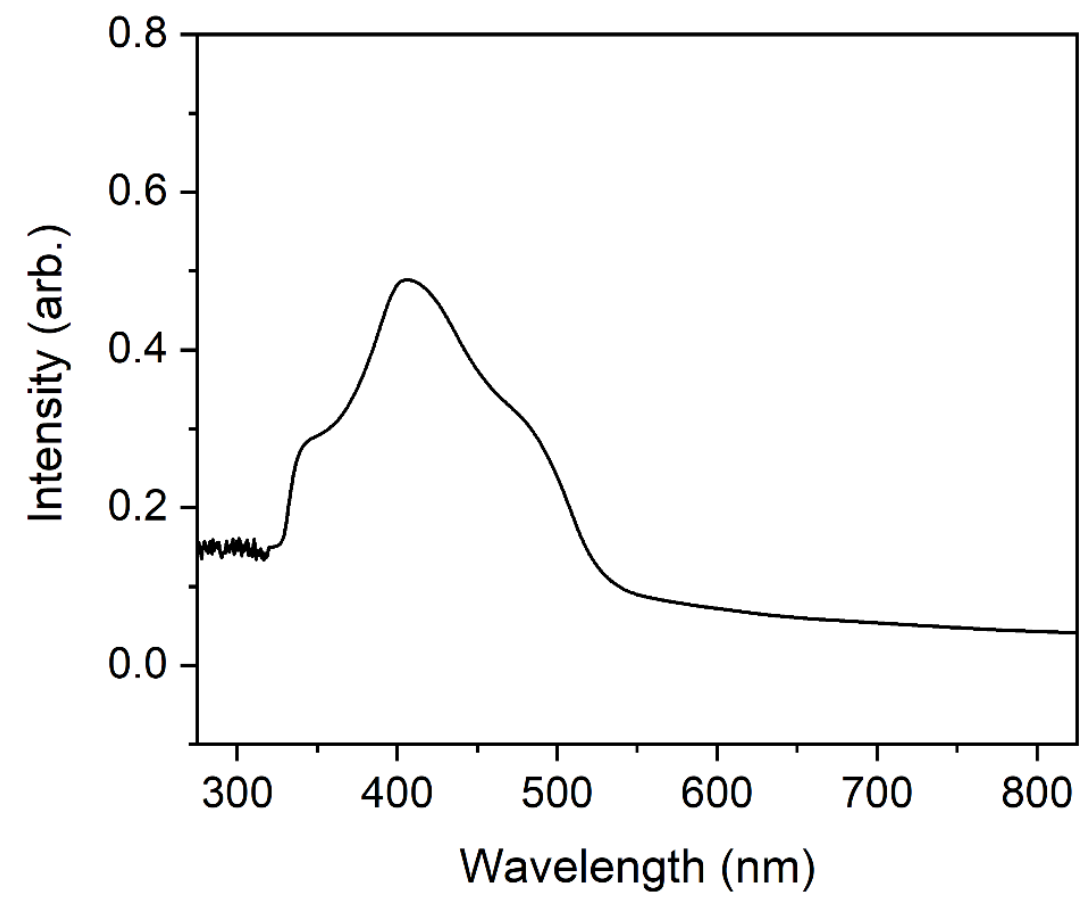

Figure S31. UV-Vis spectrum of Ni-(m-bdc) solvated in DCM at a concentration of $0.01 \mathrm{mM}$.

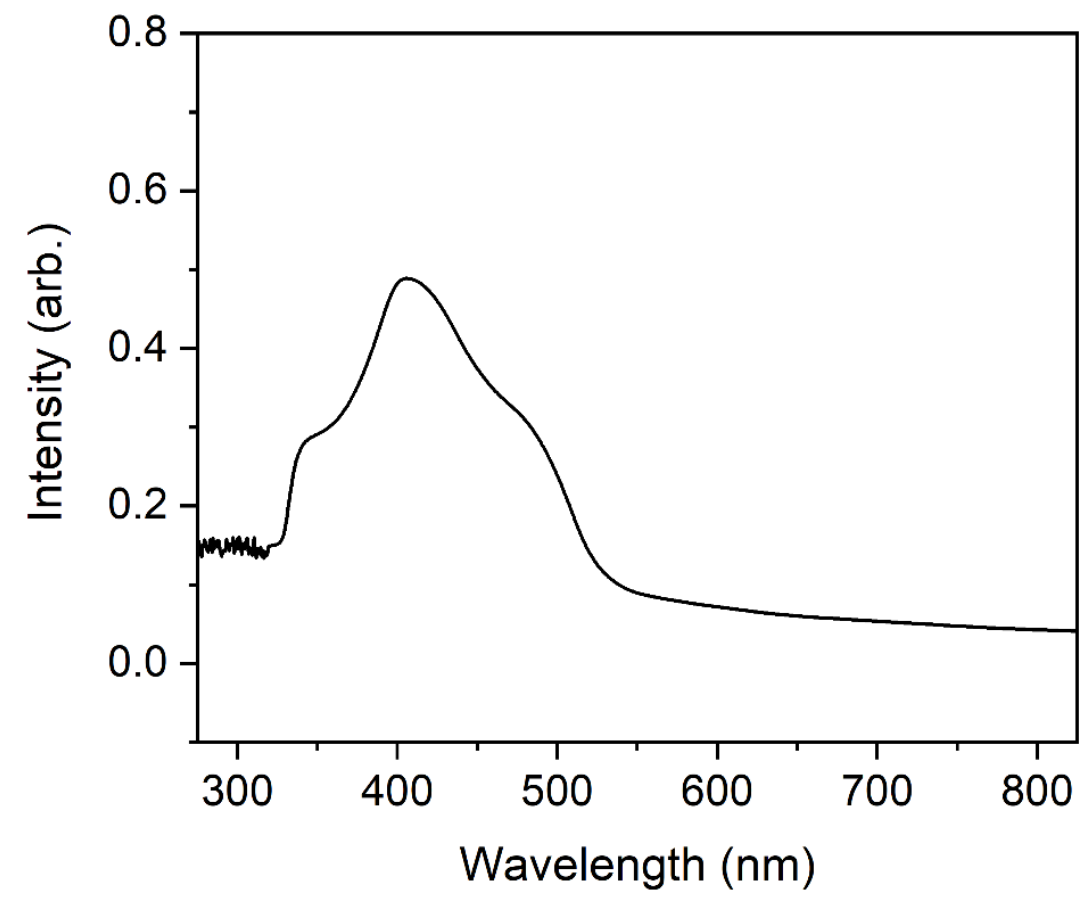

Figure S32. UV-Vis spectrum of Ni-(m-bdc) solvated in THF at a concentration of $0.01 \mathrm{mM}$. 


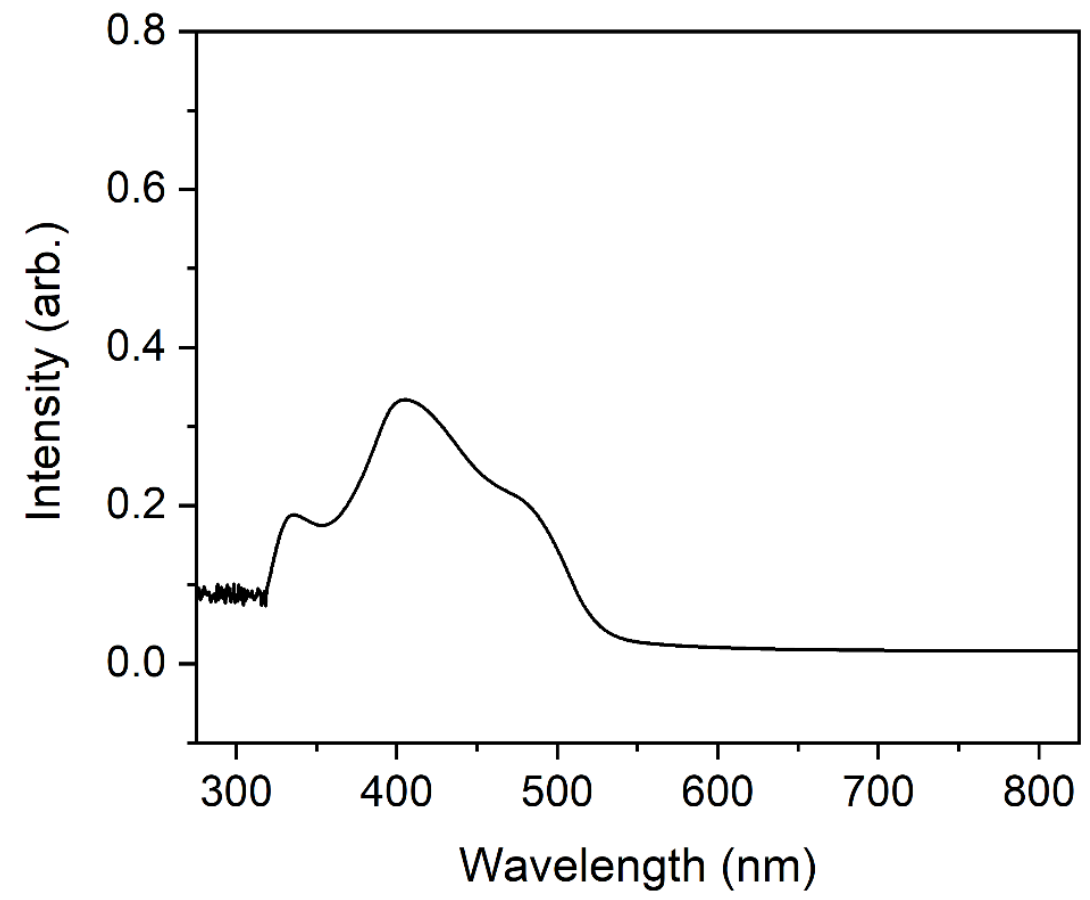

Figure S33. UV-Vis spectrum of $\mathrm{Ni}-(\mathrm{m}-\mathrm{bdc})$ solvated in benzene at a concentration of $0.01 \mathrm{mM}$.

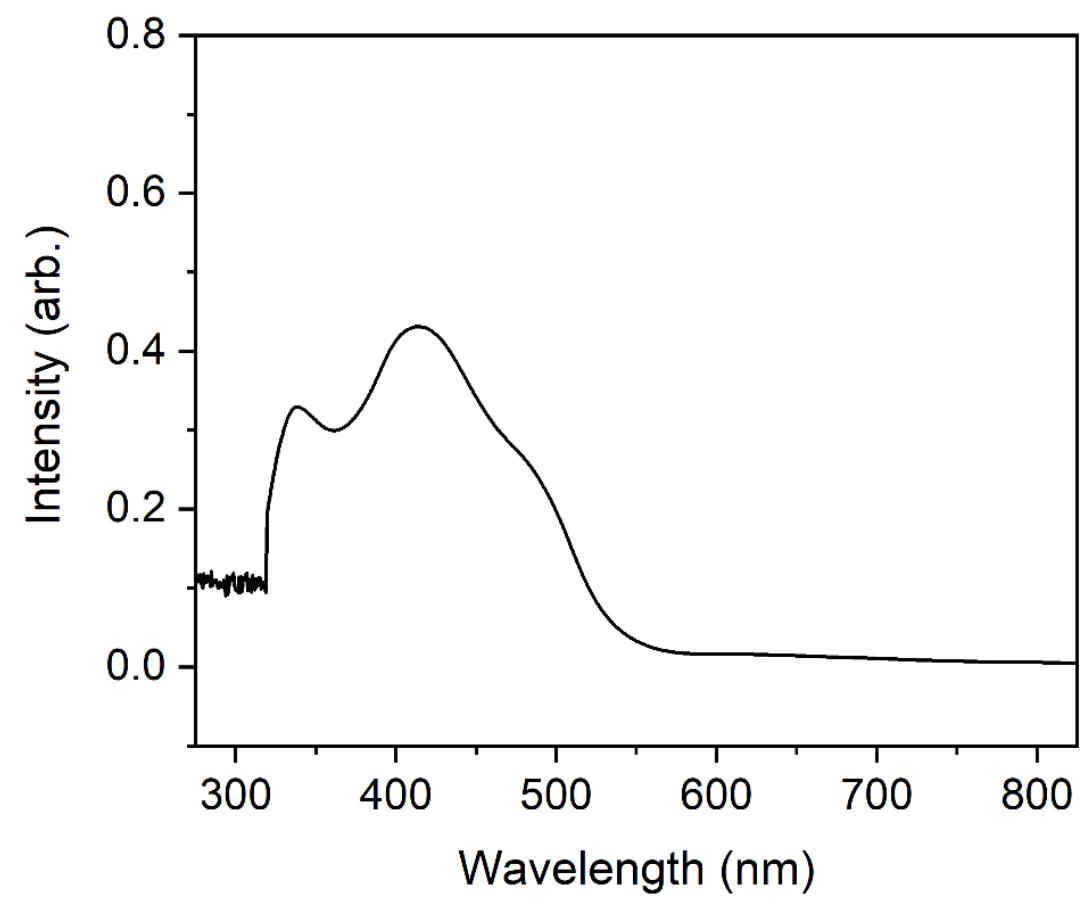

Figure S34. UV-Vis spectrum of Co-(5-Sulfo) solvated in DMF at a concentration of $0.01 \mathrm{mM}$. 


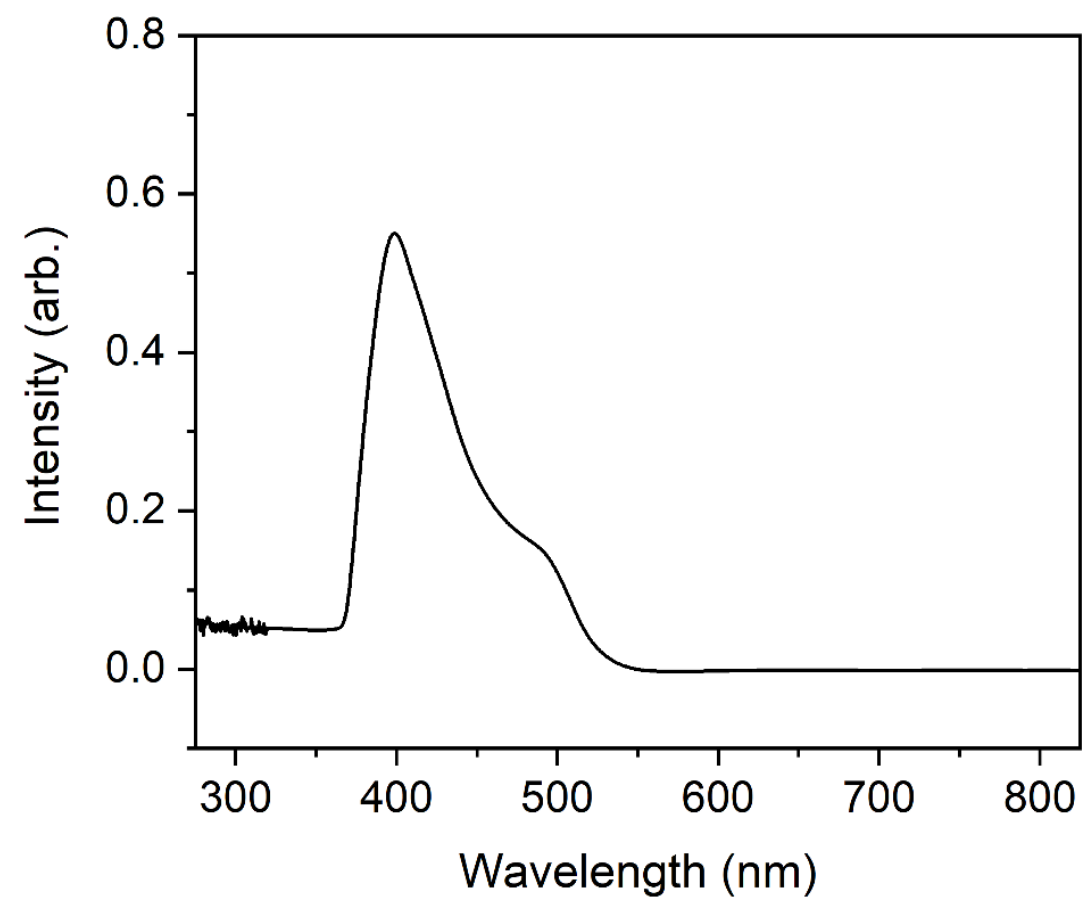

Figure S35. UV-Vis spectrum of Co-(5-Sulfo) solvated in acetone at a concentration of $0.01 \mathrm{mM}$.

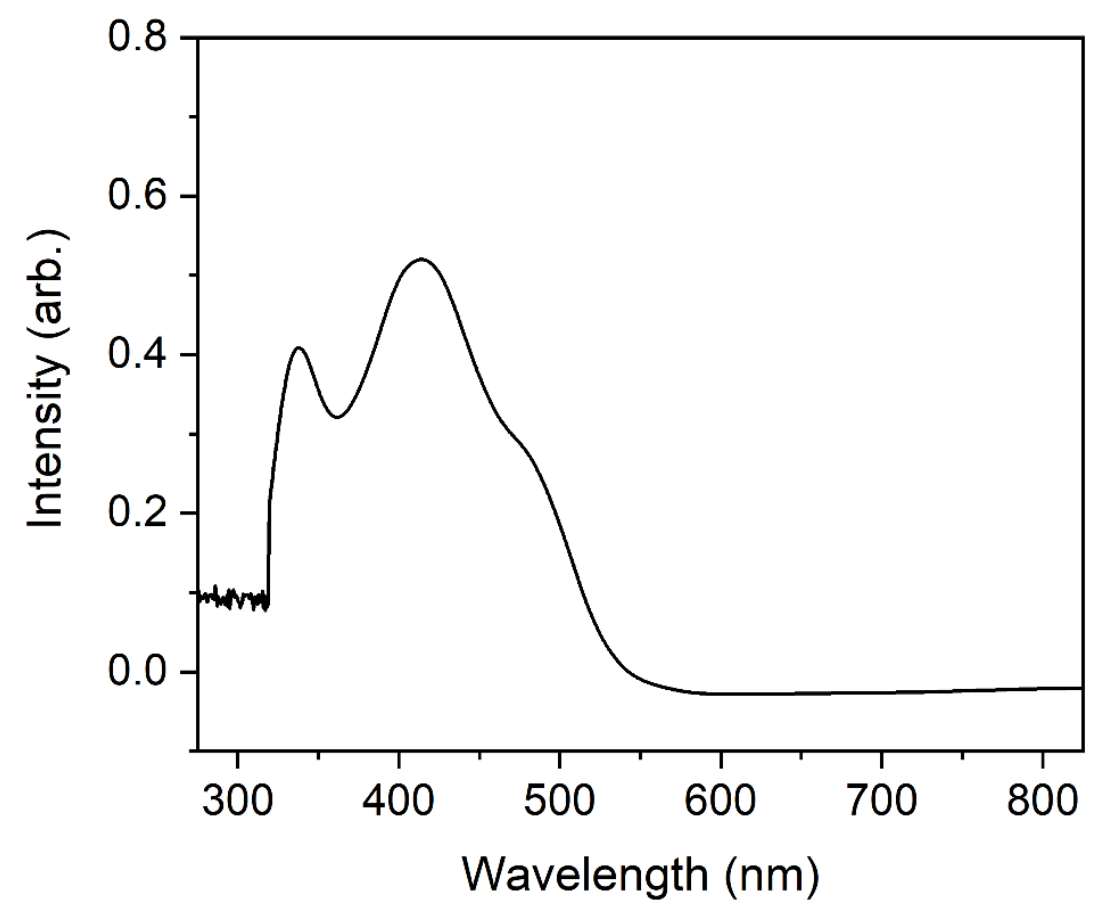

Figure S36. UV-Vis spectrum of Ni-(2-Methyl) solvated in DMF at a concentration of $0.01 \mathrm{mM}$. 


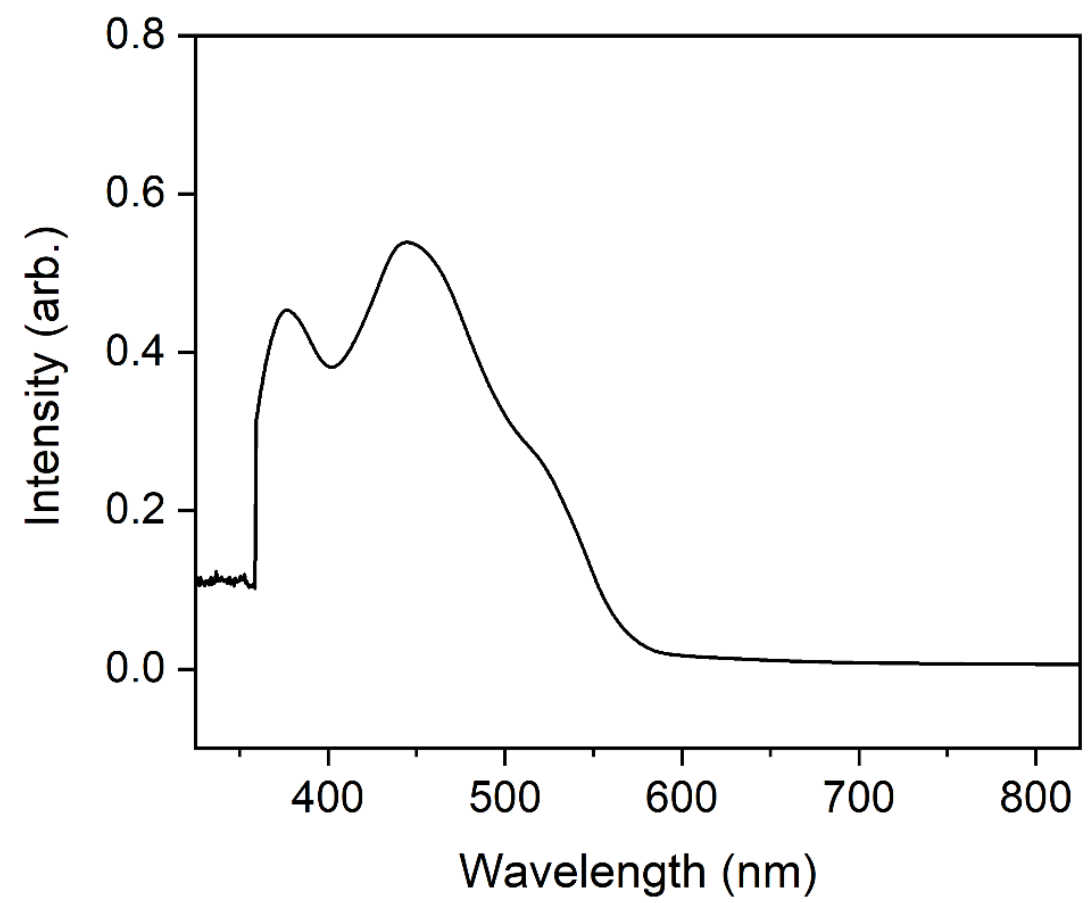

Figure S37. UV-Vis spectrum of Ni-(2-Methyl) solvated in $\mathrm{CHCl}_{3}$ at a concentration of $0.01 \mathrm{mM}$.

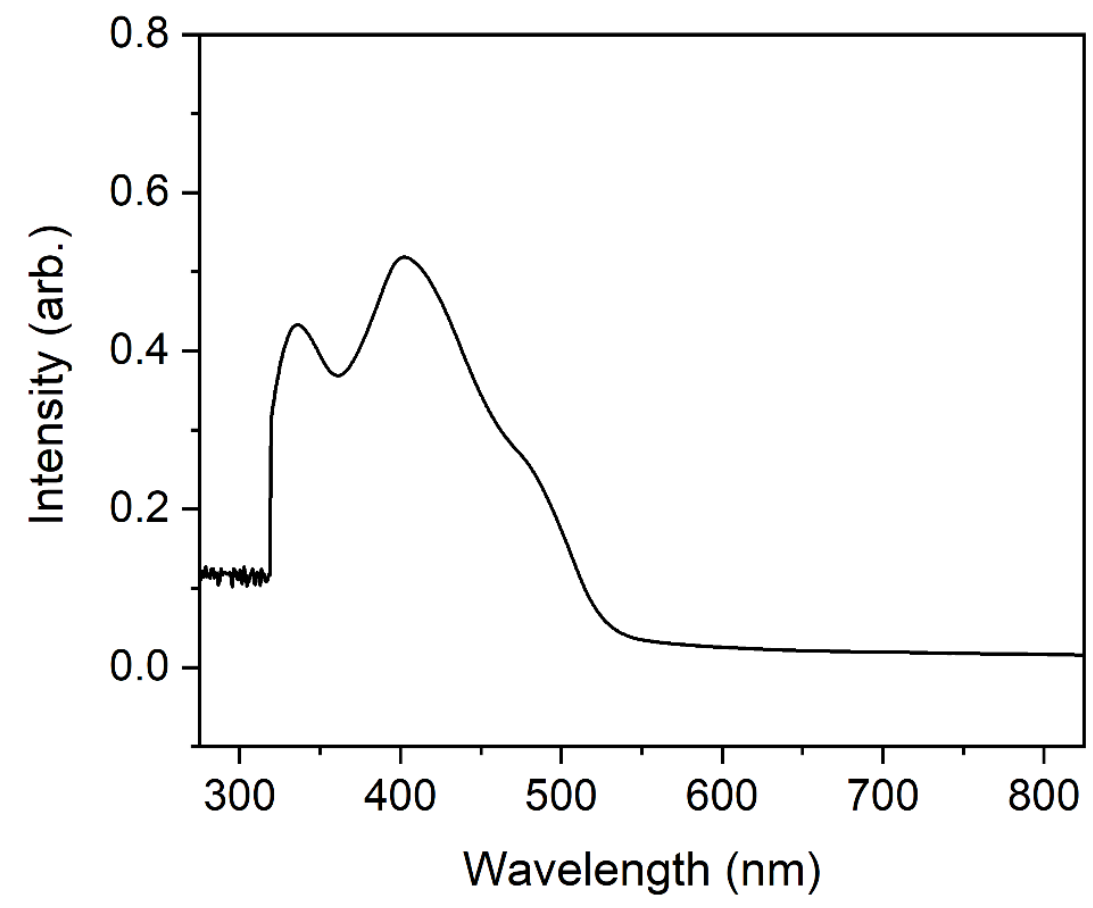

Figure S38. UV-Vis spectrum of Ni-(2-Methyl) solvated in DCM at a concentration of $0.01 \mathrm{mM}$. 


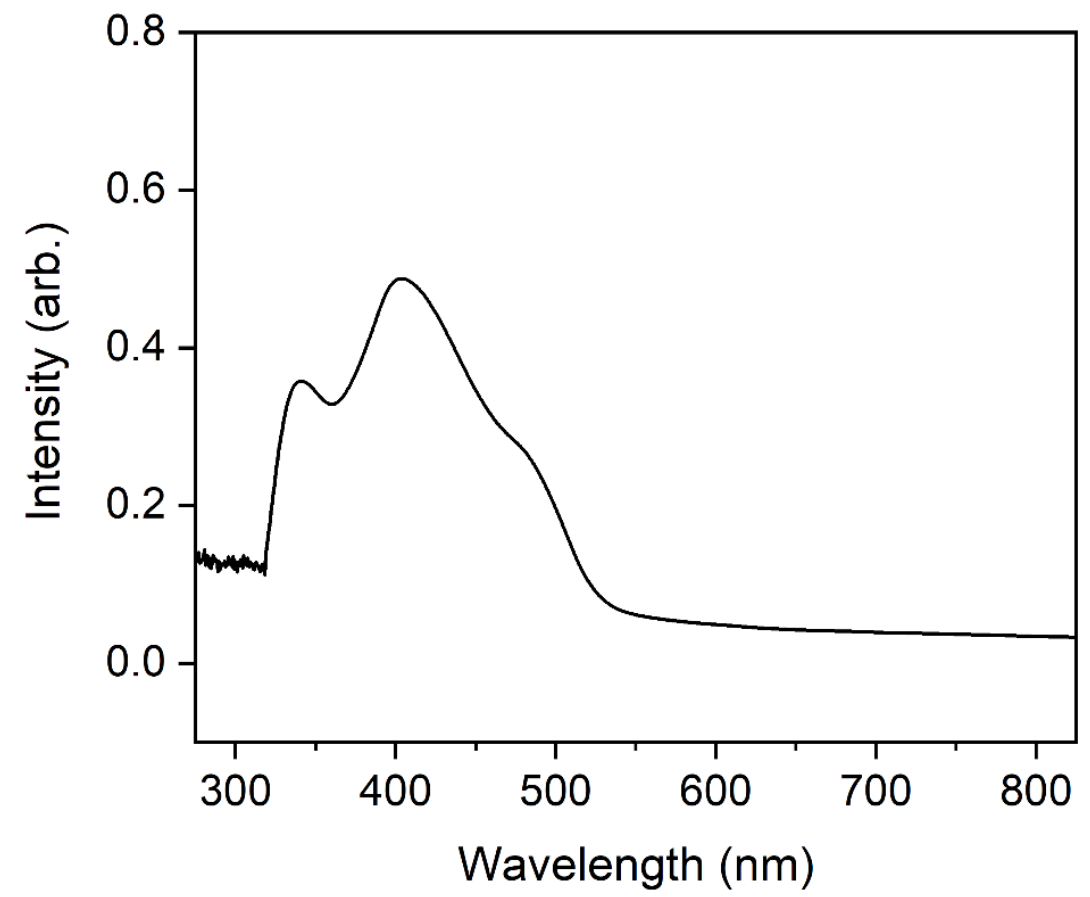

Figure S39. UV-Vis spectrum of Ni-(2-Methyl) solvated in benzene at a concentration of 0.01 $\mathrm{mM}$.

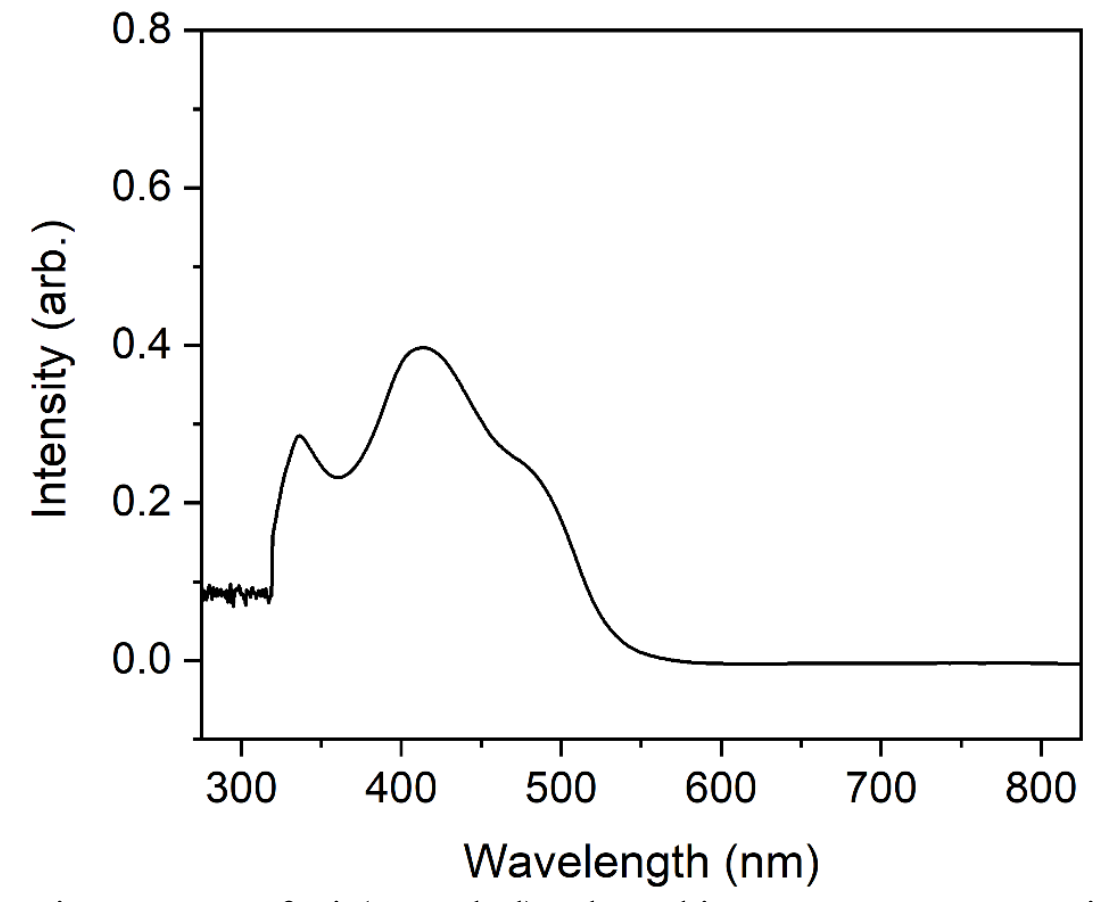

Figure S40. UV-Vis spectrum of Ni-(5-Methyl) solvated in DMF at a concentration of $0.01 \mathrm{mM}$. 


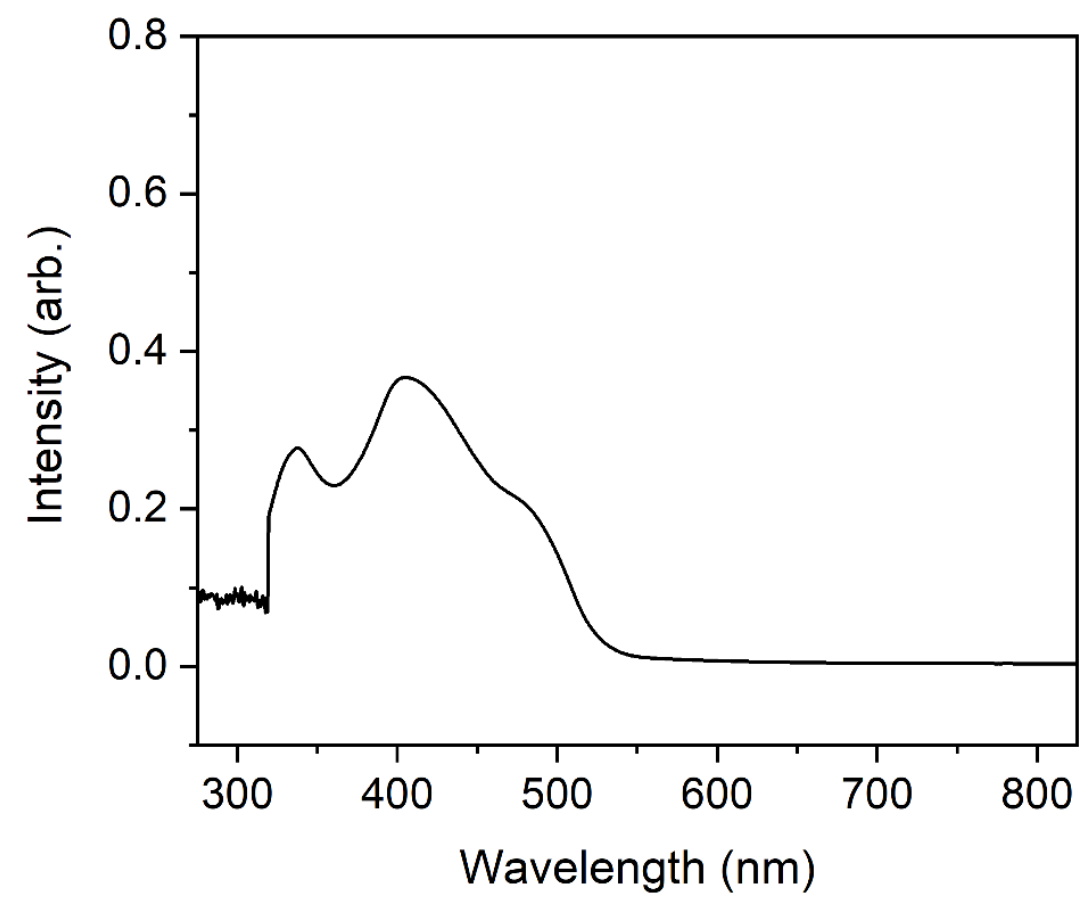

Figure S41. UV-Vis spectrum of Ni-(5-Methyl) solvated in $\mathrm{CHCl}_{3}$ at a concentration of $0.01 \mathrm{mM}$.

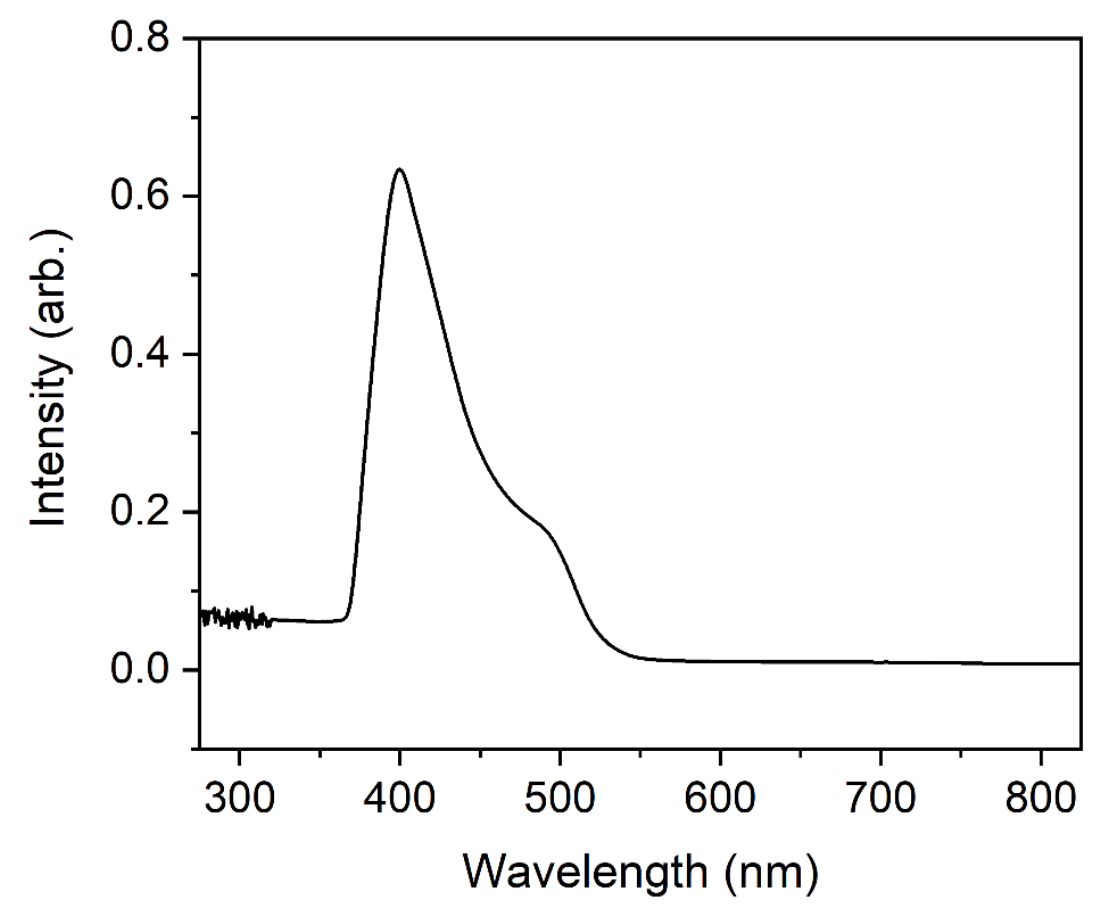

Figure S42. UV-Vis spectrum of Ni-(5-Methyl) solvated in acetone at a concentration of 0.01 $\mathrm{mM}$. 


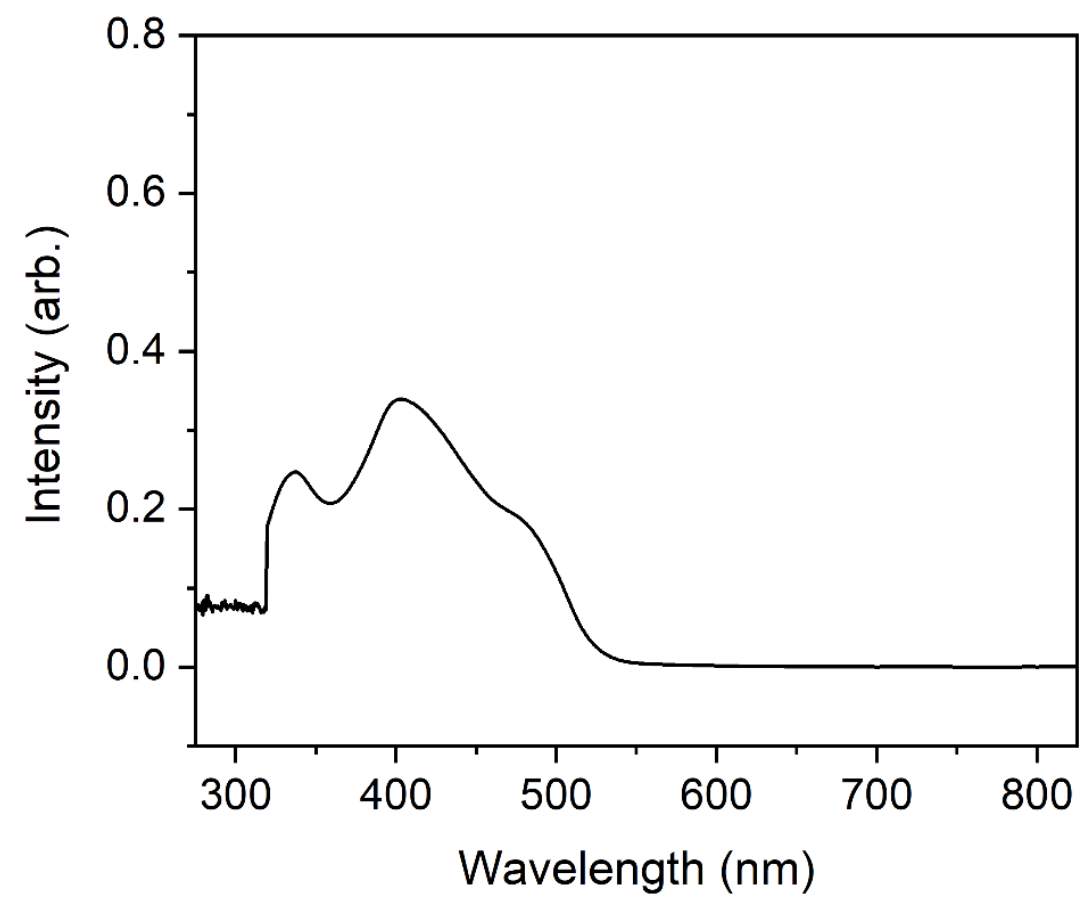

Figure S43. UV-Vis spectrum of Ni-(5-Methyl) solvated in DCM at a concentration of $0.01 \mathrm{mM}$.

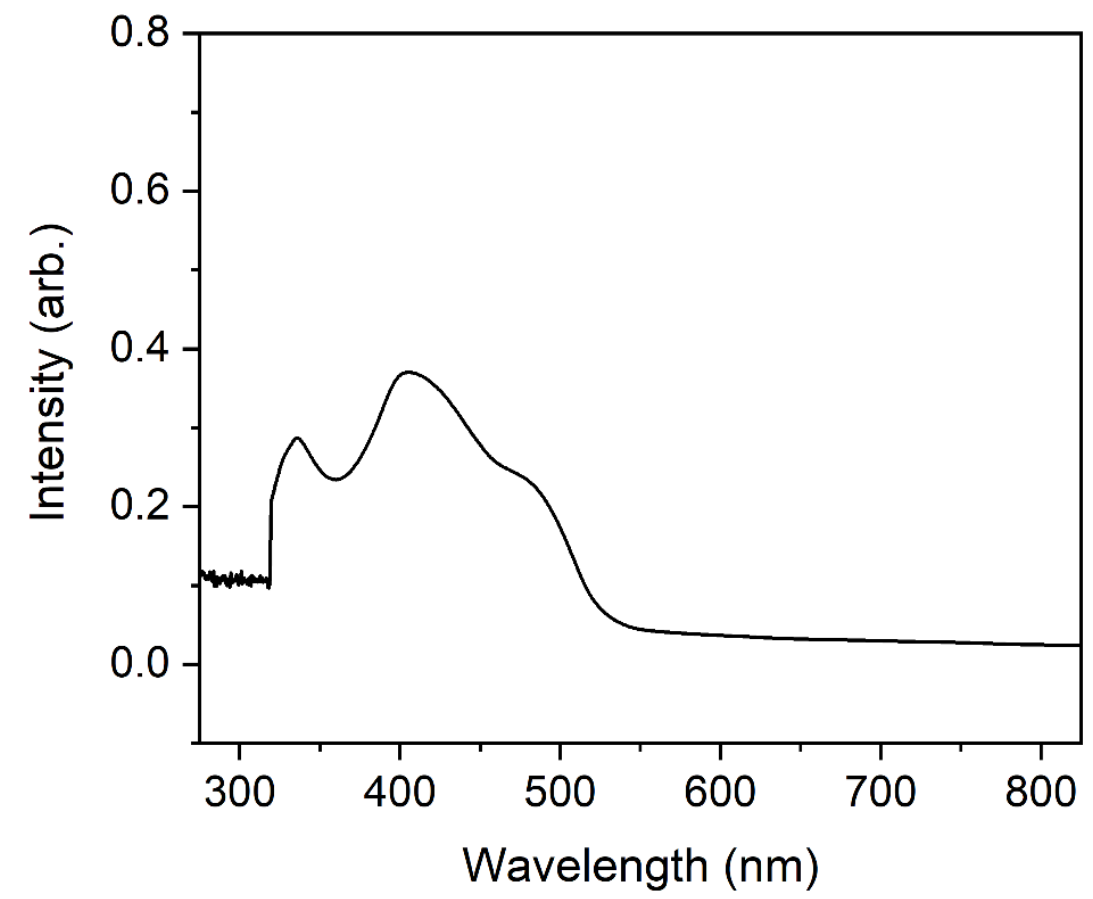

Figure S44. UV-Vis spectrum of Ni-(5-Methyl) solvated in EtOAc at a concentration of $0.01 \mathrm{mM}$. 


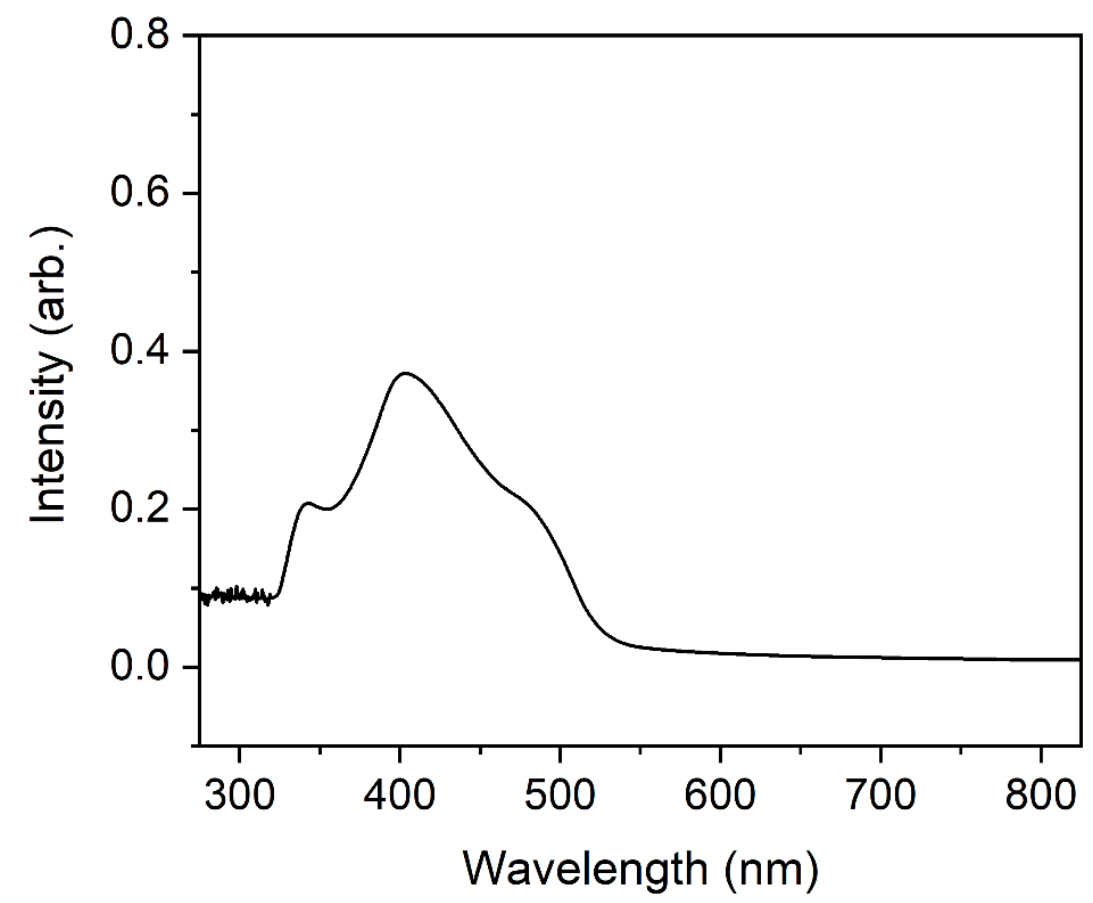

Figure S45. UV-Vis spectrum of Ni-(5-Methyl) solvated in toluene at a concentration of $0.01 \mathrm{mM}$.

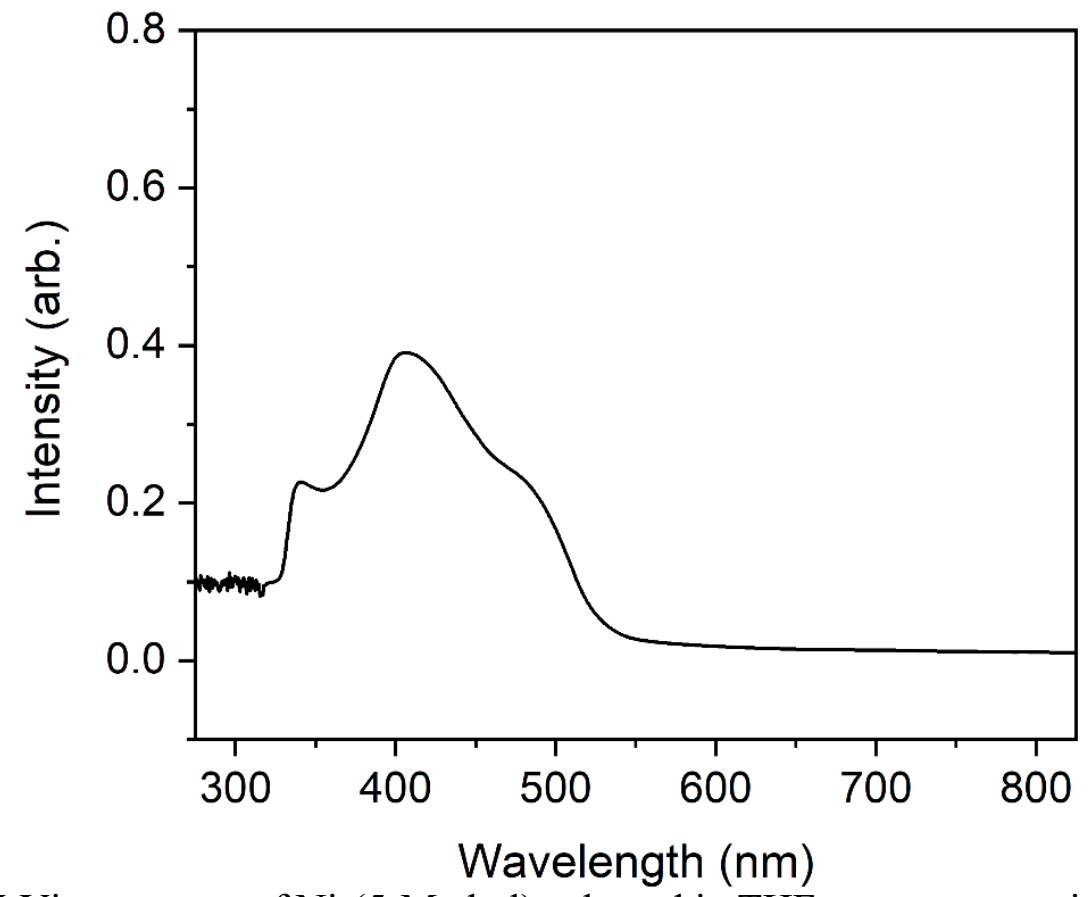

Figure S46. UV-Vis spectrum of Ni-(5-Methyl) solvated in THF at a concentration of $0.01 \mathrm{mM}$. 


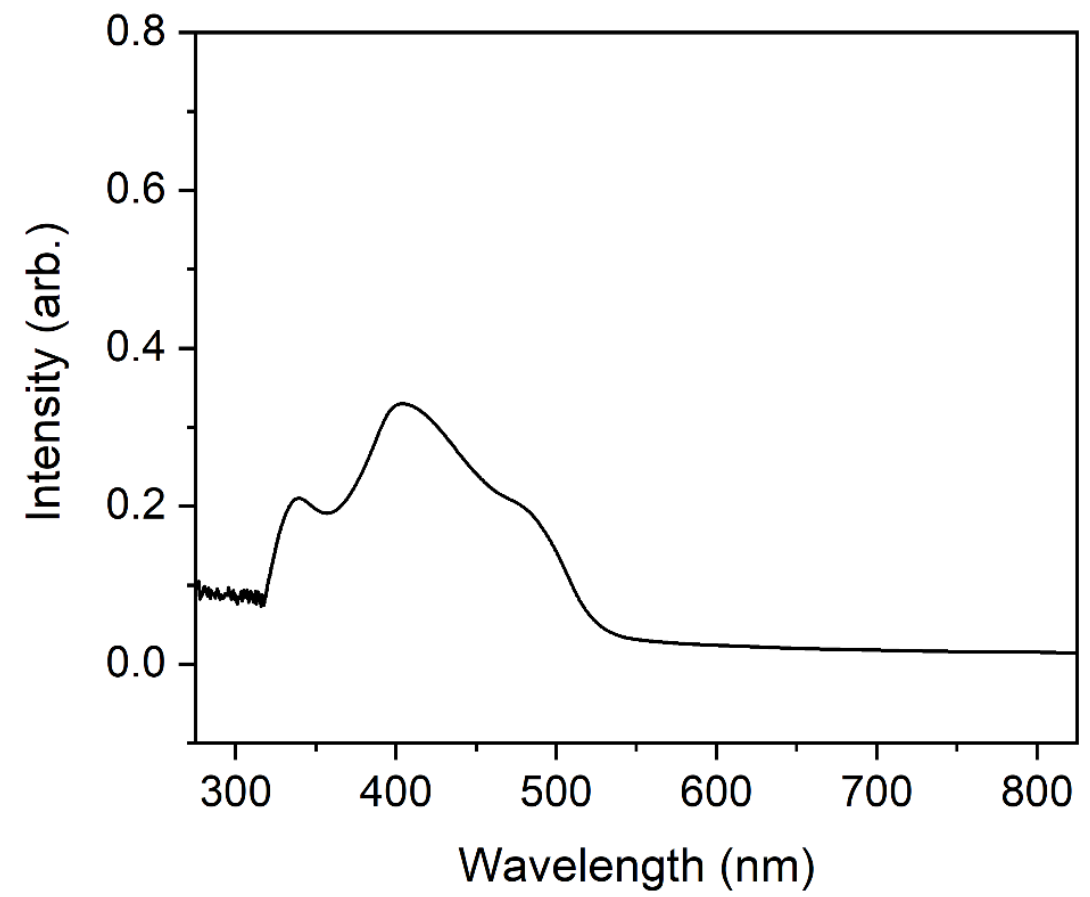

Figure S47. UV-Vis spectrum of Ni-(5-Methyl) solvated in benzene at a concentration of 0.01 $\mathrm{mM}$.

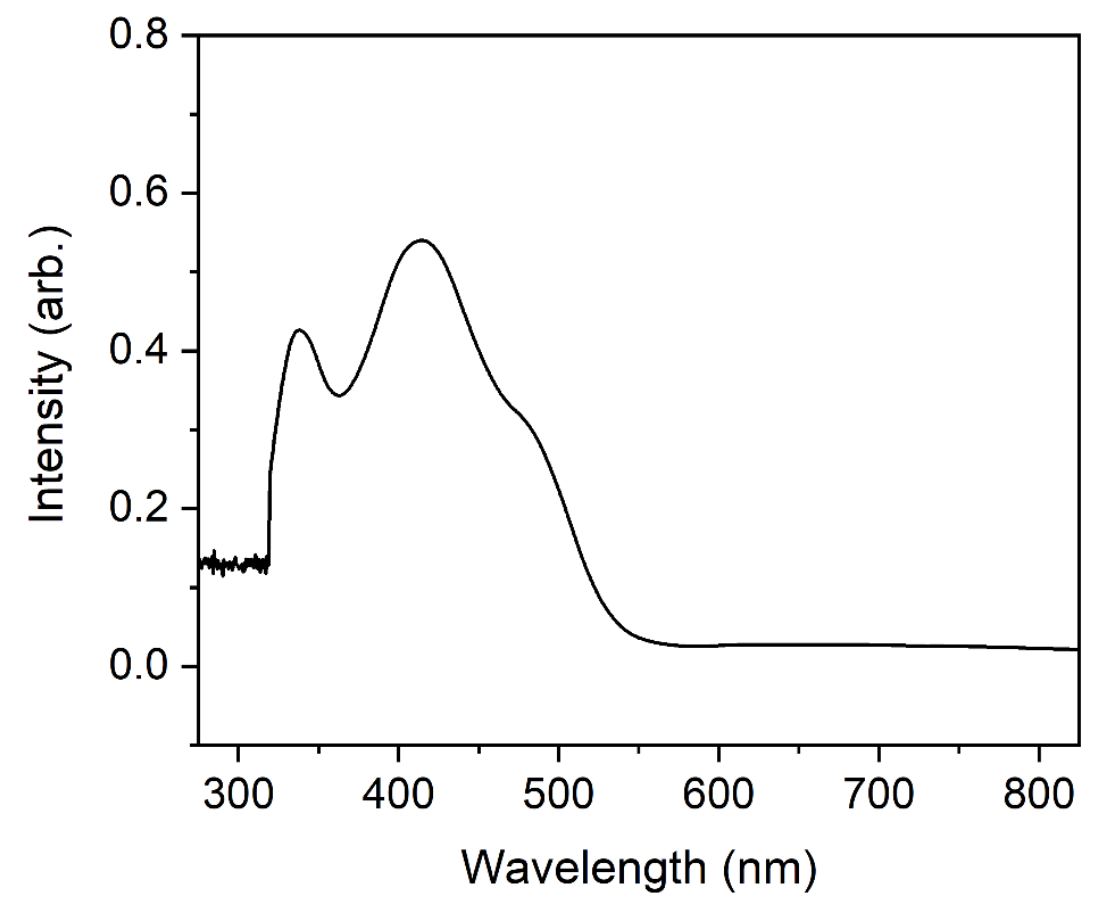

Figure S48. UV-Vis spectrum of Ni-(2-Br) solvated in DMF at a concentration of $0.01 \mathrm{mM}$. 


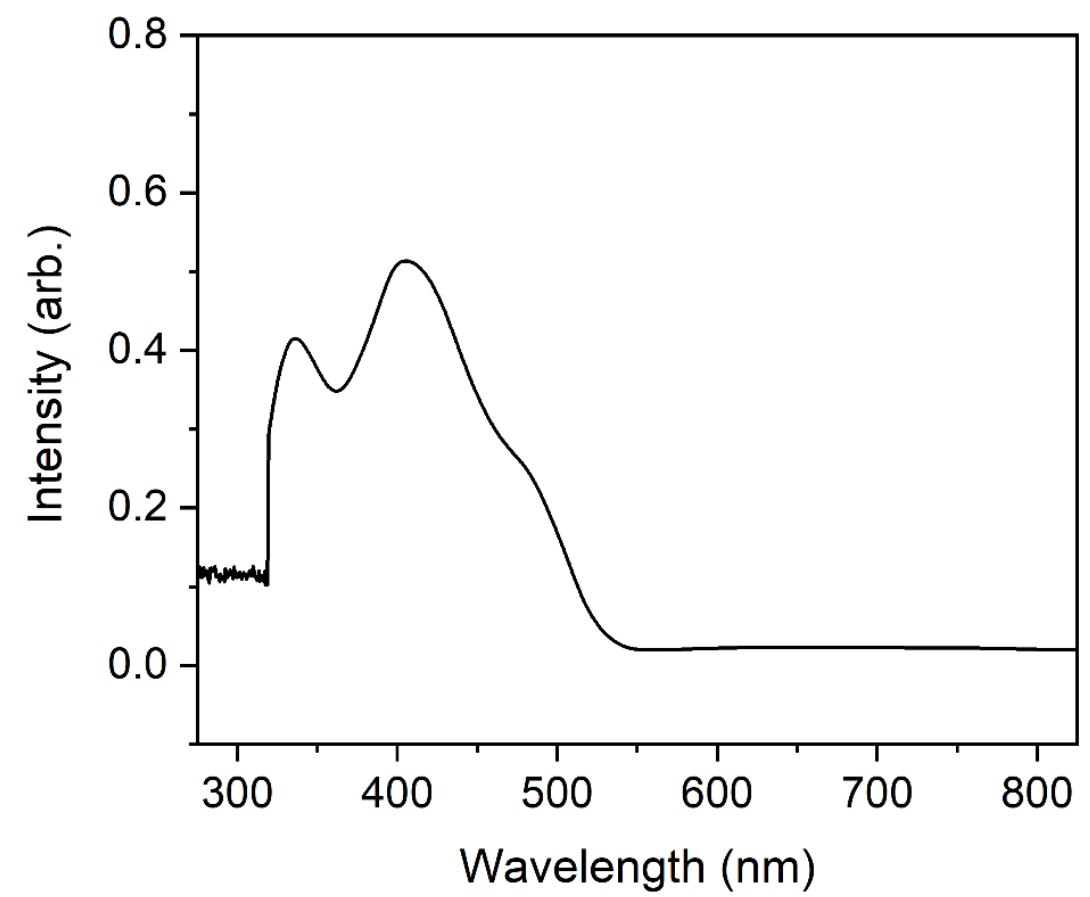

Figure S49. UV-Vis spectrum of Ni-(2-Br) solvated in $\mathrm{CHCl}_{3}$ at a concentration of $0.01 \mathrm{mM}$.

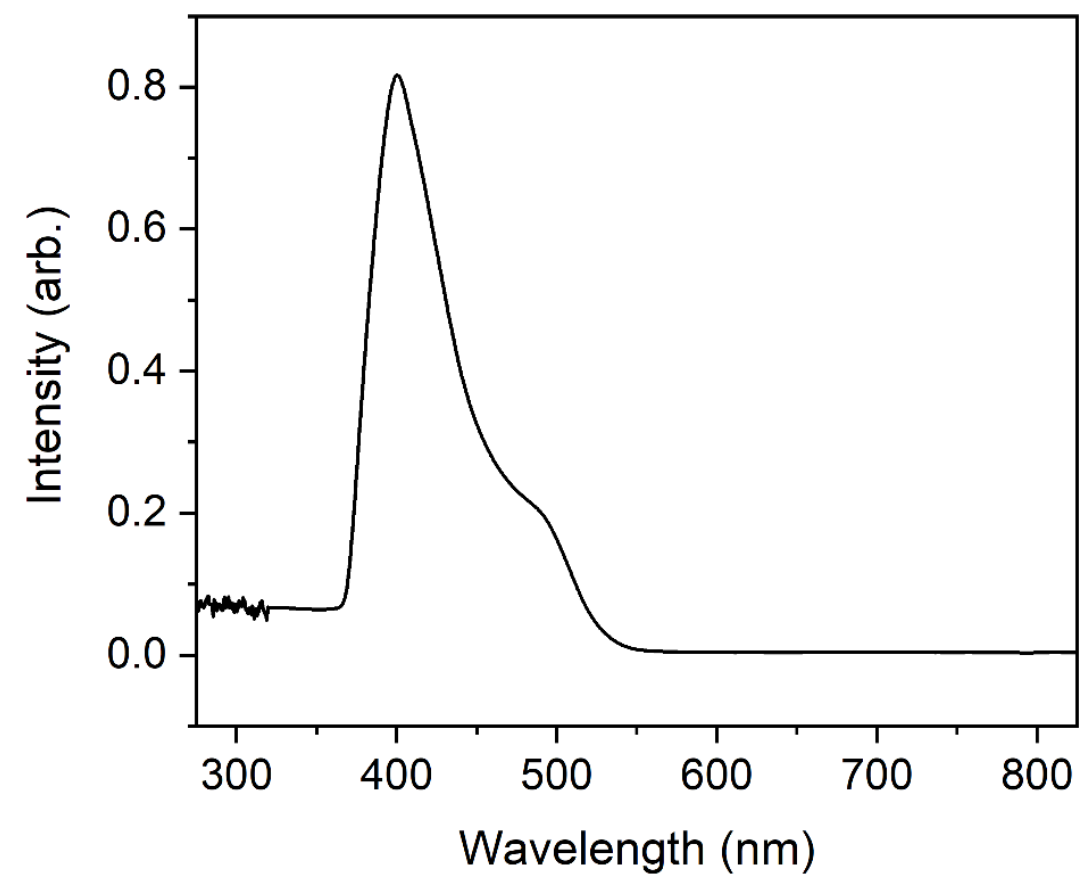

Figure S50. UV-Vis spectrum of Ni-(2-Br) solvated in acetone at a concentration of $0.01 \mathrm{mM}$. 


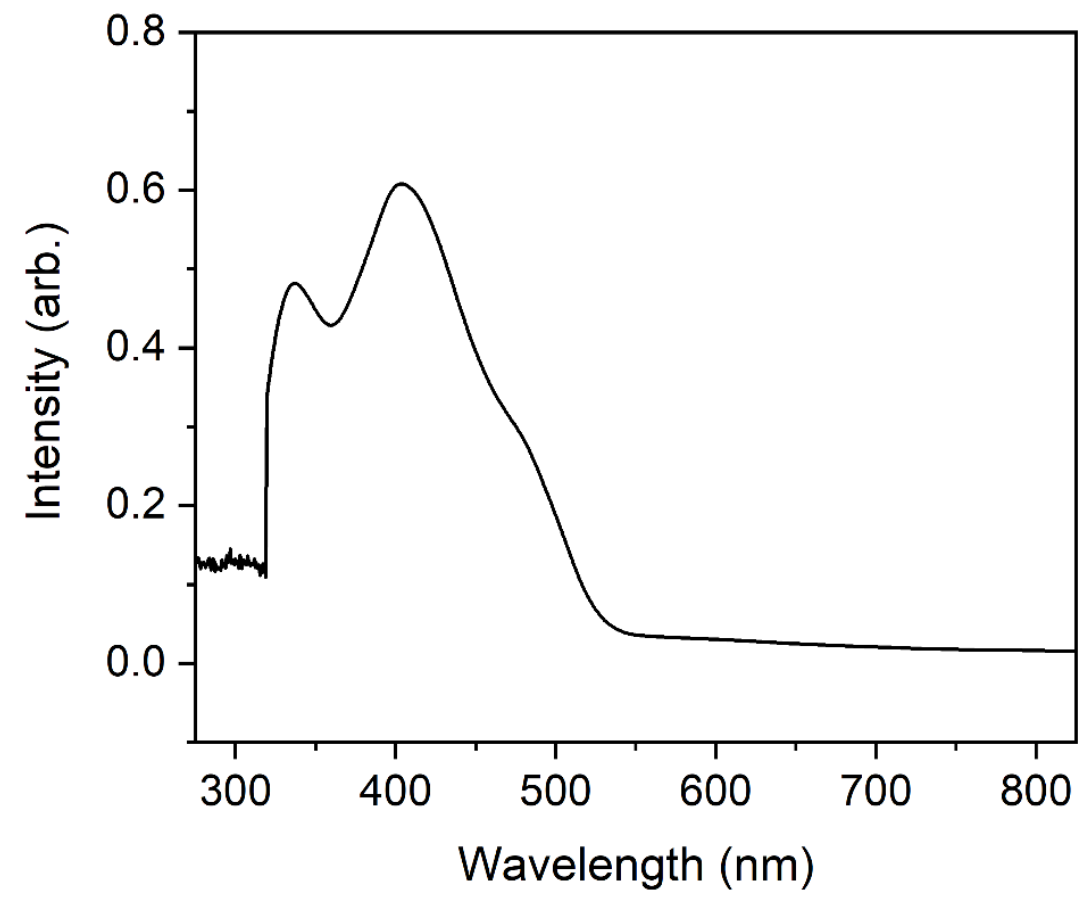

Figure S51. UV-Vis spectrum of Ni-(2-Br) solvated in DCM at a concentration of $0.01 \mathrm{mM}$.

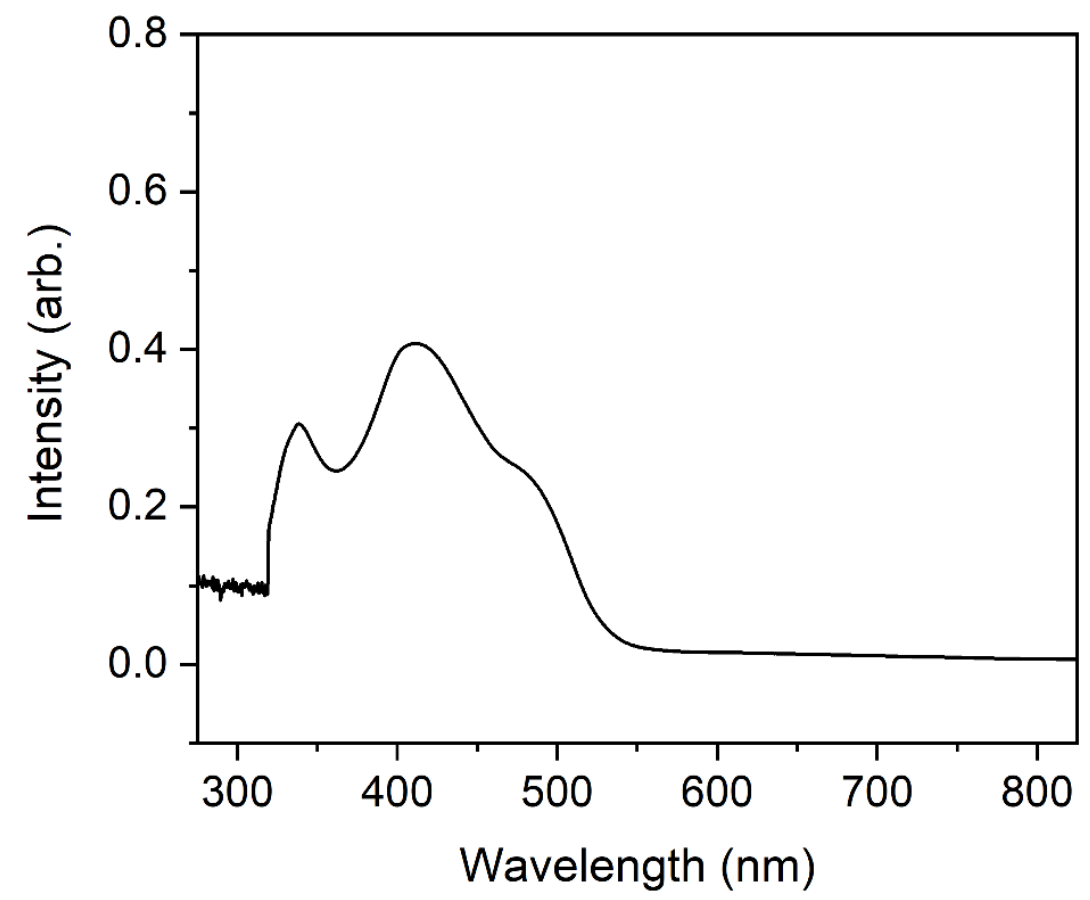

Figure S52. UV-Vis spectrum of $\mathrm{Ni}-(5-\mathrm{Br})$ solvated in DMF at a concentration of $0.01 \mathrm{mM}$. 


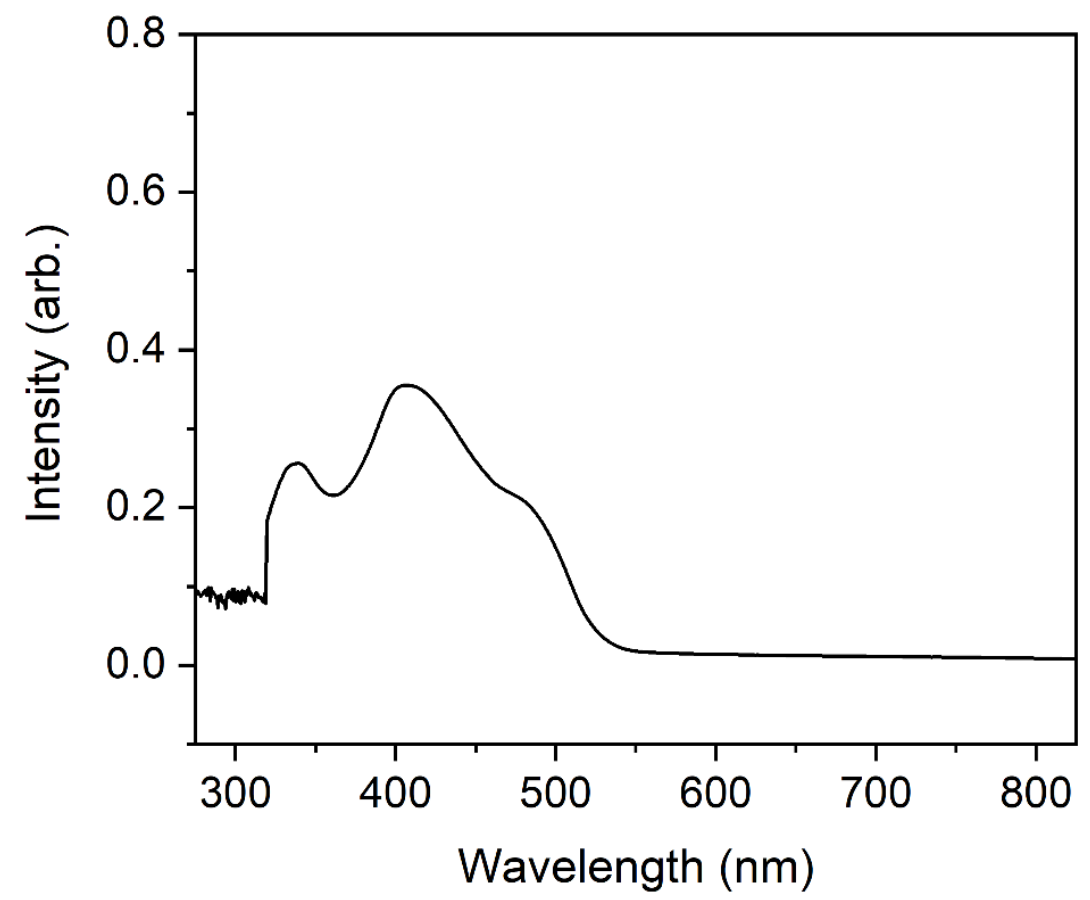

Figure S52. UV-Vis spectrum of $\mathrm{Ni}-(5-\mathrm{Br})$ solvated in $\mathrm{CHCl}_{3}$ at a concentration of $0.01 \mathrm{mM}$.

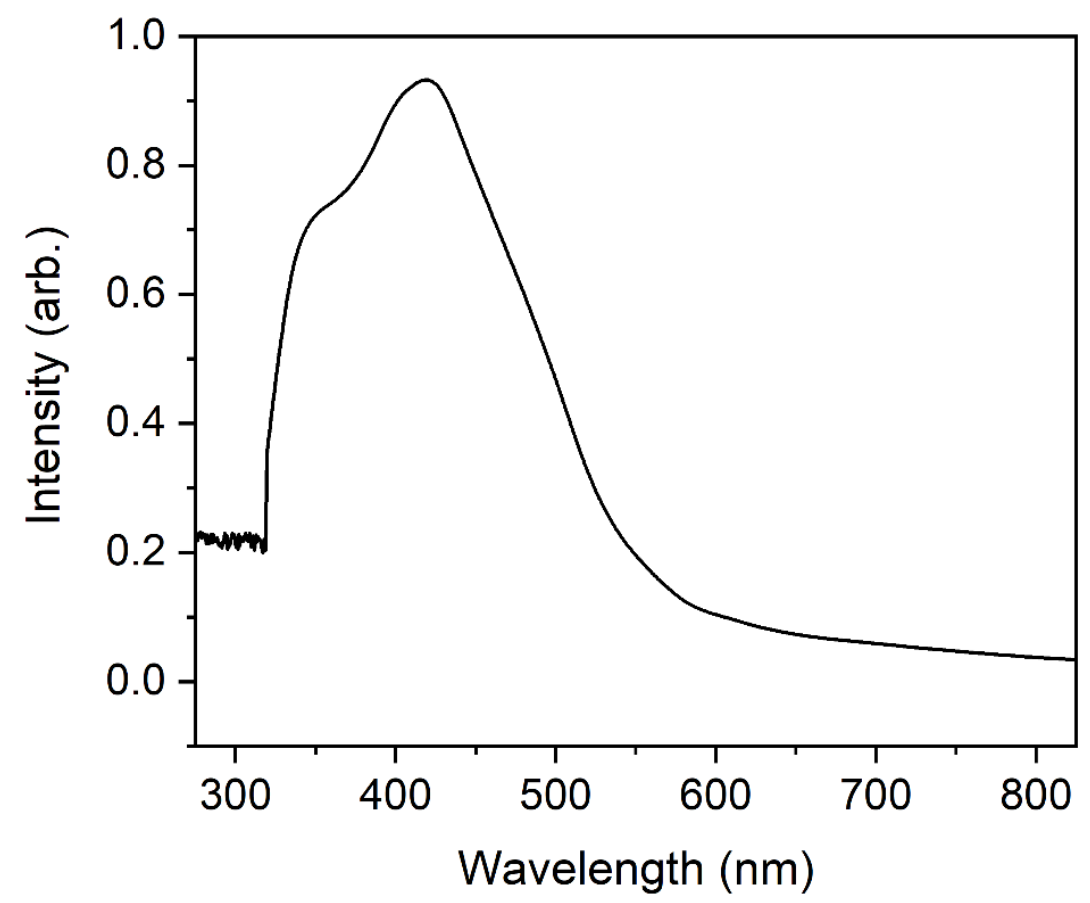

Figure S53. UV-Vis spectrum of Ni-(dobdc) solvated in DMF at a concentration of $0.01 \mathrm{mM}$. 


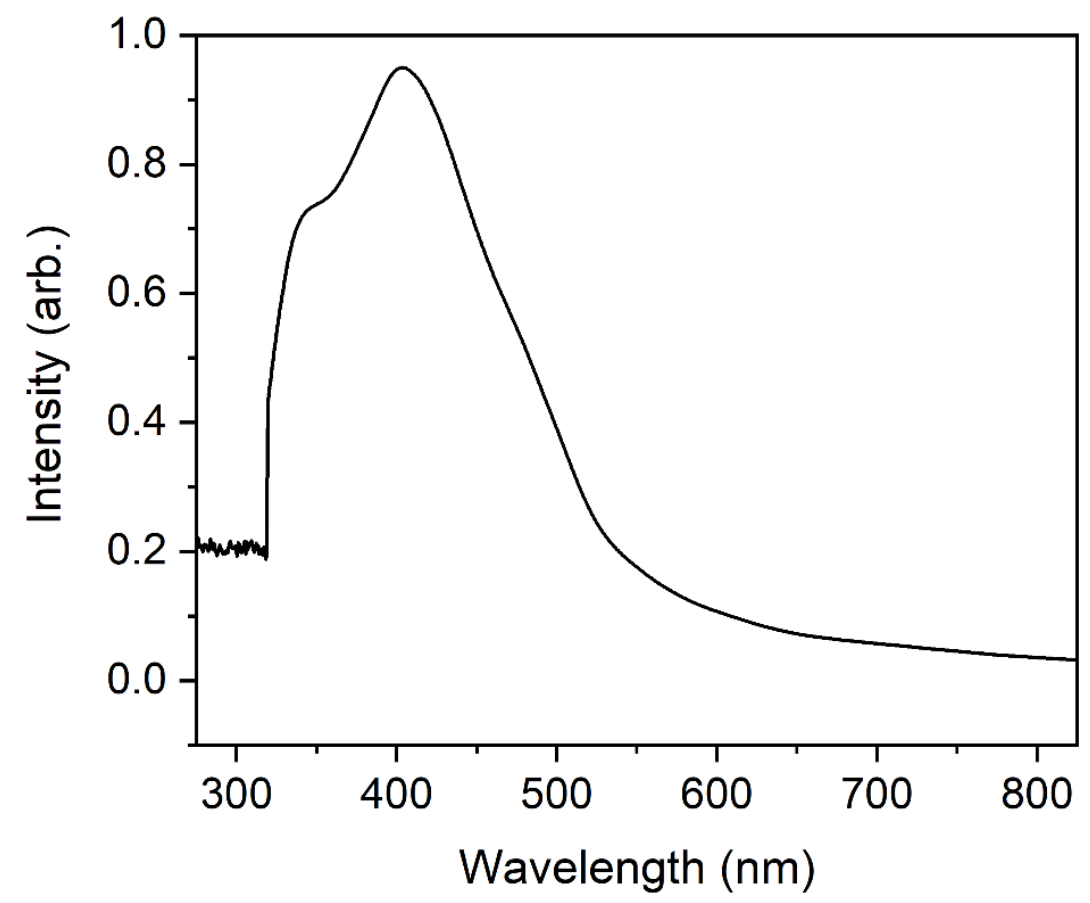

Figure S54. UV-Vis spectrum of $\mathrm{Ni}-\left(\right.$ dobdc) solvated in $\mathrm{CHCl}_{3}$ at a concentration of $0.01 \mathrm{mM}$.

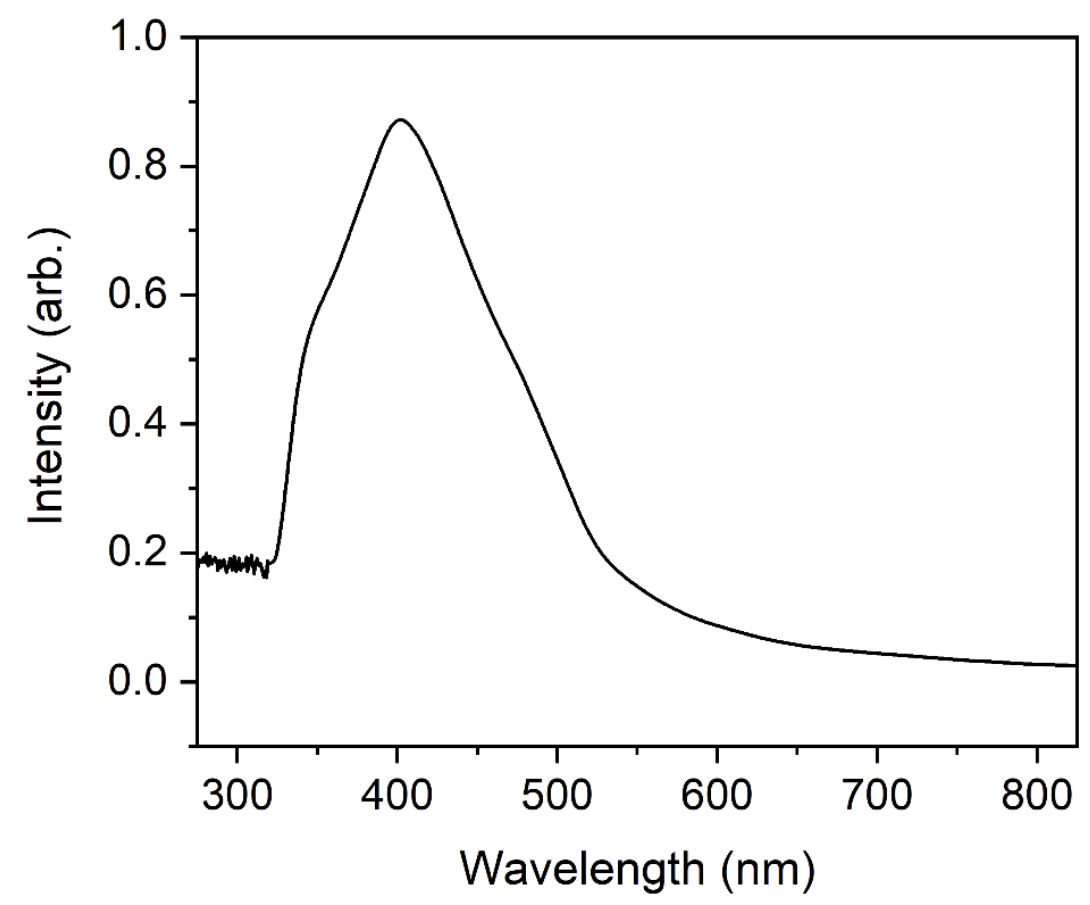

Figure S55. UV-Vis spectrum of Ni-(dobdc) solvated in toluene at a concentration of $0.01 \mathrm{mM}$. 


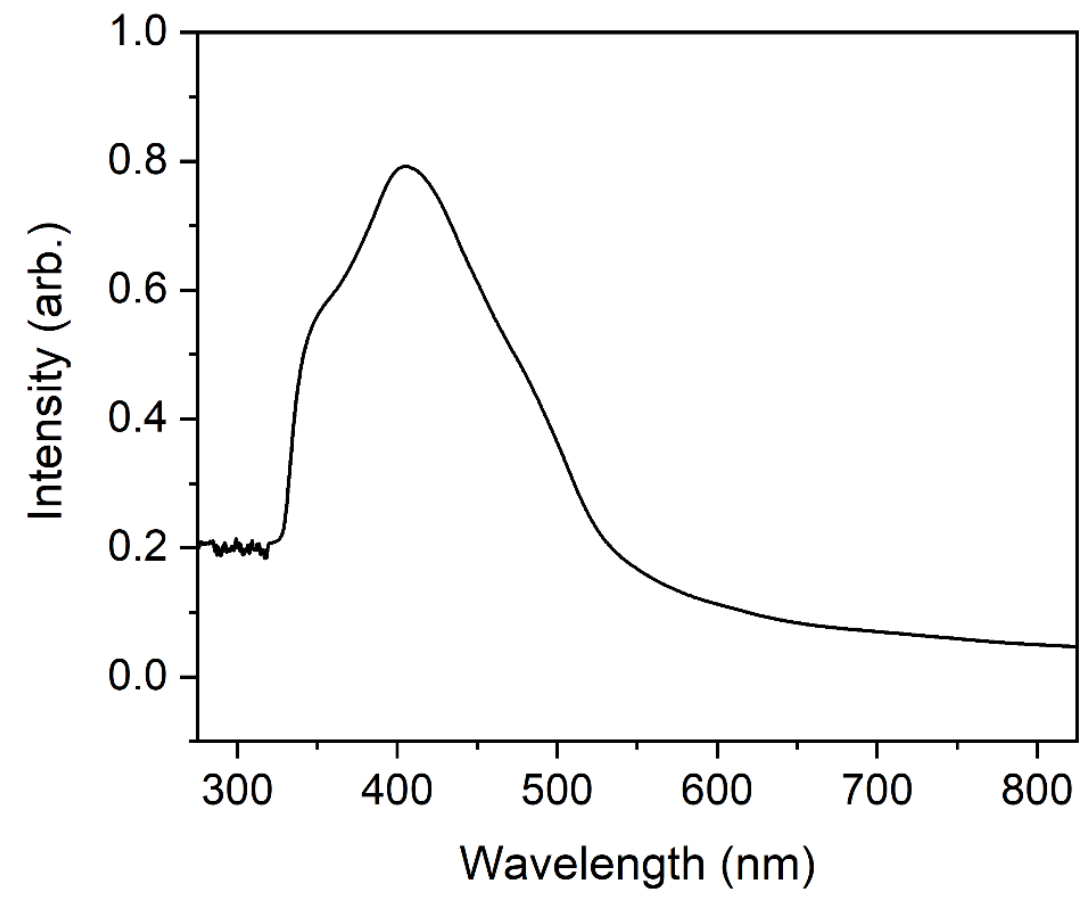

Figure S56. UV-Vis spectrum of Ni-(dobdc) solvated in THF at a concentration of $0.01 \mathrm{mM}$.

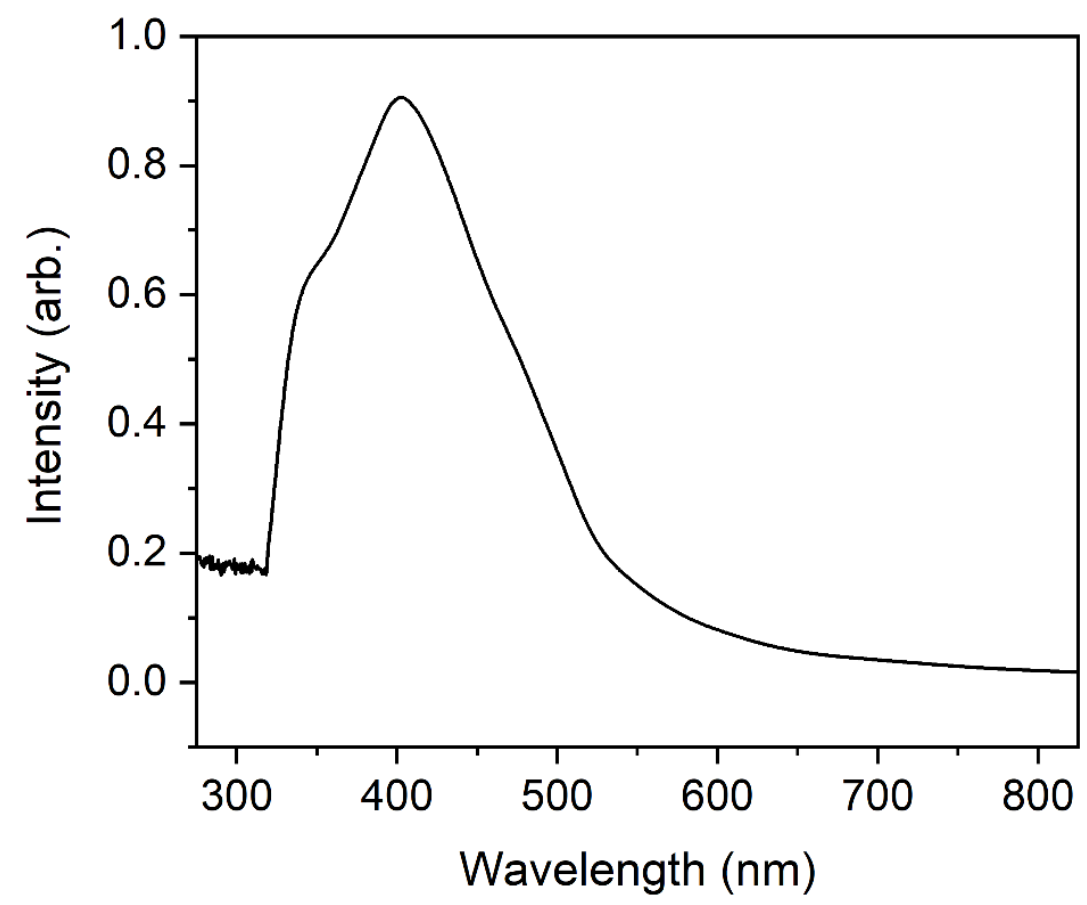

Figure S57. UV-Vis spectrum of Ni-(dobdc) solvated in benzene at a concentration of $0.01 \mathrm{mM}$. 


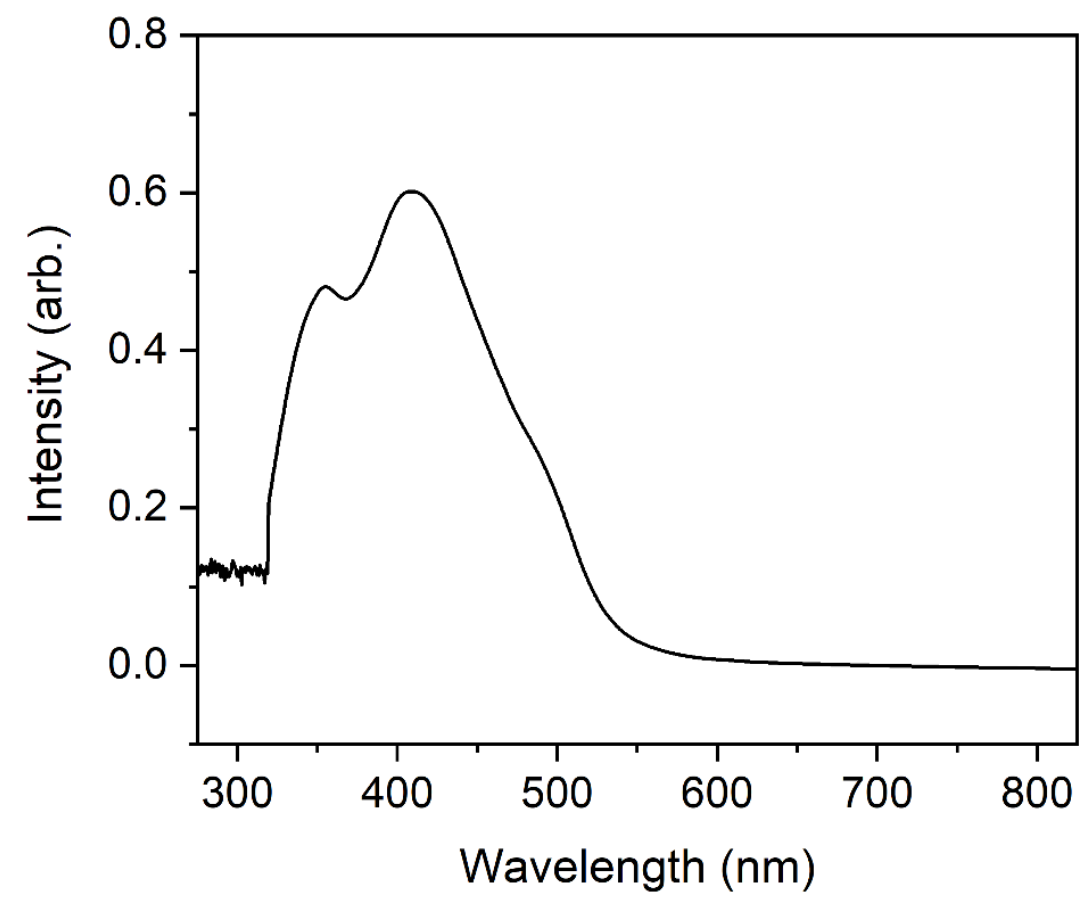

Figure S58. UV-Vis spectrum of Ni-(5-OProp) solvated in DMF at a concentration of $0.01 \mathrm{mM}$.

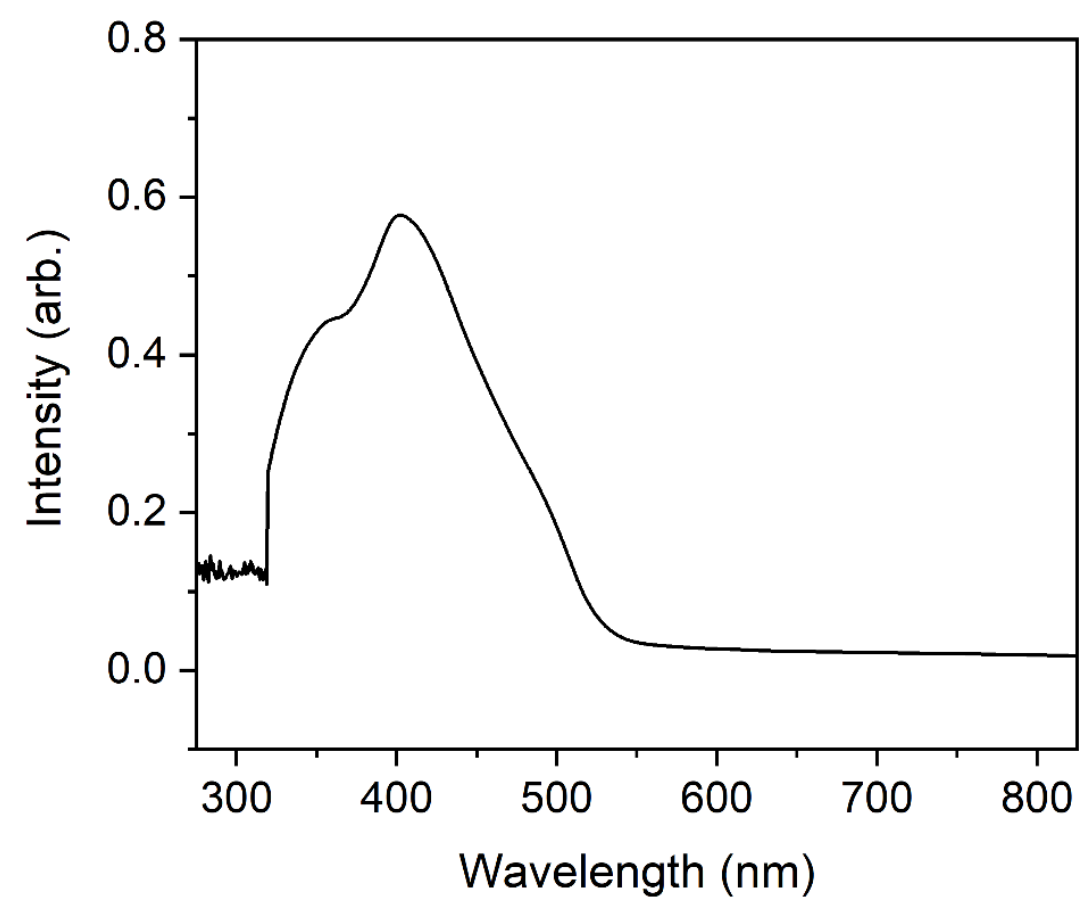

Figure S59. UV-Vis spectrum of Ni-(5-OProp) solvated in $\mathrm{CHCl}_{3}$ at a concentration of $0.01 \mathrm{mM}$. 


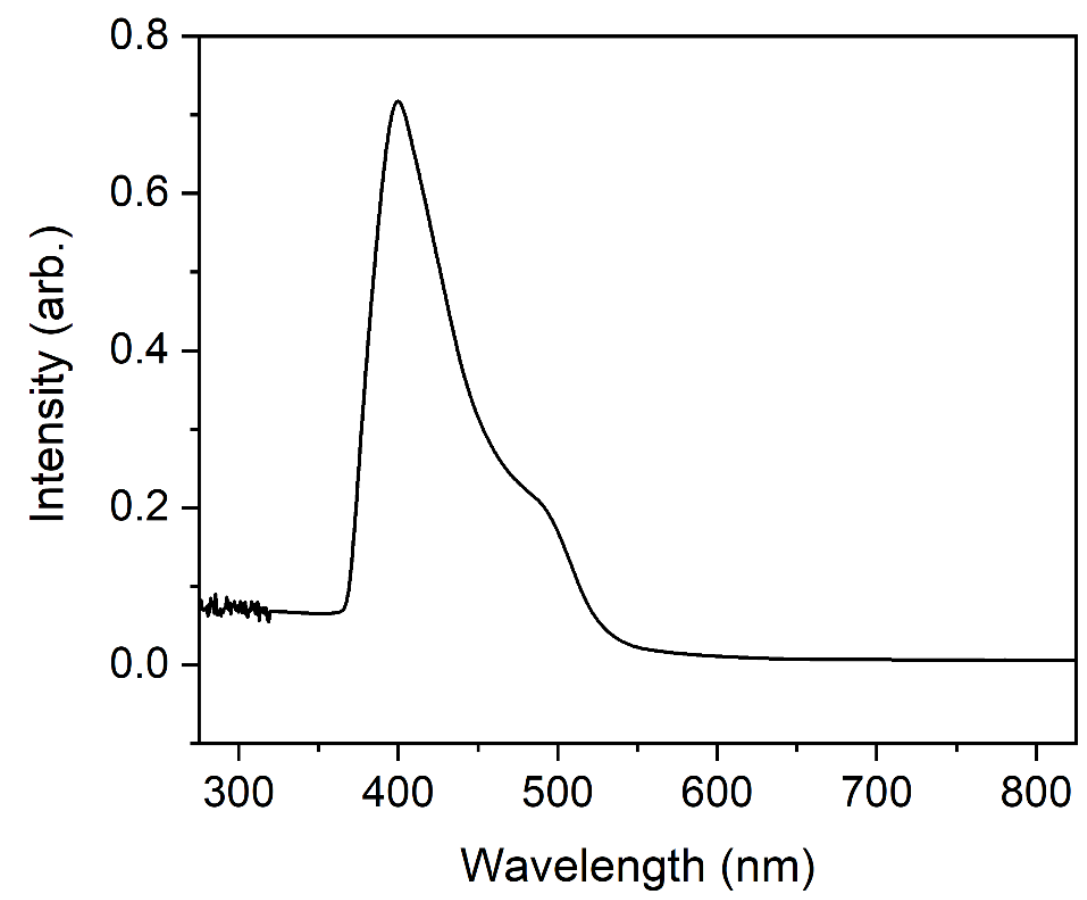

Figure S60. UV-Vis spectrum of Ni-(5-OProp) solvated in acetone at a concentration of $0.01 \mathrm{mM}$.

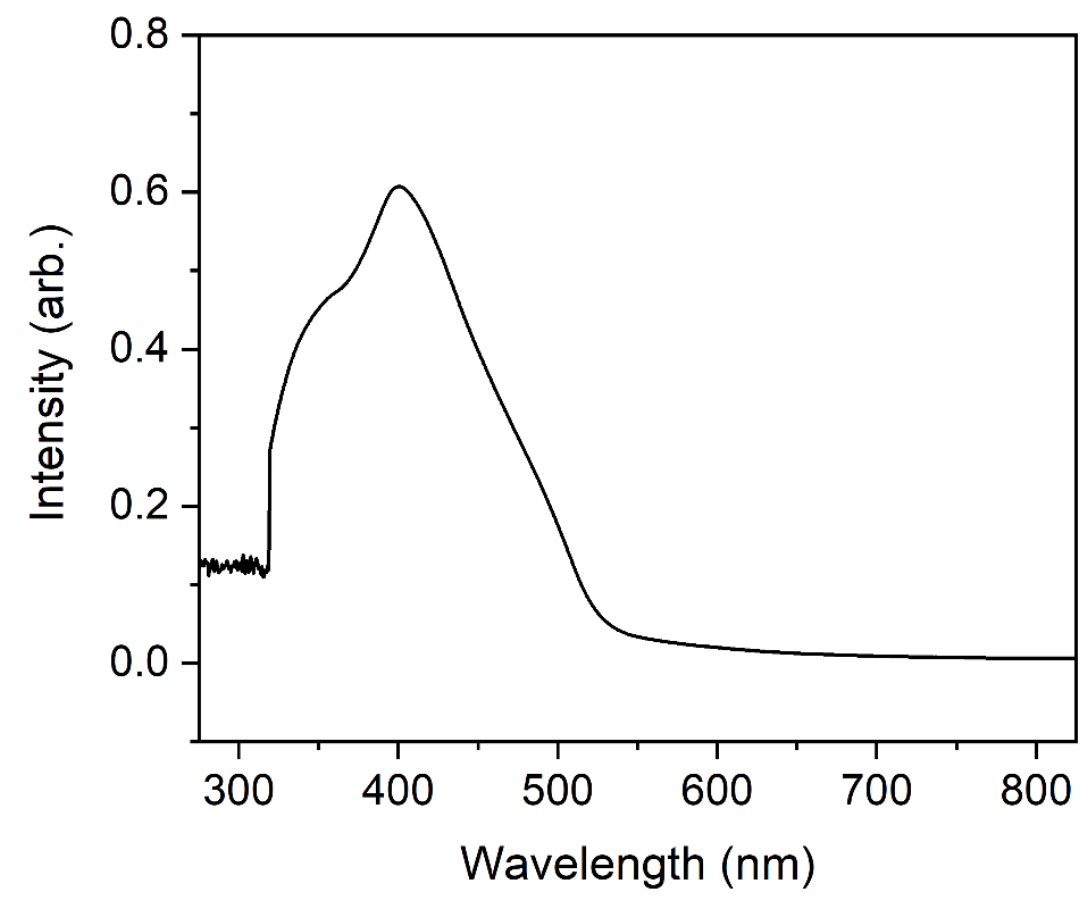

Figure S61. UV-Vis spectrum of Ni-(5-OProp) solvated in DCM at a concentration of $0.01 \mathrm{mM}$. 


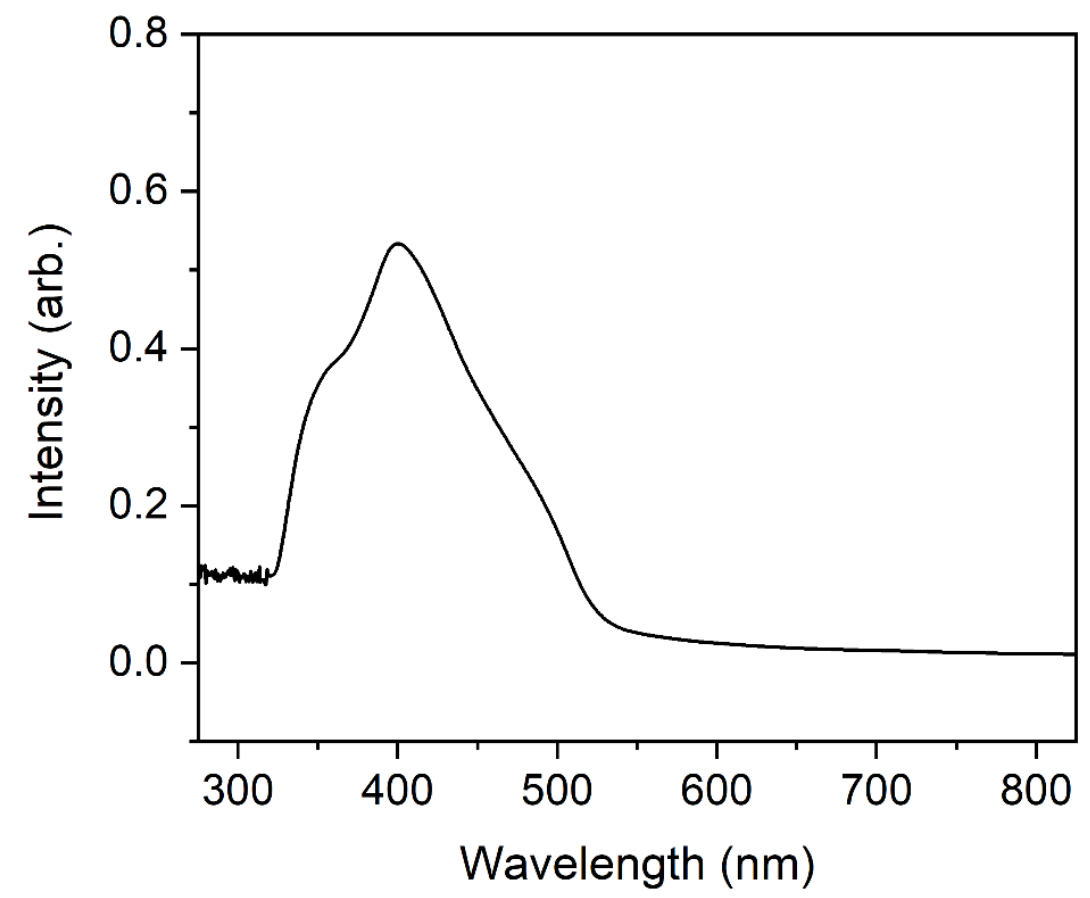

Figure S62. UV-Vis spectrum of Ni-(5-OProp) solvated in toluene at a concentration of $0.01 \mathrm{mM}$.

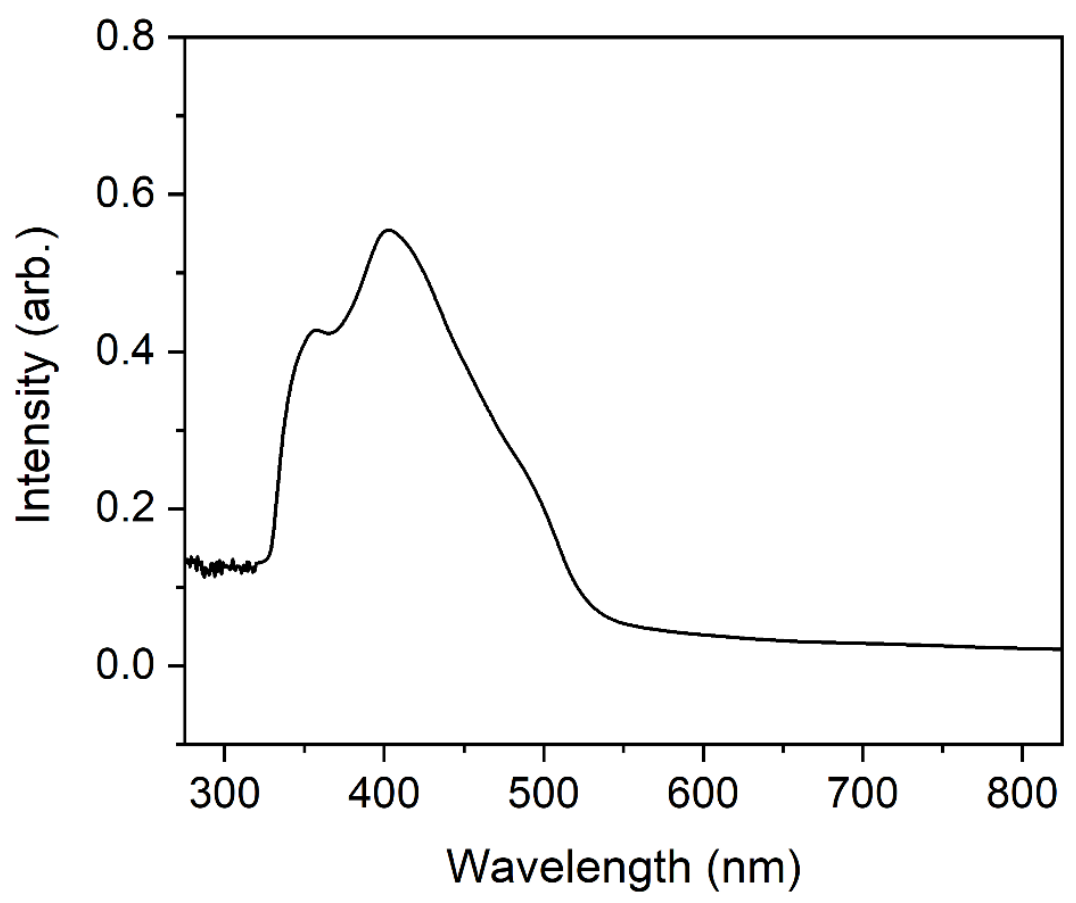

Figure S63. UV-Vis spectrum of Ni-(5-OProp) solvated in THF at a concentration of $0.01 \mathrm{mM}$. 


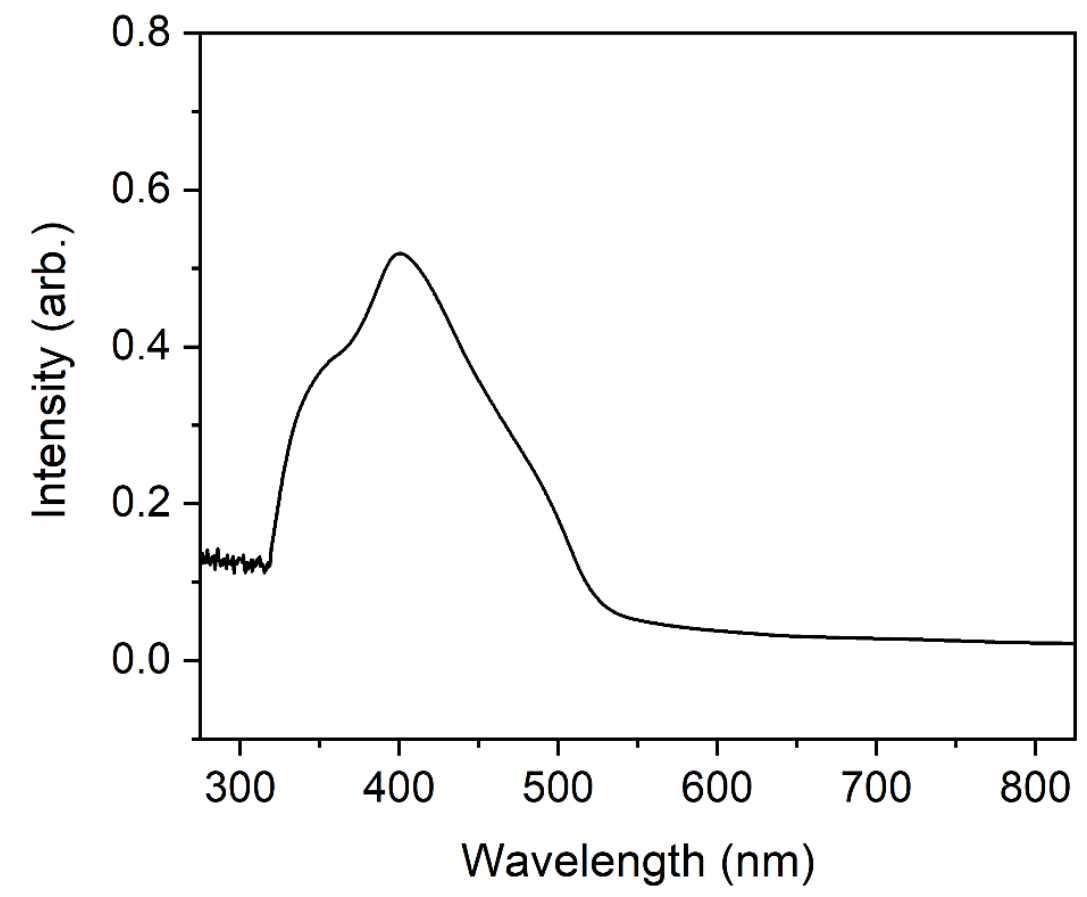

Figure S64. UV-Vis spectrum of Ni-(5-OProp) solvated in benzene at a concentration of $0.01 \mathrm{mM}$.

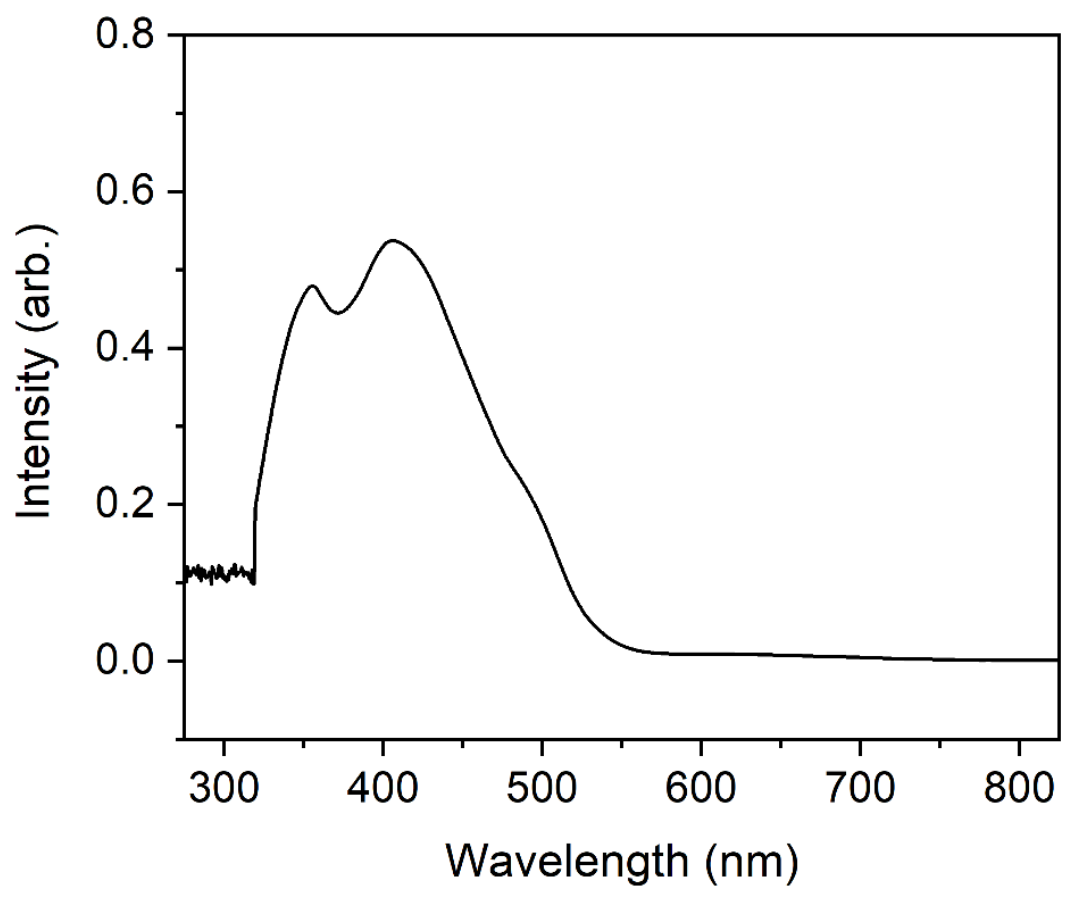

Figure S65. UV-Vis spectrum of Co-(5-OHept) solvated in DMF at a concentration of $0.01 \mathrm{mM}$. 


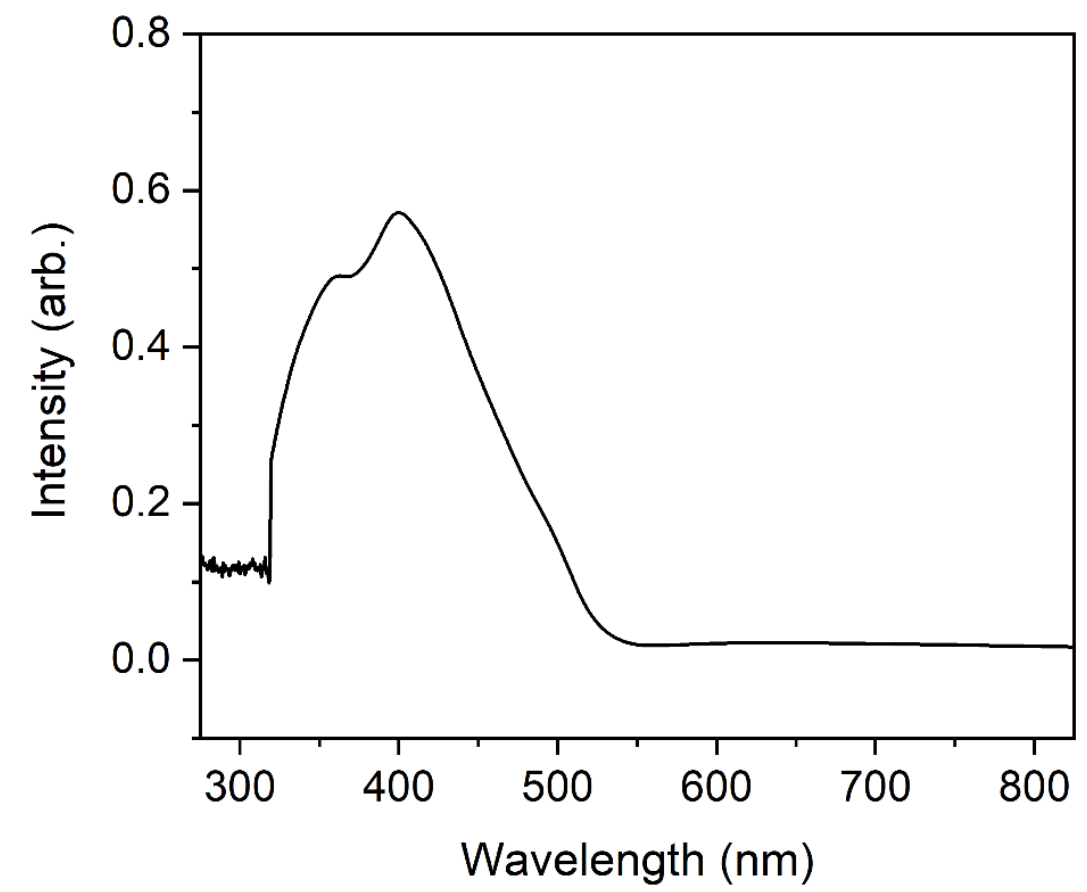

Figure S66. UV Vis solution $\mathrm{Co}-(5-\mathrm{OHept})$ solvated in $\mathrm{CHCl}_{3}$ at a concentration of $0.01 \mathrm{mM}$.

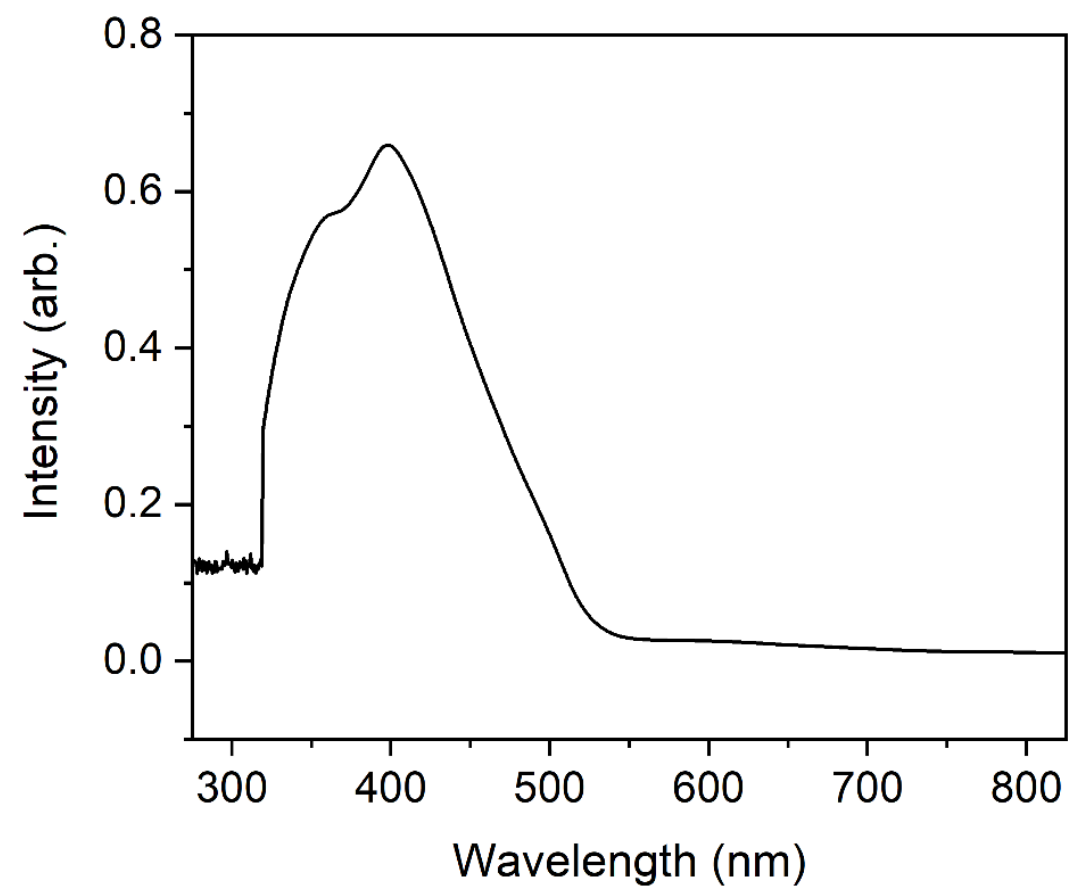

Figure S67. UV-Vis spectrum of Co-(5-OHept) solvated in DCM at a concentration of $0.01 \mathrm{mM}$. 


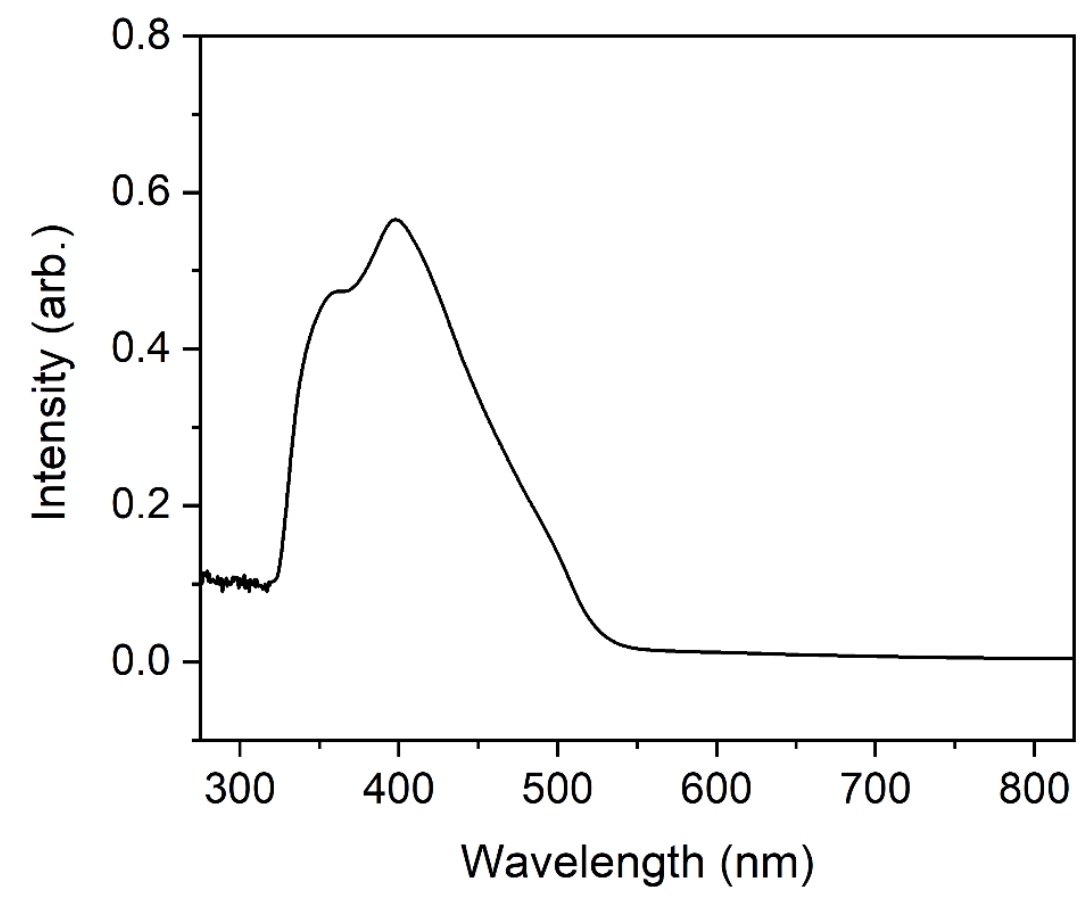

Figure S68. UV-Vis spectrum of Co-(5-OHept) solvated in toluene at a concentration of $0.01 \mathrm{mM}$.

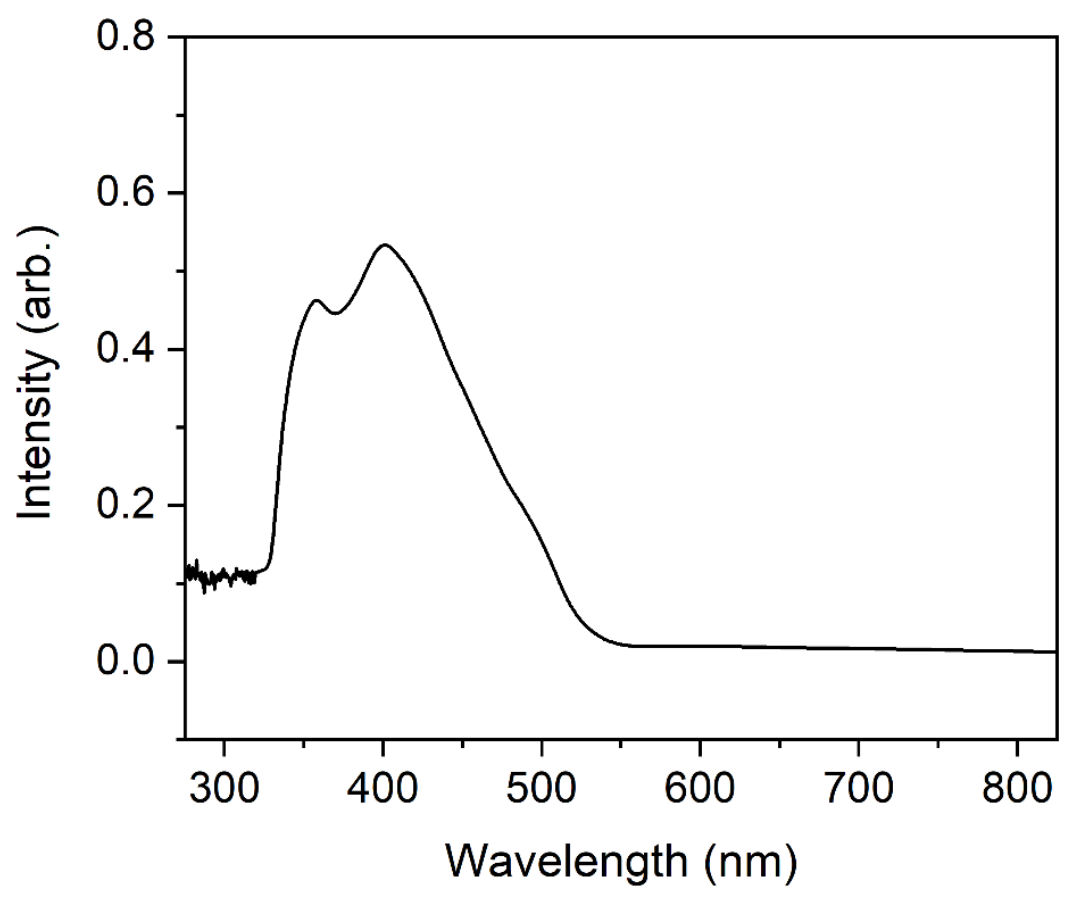

Figure S69. UV-Vis spectrum of Co-(5-OHept) solvated in THF at a concentration of $0.01 \mathrm{mM}$. 


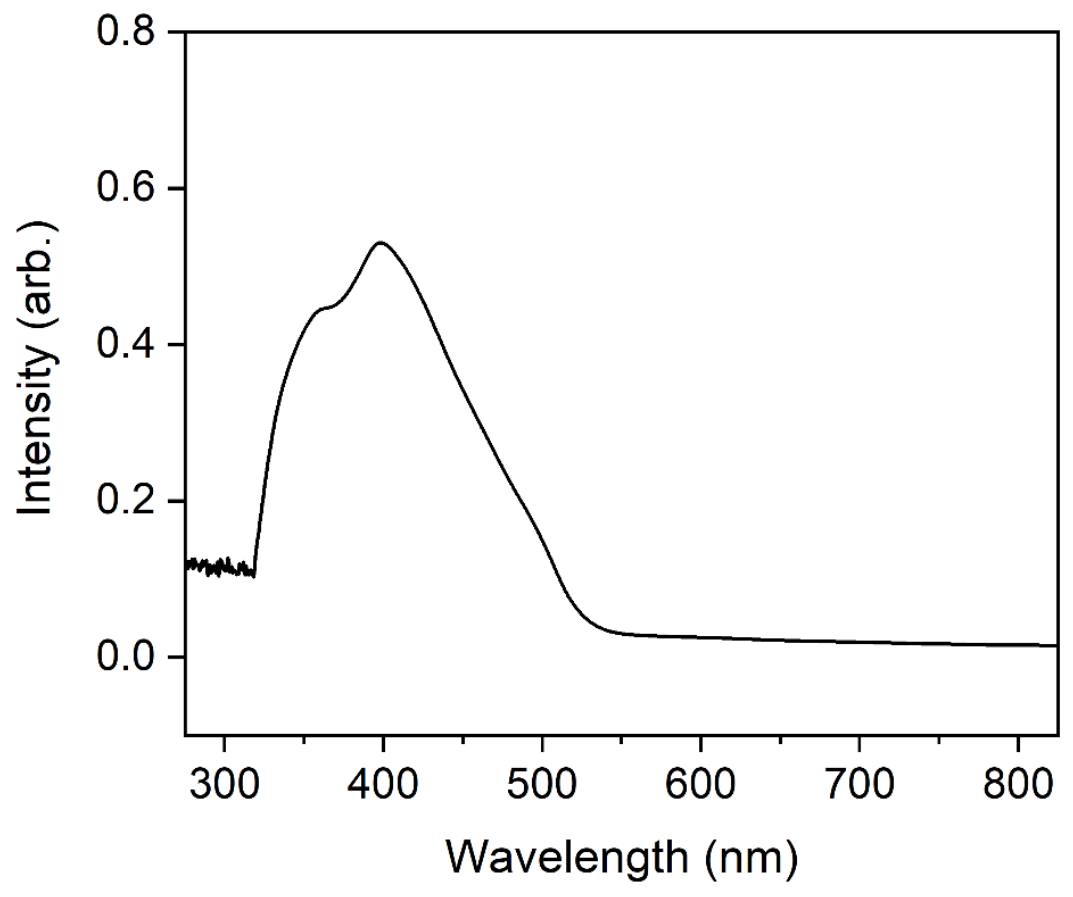

Figure S70. UV-Vis spectrum of Co-(5-OHept) solvated in benzene at a concentration of 0.01 $\mathrm{mM}$. 


\section{Thermogravimetric Analysis (TGA)}

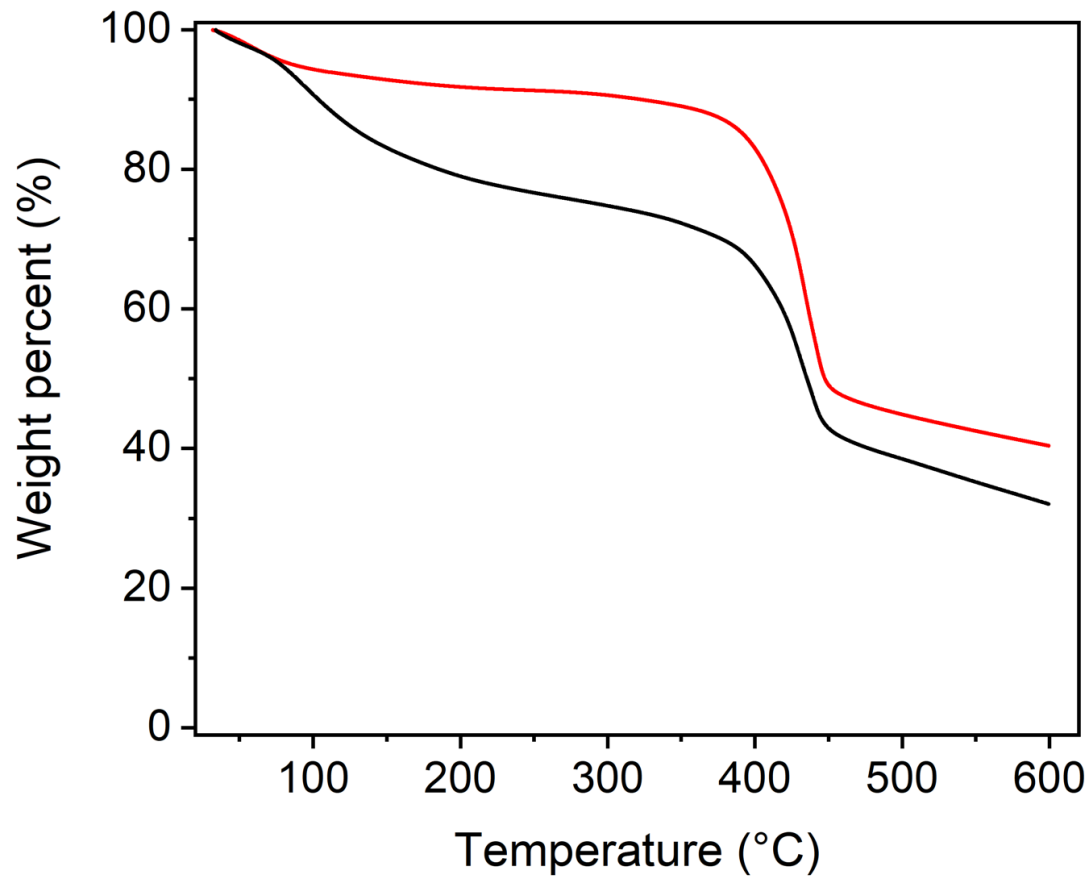

Figure S71. TGA of Co-(5-Sulfo) as synthesized (black) and solvent exchanged with EtOH (red).

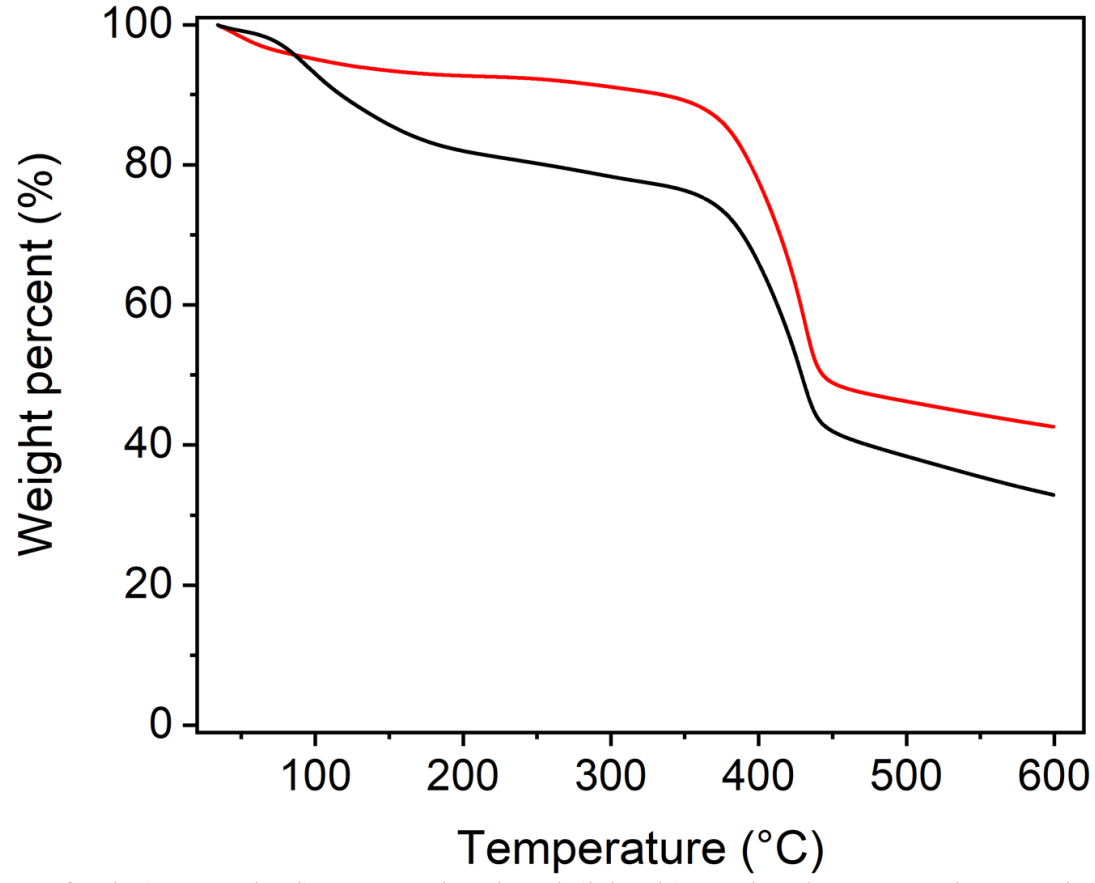

Figure S72. TGA of Ni-(2-Methyl) as synthesized (black) and solvent exchanged with EtOH (red). 


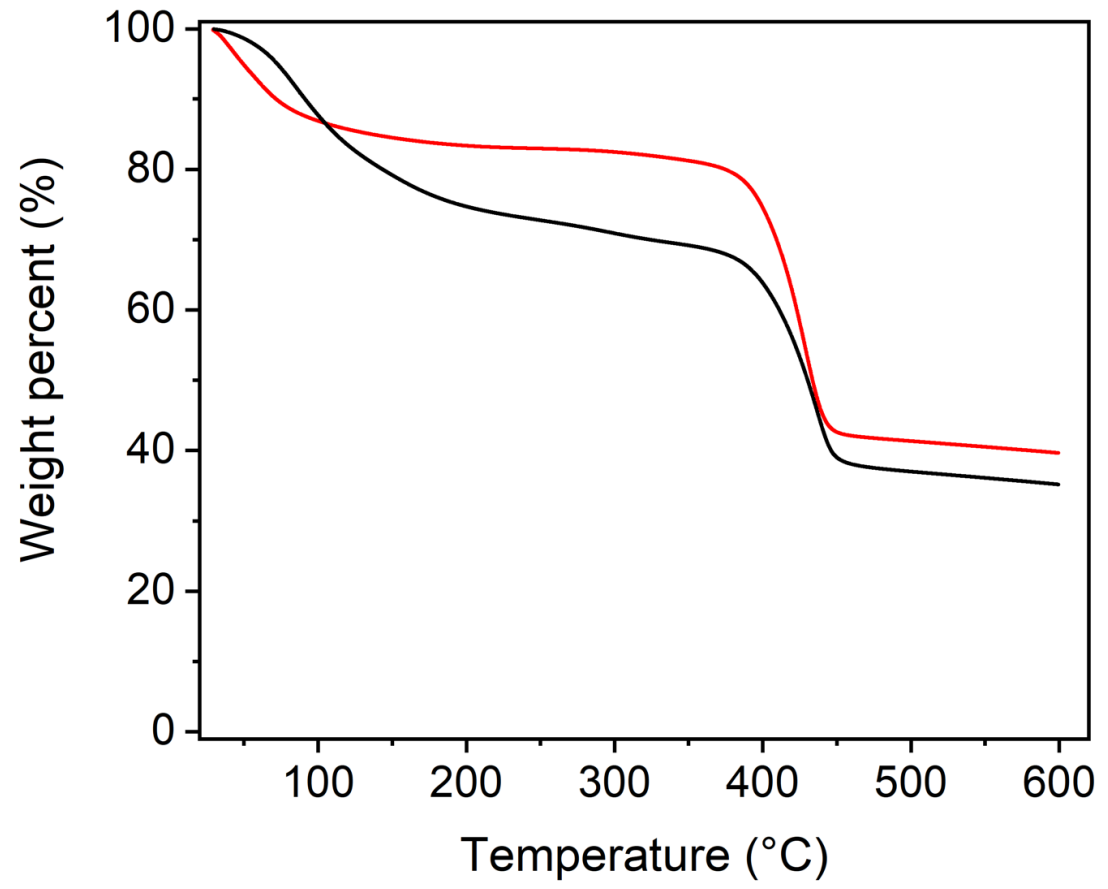

Figure S73. TGA of Ni-(5-Methyl) as synthesized (black) and solvent exchanged with EtOH (red).

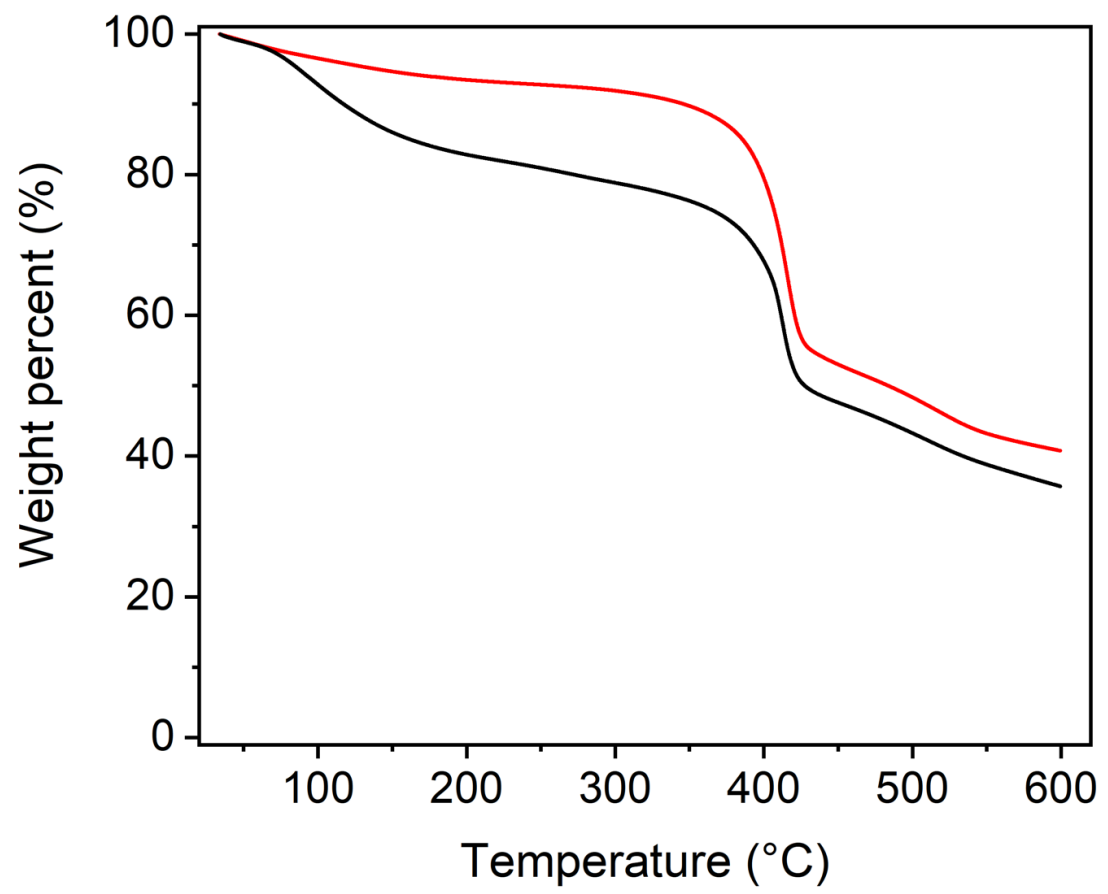

Figure S74. TGA of Ni-(2-Br) as synthesized (black) and solvent exchanged with EtOH (red). 


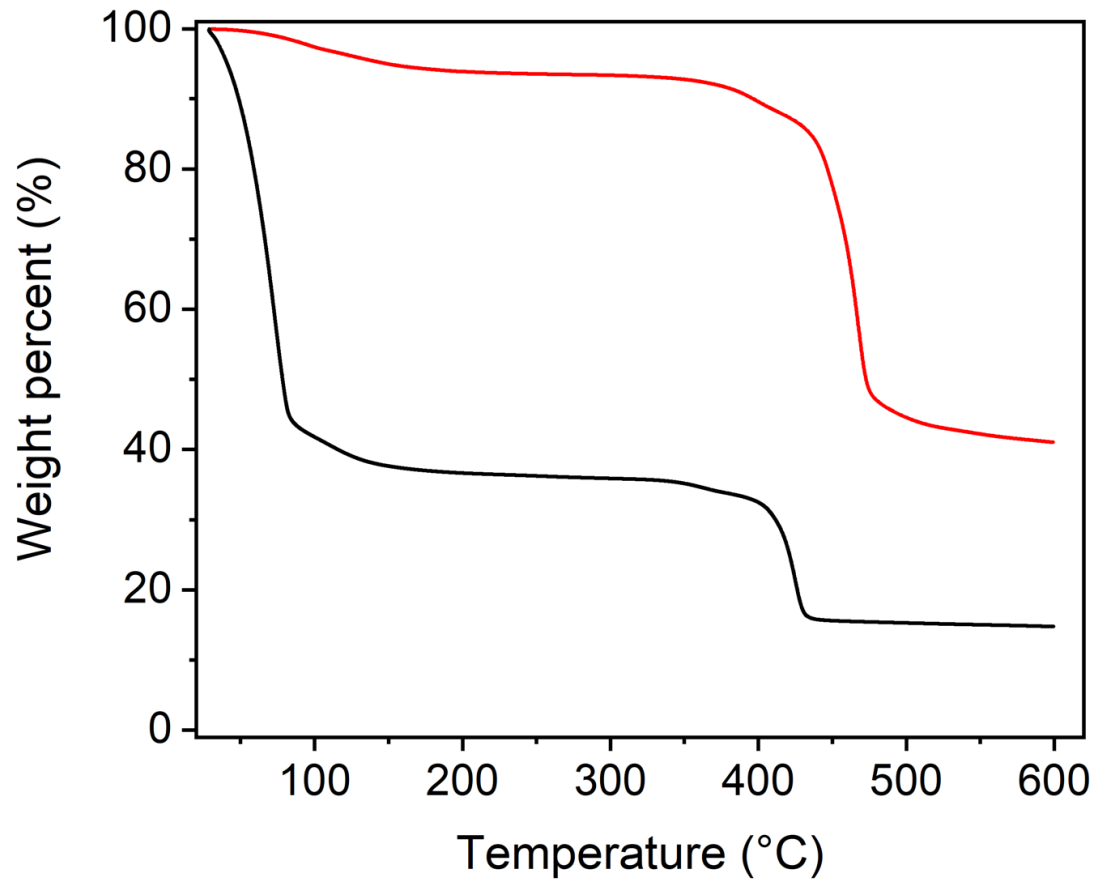

Figure S75. TGA of Ni-(5-Br) as synthesized (black) and solvent exchanged with EtOH (red).

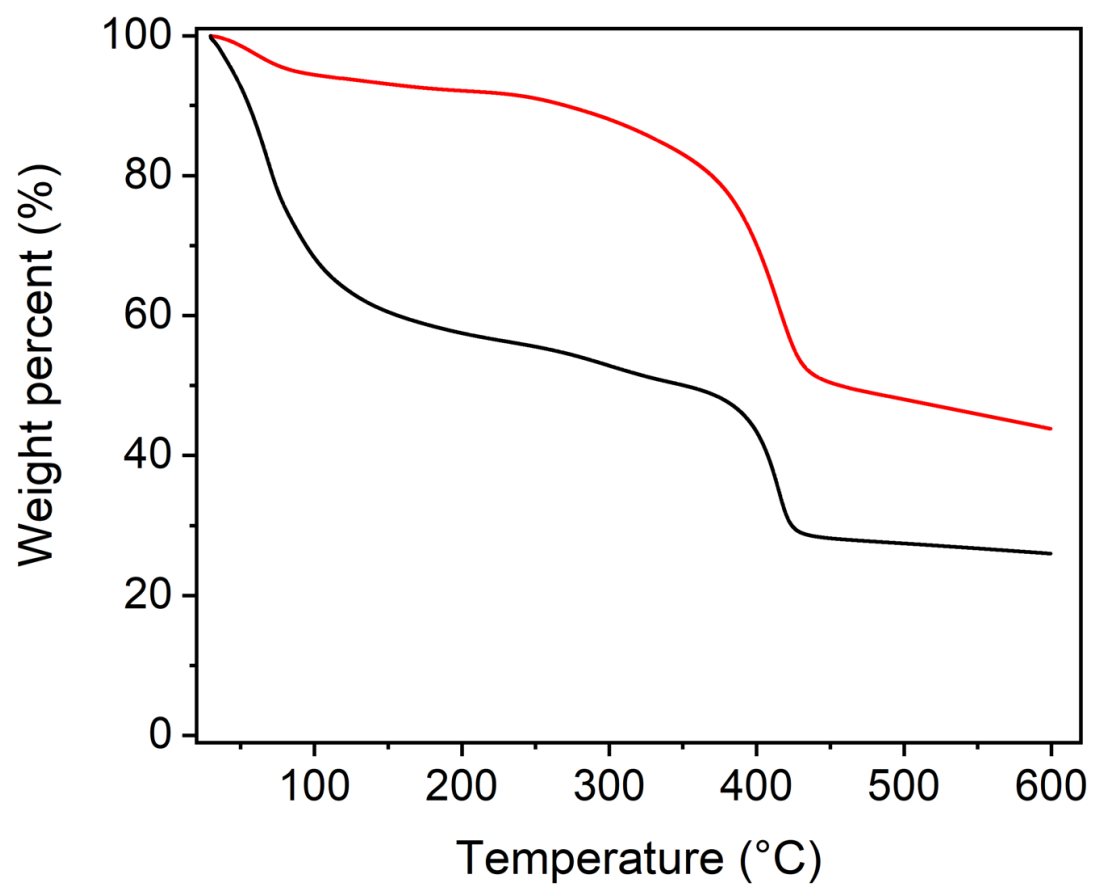

Figure S76. TGA of Ni-(dobdc) as synthesized (black) and solvent exchanged with EtOH (red). 


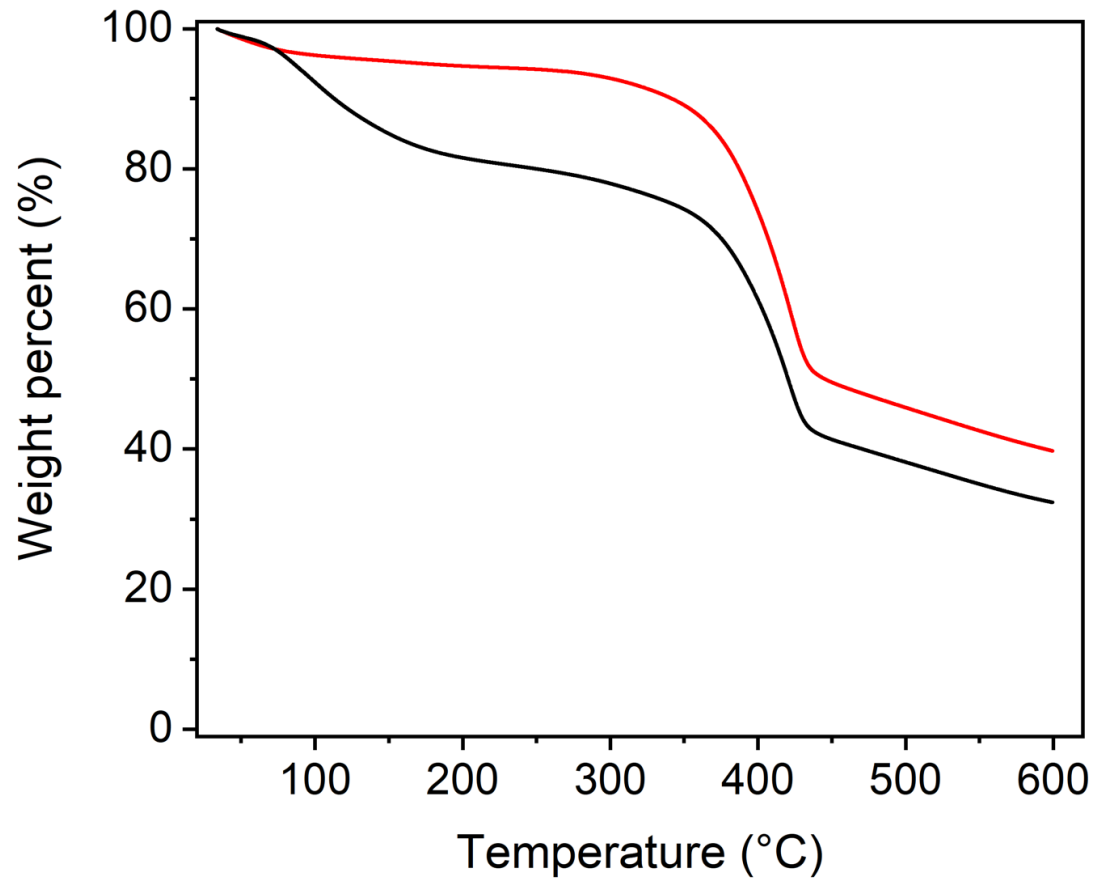

Figure S77. TGA of Ni-(5-OProp) as synthesized (black) and solvent exchanged with EtOH (red).

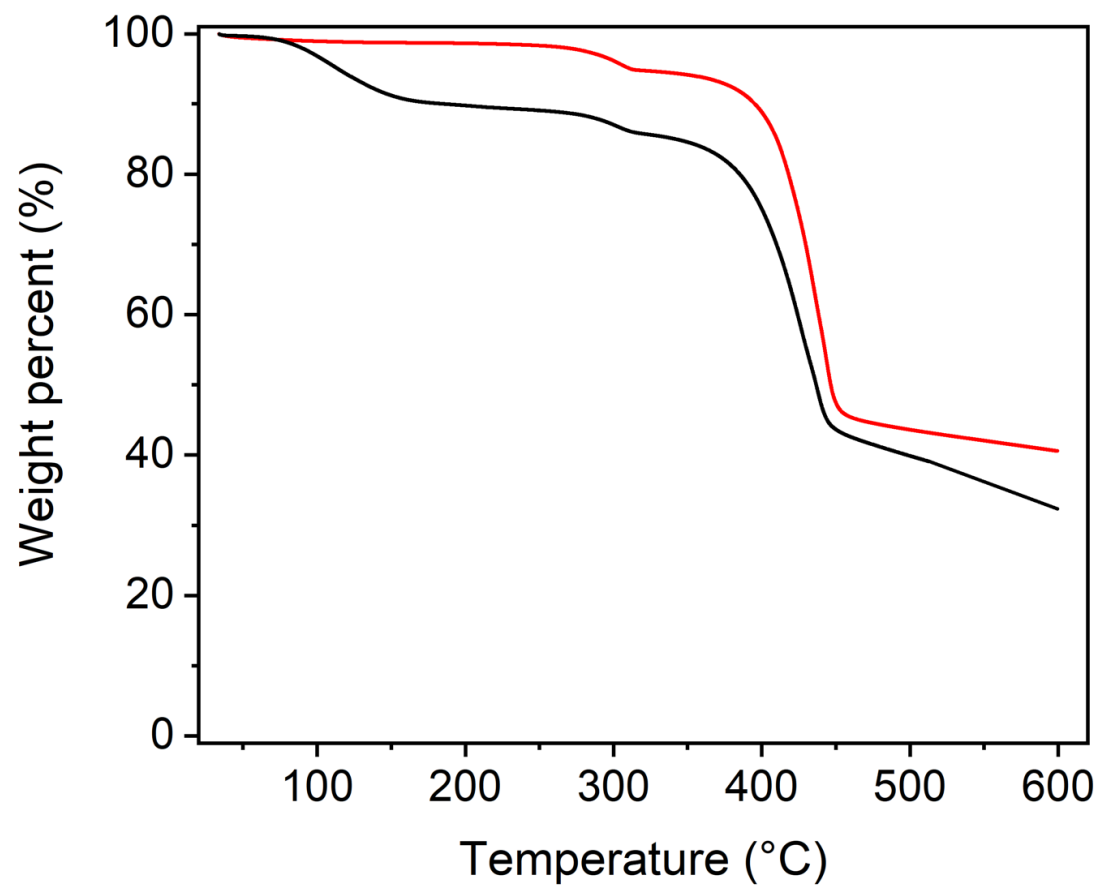

Figure S78. TGA of Co-(5-OHept) as synthesized (black) and solvent exchanged with EtOH (red).

\section{Gas Adsorption Measurements}




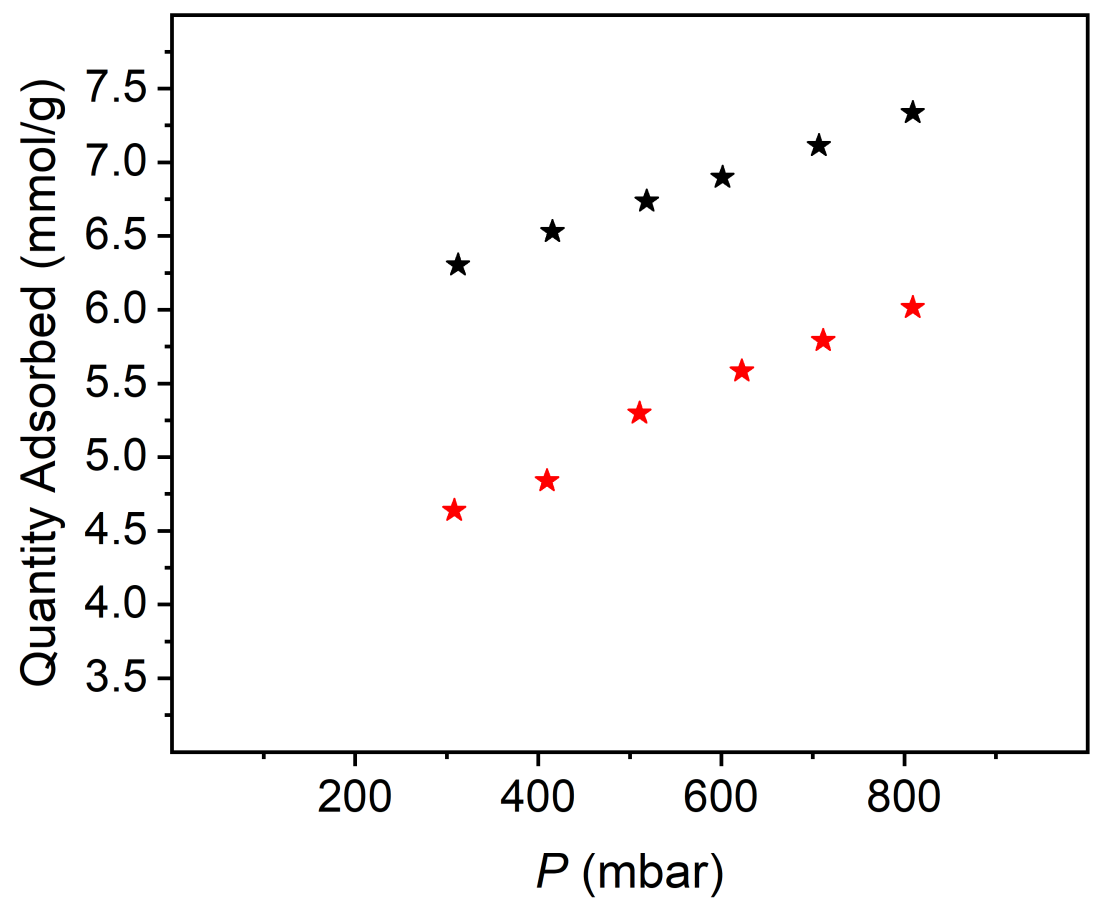

Figure S79. $\mathrm{N}_{2}$ adsorption in $\mathrm{Ni}-($ btc) (black) and Co-(btc) (red) at $77 \mathrm{~K}$.

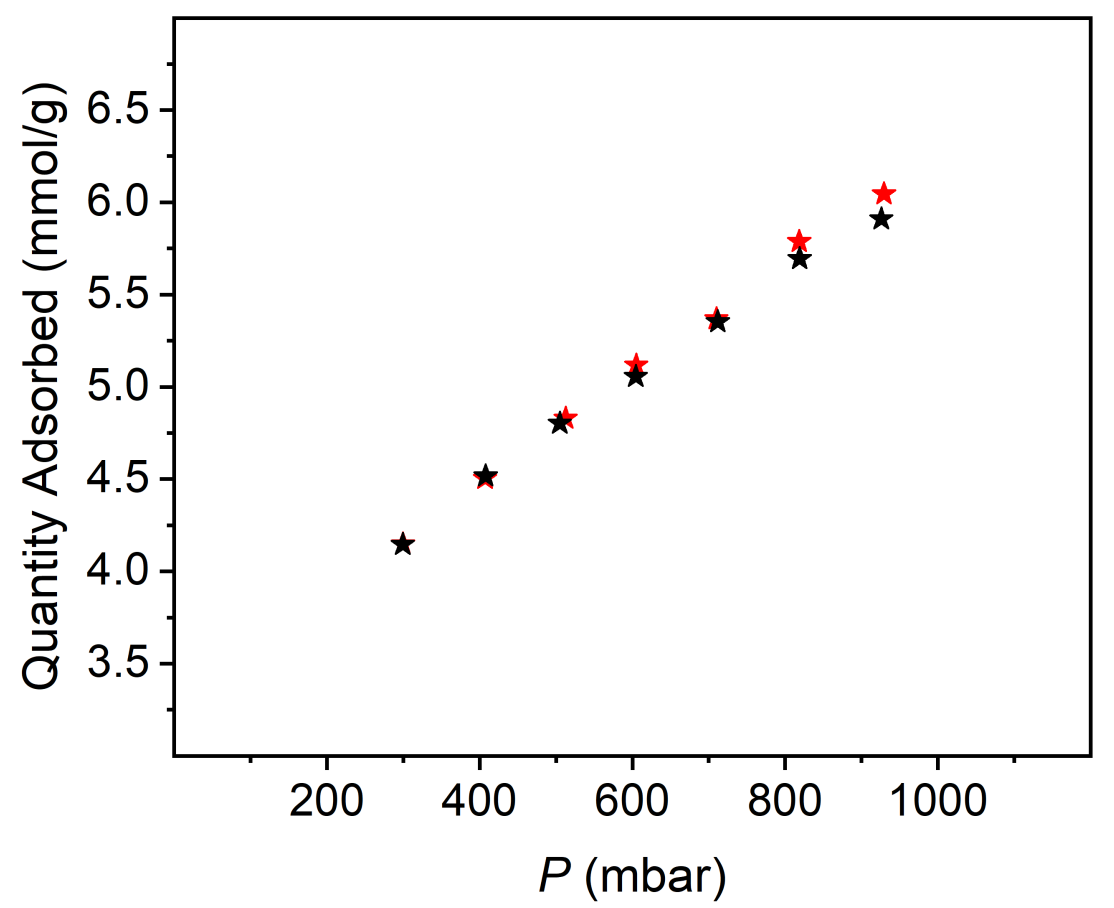

Figure S80. $\mathrm{CO}_{2}$ adsorption in Ni-(btc) (black) and Co-(btc) (red) at $195 \mathrm{~K}$. 


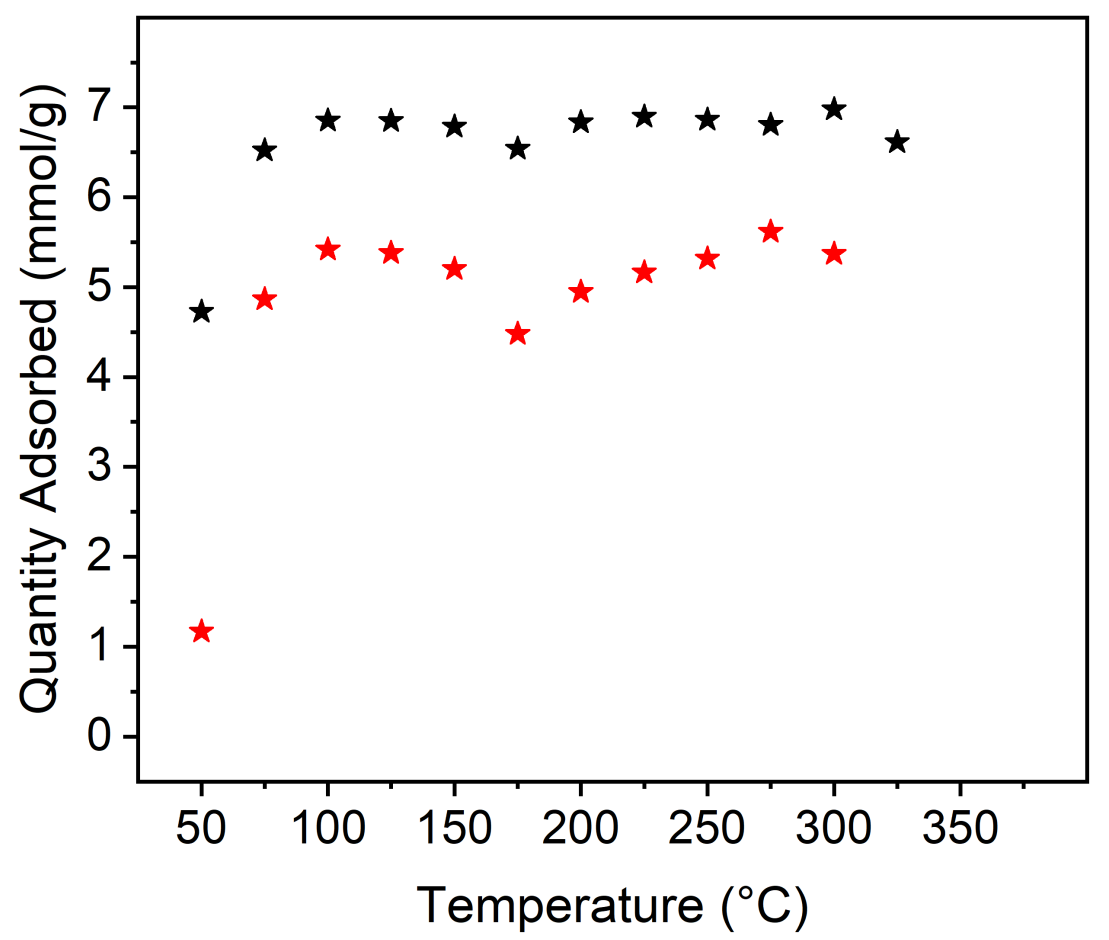

Figure S81. $\mathrm{N}_{2}$ adsorption (77 K, 900 mbar) following activation at varied temperatures for Ni(p-bdc) (black) and Co-(p-bdc) (red).

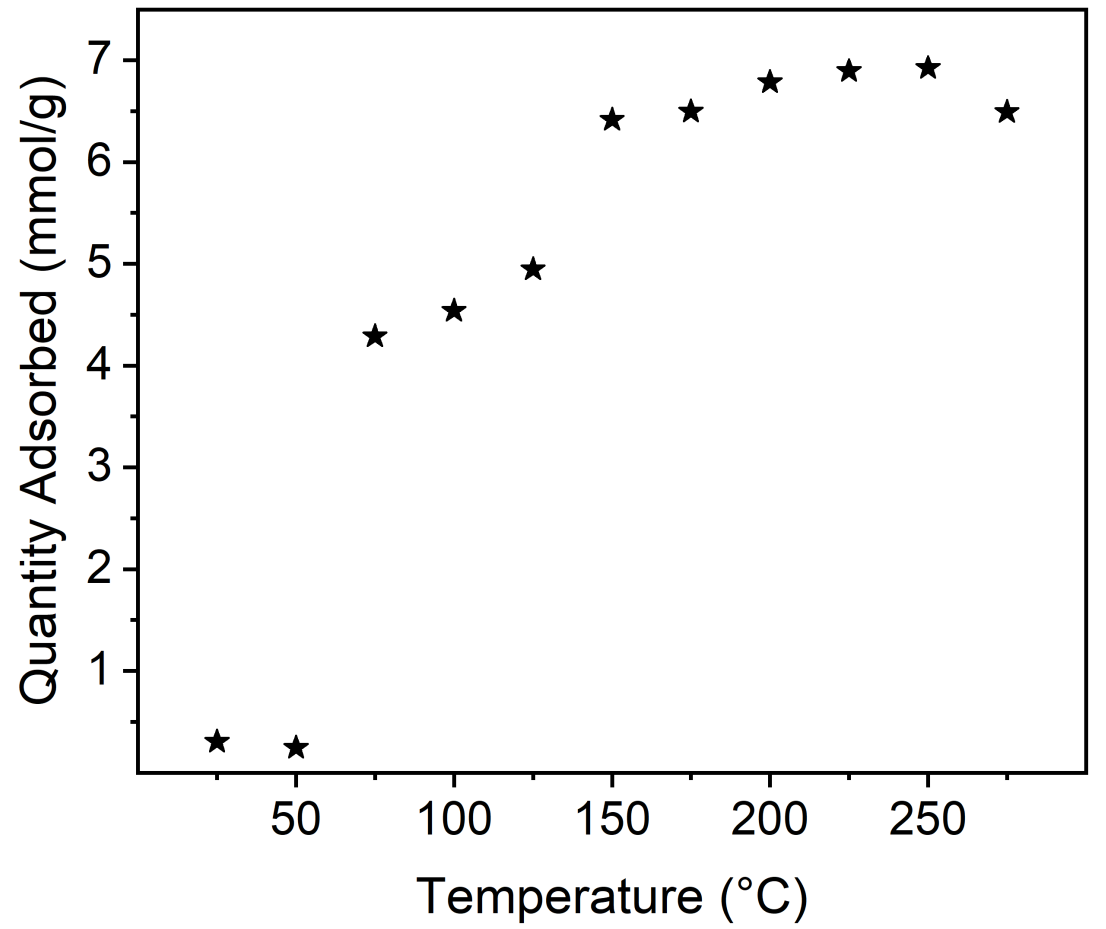

Figure S82. $\mathrm{N}_{2}$ adsorption (77 K, $900 \mathrm{mbar}$ ) following activation at varied temperatures for NiIII. 


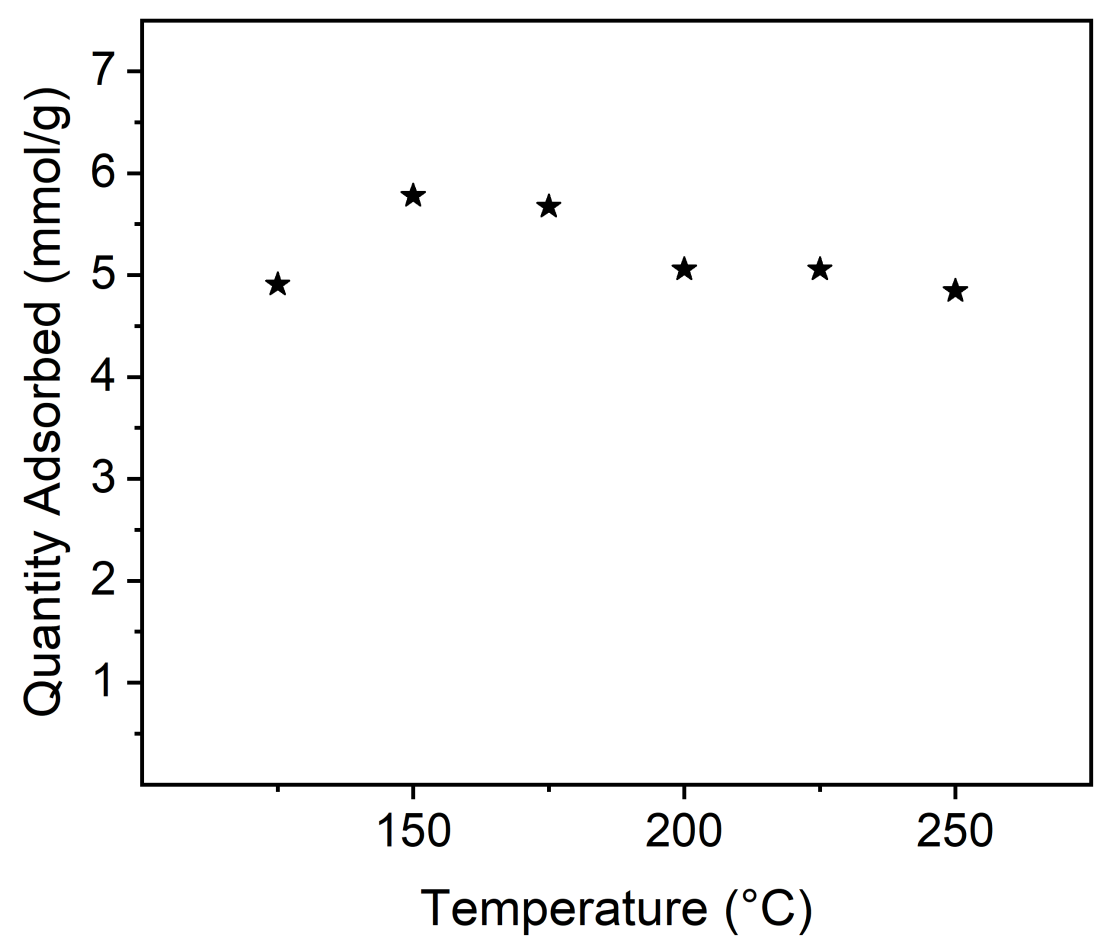

Figure S83. $\mathrm{CO}_{2}$ adsorption (195 K, 900 mbar) following activation at varied temperatures for $\mathrm{Co}(\mathrm{m}-\mathrm{bdc})$.

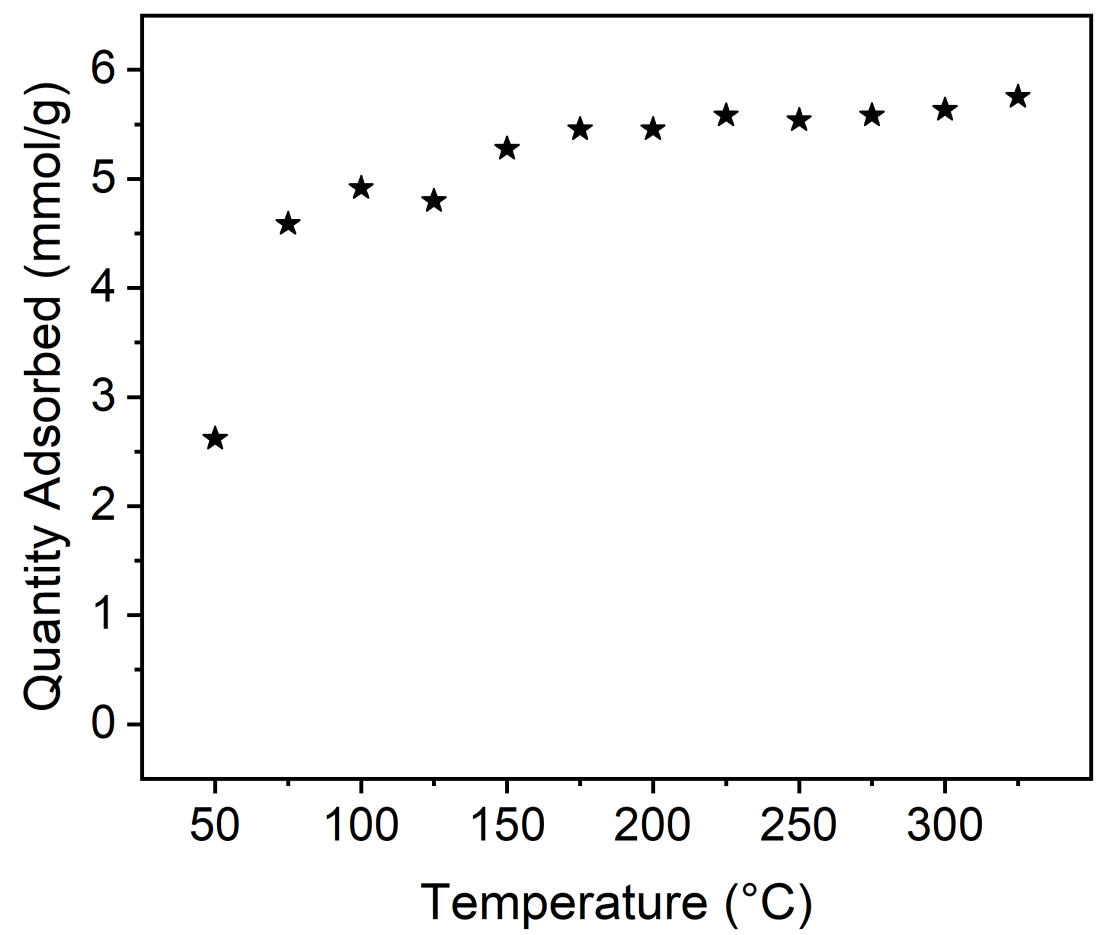

Figure S84. $\mathrm{N}_{2}$ adsorption (77 K, $800 \mathrm{mbar}$ ) following activation at varied temperatures for Ni(5-Sulfo). 


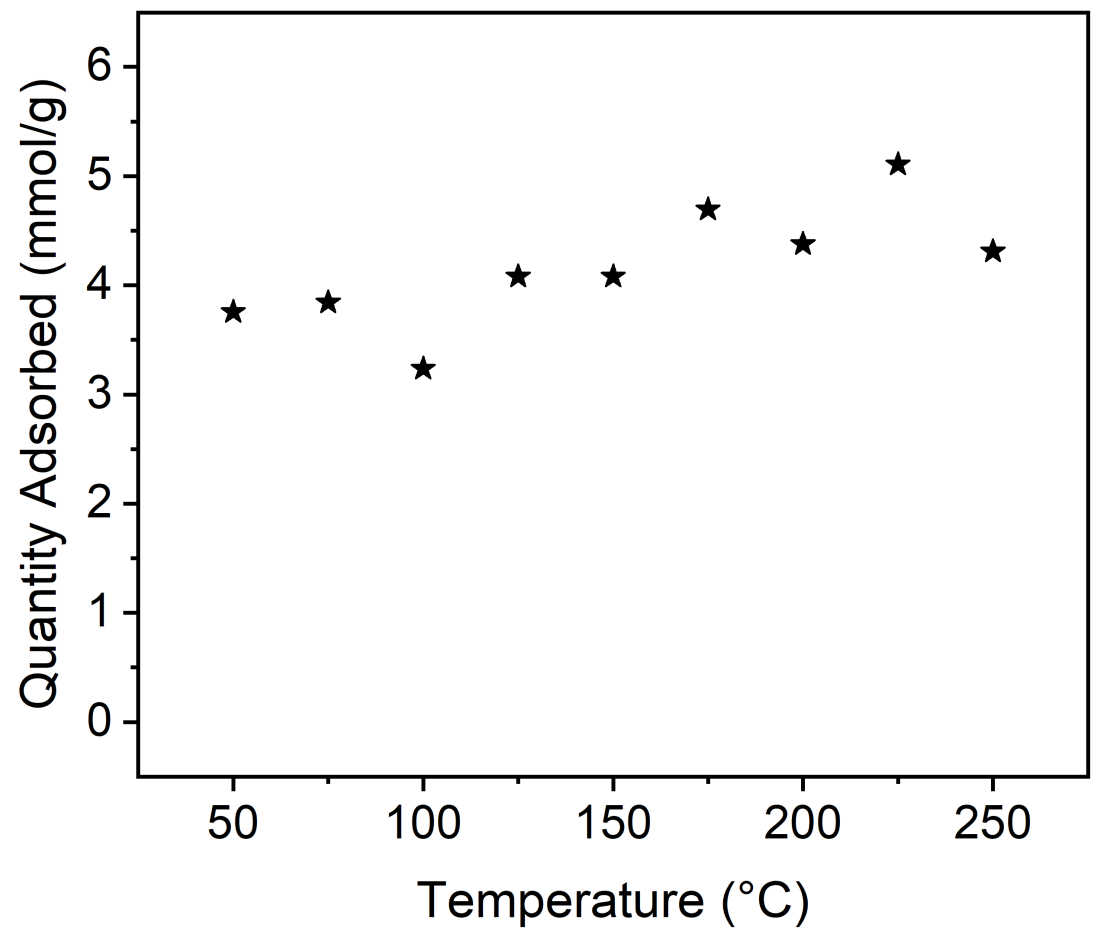

Figure S85. $\mathrm{N}_{2}$ adsorption (77 K, 800 mbar) following activation at varied temperatures for Co(5-Sulfo).

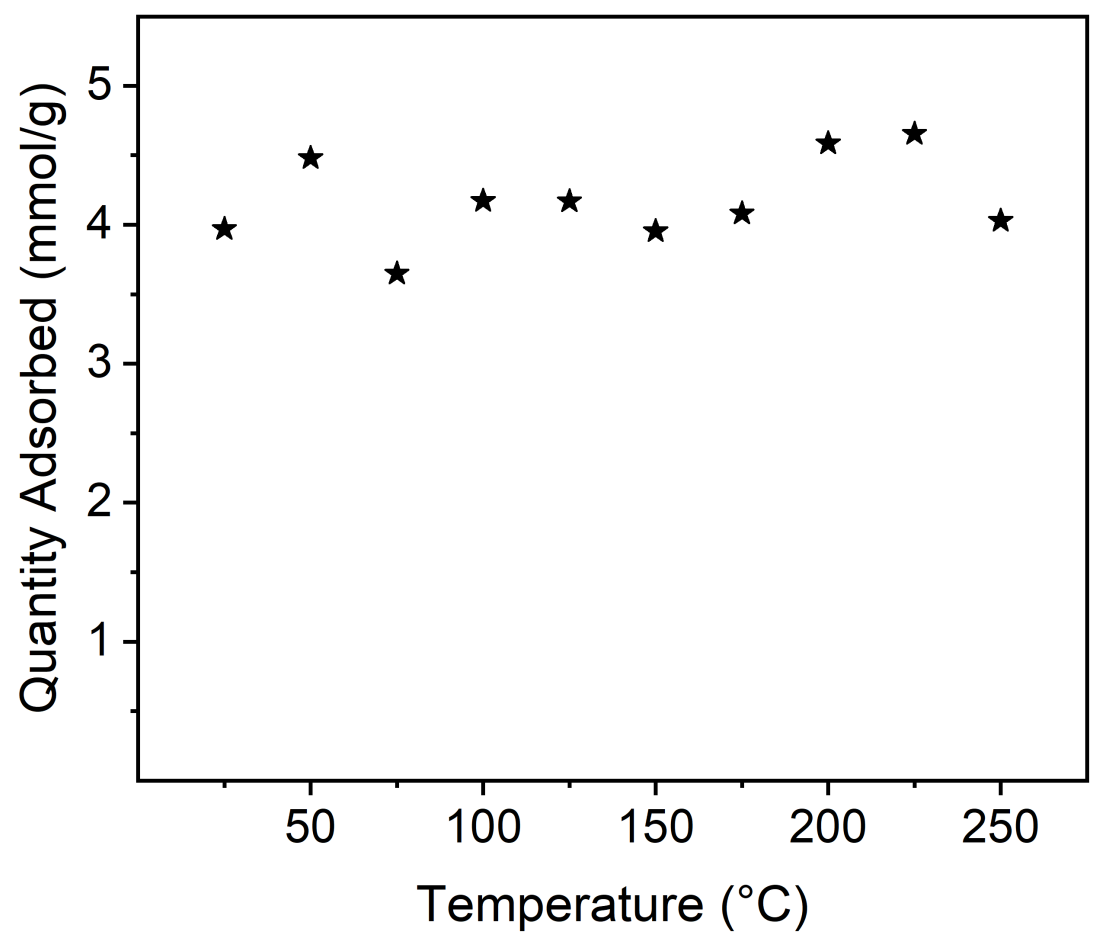

Figure S86. $\mathrm{N}_{2}$ adsorption (77 K, 800 mbar) following activation at varied temperatures for Ni(5-Methyl). 


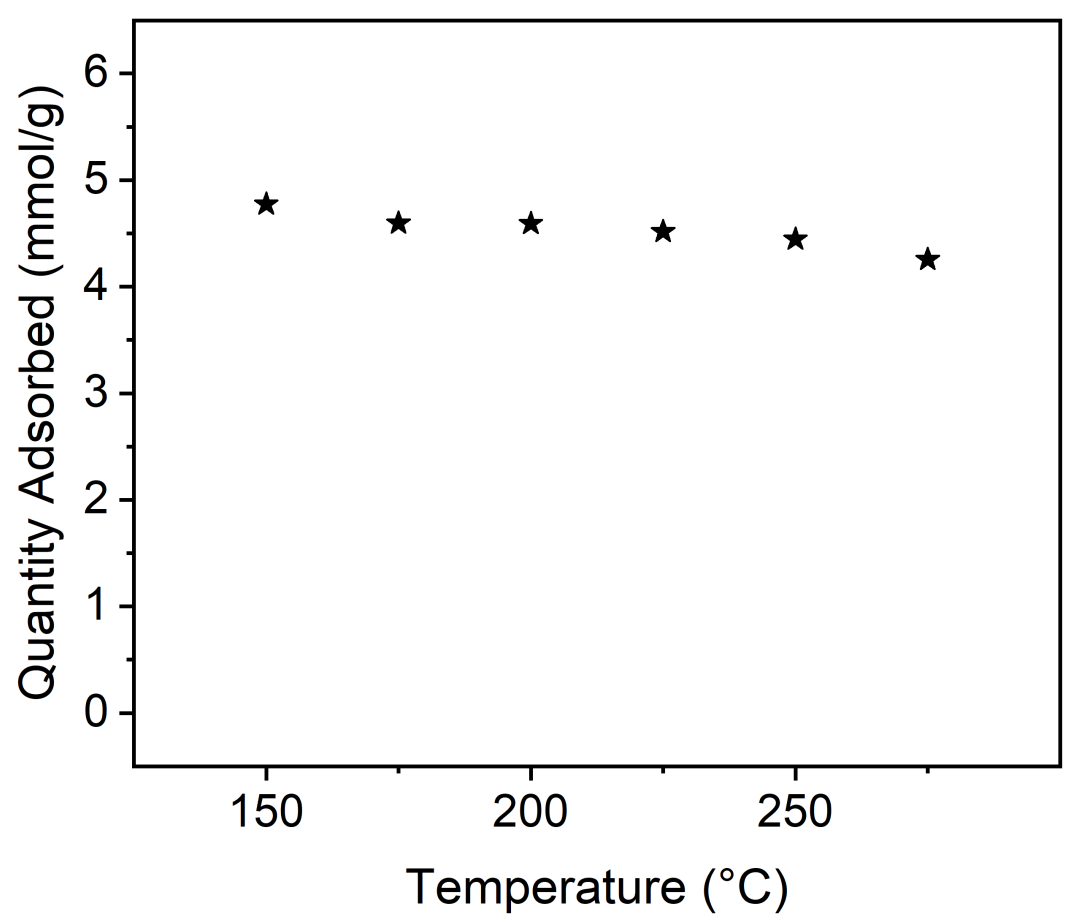

Figure S87. $\mathrm{CO}_{2}$ adsorption (195 K, 900 mbar) following activation at varied temperatures for Ni(2-Br).

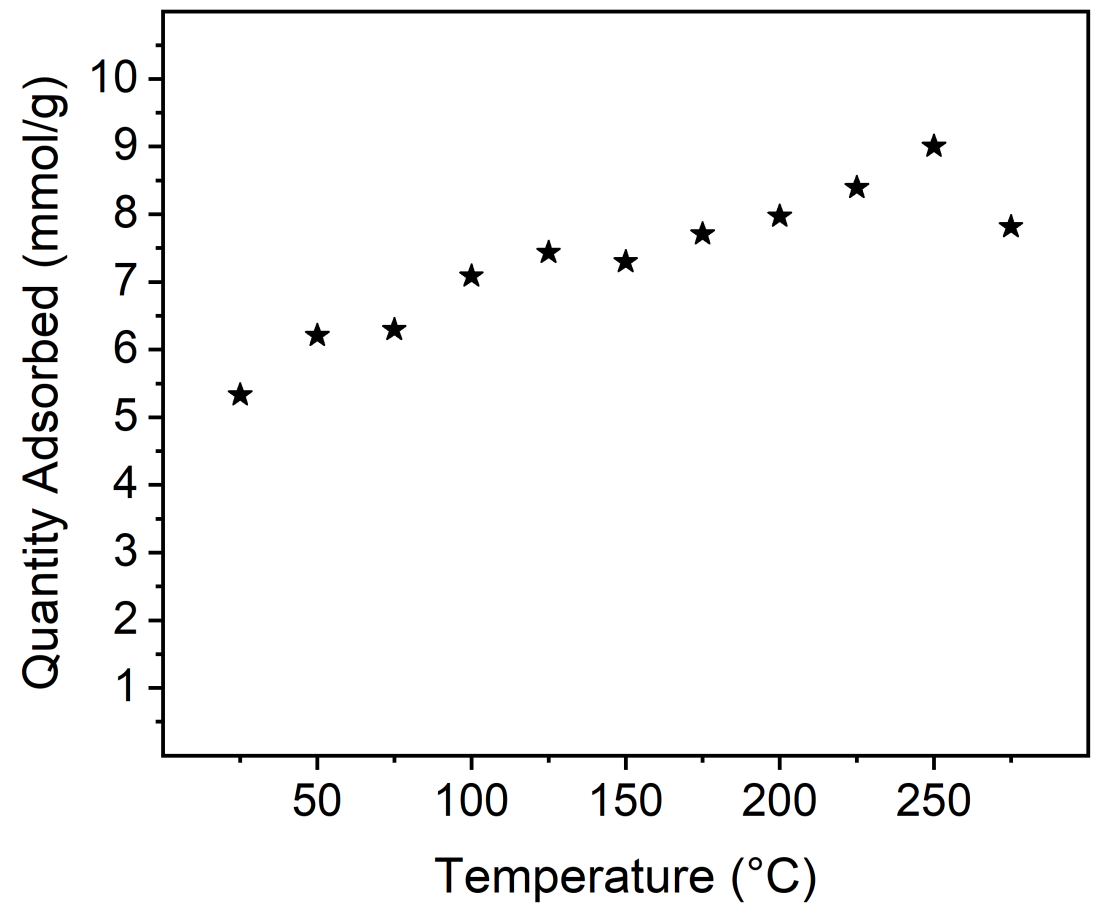

Figure S88. $\mathrm{N}_{2}$ adsorption (77 K, $800 \mathrm{mbar}$ ) following activation at varied temperatures for Ni(dobdc). 


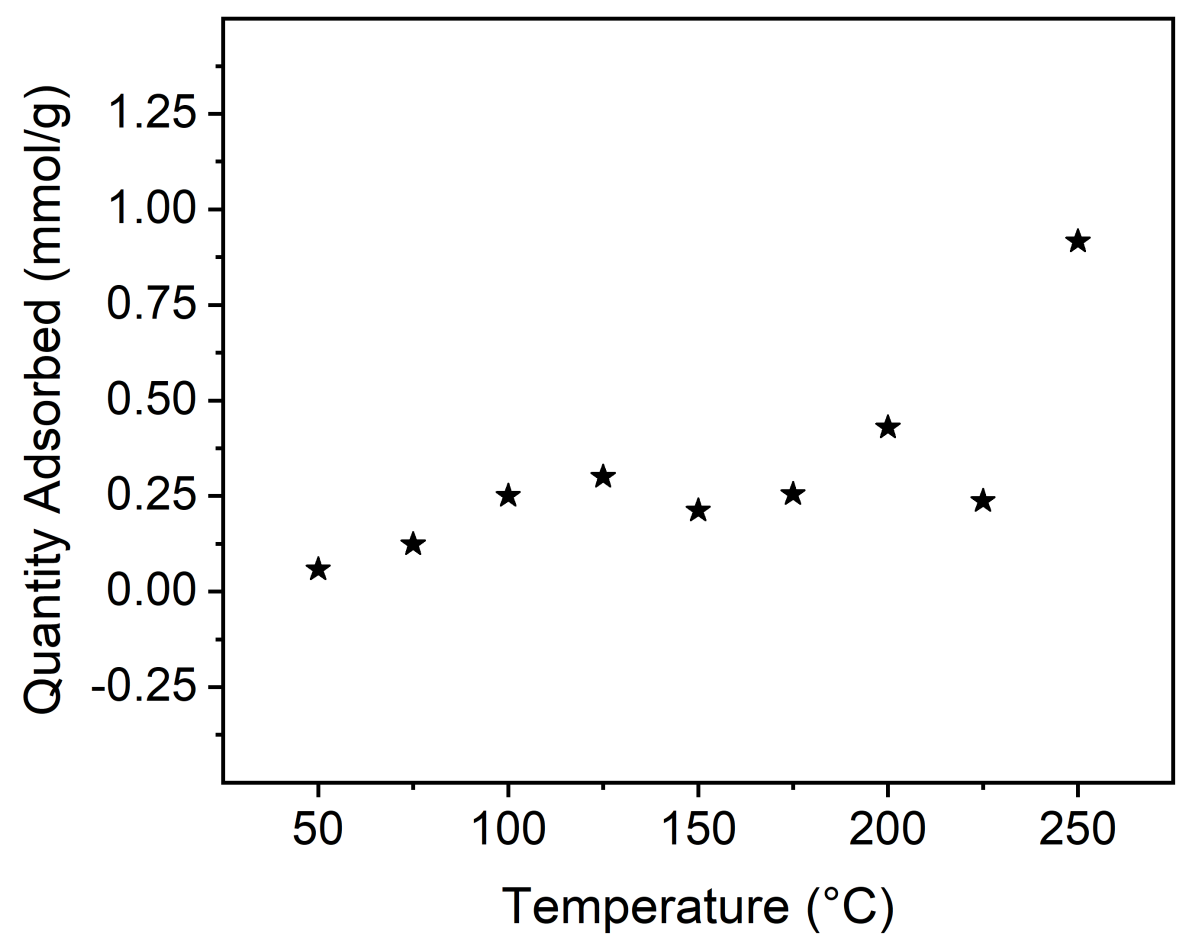

Figure S89. $\mathrm{N}_{2}$ adsorption (77 K, 800 mbar) following activation at varied temperatures for Ni(5-OProp).

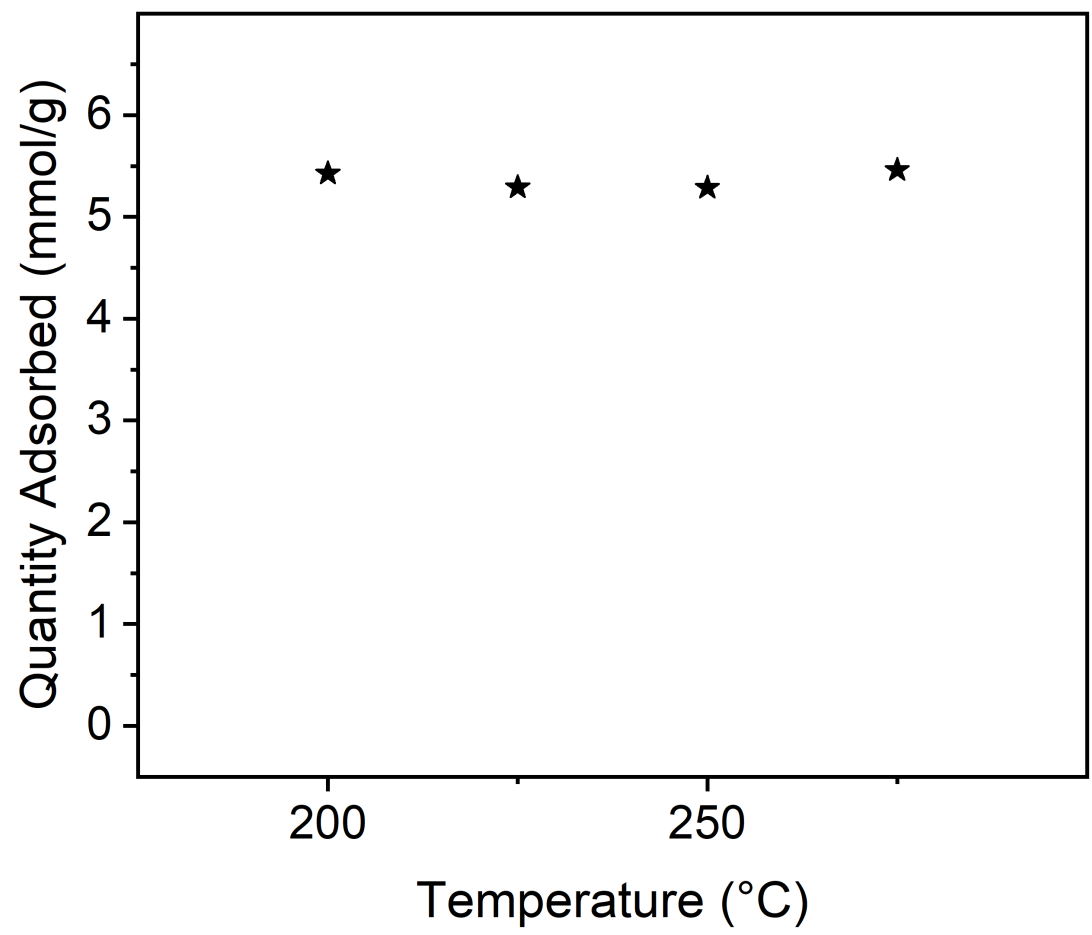

Figure S90. $\mathrm{CO}_{2}$ adsorption (195 K, 900 mbar) following activation at varied temperatures for $\mathrm{Ni}$ (5-OProp). 


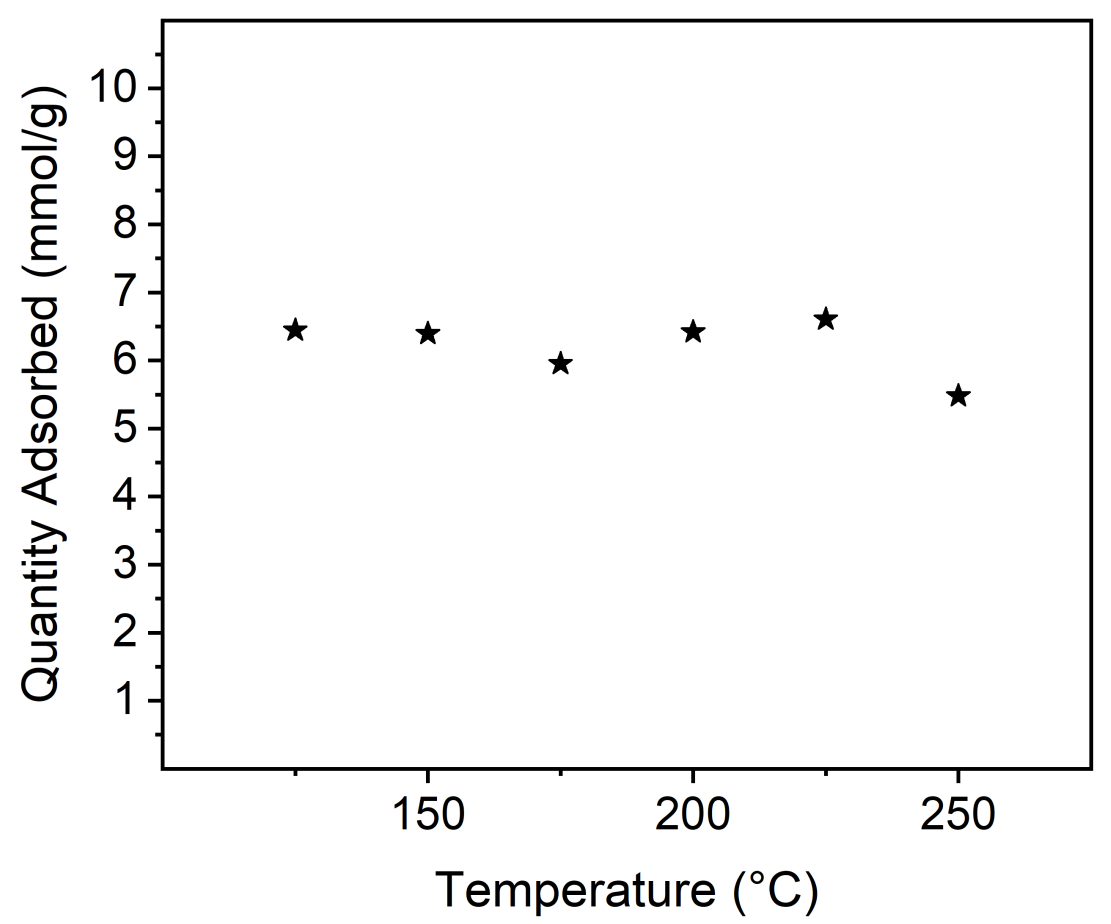

Figure S91. $\mathrm{CO}_{2}$ adsorption (195 K, 900 mbar) following activation at varied temperatures for Co-(5-OHept). 


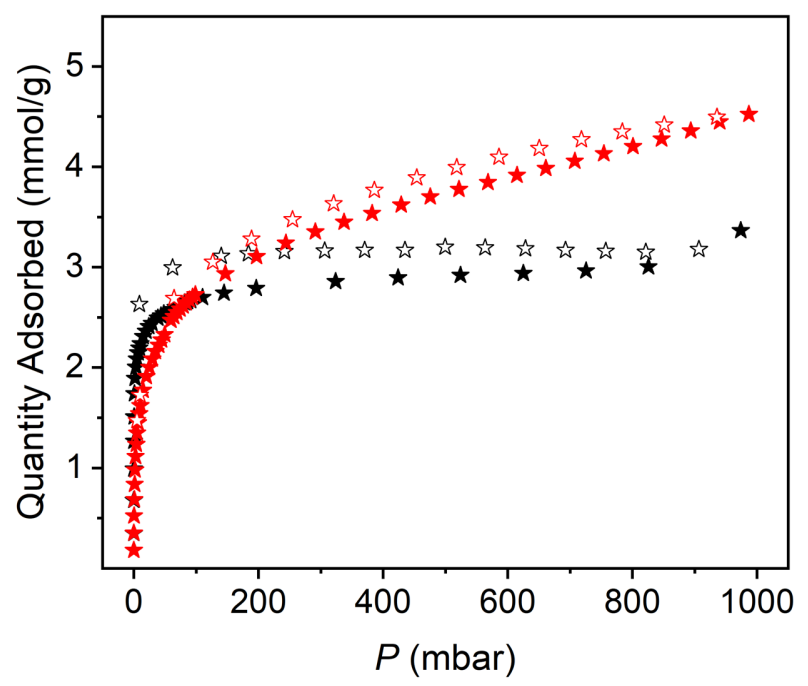

Figure S92. $\mathrm{N}_{2}$ adsorption (solid black stars) and desorption (hollow black stars) at $77 \mathrm{~K}$ and $\mathrm{CO}_{2}$ adsorption (solid red stars) and desorption (hollow red stars) at $195 \mathrm{~K}$ for Co-(5-Sulfo).
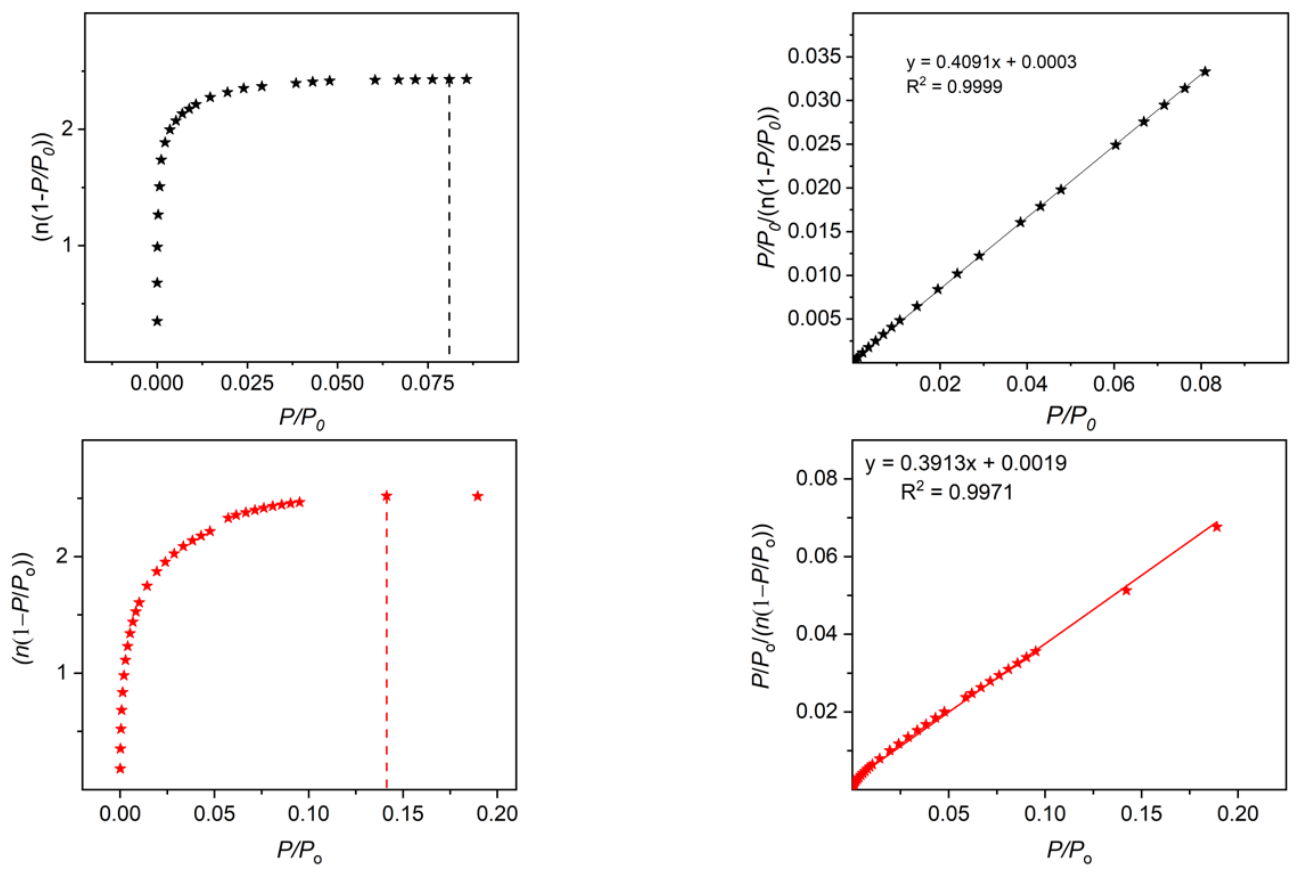

Figure S93. Top left: Plot of $\mathrm{n}\left(1-\mathrm{P} / \mathrm{P}_{0}\right)$ vs. $\mathrm{P} / \mathrm{P}_{0}$ to determine the maximum $\mathrm{P} / \mathrm{P}_{0}$ used in the $\mathrm{BET}$ linear fit according to the first BET consistency criterion for $\mathrm{N}_{2}$ adsorption at $77 \mathrm{~K}$ for the Co- $(5-$ Sulfo) MOSC. Top right: The slope of the best fit line for $\mathrm{P} / \mathrm{P}_{0}<0.0809$ is 0.4091 and the $\mathrm{y}-$ intercept is 0.0003 , which satisfies the second BET consistency criterion. This results in a measured surface area of $238 \mathrm{~m}^{2} / \mathrm{g}$ to $\mathrm{N}_{2}$. Bottom left: Plot of $\mathrm{n}\left(1-\mathrm{P} / \mathrm{P}_{0}\right)$ vs. $\mathrm{P} / \mathrm{P}_{0}$ to determine the maximum $\mathrm{P} / \mathrm{P}_{0}$ used in the $\mathrm{BET}$ linear fit according to the first $\mathrm{BET}$ consistency criterion for $\mathrm{CO}_{2}$ adsorption at $195 \mathrm{~K}$ for the Co-(5-Sulfo) MOSC. Bottom right: The slope of the best fit line for $\mathrm{P} / \mathrm{P}_{0}<0.141$ is 0.3913 and the $\mathrm{y}$-intercept is 0.0019 , which satisfies the second BET consistency criterion. This results in a measured surface area of $262 \mathrm{~m}^{2} / \mathrm{g}$ to $\mathrm{CO}_{2}$. 


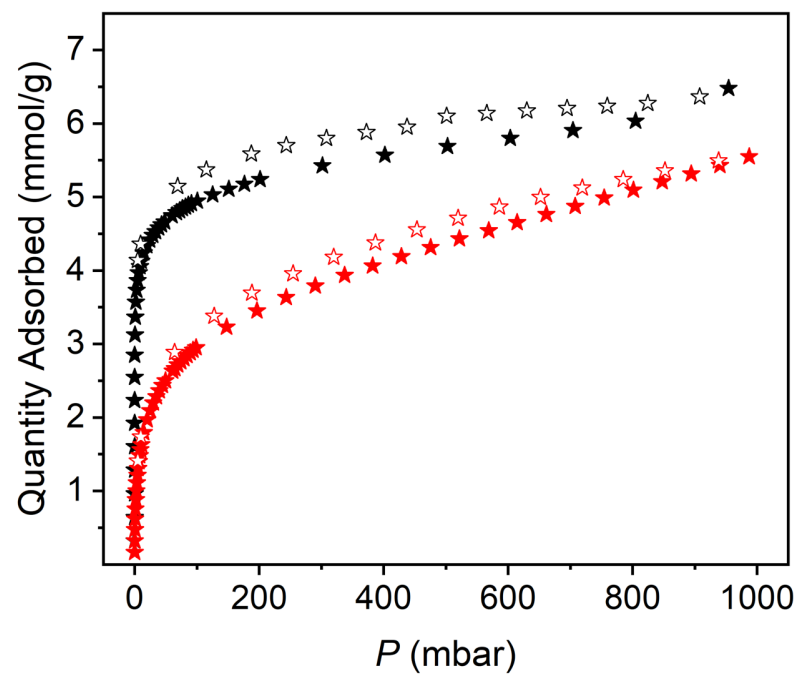

Figure S94. $\mathrm{N}_{2}$ adsorption (solid black stars) and desorption (hollow black stars) at $77 \mathrm{~K}$ and $\mathrm{CO}_{2}$ adsorption (solid red stars) and desorption (hollow red stars) at $195 \mathrm{~K}$ for Ni-(2-Methyl).
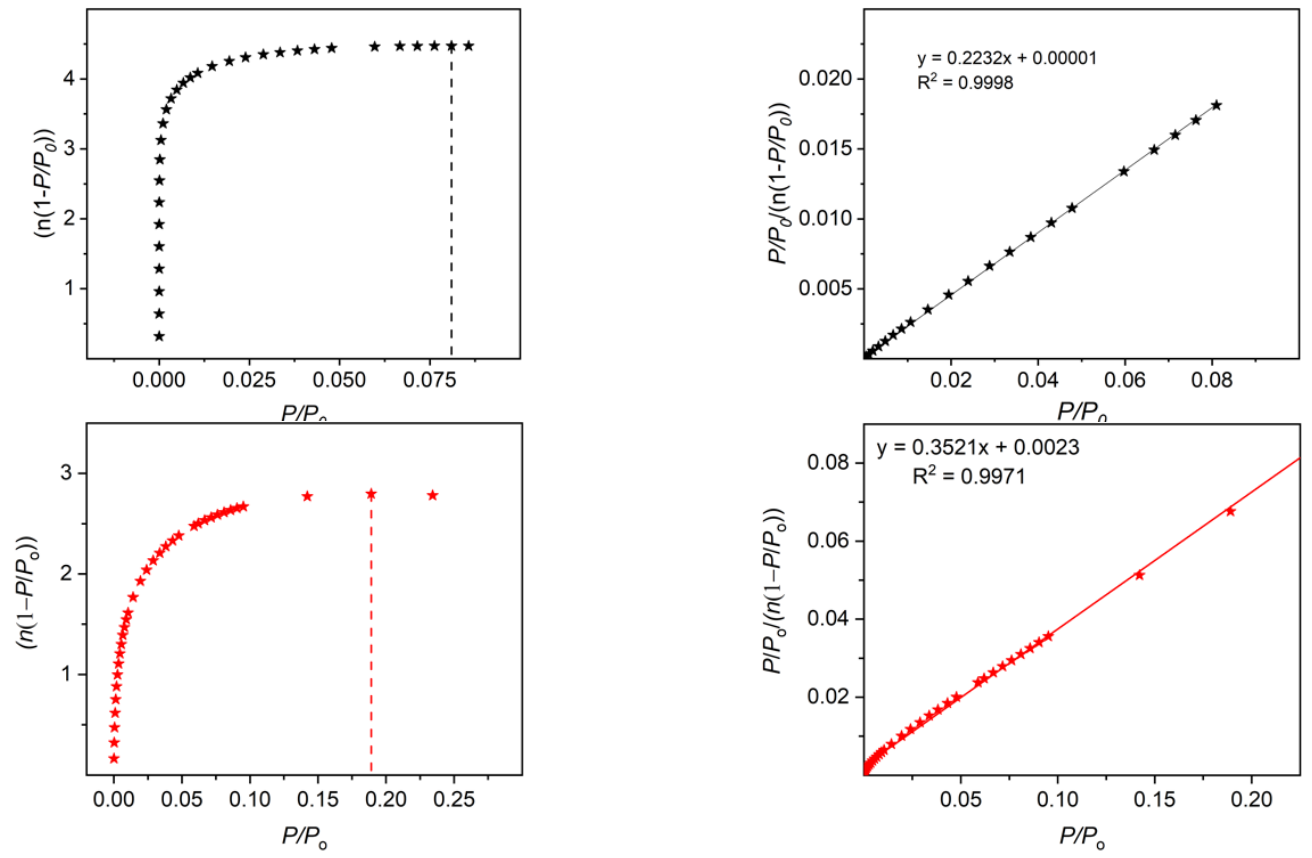

Figure S95. Top left: Plot of $\mathrm{n}\left(1-\mathrm{P} / \mathrm{P}_{0}\right)$ vs. $\mathrm{P} / \mathrm{P}_{0}$ to determine the maximum $\mathrm{P} / \mathrm{P}_{0}$ used in the $\mathrm{BET}$ linear fit according to the first BET consistency criterion for $\mathrm{N}_{2}$ adsorption at $77 \mathrm{~K}$ for the Ni-(2Methyl) MOSC. Top right: The slope of the best fit line for $\mathrm{P} / \mathrm{P}_{0}<0.0810$ is 0.2232 and the $\mathrm{y}-$ intercept is 0.00001, which satisfies the second BET consistency criterion. This results in a measured surface area of $437 \mathrm{~m}^{2} / \mathrm{g}$ to $\mathrm{N}_{2}$. Bottom left: Plot of $\mathrm{n}\left(1-\mathrm{P} / \mathrm{P}_{0}\right)$ vs. $\mathrm{P} / \mathrm{P}_{0}$ to determine the maximum $\mathrm{P} / \mathrm{P}_{0}$ used in the $\mathrm{BET}$ linear fit according to the first $\mathrm{BET}$ consistency criterion for $\mathrm{CO}_{2}$ adsorption at $195 \mathrm{~K}$ for the Ni-(2-Methyl) MOSC. Bottom right: The slope of the best fit line for $\mathrm{P} / \mathrm{P}_{0}<0.189$ is 0.3521 and the $\mathrm{y}$-intercept is 0.0023 , which satisfies the second BET consistency criterion. This results in a measured surface area of $291 \mathrm{~m}^{2} / \mathrm{g}$ to $\mathrm{CO}_{2}$. 


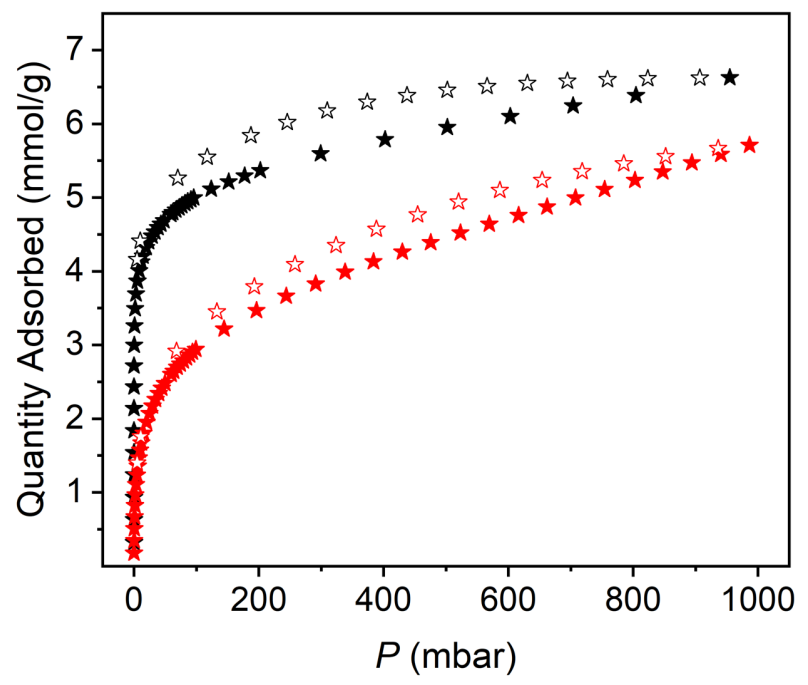

Figure S96. $\mathrm{N}_{2}$ adsorption (solid black stars) and desorption (hollow black stars) at $77 \mathrm{~K}$ and $\mathrm{CO}_{2}$ adsorption (solid red stars) and desorption (hollow red stars) at $195 \mathrm{~K}$ for Ni-(5-Methyl).
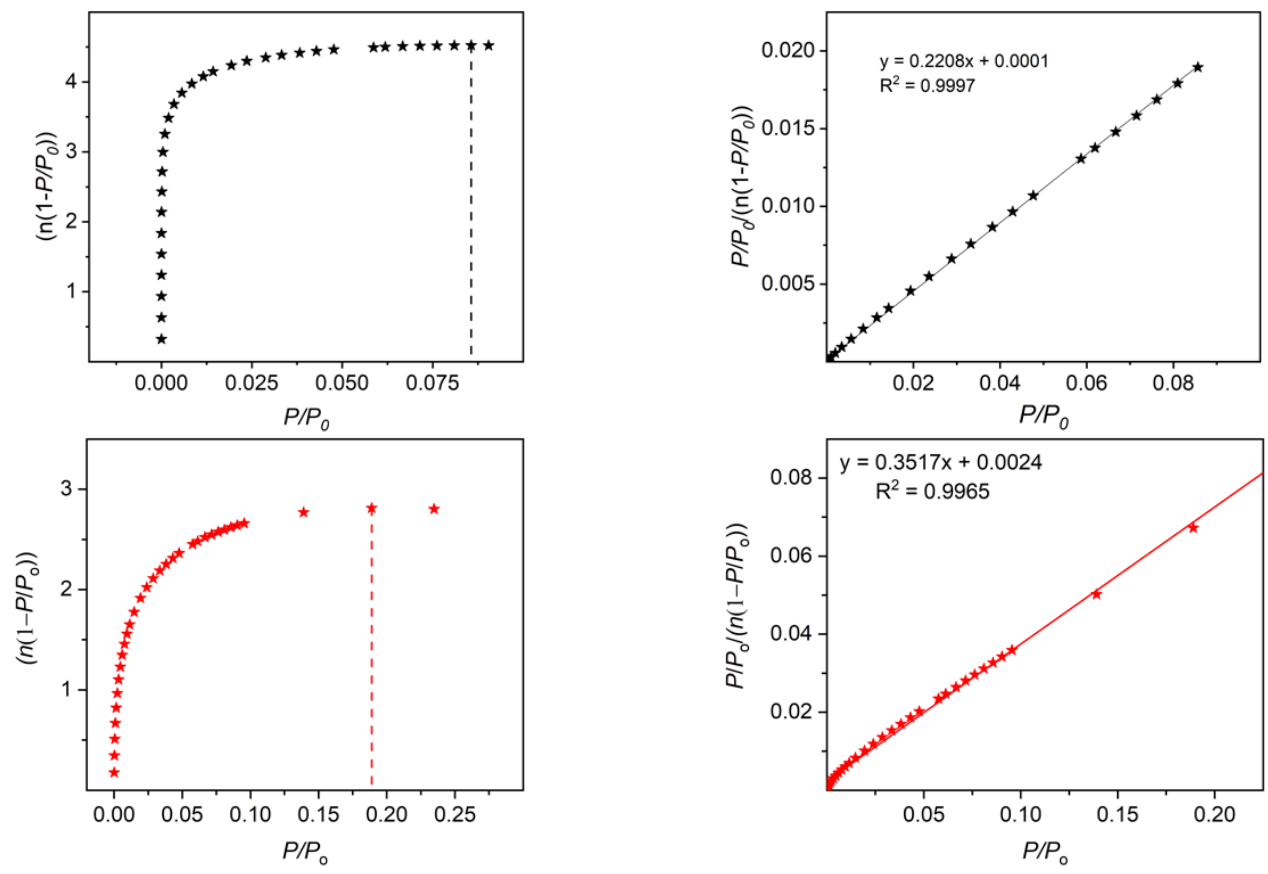

Figure S97. Top left: Plot of $\mathrm{n}\left(1-\mathrm{P} / \mathrm{P}_{0}\right)$ vs. $\mathrm{P} / \mathrm{P}_{0}$ to determine the maximum $\mathrm{P} / \mathrm{P}_{0}$ used in the $\mathrm{BET}$ linear fit according to the first BET consistency criterion for $\mathrm{N}_{2}$ adsorption at $77 \mathrm{~K}$ for the Ni- $(5$ Methyl) MOSC. Top right: The slope of the best fit line for $\mathrm{P} / \mathrm{P}_{0}<0.0856$ is 0.2208 and the $\mathrm{y}-$ intercept is 0.0001, which satisfies the second BET consistency criterion. This results in a measured surface area of $442 \mathrm{~m}^{2} / \mathrm{g}$ to $\mathrm{N}_{2}$. Bottom left: Plot of $\mathrm{n}\left(1-\mathrm{P} / \mathrm{P}_{0}\right)$ vs. $\mathrm{P} / \mathrm{P}_{0}$ to determine the maximum $\mathrm{P} / \mathrm{P}_{0}$ used in the $\mathrm{BET}$ linear fit according to the first $\mathrm{BET}$ consistency criterion for $\mathrm{CO}_{2}$ adsorption at $195 \mathrm{~K}$ for the Ni-(5-Methyl) MOSC. Bottom right: The slope of the best fit line for $\mathrm{P} / \mathrm{P}_{0}<0.189$ is 0.3517 and the $\mathrm{y}$-intercept is 0.0024 , which satisfies the second BET consistency criterion. This results in a measured surface area of $292 \mathrm{~m}^{2} / \mathrm{g}$ to $\mathrm{CO}_{2}$. 


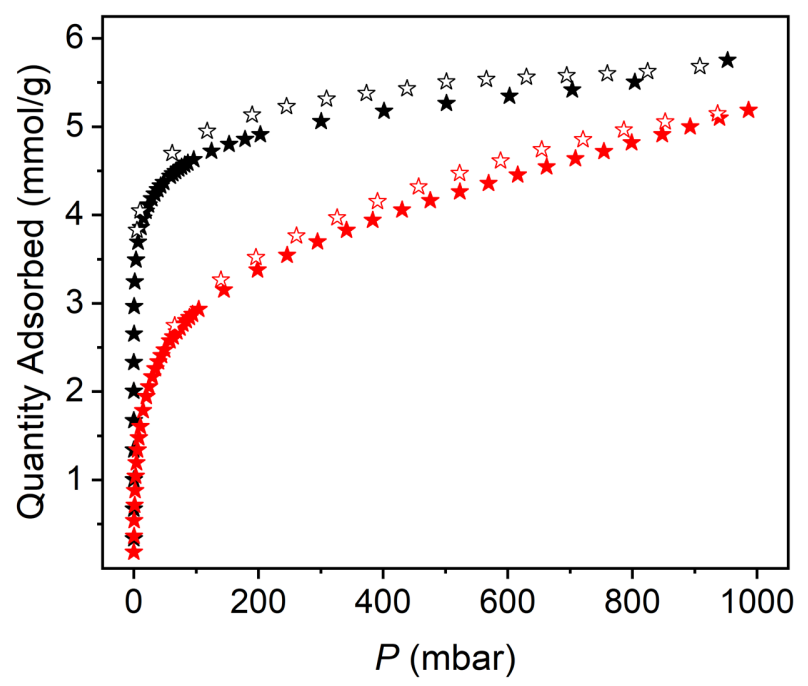

Figure S98. $\mathrm{N}_{2}$ adsorption (solid black stars) and desorption (hollow black stars) at $77 \mathrm{~K}$ and $\mathrm{CO}_{2}$ adsorption (solid red stars) and desorption (hollow red stars) at $195 \mathrm{~K}$ for Ni-(2-Br).
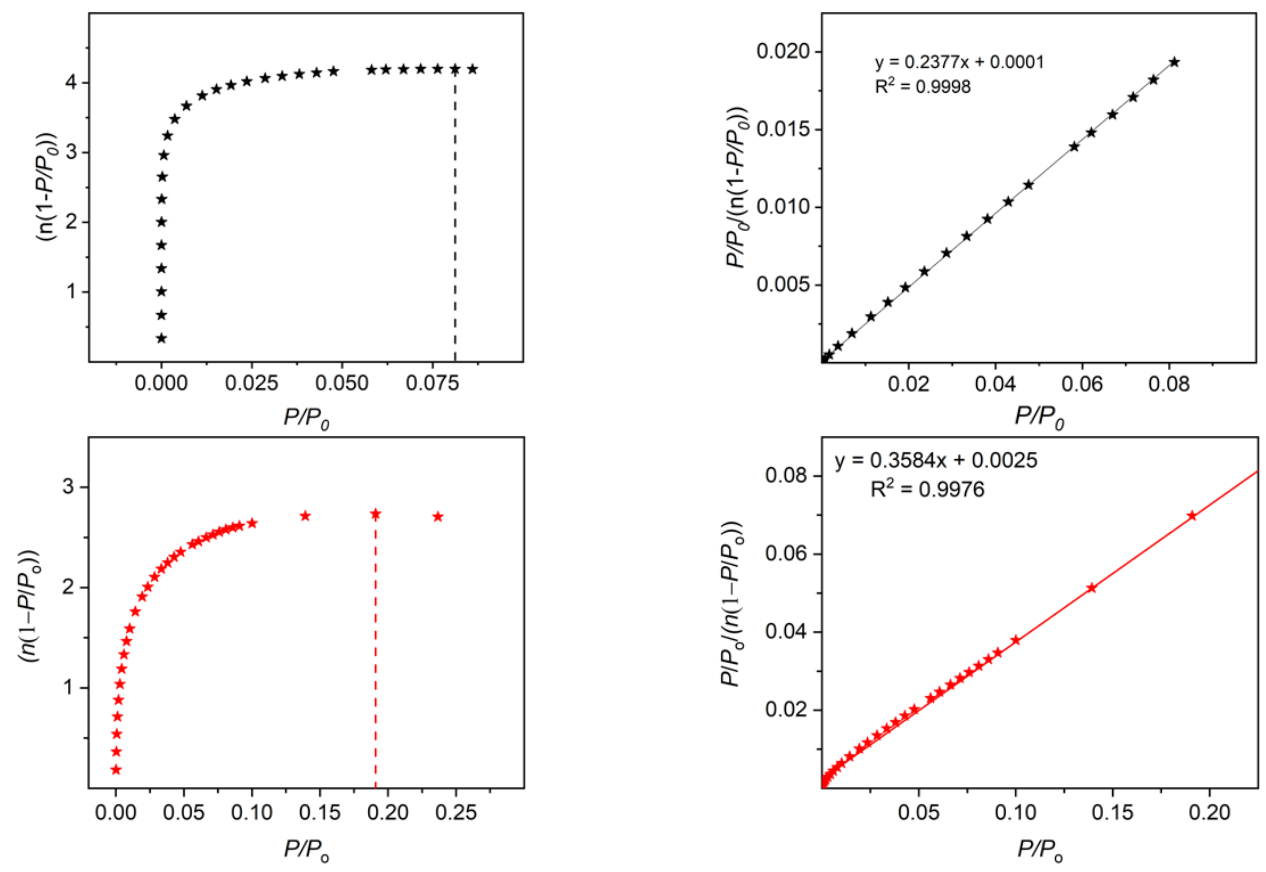

Figure S99. Top left: Plot of $\mathrm{n}\left(1-\mathrm{P} / \mathrm{P}_{0}\right)$ vs. $\mathrm{P} / \mathrm{P}_{0}$ to determine the maximum $\mathrm{P} / \mathrm{P}_{0}$ used in the $\mathrm{BET}$ linear fit according to the first BET consistency criterion for $\mathrm{N}_{2}$ adsorption at $77 \mathrm{~K}$ for the Ni-(2$\mathrm{Br}$ ) MOSC. Top right: The slope of the best fit line for $\mathrm{P} / \mathrm{P}_{0}<0.0812$ is 0.2377 and the $\mathrm{y}$-intercept is 0.0001 , which satisfies the second BET consistency criterion. This results in a measured surface area of $410 \mathrm{~m}^{2} / \mathrm{g}$ to $\mathrm{N}_{2}$. Bottom left: Plot of $\mathrm{n}\left(1-\mathrm{P} / \mathrm{P}_{0}\right)$ vs. $\mathrm{P} / \mathrm{P}_{0}$ to determine the maximum $\mathrm{P} / \mathrm{P}_{0}$ used in the BET linear fit according to the first BET consistency criterion for $\mathrm{CO}_{2}$ adsorption at $195 \mathrm{~K}$ for the Co-(5-Sulfo) MOSC. Bottom right: The slope of the best fit line for $\mathrm{P} / \mathrm{P}_{0}<0.191$ is 0.3584 and the y-intercept is 0.0025 , which satisfies the second BET consistency criterion. This results in a measured surface area of $286 \mathrm{~m}^{2} / \mathrm{g}$ to $\mathrm{CO}_{2}$. 


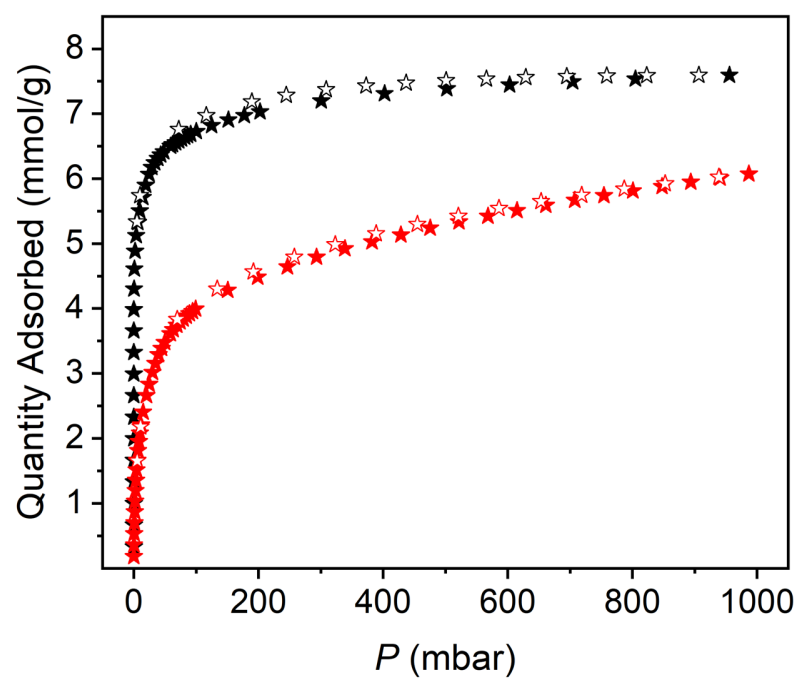

Figure S100. $\mathrm{N}_{2}$ adsorption (solid black stars) and desorption (hollow black stars) at $77 \mathrm{~K}$ and $\mathrm{CO}_{2}$ adsorption (solid red stars) and desorption (hollow red stars) at $195 \mathrm{~K}$ for Ni-(5-Br).
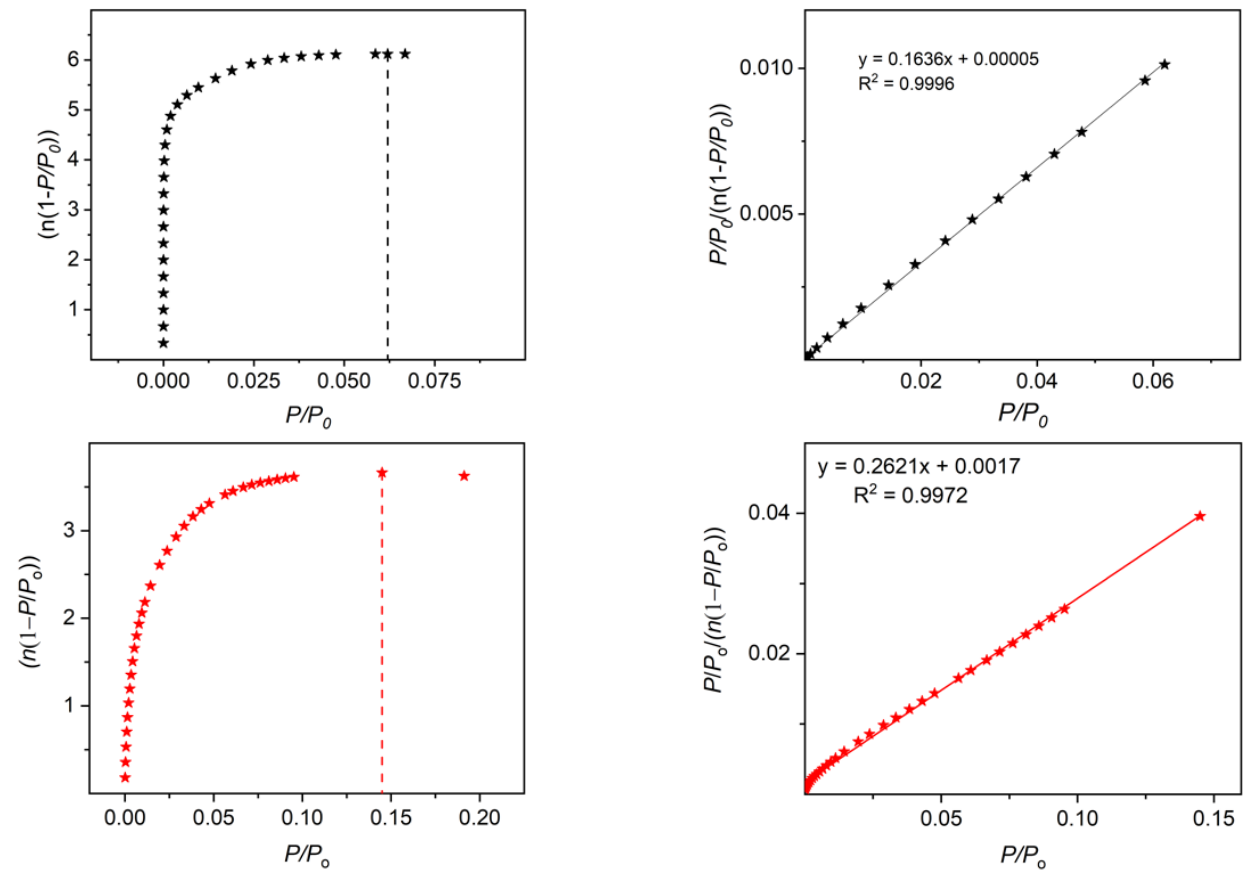

Figure S101. Top left: Plot of $\mathrm{n}\left(1-\mathrm{P} / \mathrm{P}_{0}\right)$ vs. $\mathrm{P} / \mathrm{P}_{0}$ to determine the maximum $\mathrm{P} / \mathrm{P}_{0}$ used in the $\mathrm{BET}$ linear fit according to the first BET consistency criterion for $\mathrm{N}_{2}$ adsorption at $77 \mathrm{~K}$ for the Ni- $(5$ $\mathrm{Br}$ ) MOSC. Top right: The slope of the best fit line for $\mathrm{P} / \mathrm{P}_{0}<0.0620$ is 0.1636 and the $\mathrm{y}$-intercept is 0.00005 , which satisfies the second BET consistency criterion. This results in a measured surface area of $596 \mathrm{~m}^{2} / \mathrm{g}$ to $\mathrm{N}_{2}$. Bottom left: Plot of $\mathrm{n}\left(1-\mathrm{P} / \mathrm{P}_{0}\right)$ vs. $\mathrm{P} / \mathrm{P}_{0}$ to determine the maximum $\mathrm{P} / \mathrm{P}_{0}$ used in the BET linear fit according to the first BET consistency criterion for $\mathrm{CO}_{2}$ adsorption at $195 \mathrm{~K}$ for the Ni-(5-Br) MOSC. Bottom right: The slope of the best fit line for $\mathrm{P} / \mathrm{P}_{0}<0.145$ is 0.2621 and the y-intercept is 0.0017 , which satisfies the second BET consistency criterion. This results in a measured surface area of $391 \mathrm{~m}^{2} / \mathrm{g}$ to $\mathrm{CO}_{2}$. 


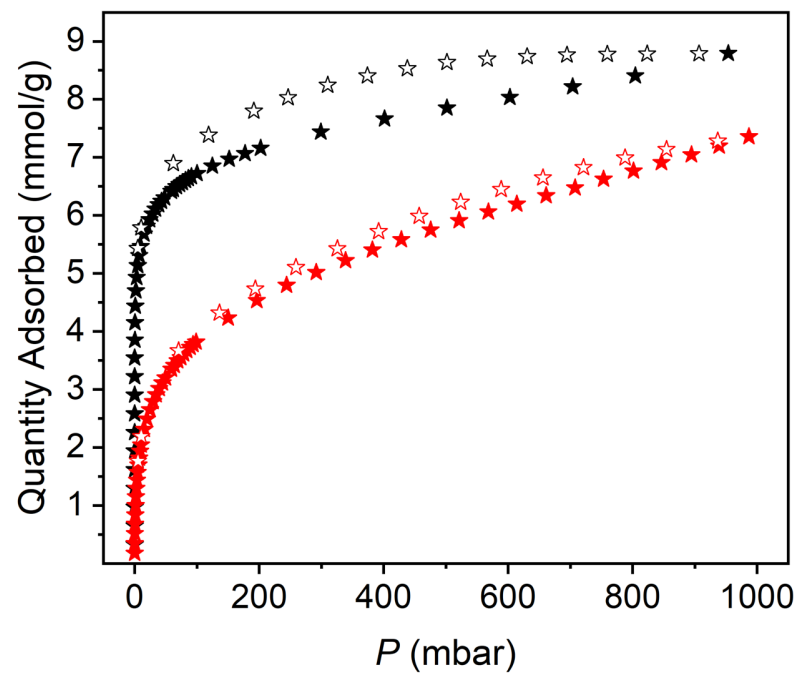

Figure S102. $\mathrm{N}_{2}$ adsorption (solid black stars) and desorption (hollow black stars) at $77 \mathrm{~K}$ and $\mathrm{CO}_{2}$ adsorption (solid red stars) and desorption (hollow red stars) at $195 \mathrm{~K}$ for Ni-(dobdc).
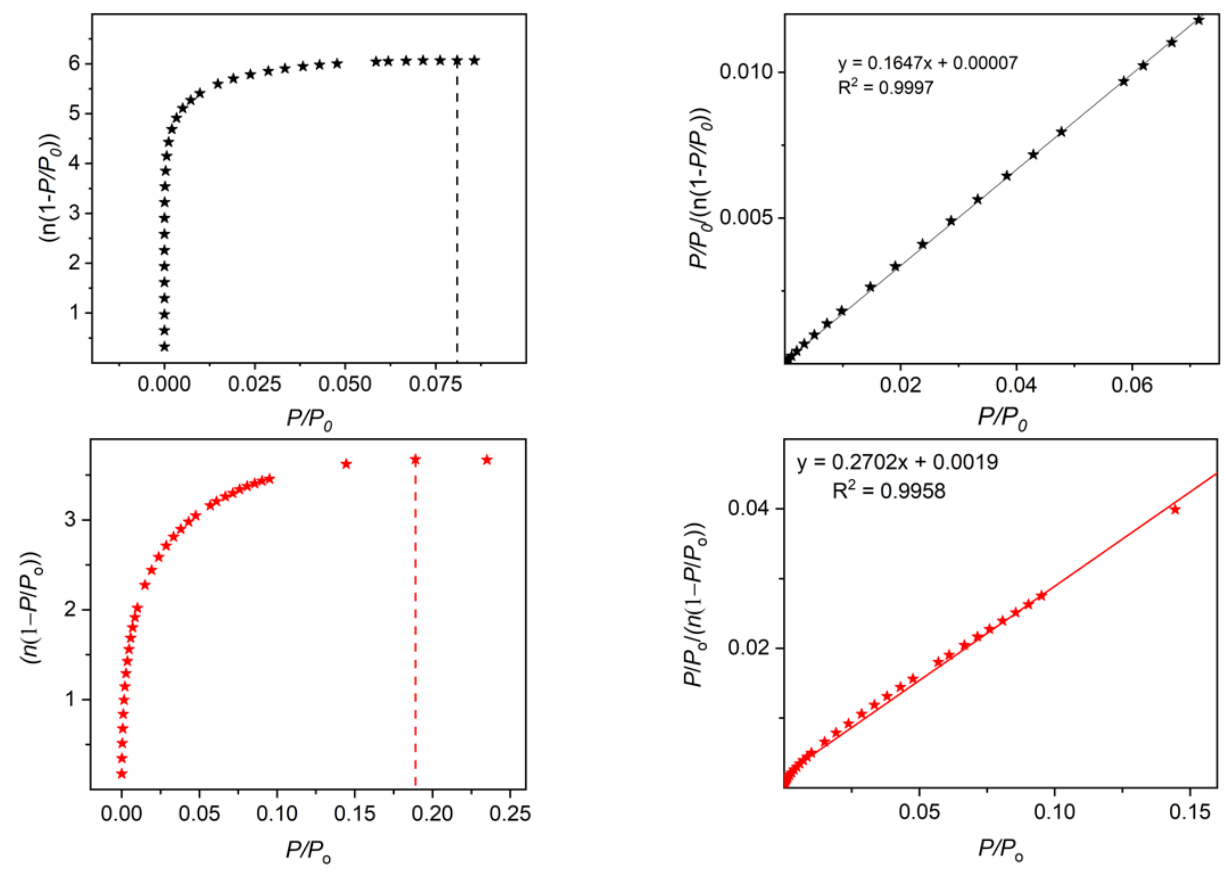

Figure S103. Top left: Plot of $\mathrm{n}\left(1-\mathrm{P} / \mathrm{P}_{0}\right)$ vs. $\mathrm{P} / \mathrm{P}_{0}$ to determine the maximum $\mathrm{P} / \mathrm{P}_{0}$ used in the $\mathrm{BET}$ linear fit according to the first BET consistency criterion for $\mathrm{N}_{2}$ adsorption at $77 \mathrm{~K}$ for the Ni(dobdc) MOSC. Top right: The slope of the best fit line for $\mathrm{P} / \mathrm{P}_{0}<0.0809$ is 0.1647 and the $\mathrm{y}-$ intercept is 0.00007, which satisfies the second BET consistency criterion. This results in a measured surface area of $592 \mathrm{~m}^{2} / \mathrm{g}$ to $\mathrm{N}_{2}$. Bottom left: Plot of $\mathrm{n}\left(1-\mathrm{P} / \mathrm{P}_{0}\right)$ vs. $\mathrm{P} / \mathrm{P}_{0}$ to determine the maximum $\mathrm{P} / \mathrm{P}_{0}$ used in the $\mathrm{BET}$ linear fit according to the first $\mathrm{BET}$ consistency criterion for $\mathrm{CO}_{2}$ adsorption at $195 \mathrm{~K}$ for the Ni-(dobdc) MOSC. Bottom right: The slope of the best fit line for $\mathrm{P} / \mathrm{P}_{0}$ $<0.189$ is 0.2702 and the $y$-intercept is 0.0019 , which satisfies the second BET consistency criterion. This results in a measured surface area of $379 \mathrm{~m}^{2} / \mathrm{g}$ to $\mathrm{CO}_{2}$. 


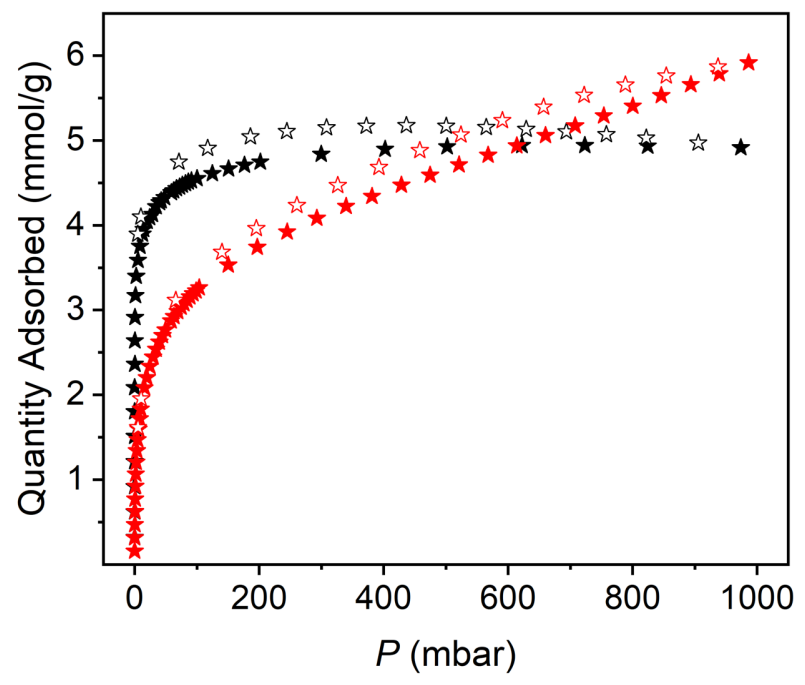

Figure S104. $\mathrm{N}_{2}$ adsorption (solid black stars) and desorption (hollow black stars) at $77 \mathrm{~K}$ and $\mathrm{CO}_{2}$ adsorption (solid red stars) and desorption (hollow red stars) BET at $195 \mathrm{~K}$ for Ni-(5-Propoxy).
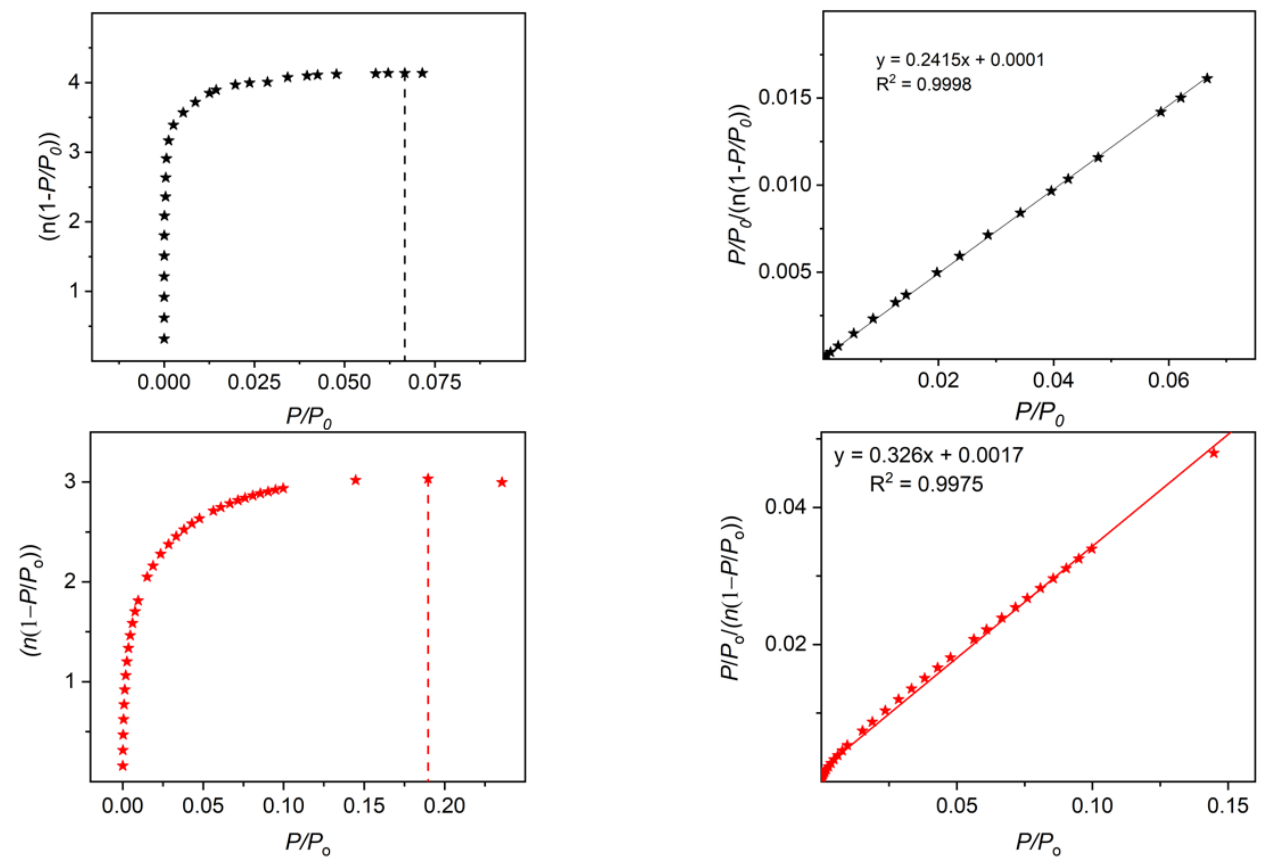

Figure S105. Top left: Plot of $\mathrm{n}\left(1-\mathrm{P} / \mathrm{P}_{0}\right)$ vs. $\mathrm{P} / \mathrm{P}_{0}$ to determine the maximum $\mathrm{P} / \mathrm{P}_{0}$ used in the $\mathrm{BET}$ linear fit according to the first BET consistency criterion for $\mathrm{N}_{2}$ adsorption at $77 \mathrm{~K}$ for the Ni-(5Oprop) MOSC. Top right: The slope of the best fit line for $\mathrm{P} / \mathrm{P}_{0}<0.0667$ is 0.2415 and the $\mathrm{y}-$ intercept is 0.0001 , which satisfies the second BET consistency criterion. This results in a measured surface area of $404 \mathrm{~m}^{2} / \mathrm{g}$ to $\mathrm{N}_{2}$. Bottom left: Plot of $\mathrm{n}\left(1-\mathrm{P} / \mathrm{P}_{0}\right) \mathrm{vs}$. $\mathrm{P} / \mathrm{P}_{0}$ to determine the maximum $\mathrm{P} / \mathrm{P}_{0}$ used in the $\mathrm{BET}$ linear fit according to the first $\mathrm{BET}$ consistency criterion for $\mathrm{CO}_{2}$ adsorption at $195 \mathrm{~K}$ for the Ni-(5-OProp) MOSC. Bottom right: The slope of the best fit line for $\mathrm{P} / \mathrm{P}_{0}<0.190$ is 0.326 and the $\mathrm{y}$-intercept is 0.0017 , which satisfies the second BET consistency criterion. This results in a measured surface area of $314 \mathrm{~m}^{2} / \mathrm{g}$ to $\mathrm{CO}_{2}$. 


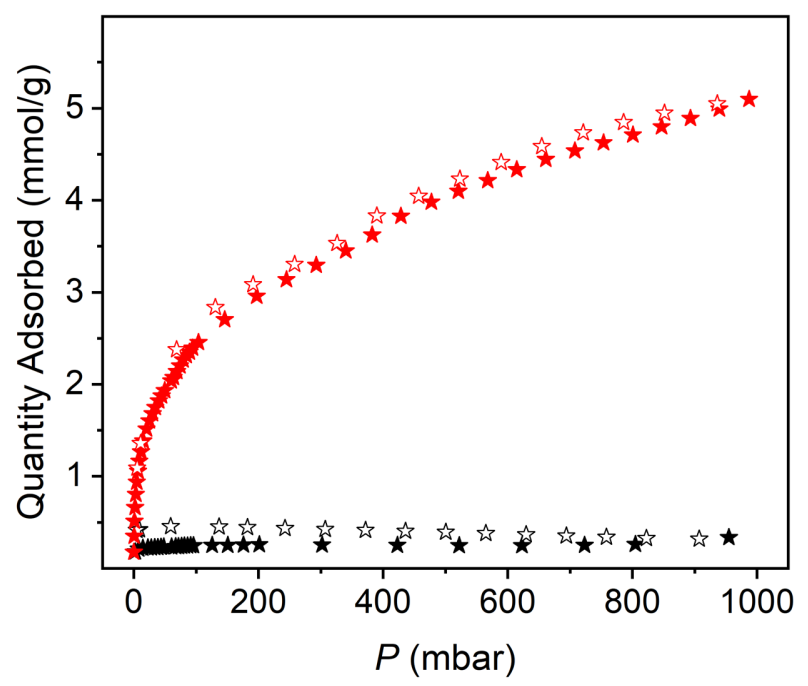

Figure S106. $\mathrm{N}_{2}$ adsorption (solid black stars) and desorption (hollow black stars) at $77 \mathrm{~K}$ and $\mathrm{CO}_{2}$ adsorption (solid red stars) and desorption (hollow red stars) $195 \mathrm{~K}$ for Co-(5-Heptoxy).
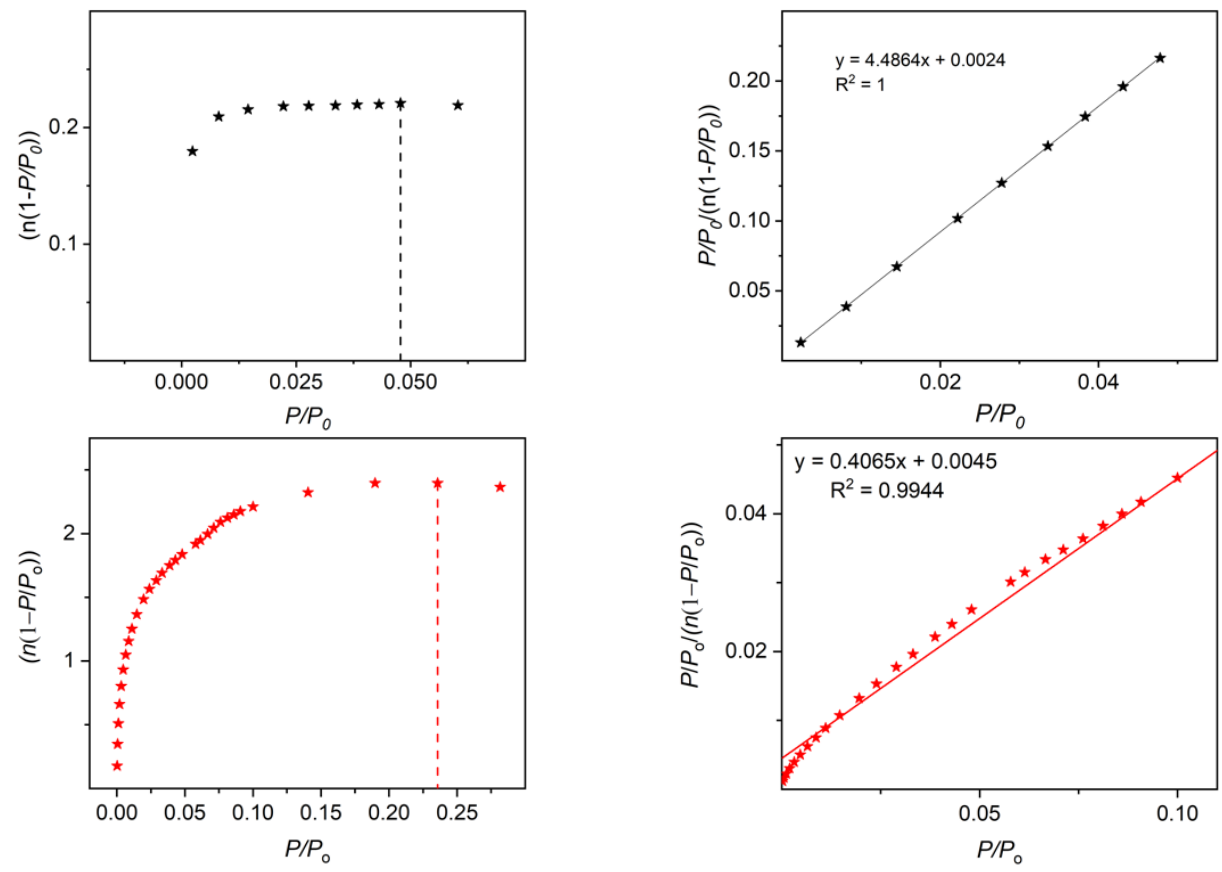

Figure S107. Top left: Plot of $\mathrm{n}\left(1-\mathrm{P} / \mathrm{P}_{0}\right)$ vs. $\mathrm{P} / \mathrm{P}_{0}$ to determine the maximum $\mathrm{P} / \mathrm{P}_{0}$ used in the $\mathrm{BET}$ linear fit according to the first BET consistency criterion for $\mathrm{N}_{2}$ adsorption at $77 \mathrm{~K}$ for the Co- $(5-$ OHept) MOSC. Top right: The slope of the best fit line for $\mathrm{P} / \mathrm{P}_{0}<0.0478$ is 4.4864 and the $\mathrm{y}-$ intercept is 0.0024, which satisfies the second BET consistency criterion. This results in a measured surface area of $22 \mathrm{~m}^{2} / \mathrm{g}$ to $\mathrm{N}_{2}$. Bottom left: Plot of $\mathrm{n}\left(1-\mathrm{P} / \mathrm{P}_{0}\right)$ vs. $\mathrm{P} / \mathrm{P}_{0}$ to determine the maximum $\mathrm{P} / \mathrm{P}_{0}$ used in the $\mathrm{BET}$ linear fit according to the first $\mathrm{BET}$ consistency criterion for $\mathrm{CO}_{2}$ adsorption at $195 \mathrm{~K}$ for the Co-(5-OHept) MOSC. Bottom right: The slope of the best fit line for $\mathrm{P} / \mathrm{P}_{0}<0.236$ is 0.4065 and the $\mathrm{y}$-intercept is 0.0045 , which satisfies the second BET consistency criterion. This results in a measured surface area of $252 \mathrm{~m}^{2} / \mathrm{g}$ to $\mathrm{CO}_{2}$. 


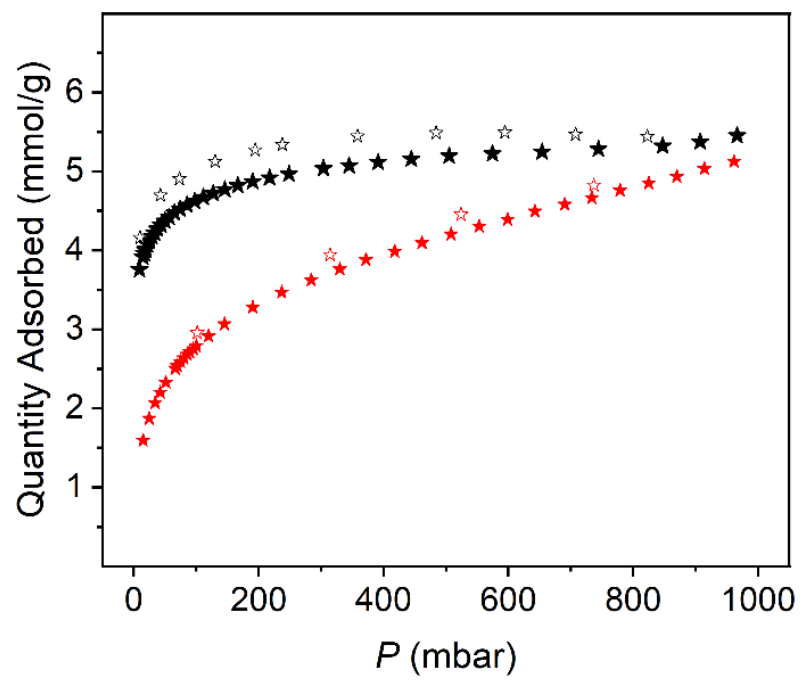

Figure S108. $\mathrm{N}_{2}$ adsorption (solid black stars) and desorption (hollow black stars) at $77 \mathrm{~K}$ and $\mathrm{CO}_{2}$ adsorption (solid red stars) and desorption (hollow red stars) $195 \mathrm{~K}$ for Ni-(2-Methyl)BzFD.
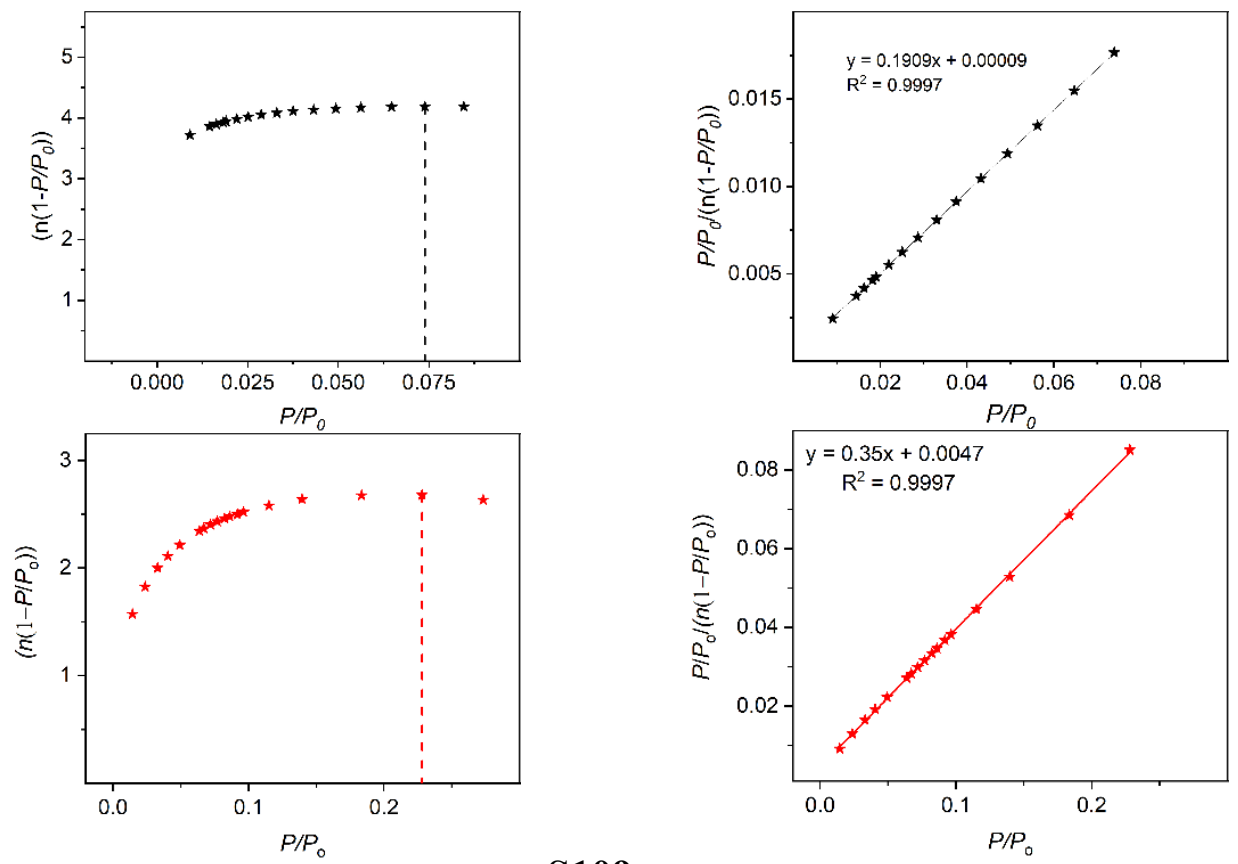

Figure

S109.

Top left:

Plot of $\mathrm{n}\left(1-\mathrm{P} / \mathrm{P}_{0}\right)$ vs. $\mathrm{P} / \mathrm{P}_{0}$ to determine the maximum $\mathrm{P} / \mathrm{P}_{0}$ used in the $\mathrm{BET}$ linear fit according to the first BET consistency criterion for $\mathrm{N}_{2}$ adsorption at $77 \mathrm{~K}$ for the Ni-(2-Methyl)BzFD MOSC. Top right: The slope of the best fit line for $\mathrm{P} / \mathrm{P}_{0}<0.0739$ is 0.1909 and the $\mathrm{y}$-intercept is 0.00009 , which satisfies the second BET consistency criterion. This results in a measured surface area of $418 \mathrm{~m}^{2} / \mathrm{g}$ to $\mathrm{N}_{2}$. Bottom left: Plot of $\mathrm{n}\left(1-\mathrm{P} / \mathrm{P}_{0}\right)$ vs. $\mathrm{P} / \mathrm{P}_{0}$ to determine the maximum $\mathrm{P} / \mathrm{P}_{0}$ used in the BET linear fit according to the first BET consistency criterion for $\mathrm{CO}_{2}$ adsorption at $195 \mathrm{~K}$ for the Ni-(2-Methyl)BzFD MOSC. Bottom right: The slope of the best fit line for $\mathrm{P} / \mathrm{P}_{0}<0.228$ is 0.350 and the $y$-intercept is 0.0047 , which satisfies the second BET consistency criterion. This results in a measured surface area of $293 \mathrm{~m}^{2} / \mathrm{g}$ to $\mathrm{CO}_{2}$. 


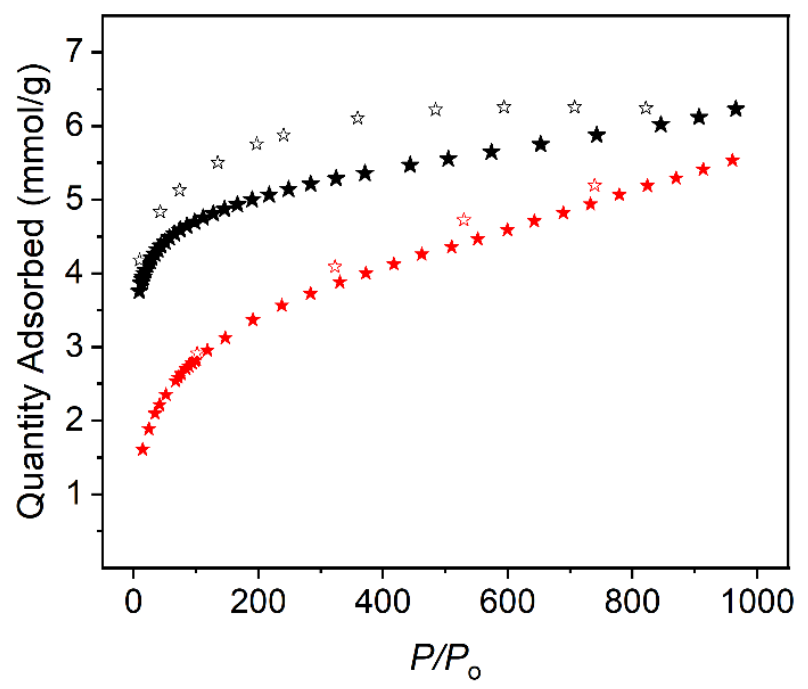

Figure S110. $\mathrm{N}_{2}$ adsorption (solid black stars) and desorption (hollow black stars) at $77 \mathrm{~K}$ and $\mathrm{CO}_{2}$ adsorption (solid red stars) and desorption (hollow red stars) $195 \mathrm{~K}$ for Ni-(5-Methyl)BzFD.
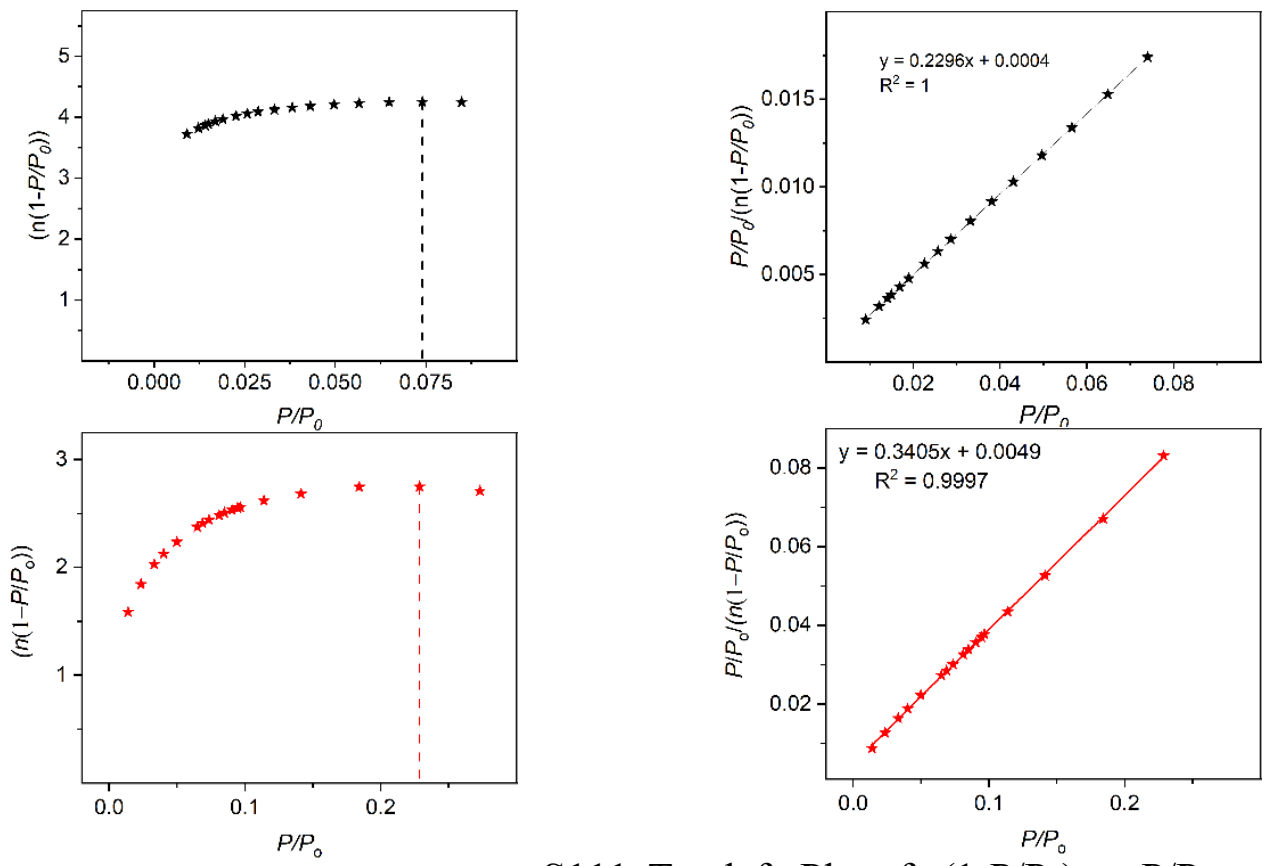

Figure

S111. Top left: Plot of $\mathrm{n}\left(1-\mathrm{P} / \mathrm{P}_{0}\right)$ vs. $\mathrm{P} / \mathrm{P}_{0}$ to determine the maximum $\mathrm{P} / \mathrm{P}_{0}$ used in the BET linear fit according to the first BET consistency criterion for $\mathrm{N}_{2}$ adsorption at $77 \mathrm{~K}$ for the Ni-(5-Methyl)BzFD MOSC. Top right: The slope of the best fit line for $\mathrm{P} / \mathrm{P}_{0}<0.0740$ is 0.2296 and the $\mathrm{y}$-intercept is 0.0004 , which satisfies the second BET consistency criterion. This results in a measured surface area of $425 \mathrm{~m}^{2} / \mathrm{g}$ to $\mathrm{N}_{2}$. Bottom left: Plot of $\mathrm{n}\left(1-\mathrm{P} / \mathrm{P}_{0}\right)$ vs. $\mathrm{P} / \mathrm{P}_{0}$ to determine the maximum $\mathrm{P} / \mathrm{P}_{0}$ used in the $\mathrm{BET}$ linear fit according to the first BET consistency criterion for $\mathrm{CO}_{2}$ adsorption at $195 \mathrm{~K}$ for the Ni-(5-Methyl)BzFD MOSC. Bottom right: The slope of the best fit line for $\mathrm{P} / \mathrm{P}_{0}<0.229$ is 0.3405 and the $\mathrm{y}$-intercept is 0.0049 , which satisfies the second BET consistency criterion. This results in a measured surface area of $301 \mathrm{~m}^{2} / \mathrm{g}$ to $\mathrm{CO}_{2}$. 


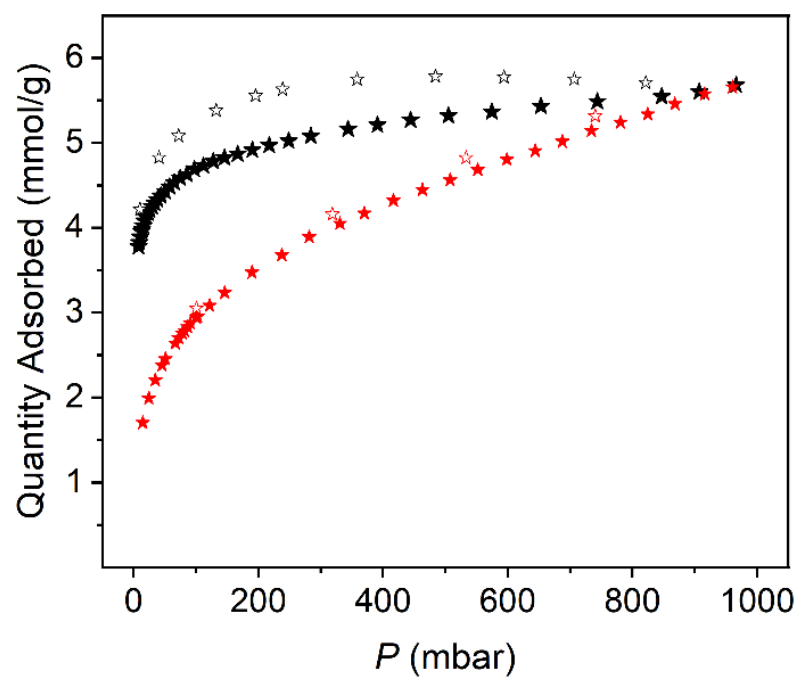

Figure S110. $\mathrm{N}_{2}$ adsorption (solid black stars) and desorption (hollow black stars) at $77 \mathrm{~K}$ and $\mathrm{CO}_{2}$ adsorption (solid red stars) and desorption (hollow red stars) $195 \mathrm{~K}$ for Ni-(5-OProp)BzFD.
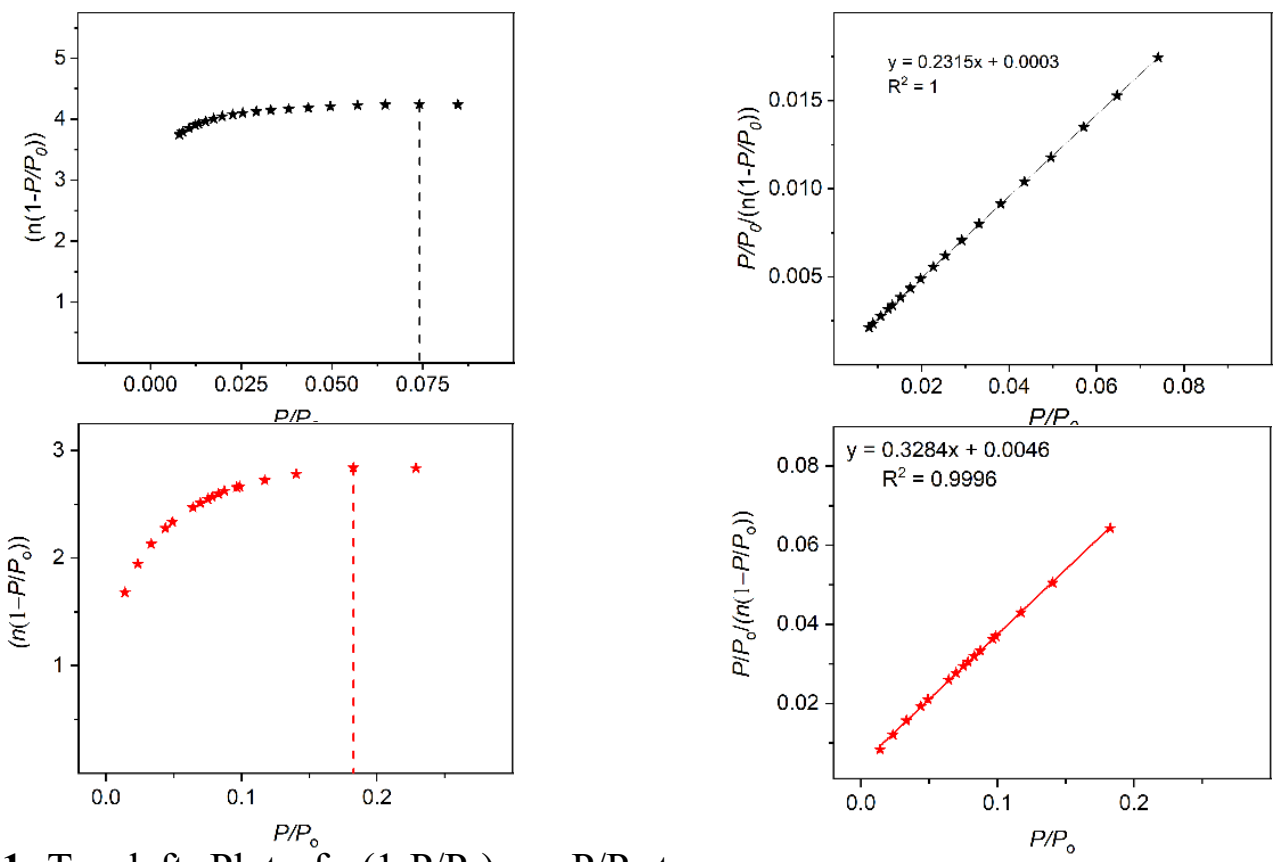

Figure S111. Top left: Plot of $\mathrm{n}\left(1-\mathrm{P} / \mathrm{P}_{0}\right)$ vs. $\mathrm{P} / \mathrm{P}_{0}$ to determine the maximum $\mathrm{P} / \mathrm{P}_{0}$ used in the BET linear fit according to the first BET consistency criterion for $\mathrm{N}_{2}$ adsorption at $77 \mathrm{~K}$ for the Ni-(5-OProp)BzFD MOSC. Top right: The slope of the best fit line for $\mathrm{P} / \mathrm{P}_{0}<0.0740$ is 0.2296 and the $\mathrm{y}$-intercept is 0.0004 , which satisfies the second BET consistency criterion. This results in a measured surface area of $425 \mathrm{~m}^{2} / \mathrm{g}$ to $\mathrm{N}_{2}$. Bottom left: Plot of $\mathrm{n}\left(1-\mathrm{P} / \mathrm{P}_{0}\right)$ vs. $\mathrm{P} / \mathrm{P}_{0}$ to determine the maximum $\mathrm{P} / \mathrm{P}_{0}$ used in the $\mathrm{BET}$ linear fit according to the first BET consistency criterion for $\mathrm{CO}_{2}$ adsorption at $195 \mathrm{~K}$ for the $\mathrm{Ni}$-(5-OProp)BzFD MOSC. Bottom right: The slope of the best fit line for $\mathrm{P} / \mathrm{P}_{0}<0.183$ is 0.3284 and the $\mathrm{y}$-intercept is 0.0046 , which satisfies the second BET consistency criterion. This results in a measured surface area of $312 \mathrm{~m}^{2} / \mathrm{g}$ to $\mathrm{CO}_{2}$. 
Table S1. Nitrogen and CO2 surface areas of novel calix[4]arene capped cages and cages with comparable surface areas from previously published manuscripts.

\begin{tabular}{|c|c|c|c|c|}
\hline Material & $\begin{array}{c}\mathrm{N}_{2} \text { BET } \\
\left(\mathrm{m}^{2} / \mathrm{g}\right)\end{array}$ & $\begin{array}{l}\mathrm{N}_{2} \text { Langmuir } \\
\left(\mathrm{m}^{2} / \mathrm{g}\right)\end{array}$ & $\begin{array}{c}\mathrm{CO}_{2} \mathrm{BET} \\
\left(\mathrm{m}^{2} / \mathrm{g}\right)\end{array}$ & $\begin{array}{c}\mathrm{CO}_{2} \text { Langmuir } \\
\left(\mathrm{m}^{2} / \mathrm{g}\right)\end{array}$ \\
\hline Co-(5-Sulfo) & 238 & 476 & 262 & 406 \\
\hline Ni-(2-Methyl) & 437 & 607 & 291 & 516 \\
\hline Ni-(5-Methyl) & 442 & 649 & 291 & 536 \\
\hline $\mathrm{Ni}-(2-\mathrm{Br})$ & 410 & 551 & 286 & 479 \\
\hline $\mathrm{Ni}-(5-\mathrm{Br})$ & 596 & 749 & 391 & 552 \\
\hline $\mathrm{Ni}-($ dobdc $)$ & 592 & 849 & 379 & 690 \\
\hline Ni-(5-OProp) & 403 & 489 & 314 & 460 \\
\hline Co-(5-OHept) & 22 & 25 & 252 & 507 \\
\hline Ni-(2-Methyl)Bz FD & 418 & 557 & 293 & 581 \\
\hline Ni-(5-Methyl)Bz FD & 425 & 698 & 301 & 636 \\
\hline Ni-(5-OProp)Bz FD & 421 & 594 & 312 & 653 \\
\hline $\mathrm{Co}_{24}\left({ }^{\mathrm{i}} \mathrm{Pr}-\mathrm{cdc}\right)_{12}{ }^{1}$ & - & - & 126 & 283 \\
\hline $\mathrm{Ni}_{24}\left({ }^{\mathrm{i}} \mathrm{Pr}-\mathrm{cdc}\right)_{12}{ }^{1}$ & - & - & 338 & 491 \\
\hline $\mathrm{Ni}_{24}(\mathrm{OH}-\mathrm{bdc})_{24} 1$ & 207 & 308 & - & - \\
\hline $\mathrm{Zr}_{12} \mathrm{CP}_{12}(\mathrm{Me} 2-\mathrm{bdc})_{6}{ }^{2}$ & 416 & 606 & 129 & 331 \\
\hline $\mathrm{Zr}_{\mathrm{x}} \mathrm{CP}_{3 \mathrm{x}}(2,6-\mathrm{ndc})_{\mathrm{y}}(\mathrm{T} / \mathrm{C})^{2}$ & 418 & 525 & 201 & 402 \\
\hline $\mathrm{Cu}_{4}(\mathrm{tdb})_{4}{ }^{3}$ & - & - & 218 & 527 \\
\hline $\mathrm{Cr}_{4}(\mathrm{tdb})_{4}{ }^{3}$ & - & - & 145 & 401 \\
\hline
\end{tabular}




\section{$\underline{\text { Powder X-Ray Diffraction Patterns }}$}

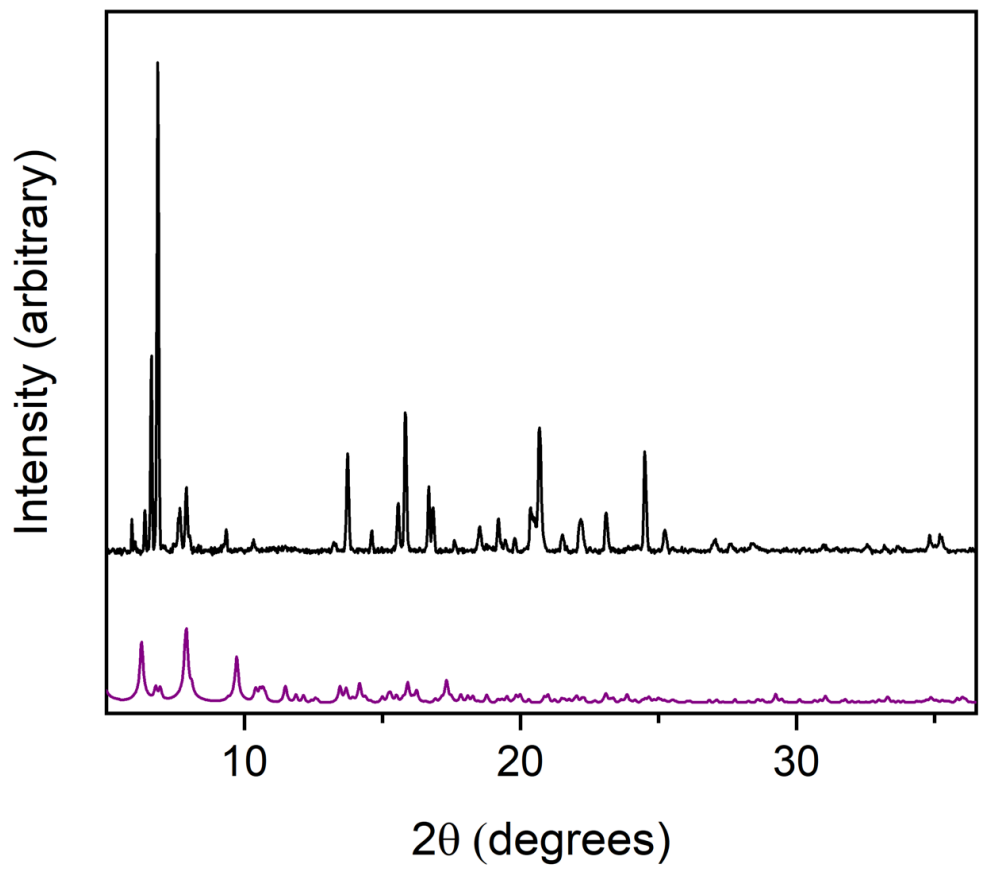

Figure S112. PXRD pattern of as synthesized Ni-(btc) (black) as compared to the simulated pattern from the previously reported single crystal XRD (purple). ${ }^{4}$

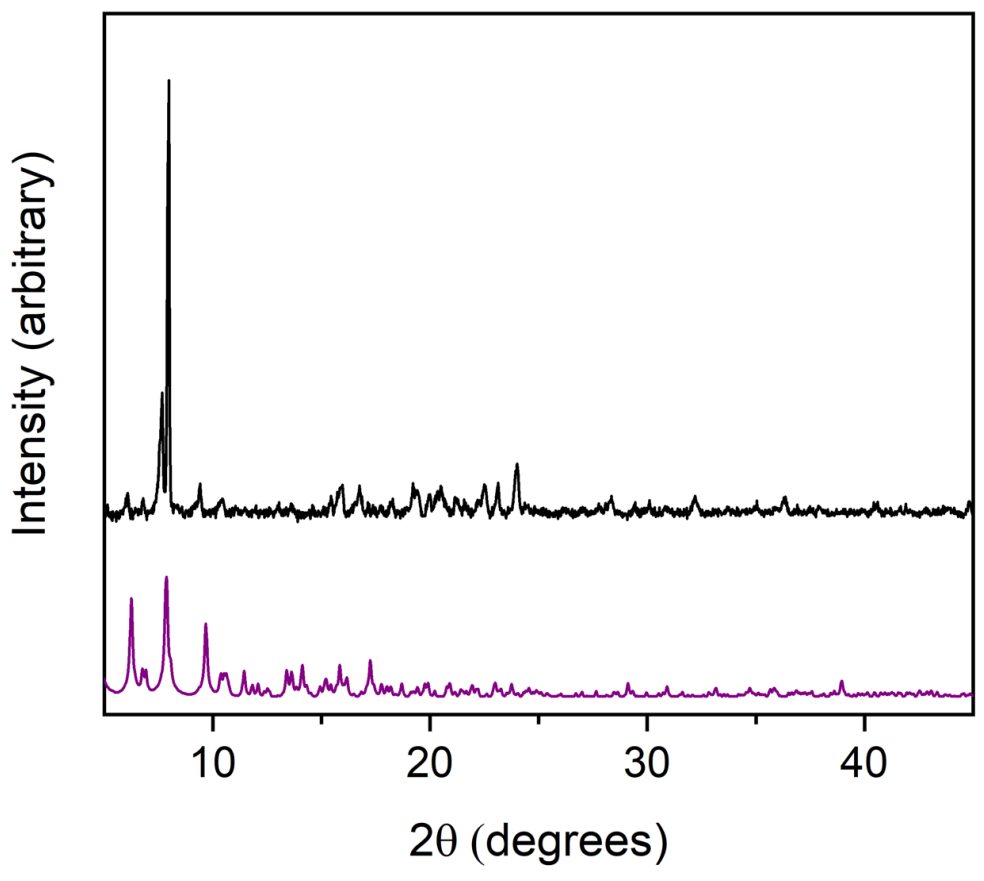

Figure S113. PXRD pattern of as-synthesized Co-(btc) (black) as compared to the simulated pattern from the previously reported single crystal XRD (purple). ${ }^{4}$ 


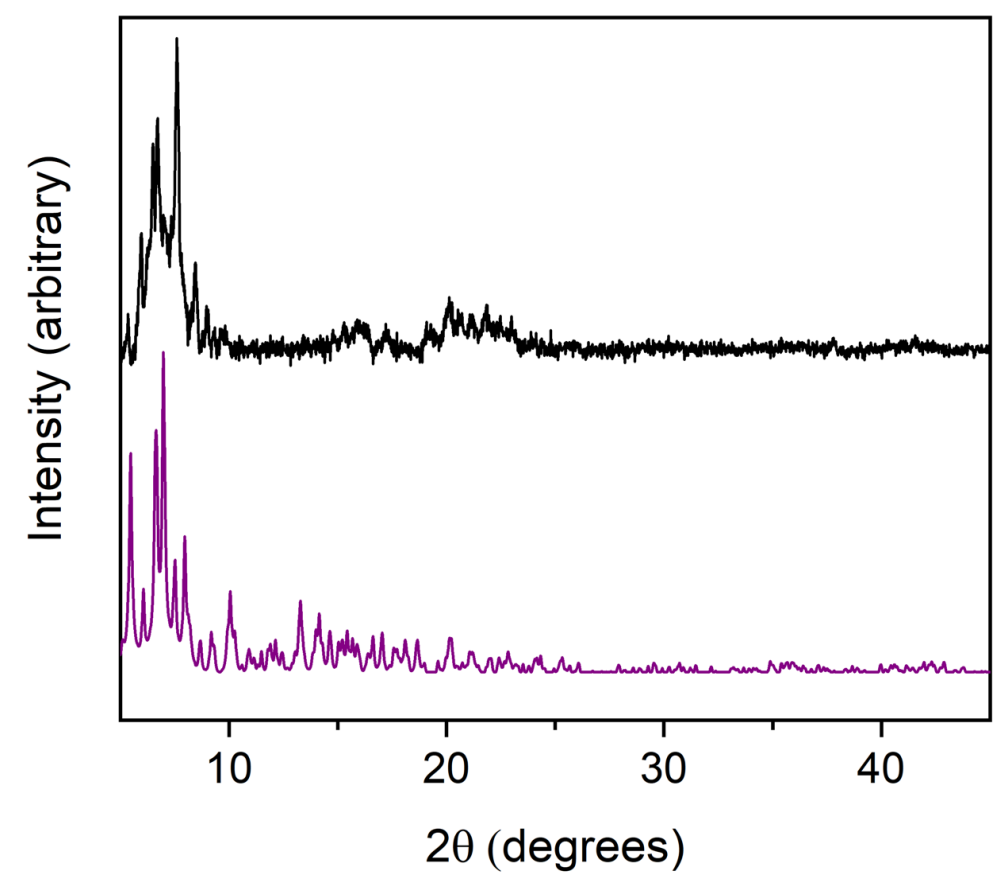

Figure S114. PXRD pattern of as synthesized Ni-(p-bdc) (black) as compared to the simulated pattern from the previously reported single crystal XRD (purple). ${ }^{5}$

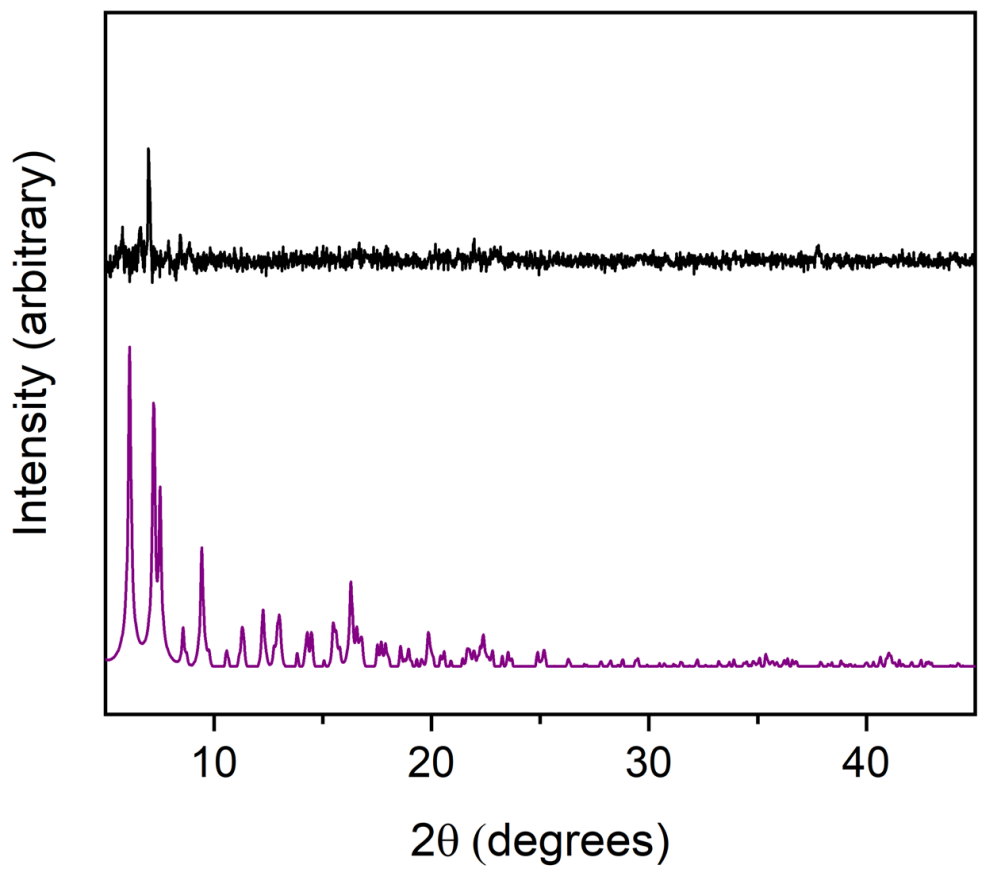

Figure S115. PXRD pattern of as synthesized Co-(p-bdc) (black) as compared to the simulated pattern from the previously reported single crystal XRD (purple). ${ }^{5}$ 


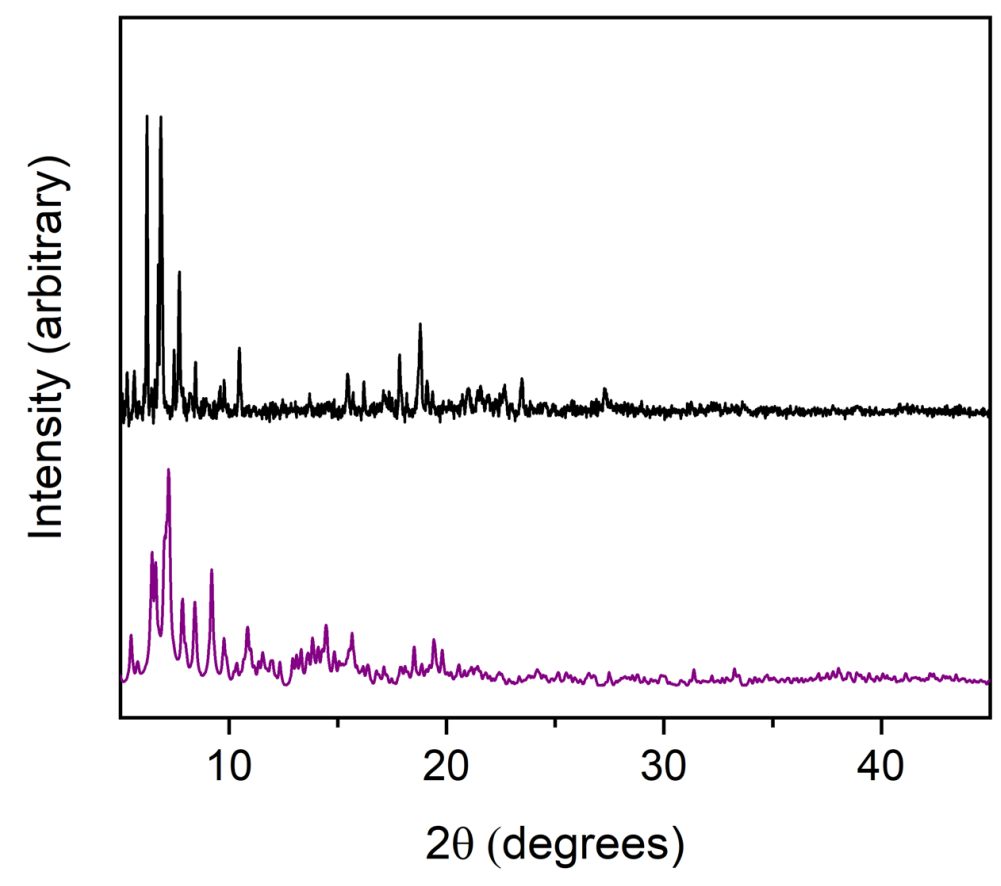

Figure S116. PXRD pattern of as synthesized Ni-(m-bdc) (black) as compared to the simulated pattern from the previously reported single crystal XRD (purple). ${ }^{6}$

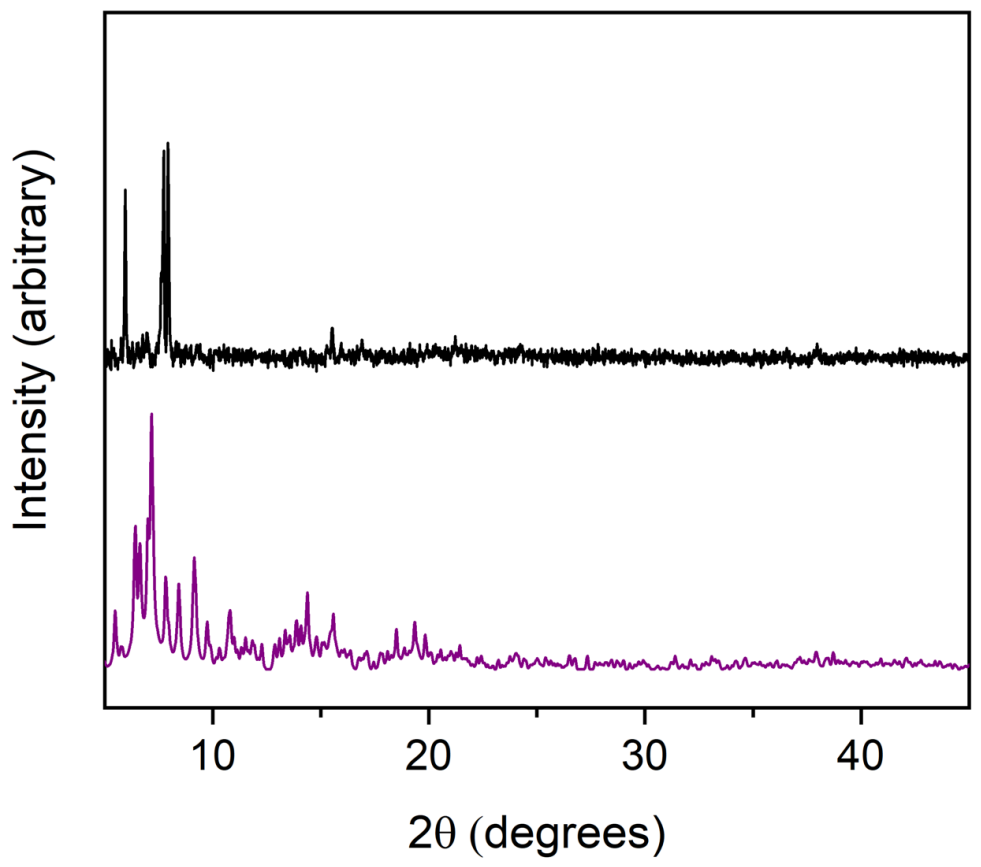

Figure S117. PXRD pattern of as synthesized Co-(m-bdc) (black) as compared to the simulated pattern from the previously reported single crystal XRD (purple). ${ }^{6}$ 


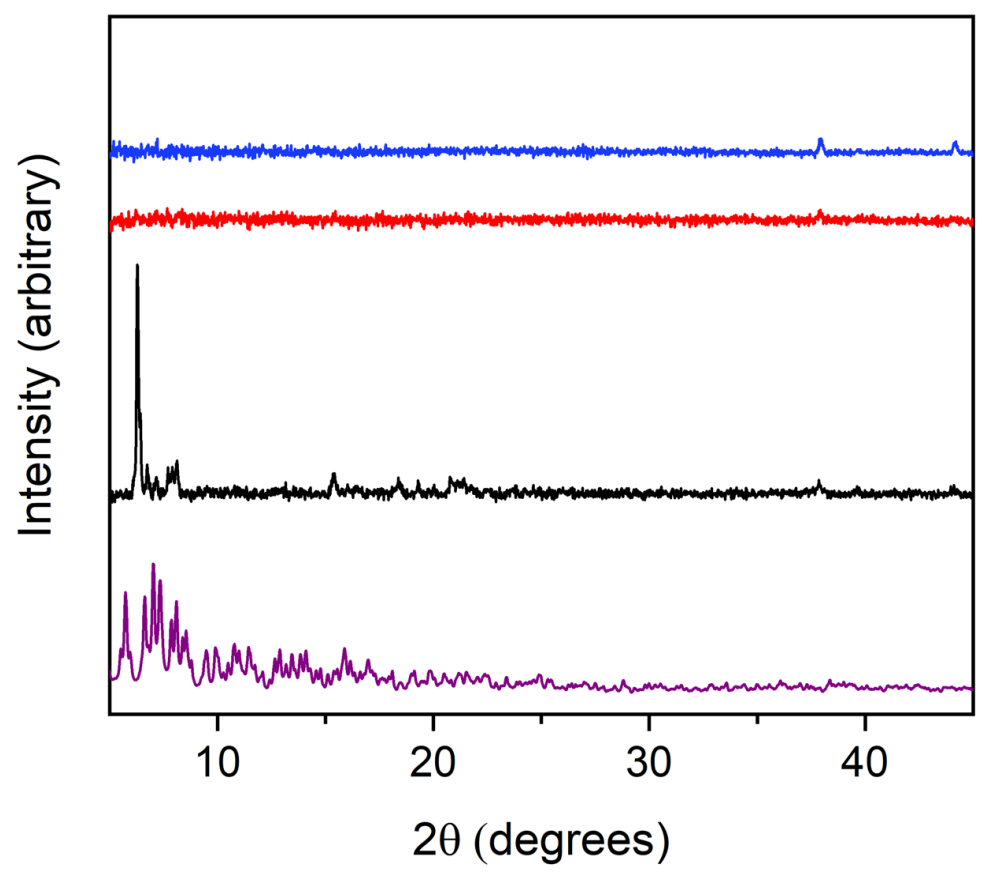

Figure S118. PXRD pattern of as synthesized (black), solvent exchanged with EtOH (red), and activated (blue) Co-(5-Sulfo) as compared to the simulated pattern from the previously reported single crystal XRD of Ni-(5-Sulfo) (purple). ${ }^{6}$

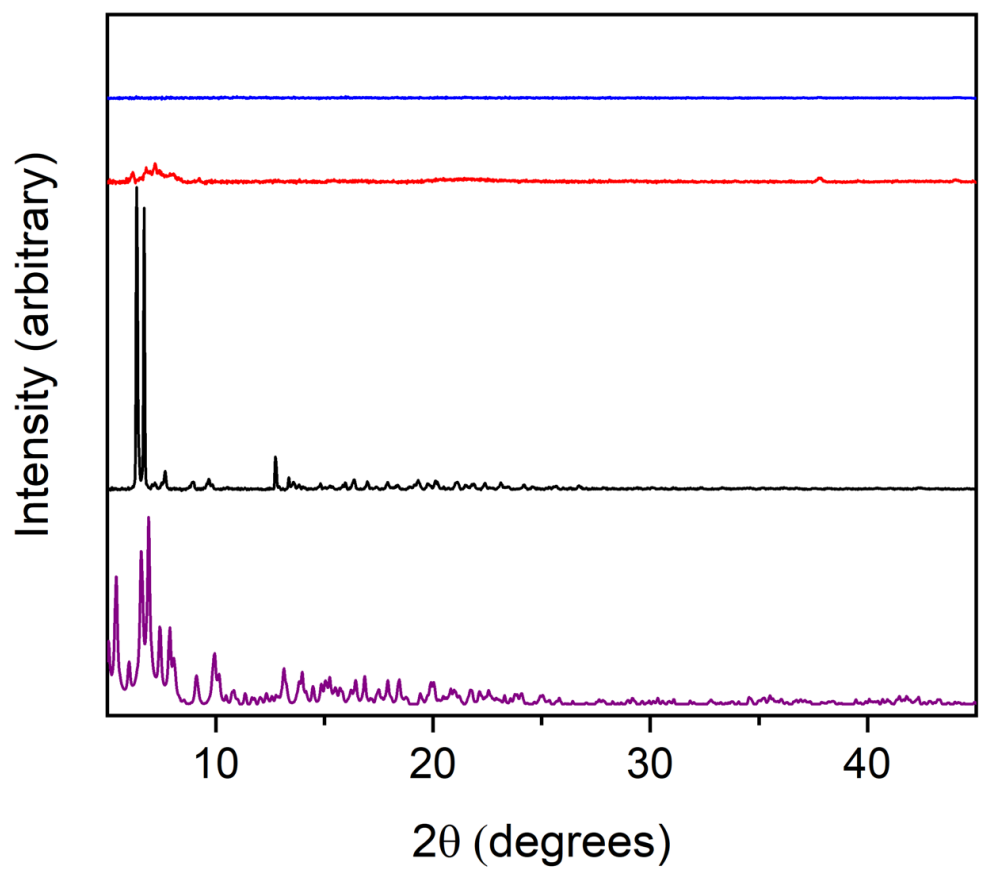

Figure S119. PXRD pattern of as synthesized (black), solvent exchanged with EtOH (red), and activated (blue) Ni-(2-Methyl) as compared to the simulated pattern from the single crystal XRD (purple). 


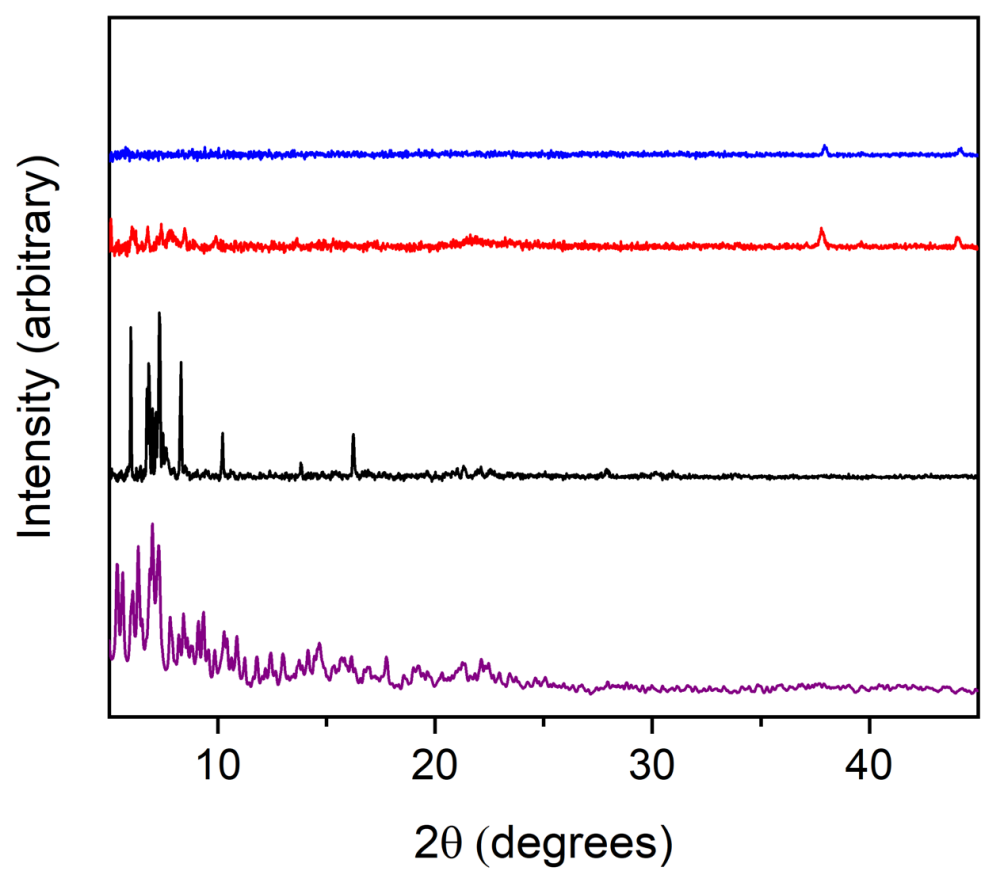

Figure S120. PXRD pattern of as synthesized (black), solvent exchanged with EtOH (red), and activated (blue) Ni-(5-Methyl) as compared to the simulated pattern from the single crystal XRD (purple).

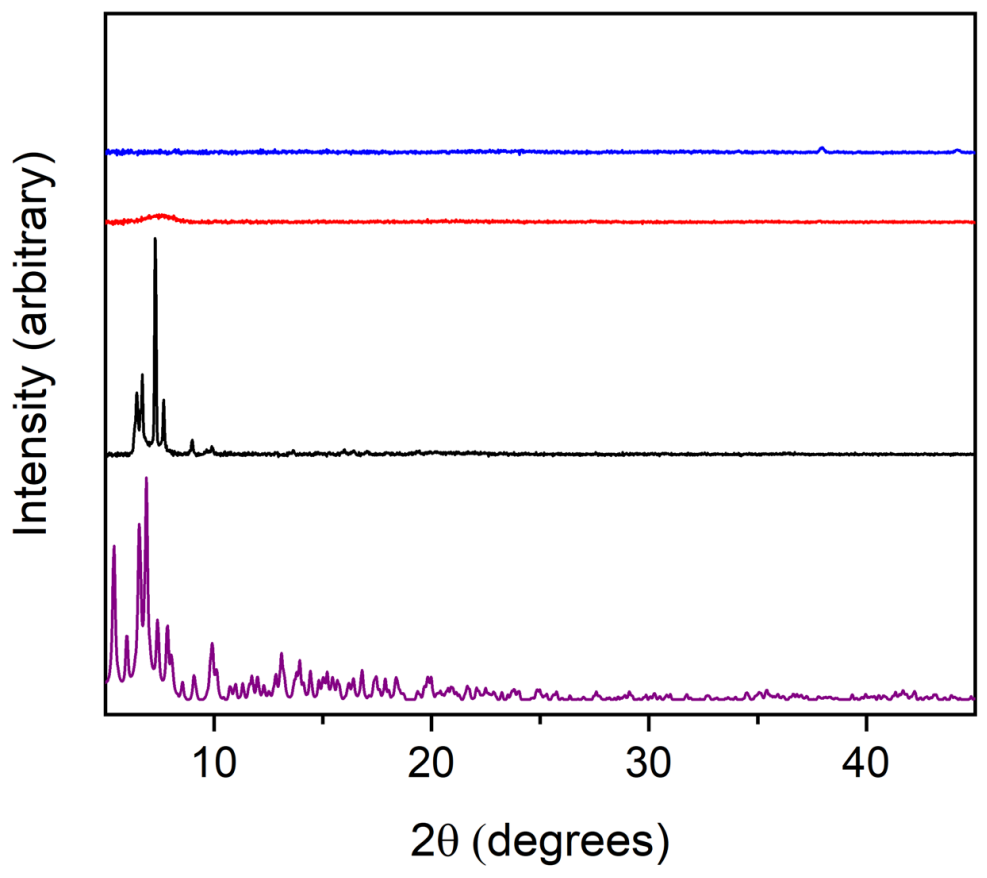

Figure S121. PXRD pattern of as synthesized (black), solvent exchanged with EtOH (red), and activated (blue) $\mathrm{Ni}-(2-\mathrm{Br})$ as compared to the simulated pattern from the single crystal XRD (purple). 


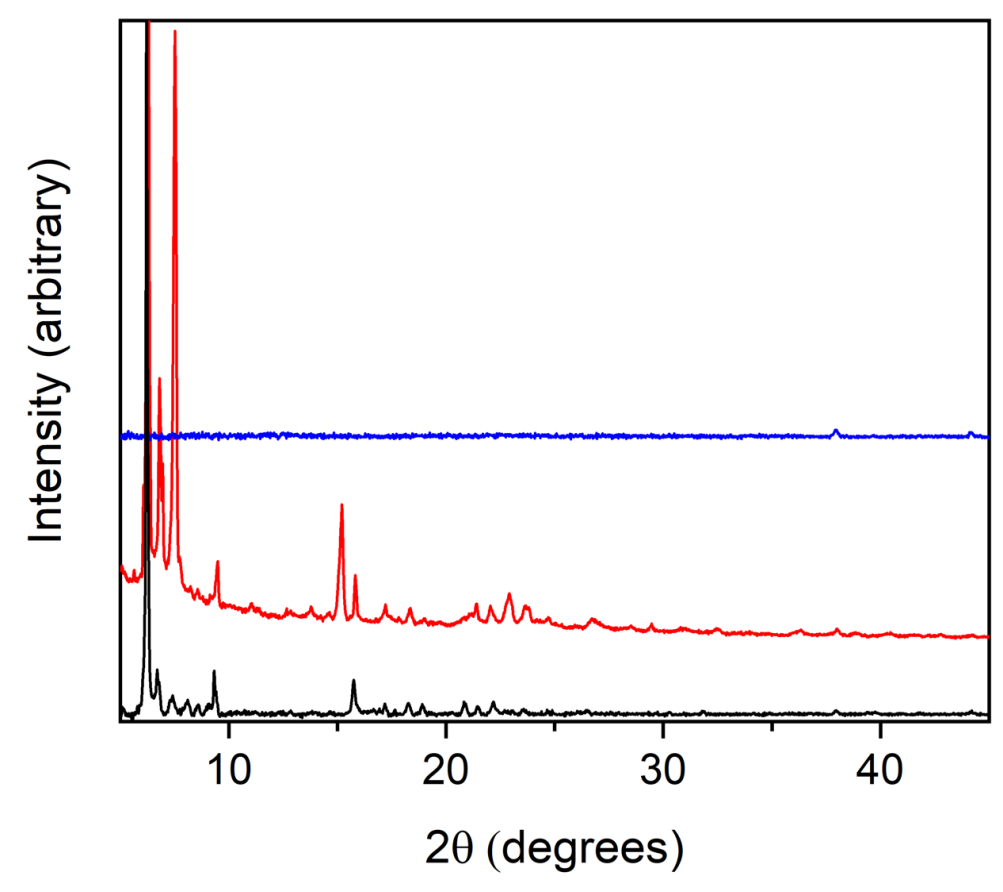

Figure S122. PXRD pattern of as synthesized (black), solvent exchanged with EtOH (red), and activated (blue) $\mathrm{Ni}-(5-\mathrm{Br})$.

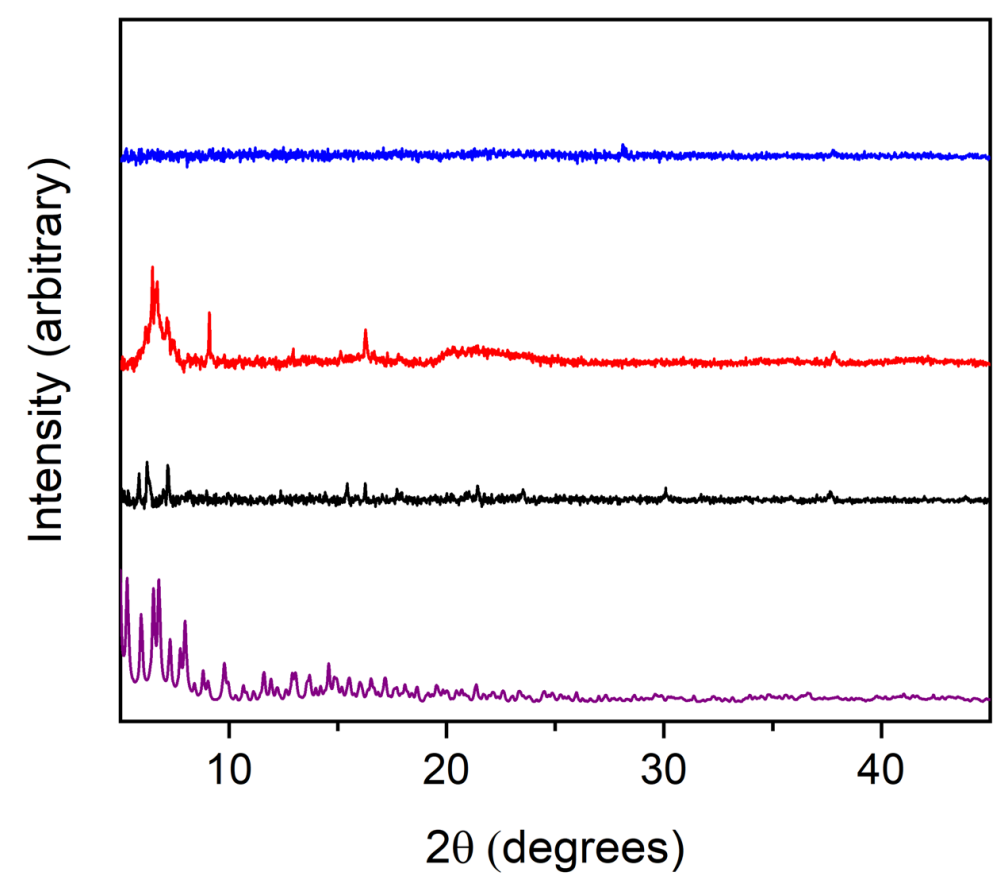

Figure S123. PXRD pattern of as synthesized (black), solvent exchanged with EtOH (red), and activated (blue) $\mathrm{Ni}$-(dobdc) as compared to the simulated pattern from the single crystal XRD (purple). 


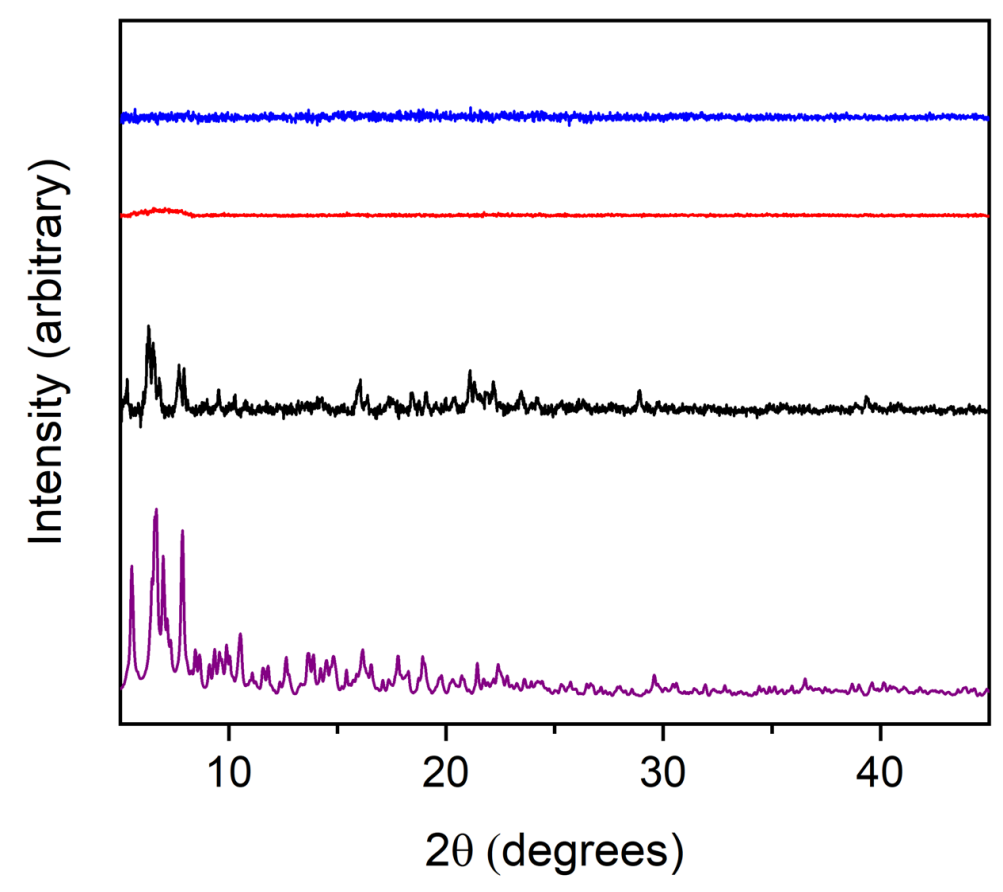

Figure S124. PXRD pattern of as synthesized (black), solvent exchanged with EtOH (red), and activated (blue) Ni-(5-OProp) as compared to the simulated pattern from the single crystal XRD (purple).

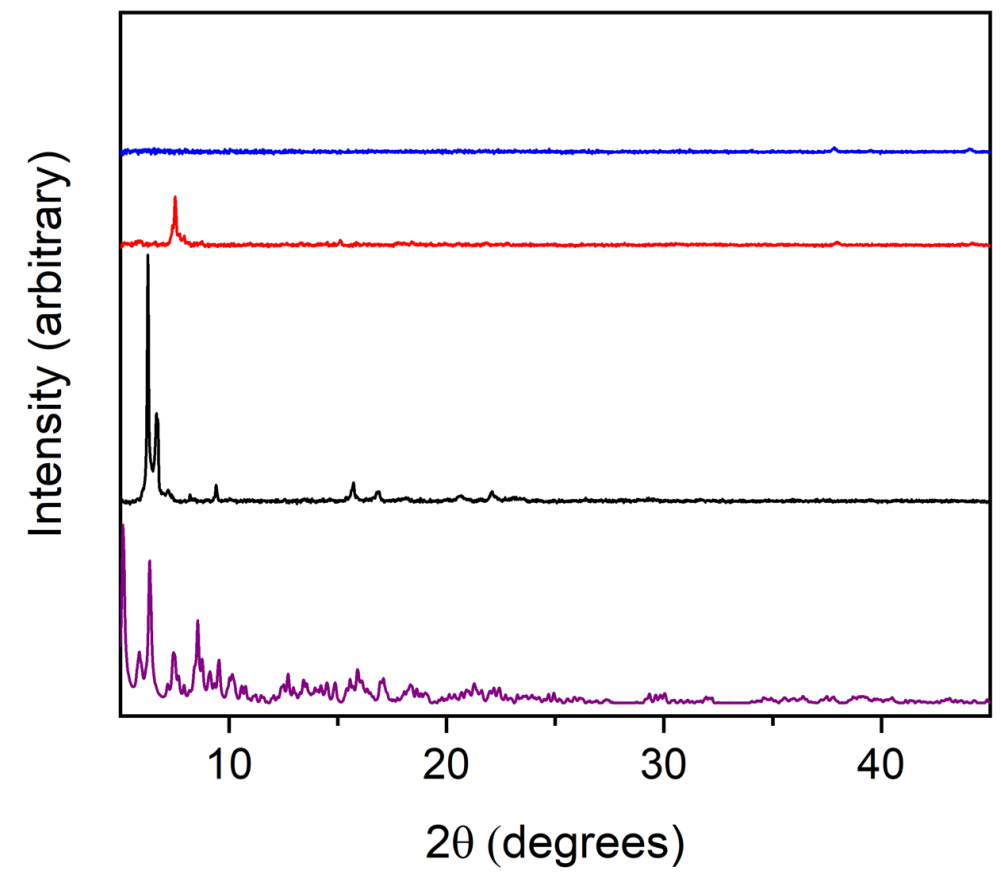

Figure S125. PXRD pattern of as synthesized (black), solvent exchanged with EtOH (red), and activated (blue) Co-(5-OHept) as compared to the simulated pattern from the single crystal $\mathrm{XRD}($ purple). 


\section{Crystal Structures}

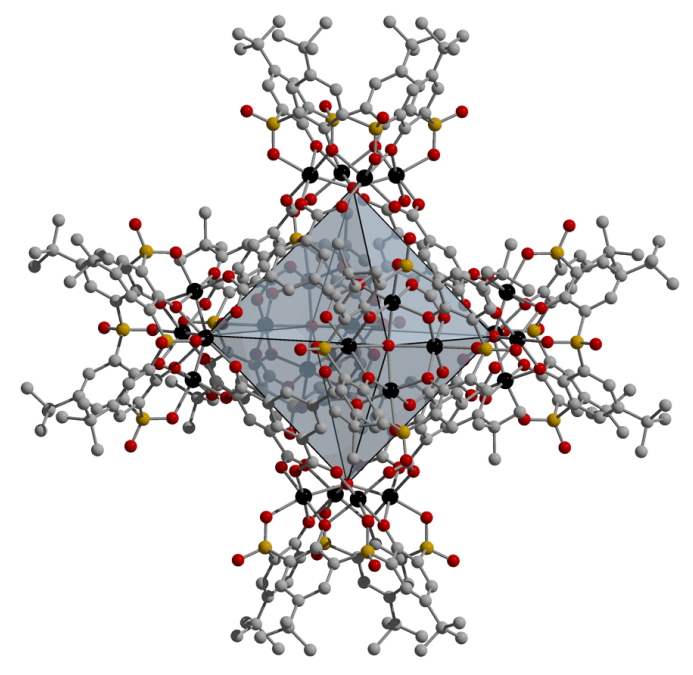

Figure S126. Single crystal structural depiction of the previously reported Ni-(btc) MOSC. ${ }^{4}$

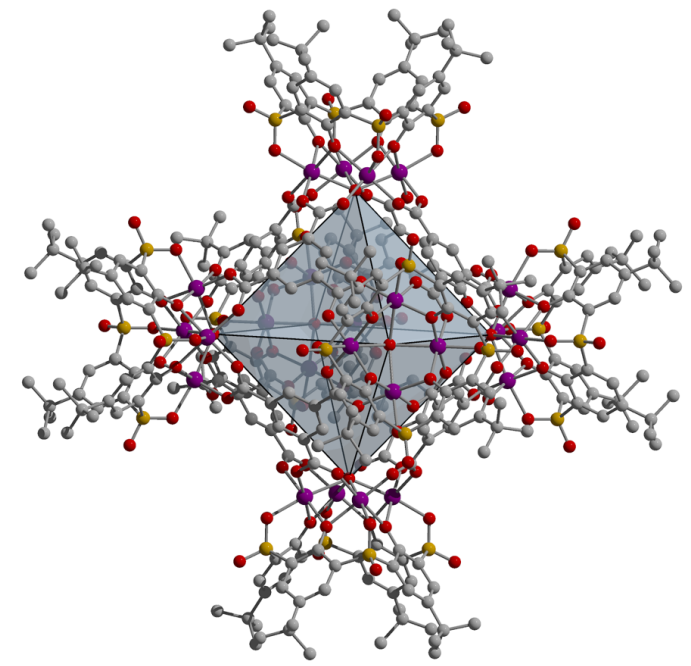

Figure S127. Single crystal structural depiction of the previously reported Co-(btc) MOSC. ${ }^{4}$ 


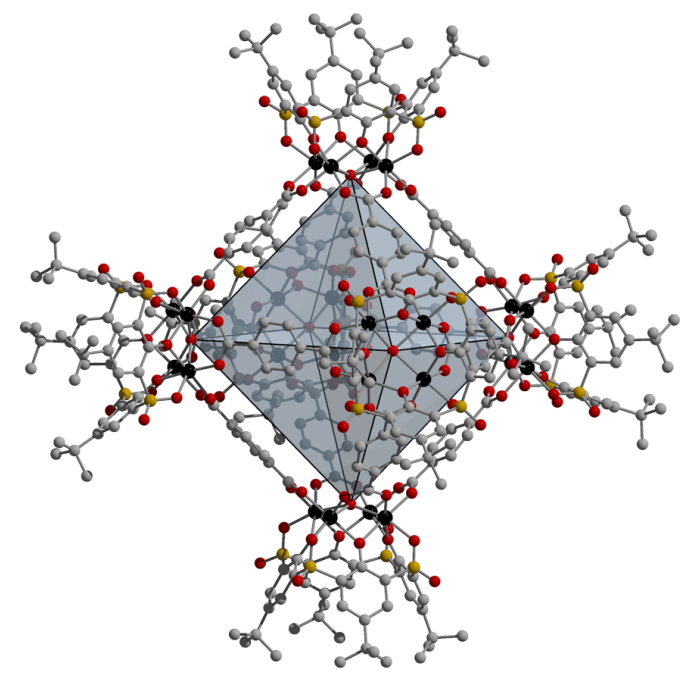

Figure S128. Single crystal structural depiction of the previously reported Ni-(p-bdc) MOSC. ${ }^{5}$

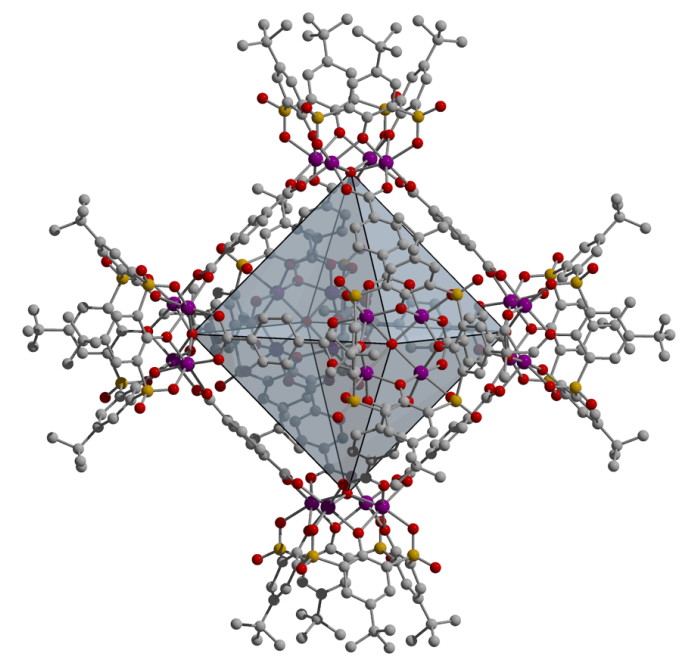

Figure S129. Single crystal structural depiction of the previously reported Co-(p-bdc) MOSC..$^{5}$ 


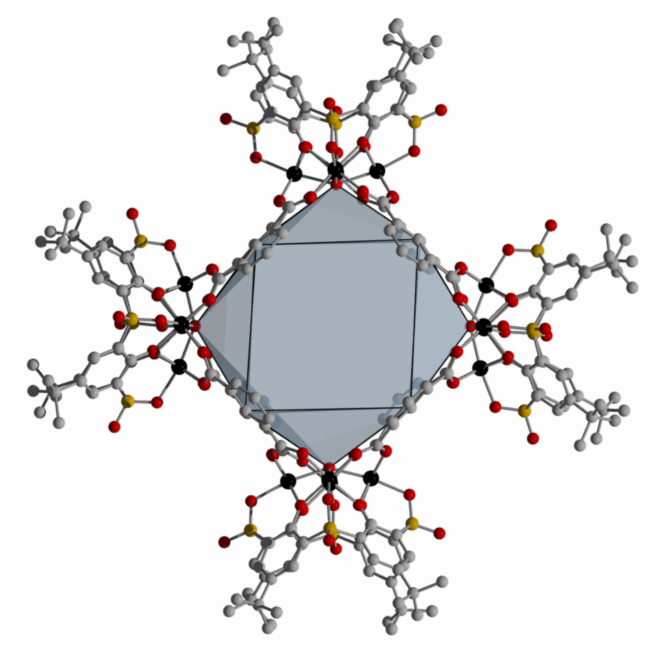

Figure S130. Single crystal structural depiction of the previously reported Ni-(mbdc) MOSC. ${ }^{6}$

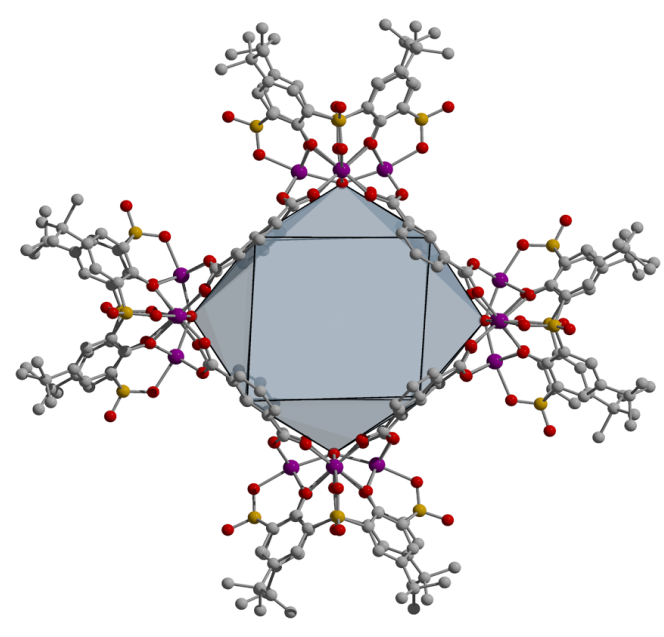

Figure S131. Single crystal structural depiction of the previously reported Co-(m-bdc) MOSC. ${ }^{6}$ 


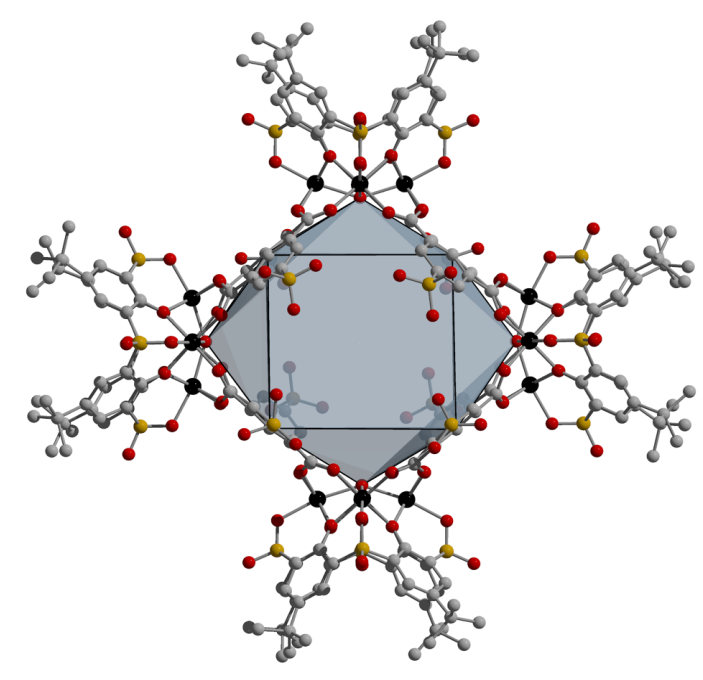

Figure S132. Single crystal structural depiction of the previously reported Ni-(5-Sulfo) MOSC. ${ }^{6}$

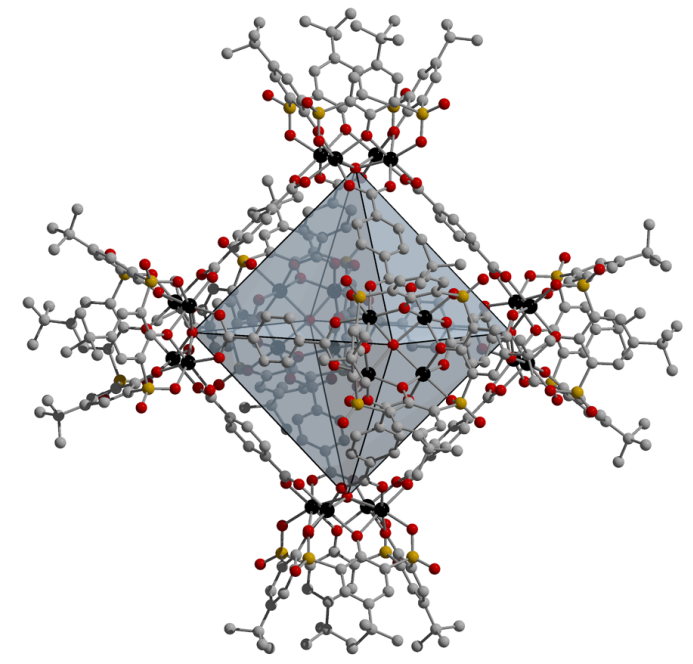

Figure S133. Single crystal structural depiction of the Ni-(2-Methyl) MOSC. Poor structural data let to incomplete refinement of the position of the appended methyl groups, which are likely disordered over four possible positions. 


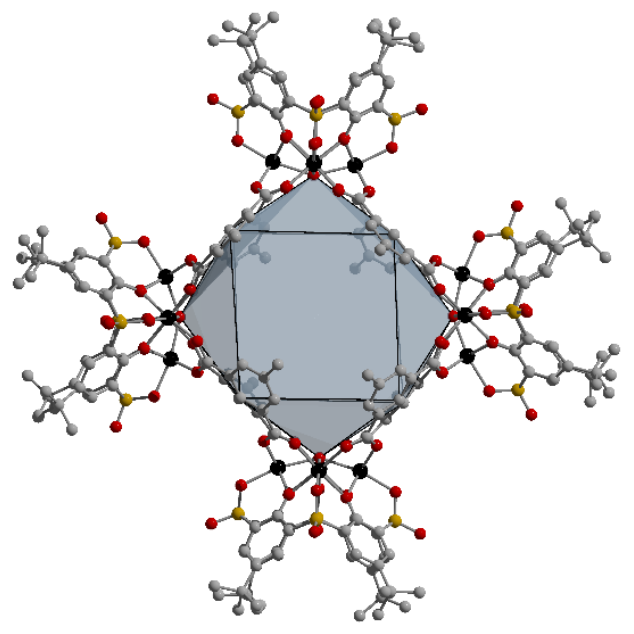

Figure S134. Single crystal structural depiction of the Ni-(5-Methyl) MOSC.

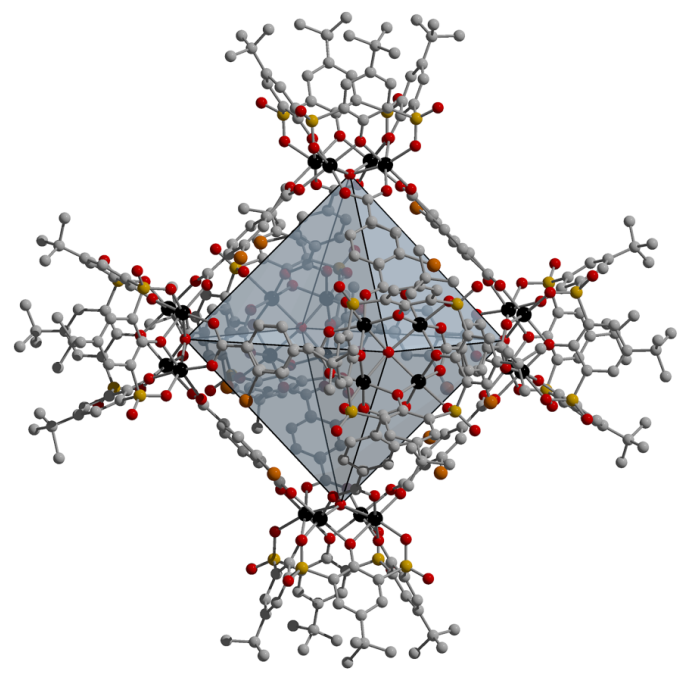

Figure S135. Single crystal structural depiction of the Ni-(2-Br) MOSC. Disordered bromo residues are omitted for clarity. 


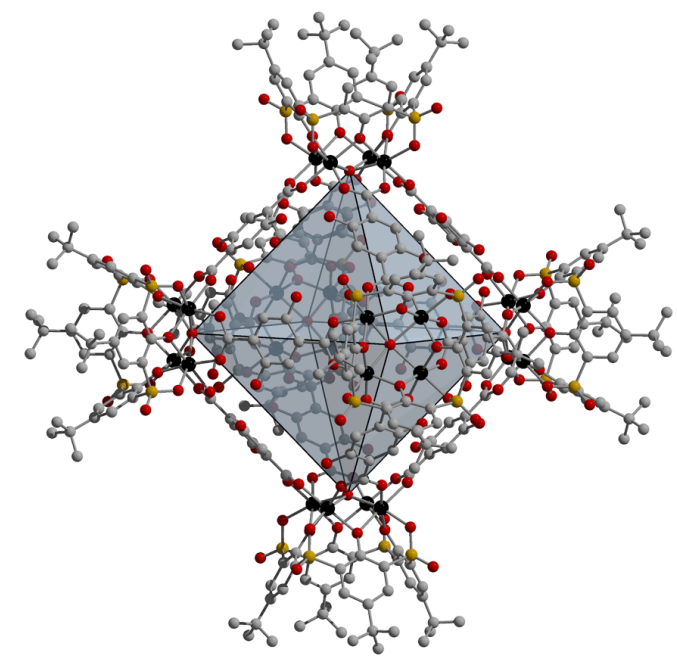

Figure S136. Single crystal structural depiction of the Ni-(dobdc) MOSC. Disorder of the hydroxyl residues over two possible positions is omitted for clarity.

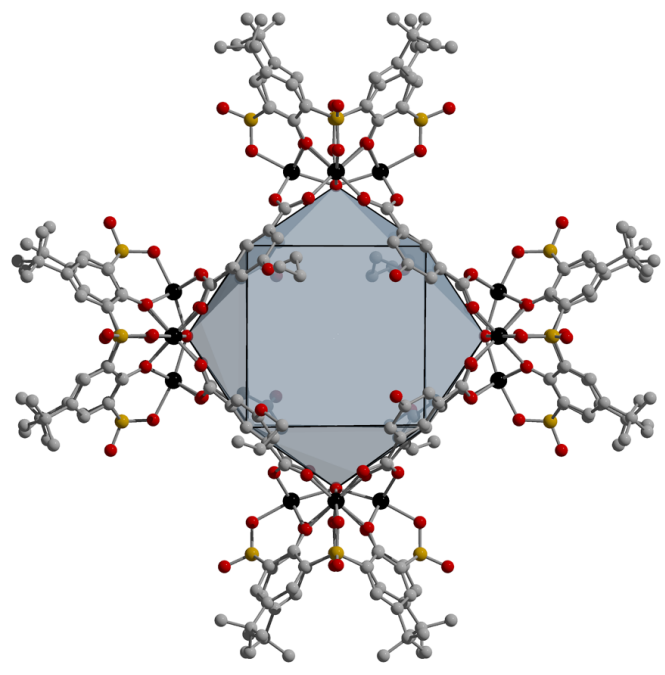

Figure S137. Single crystal structural depiction of the Ni-(5-OProp) MOSC. 


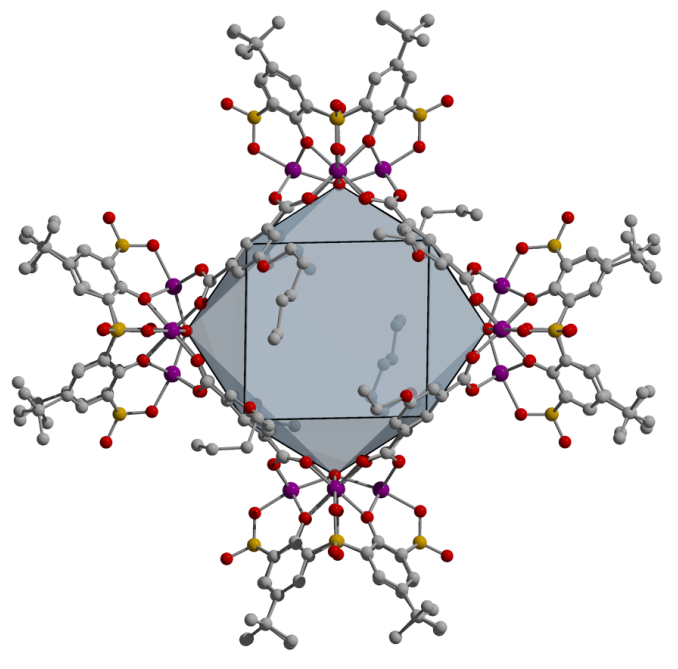

Figure S138. Single crystal structural depiction of the Co-(5-Heptoxy) MOSC.
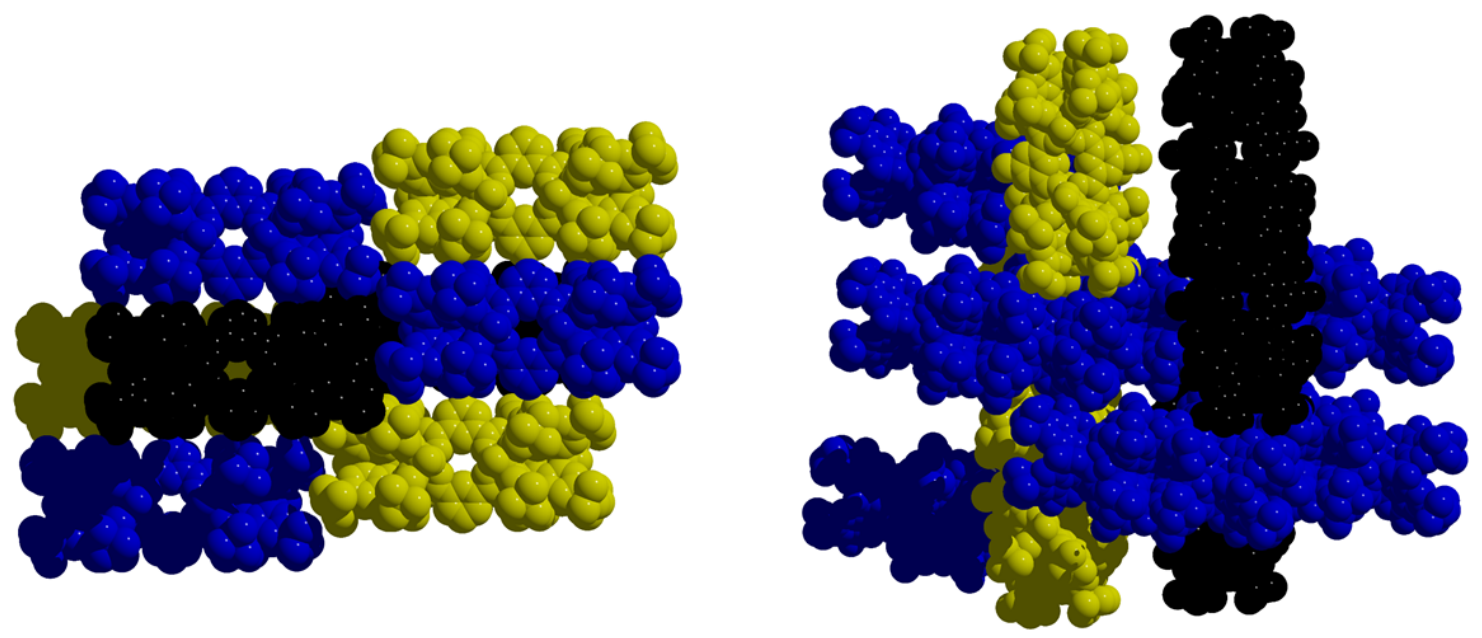

Figure S139. Crystal packing diagram of Ni-(m-bdc) (left) and Ni-(5-Methyl) (right). 


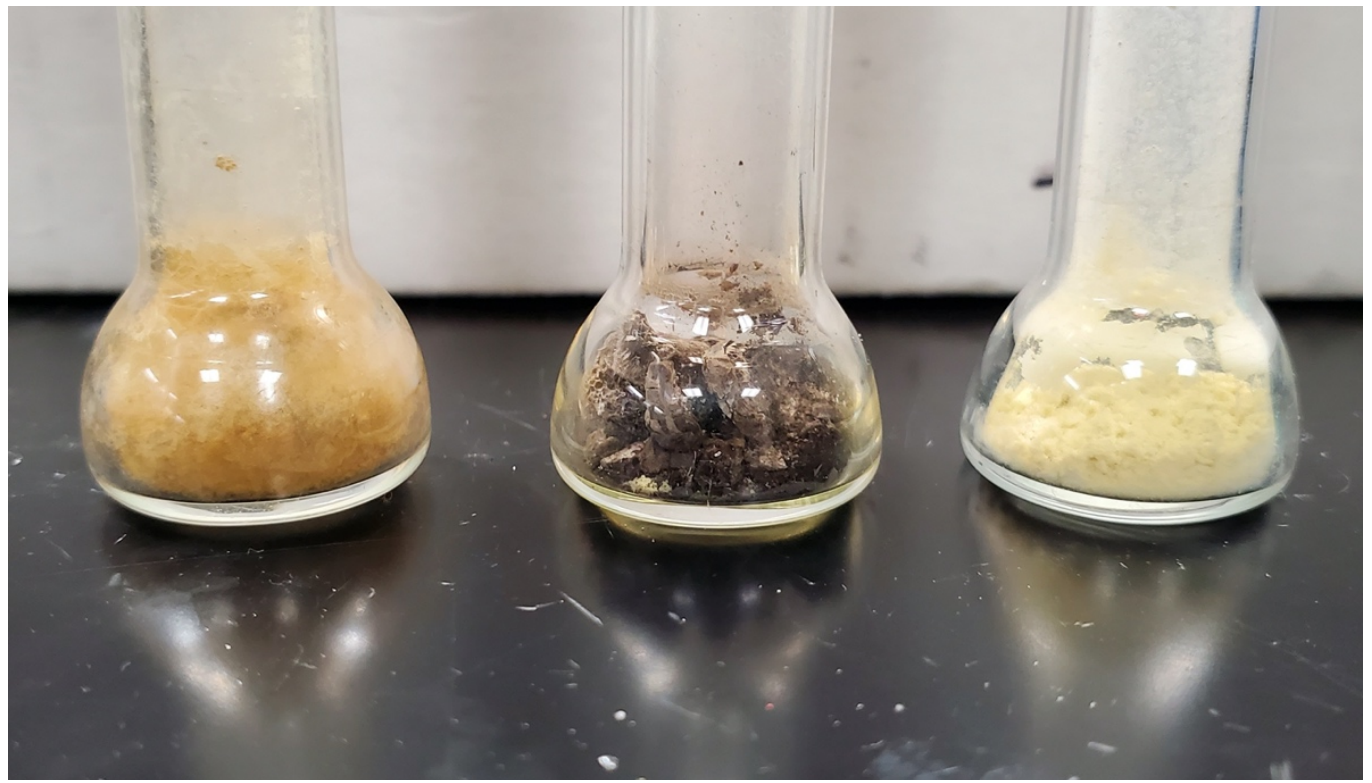

Figure S140. Benzene freeze dried samples (Left to right: Ni-(5-OProp), Ni-(2-Methyl), Ni-(5Methyl)) in gas adsorption analysis tubes after activation.

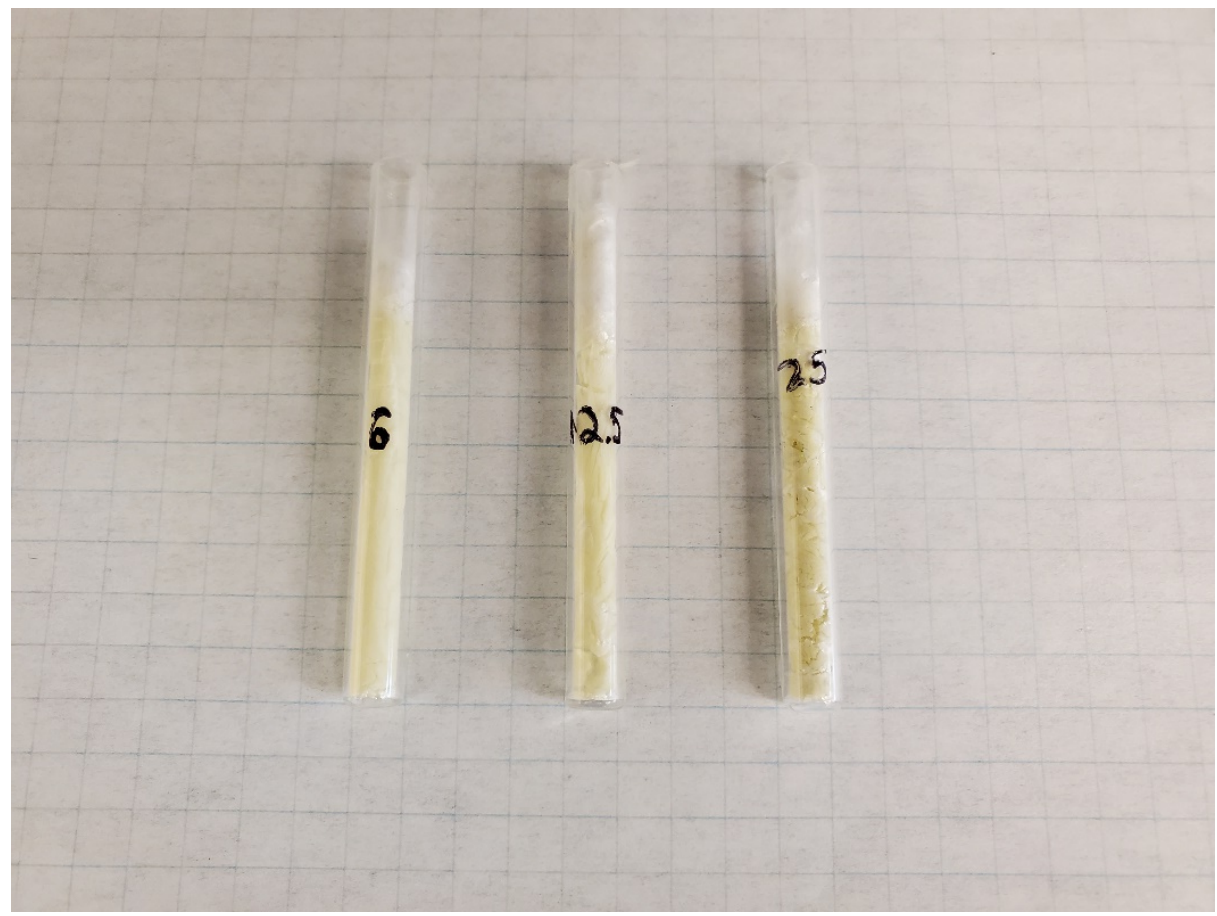

Figure S141. Vacuum evaporated, freeze dried samples of Ni-(2-Methyl) (Left to right: $25 \mathrm{mg}$, $12.5 \mathrm{mg}$, and $6 \mathrm{mg}$, in $1 \mathrm{~mL}$ of benzene) in glass cells. 
Table S2. Unit cell information for the Co-III5-Sulfo) and Ni-(5-Br) cages.

\begin{tabular}{|l|l|l|}
\hline Compound: & $\mathrm{Co}-(5-\mathrm{Sulfo})$ & $\mathrm{Ni}-(5-\mathrm{Br})$ \\
\hline Empirical Formula & $\mathrm{Co}_{16} \mathrm{C}_{224} \mathrm{H}_{204} \mathrm{O}_{96} \mathrm{~S}_{24}$ & $\mathrm{Ni}_{16} \mathrm{C}_{224} \mathrm{H}_{204} \mathrm{O}_{84} \mathrm{~S}_{16} \mathrm{Br}_{8}$ \\
\hline Temperature, K & $175(2)$ & $175(2)$ \\
\hline Crystal System & Triclinic & Triclinic \\
\hline Space Group & $P-1$ & $P-1$ \\
\hline Cell Dimentions: & & \\
\hline $\mathrm{a}, \AA$ & $21.102(5)$ & $20.54(7)$ \\
\hline $\mathrm{b}, \AA$ & $26.843(6)$ & $20.55(9)$ \\
\hline $\mathrm{c}, \AA$ & $28.549(7)$ & $28.11(11)$ \\
\hline$\alpha,^{\circ}$ & $71.945(9)$ & $94.51(15)$ \\
\hline$\beta,^{\circ}$ & $79.94(1)$ & $94.50(14)$ \\
\hline$\gamma,{ }^{\circ}$ & $88.828(10)$ & $111.20(12)$ \\
\hline Volume, $\AA^{3}$ & $15129(6)$ & $10956(11)$ \\
\hline
\end{tabular}

\section{References}

(1) Gosselin, A.J.; Rowland, C.A.; Balto, K.P.; Yap, G.P.A.; Bloch, E.D. Design and Synthesis of Porous Nickel(II) and Cobalt(II) Cages. Inorg. Chem. 2018, 57, 11847-11850.

(2) Gosselin, A.J.; Decker, G.E.; McNichols, B.W.; Baumann, J.E. Yap, G.P.A; Sellinger, A.; Bloch, E.D. Ligand-Based Phase Control in Porous Zirconium Coordination Cages. Chem. Mater. 2020, 32, 5872-5878.

(3) Taggart, G.A.; Lorzing, G.R.; Dworzak, M.R.; Yap, G.P.A.; Bloch, E.D. Synthesis and Characterization of Low-Nuclearity Lantern-Type Porous Coordination Cages. Chem. Commun. 2020, 56, 8924-8927.

(4) Dai, F.R.; Wang, Z. Modular Assembly of Metal-Organic Super Containers Incorporating Sulfonylcalixarenes. J. Am. Chem. Soc. 2012, 134, 8002-8005.

(5) Dai, F.R.; Sambasivam, U.; Hammerstrom, A.J.; Wang, Z. Synthetic Supercontainers Exhibit Distinct Solution versus Solid State Guest-Binding Behavior. J. Am. Chem. Soc. 2014, 136, 7480-7491.

(6) Dai, F.R.; Becht, D.C.; Wang, Z. Modulating Guest Binding in Sulfonylcalixarene-Based Metal-Organic Supercontainers. Chem. Commun., 2014, 50, 5385-5387. 